\title{
DESIGNER NANOPARTICLES AS \\ EFFICIENT NUCLEATION AGENTS IN POLYMER FOAMING
}

Shanqiu Liu 


\section{Members of the Committee:}

\section{Chairman}

Supervisor

Co-supervisor

Members
Prof. dr. ir. J.W.M. Hilgenkamp

Prof. dr. G.J. Vancso

Dr. J. Duvigneau

Prof. dr. I. Dékány

Prof. dr. ir. J.H. Snoeijer

Prof. dr. ir. N.E. Benes

Dr. ir. L.A.E.M. Reuvekamp

Prof. dr. ir. L.E. Govaert
University of Twente

University of Twente

University of Twente

University of Szeged

University of Twente

University of Twente

University of Twente

Eindhoven University

of Technology

The work described in this Thesis was performed at the Materials Science and Technology of Polymers (MTP) group, MESA+ Institute for Nanotechnology, Faculty of Science and Technology, University of Twente, PO Box 217, 7500 AE, Enschede, the Netherlands.

This research was supported by the MESA+ Institute for Nanotechnology of the University of Twente and the China Scholarship Council.

\section{Title: Designer Nanoparticles as Efficient Nucleation Agents in Polymer Foaming}

Copy right (C) Shanqiu Liu, Enschede, the Netherlands, 2017

All rights reserved. No part of this Thesis may be reproduced by print, photocopy or any other means without the permission of the copyright owner.

Printed by Gildeprint

ISBN: 978-90-365-4402-3

DOI: $10.3990 / 1.9789036544023$ 


\section{DESIGNER NANOPARTICLES AS \\ EFFICIENT NUCLEATION AGENTS IN \\ POLYMER FOAMING}

\section{PROEFSCHRIFT}

ter verkrijging van

de graad van doctor aan de Universiteit Twente,

op gezag van de rector magnificus,

prof. dr. T. T. M. Palstra,

volgens besluit van het College voor Promoties

in het openbaar te verdedigen

op woensdag 11 oktober 2017 om 14:45

door

\section{Shanqiu Liu}

geboren op 14 september 1987

te Jiangxi, China 
Dit proefschrift is goedgekeurd door:

Prof. dr. G.J. Vancso (promotor)

Dr. J. Duvigneau (co-promotor) 


\section{Contents}

Chapter 1 General Introduction.......................................................1

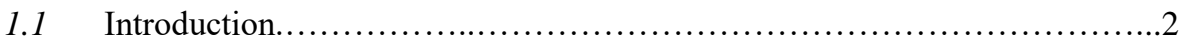

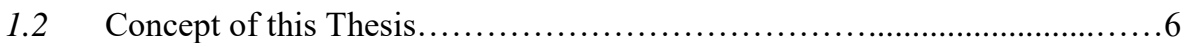

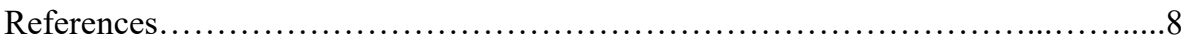

\section{Chapter 2 Nanocellular Polymer Foams as Promising High Performance}

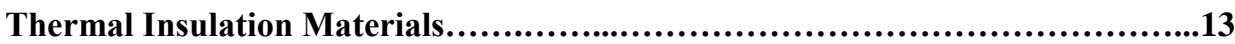

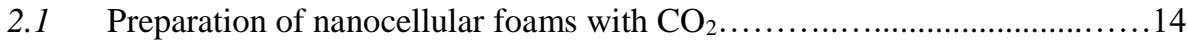

2.2 Addition of heterogeneous nucleating particles..........................18

2.3 The classical nucleation theory to describe cell nucleation...................20

2.4 Controlling particle surface chemistry to optimize heterogeneous

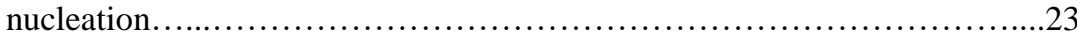

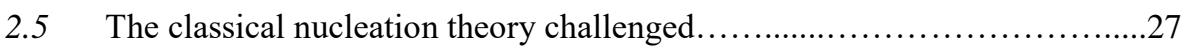

2.6 Thermal conductivity of nanocellular polymers............................32

2.7 Silica nanoparticles synthesis and surface modification.......................36

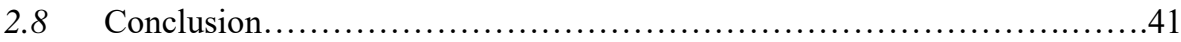

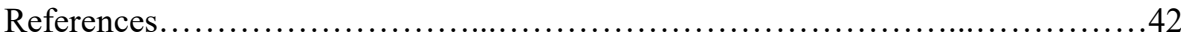

Chapter 3 Nanocellular Polymer Foams Nucleated by Core-shell

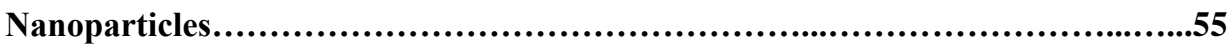

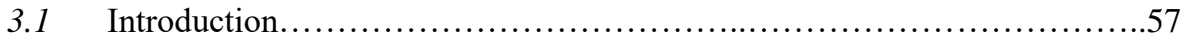

3.2 Results and discussion...............................................60 
3.2.2 Nanocomposite foams..........................................62

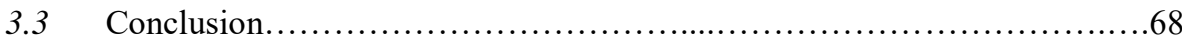

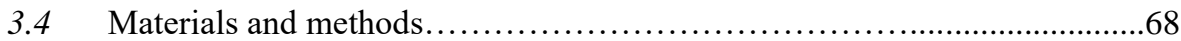

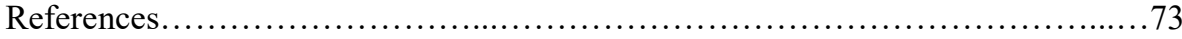

\section{Chapter 4 Silica Assisted Nucleation of Polymer Foam Cells with Nanoscopic}

Dimensions: Impact of Particle Size and Surface Functionality ....................77

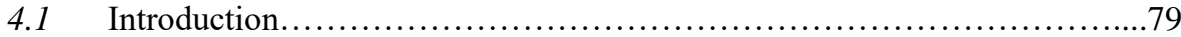

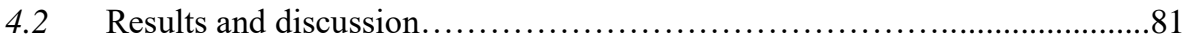

4.2.1 Preparation and characterization of silica nanoparticles...........................81

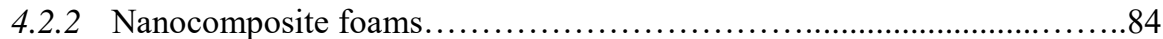

4.2.3 Line tension effects on heterogeneous nucleation....................................89

$4.3 \quad$ Conclusion......................................................... 96

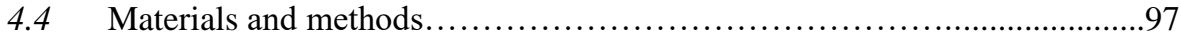

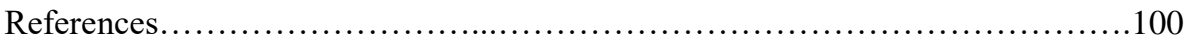

Chapter 5 Transition from Adhesion to Engulfment of Nanoparticles at the Meltpolymer Interface..................................................................105

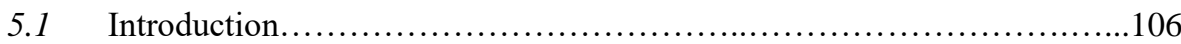

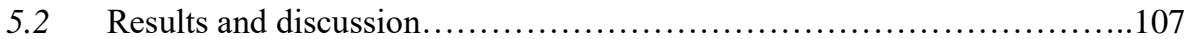

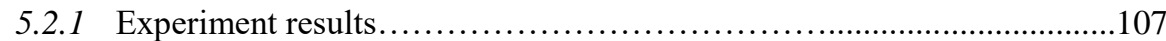

5.2.2 Thermodynamic model............................................... 110

5.2.3 Results from the thermodynamic model.........................................112

5.2.4 Comparison to experiments......................................114

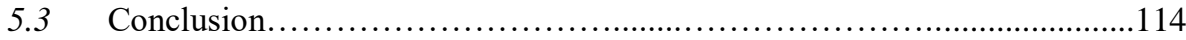


5.4 Materials and methods....

References.

\section{Chapter 6 Multiple Polymer Foam Cell Nucleation Events from PDMS Grafted}

6.1 Introduction.

6.2 Results and discussion. 126

6.2.1 Nanoparticles synthesis and characterization....... 126

6.2.2 Nanocomposite foams.... 130

6.2.3 PMMA nanocomposite foam morphology as a function of foaming time

6.2.4 PMMA foam cell nucleation versus surface roughness variation. 136

6.2.5 $\mathrm{SiO}_{2}-\mathrm{RP}$ nucleation mechanism elucidated.

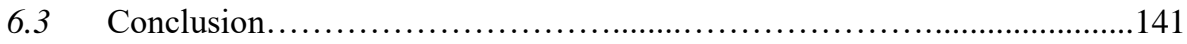

$6.4 \quad$ Materials and methods............................................. 142

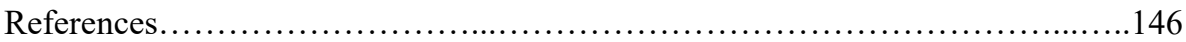

\section{Chapter 7 Outlook: New Particle Designs, Foaming Strategies and Other}

7.1 Designer particles............................................. 152

7.2 Polymer foam matrix materials..................................... 153

7.3 Bulk production challenges....................................... 154

7.4 Nanocellular foam thermal conductivity measurements..................156

References............................................................... 158

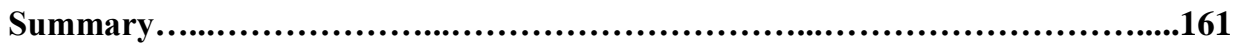


Acknowledgements.. .169

List of Publications.. .173

Curriculum Vitae. .175 
Chapter 1

General Introduction 


\subsection{Introduction}

Low density nanocellular polymer foams are considered as a new class of materials with many promising applications, e.g. in acoustic and thermal insulation, ${ }^{1-4}$ catalysis and separation, ${ }^{5-6}$ electromagnetic shielding, ${ }^{7-8}$ as well as in packaging and tissue engineering. ${ }^{9-10}$ This is ascribed to the sometimes surprising structure property relationships for these foams with cell sizes of a few hundreds of nanometers and smaller. For instance, when the cell size in a closed cell foam is smaller than the collision mean free path of gas molecules ( $70 \mathrm{~nm}$ for air at standard conditions), ${ }^{11}$ the thermal conduction by the gas phase of the foam cells will significantly decrease due to the so called Knudsen effect. ${ }^{1-2}$ This makes nanocellular polymer foams very promising candidates as high performance thermal insulation materials.

A

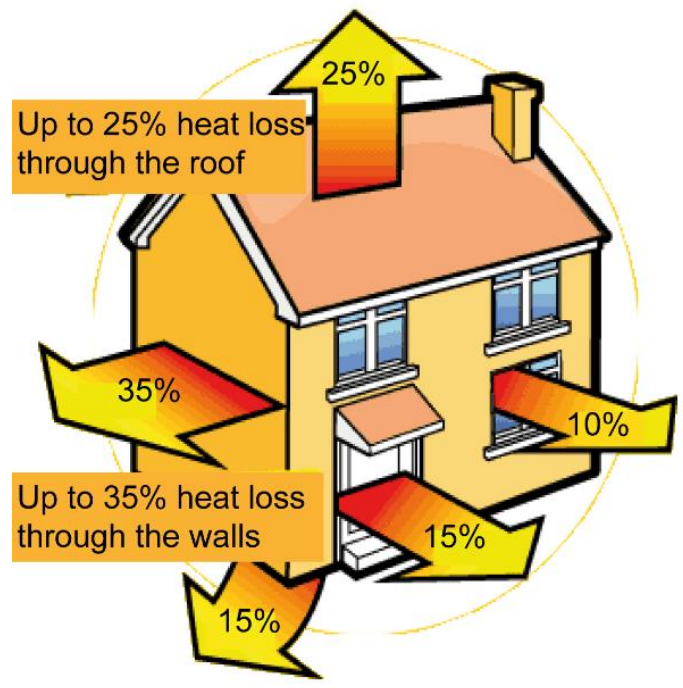

B Microcellular

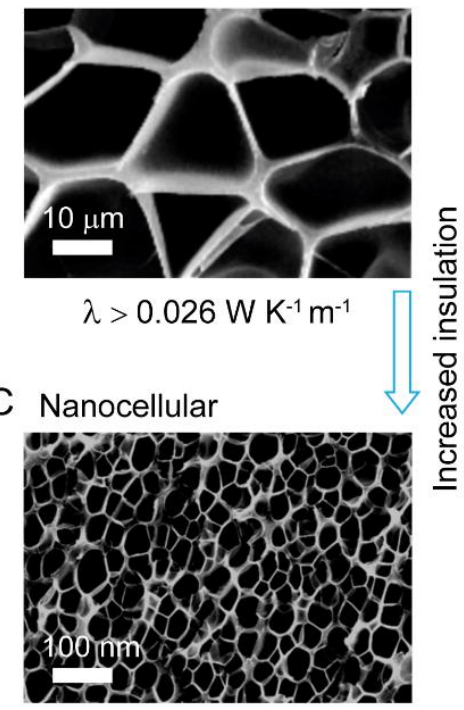

$\lambda<0.026 \mathrm{~W} \mathrm{~K}^{-1} \mathrm{~m}^{-1}$

Figure 1.1 Scheme of heat loss paths for a typical house (A); SEM images for typical microcellular foams with a relatively high thermal conductivity (B); and nanocellular foams (C) with a decreased thermal conductivity. Image (A) was obtained from reference [12]. Images (B) and $(\mathrm{C})$ were adapted with permission from reference [3]. Note that $0.026 \mathrm{~W} \mathrm{~K}^{-1} \mathrm{~m}^{-1}$ is the thermal conductivity of air under standard conditions. ${ }^{2}$

When considering that about $40 \%$ of the total energy consumption in Europe is used for heating and cooling of buildings and approximately $60 \%$ of this energy is lost through the walls and roofs of buildings, the energy saving potential by using better thermal insulation materials and strategies is evident (see Figure 1.1). ${ }^{3,13}$ In addition, when this potential is exploited globally, its contribution to national and international 
agreements concerning the reduction of fossil fuel consumption and $\mathrm{CO}_{2}$ emissions would be very significant. $^{3}$ The use of conventional materials, like expanded polystyrene (EPS) and extruded polystyrene (XPS) foam with thermal conductivities of $0.030-0.045 \mathrm{~W} \mathrm{~m}^{-1} \mathrm{~K}^{-1}$, necessitate employing thicker thermal insulation layers. This leads to increases in building costs and in highly populated areas to an expensive loss of effective floor space. Considering that for low density polystyrene foams the gas phase conduction of air inside the foam cells contributes with $0.026 \mathrm{~W} \mathrm{~m}^{-1} \mathrm{~K}^{-1}$ (i.e. significantly) to the total foam thermal conductivity ${ }^{2,14-15}$ it seems logical to focus on the development of insulation materials for which the gas phase thermal conductivity is substantially reduced.

Among the best thermal insulation materials available today are vacuum insulation panels (VIPs) ${ }^{16}$ and aerogel based materials. ${ }^{17}$ The gas phase conductivity of these materials is reduced to below $0.013 \mathrm{~W} \mathrm{~m}^{-1} \mathrm{~K}^{-1}$ as a consequence of the presence of vacuum, and pore sizes of below $100 \mathrm{~nm}$, respectively. ${ }^{17}$ Figure 1.2 shows a photo demonstrating the high thermal insulation performance of an aerogel. Despite their high thermal insulation efficiencies these materials suffer from processability and pricing issues, limiting their wide spread utilization. ${ }^{17-18}$ Therefore industrial and research efforts are directed towards the development of nanocellular polymer foams, including new foaming strategies, that will allow the economical viable bulk production of a new class of highly efficient thermal insulation materials approaching aerogel performance.

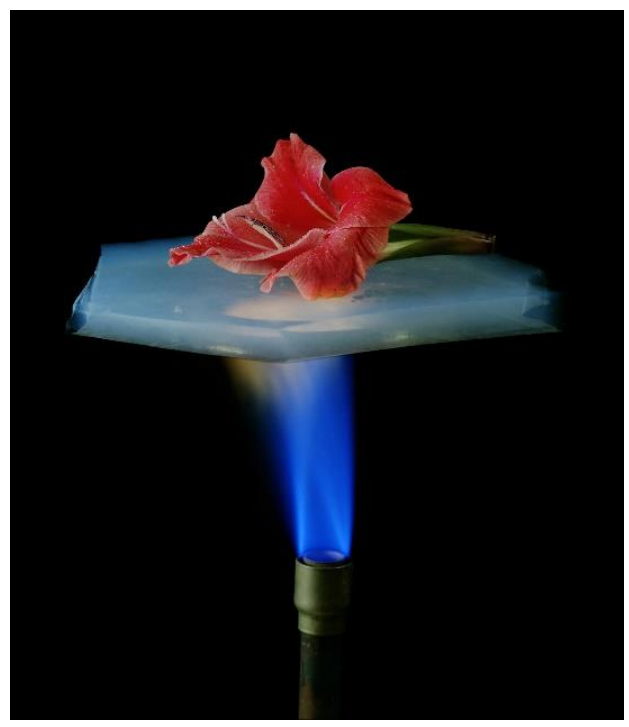

Figure 1.2 A photo showing the high thermal insulation performance of aerogel materials. The image was obtained from reference [19]. 
Unfortunately, fabrication of polymer foams with small cells at a high cell density still remains a challenge. ${ }^{5}$ In order to increase the foam cell density and decrease the cell size, the most commonly used strategy is to foam polymers following saturation with high pressure physical blowing agents, e.g. $>300$ bar $\mathrm{CO}_{2} \cdot{ }^{20-21}$ However, applications of foaming processes utilizing such high pressure gasses are limited in industrial practice. ${ }^{3}$

Besides the increase of the foaming pressure, another common strategy to improve the foam cell morphology is to introduce nanostructured heterogeneous phases, e.g. (nano)particles ${ }^{22-29}$ and block polymers, ${ }^{30-33}$ to the polymer matrix prior to foaming to act as heterogeneous nucleation sites during foaming. ${ }^{34}$ In general, it is accepted that to obtain cells with nanometer dimensions, heterogeneous cell nucleation is preferable compared to homogeneous nucleation due to the lower free energy required for this process. ${ }^{35}$ Silica nanoparticles are of particular interest as heterogeneous nucleation agents in polymer foaming due to their low cost, easy preparation, good size control and the ease of employing various surface functionalization strategies. ${ }^{25}, 36$ Figure 1.3 shows an example of the decreased cell size and increased cell density of a polystyrene foam nucleated by silica based nanoparticles as heterogeneous nucleation agents in $\mathrm{CO}_{2}$ assisted batch foaming. However, the reported nucleation efficiency for nanoparticles, defined as the ratio of foam cells obtained in $1 \mathrm{~cm}^{3}$ and number of added particles per $\mathrm{cm}^{3}$, is typically very low, i.e. below $0.01 .^{25,29,36}$ In other words, hundreds of welldispersed particles must be added to the polymer prior to foaming to eventually obtain one foam cell. Other types of nanofillers, such as nanofibers, nanotubes and nanoclay, suffer from low cell nucleation efficiencies, as well. ${ }^{23,26}$ In order to improve the nucleation efficiency of nanoparticles in nanocellular polymer foaming, new particle designs are urgently needed.

During the quest for obtaining designer nucleation agents for foaming, the influence of particles surface chemistry, surface curvature and surface texture on cell nucleation at the macromolecular length scale has been insufficiently reported in the open literature. Triggered by the apparent lack of in-depth understanding, it was of our interest to study the effect of $\mathrm{CO}_{2}$-philic low surface energy polymer shells grafted to inorganic nanoparticles, i.e. silica, on the cell nucleation efficiency. We also tackled an improved understanding of the physics behind nucleation in batch foaming processes. PDMS was selected to graft to silica nanoparticles due to its reported high $\mathrm{CO}_{2}$-philicity and low surface energy. ${ }^{37}$ Both are favorable parameters when improvements in foam cell nucleation is considered (see Chapter 2). ${ }^{37}$ Reports on nucleation agents consisting of hybrid silica polymer core shell nanoparticles were at the start of this project very sparse. $^{38-39}$ 

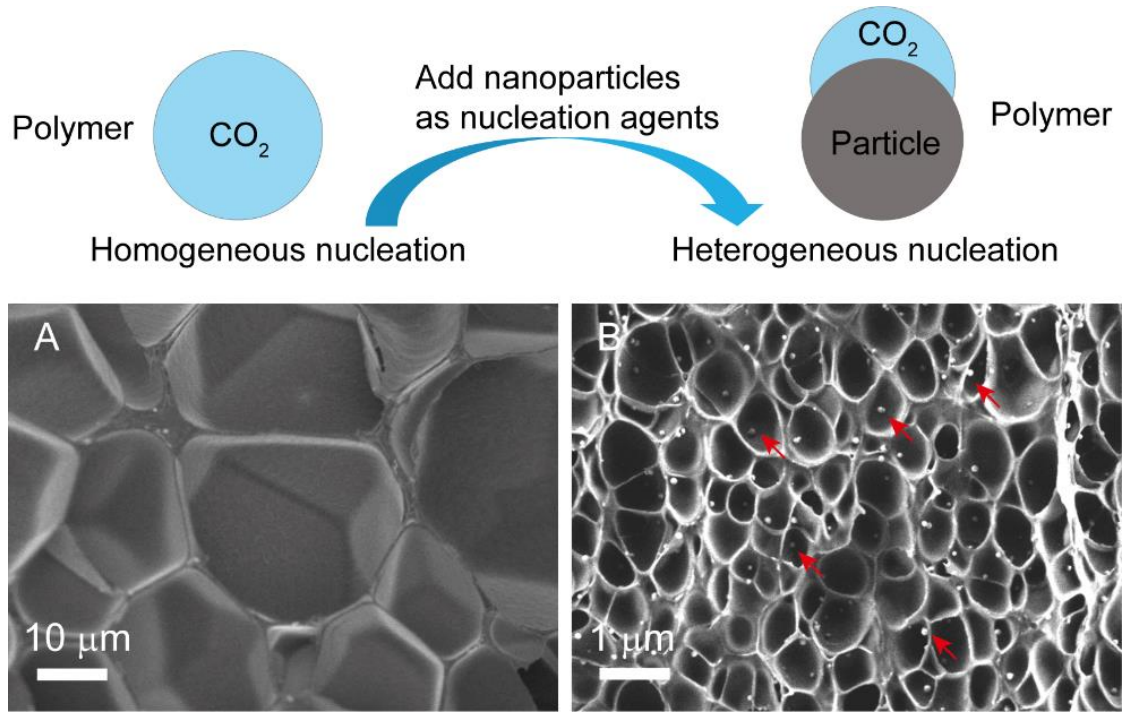

Figure 1.3 SEM images of cross sectioned polystyrene foams batch foamed without (A) and with silica based hybrid nanoparticles as heterogeneous nucleation agents (B). The red arrows in (B) point at some hybrid silica nanoparticles.

During the course of this project nucleation efficiencies of up to $\sim 0.5$ were obtained for PDMS grafted nanoparticles with a silica core diameter of $80 \mathrm{~nm}$ exploited as nucleating particles in polystyrene (PS) and poly(methyl methacrylate) (PMMA) batch foaming processes. This nucleation efficiency is significantly higher compared to the hitherto reported value of 0.01 . To study the influence of nanocavities on cell nucleation, PDMS decorated raspberry-like nanoparticles were also exploited and used as nucleation agents in PMMA foaming. Nucleation efficiencies of up to $\sim 6.2$ were achieved for this novel hybrid nucleating particle design. In fact, to the best of our knowledge, this is the first time that nanoparticle based nucleating agents with a nucleation efficiency of above unity were reported for nanocellular polymer batch foaming. This allowed us to use foaming strategies with relatively low saturation pressures (i.e. below 60 bar) while obtaining a cell nucleation density comparable to foaming strategies that require significantly higher physical blowing agent pressures. Together with the acquired deeper understanding of cell nucleation by highly curved particles and the contribution of line tension to their nucleation efficiency, a strong basis for the design and preparation of new generation nucleating particlesis presented. Eventually it is expected that the results and answers to relevant fundamental physical questions described in this work will contribute towards the development of nanocellular polymer foaming for industrial practice. 


\subsection{Concept of this Thesis}

The aim of the work described in this Thesis is to prepare and exploit designer nanoparticles as efficient foam nucleating agents in nanocellular polymer foaming. Silica nanoparticles with a $\mathrm{CO}_{2}$-philic PDMS, polystyrene or polyfluoride shells are presented as heterogeneous cell nucleation agents with high nucleation efficiencies. The ease of PDMS grafting and its excellent nucleation performance rendered the corresponding silica core shell nanoparticles as the central nucleating agent platform in this Thesis. In addition, the influence of nanoparticle surface curvature and topology on the foam cell nucleation efficiency, and on foam morphology is systematically studied and discussed.

Chapter 2 provides a literature review covering the general topics discussed in the subsequent chapters. Following a brief introduction to polymer foaming, particular attention is devoted to $\mathrm{CO}_{2}$ based foaming strategies. Emphasis is on new insights concerning heterogeneous nucleation at the macromolecular length scale and the thermal insulation performance of nanocellular polymer foams. Furthermore, the limitations and challenges in the understanding of the fundamental principles involved in cell nucleation in polymer nanocomposites foaming at the nanoscale are elucidated. Finally silica nanoparticle synthesis and subsequent surface derivatization strategies with polymers are discussed, as well.

Chapter 3 describes the synthesis of low surface energy polymer grafted silica nanoparticles and applications of the core-shell nanoparticles as heterogeneous nucleation agents in $\mathrm{CO}_{2}$ assisted PS and PMMA foaming. The cell nucleation efficiency and cell morphology of the nanocomposite foams as a function of nucleating particle type were studied. The results indicate that proper selection of the polymer grafts yields nucleation efficiency values of up to approximately 0.5 (i.e. 1 foam cell per 2 particles on average). This number was confirmed by the presence of only 2 to 4 PDMS grafted silica nanoparticles per cell in cross sectioned nanocellular PS and PMMA foams. Overall it is shown that the presence of a thin low surface energy, $\mathrm{CO}_{2}-$ philic polymer shell around silica nanoparticles is beneficial for cell nucleation compared to pristine particles.

In Chapter 4, bare and PDMS decorated core shell nanoparticles with different diameters were prepared and used as heterogeneous nucleation agents in $\mathrm{CO}_{2}$ blown PMMA nanocomposite foams. The influence of nanoparticle curvature and surface chemistry on cell nucleation and cell morphology was studied. The results obtained show that independent of the particle diameter, cell nucleation by nanoparticles was significantly enhanced by the presence of a grafted thin PDMS shell compared to their bare silica nanoparticle counterparts. The optimum core diameter of PDMS grafted nanoparticles for cell nucleation is around $80 \mathrm{~nm}$ which results in a nucleation 
efficiency of $\sim 0.5$. Strikingly, the complete engulfment of particles with a (core) diameter below 40 nanometer at the cell wall interface points toward the presence of a positive line tension of $\sim 0.42 \mathrm{nN}$. This line tension significantly increases the heterogeneous nucleation energy barrier and as a consequence reduces the nucleation efficiency, in particular for the smaller core shell particles, i.e. for particles with a diameter below $40 \mathrm{~nm}$. At higher $\mathrm{CO}_{2}$ pressure drops the line tension length increased such that particles up to 80 nanometer were nearly entirely engulfed. It is shown for the first time that the contribution of line tension to the heterogeneous nucleation energy barrier needs to be considered in foaming of viscoelastic media in the foam processing window where heterogeneous nucleation is favorable. This pointed towards the need for new strategies and particle designs to further enhance the nucleation efficiency of nanoparticles.

Chapter 5 describes the influence of nanoparticle surface curvature and surface chemistry on the adhesion behavior of particles residing at the $\mathrm{CO}_{2}$ swollen PMMA $\mathrm{CO}_{2}$ interface. The experiments reveal how silica nanoparticles adhere to an elastic PMMA film surface above its glass transition temperature. The polymer was swollen with $\mathrm{CO}_{2}$, which closely matched the conditions of nanoparticle nucleated polymer foaming as presented in Chapters 3 and 4. It is shown that the relative degree by which the particles sink into the substrate is strongly size-dependent, and can even lead to complete engulfment for particles with a diameter below $12 \mathrm{~nm}$. These findings are explained quantitatively by a thermodynamic analysis, combining elasticity, capillary adhesion and line tension. The deep understanding of the interfacial interactions between nanoparticles and $\mathrm{CO}_{2}$ swollen polymer matrix acquired is expected to aid in the optimization of nucleating nanoparticle design in combination with foaming conditions in nanocellular polymer foaming.

In Chapter 6, bare and PDMS decorated raspberry-like silica nanoparticles were synthesized and exploited as heterogeneous nucleation agents in $\mathrm{CO}_{2}$ blown PMMA nanocellular foams. Here surface texture was considered as a particle design parameter since the free energy for cell nucleation is lower for nucleation from cavities with the right surface chemistry. The results show for the first time that multiple cells can nucleate and grow from a single PDMS decorated raspberry-like nanoparticle. The effect of surface texture on the cell nucleation efficiency is qualitative presented and discussed. It is reported that PMMA films containing raspberry-like silica nanoparticles absorbed significantly more $\mathrm{CO}_{2}$ during saturation compared to the relatively smooth particles. This is ascribed to capillary condensation of $\mathrm{CO}_{2}$ in the nanocavities of the textured particles. Surprisingly, the presence of a PDMS shell resulted in a further increase of $\mathrm{CO}_{2}$ absorption for the raspberry-like silica nanoparticles. This resulted in unexpectedly high nucleation efficiencies for these particles. 
The highest nucleation efficiency of $\sim 6.2$ was obtained for a PDMS decorated raspberry silica core shell nanoparticle with a diameter of $\sim 200 \mathrm{~nm}$. This nucleation efficiency is $\sim 21$ and $\sim 40$ times higher compared to that of its bare raspberry and nearly spherical counterparts, respectively. To conclude, the significant higher cell nucleation efficiency of PDMS grafted raspberry silica nanoparticles is ascribed to a combination of $i$ ) the PDMS shell as favorable nucleation layer, ii) the significant increased absorbed $\mathrm{CO}_{2}$ concentration and iii) the reduced free energy for cell nucleation by "nano" cavities.

The fundamental insights in heterogeneous cell nucleation at the nanometer length scale obtained in this Thesis offers a framework for the design of highly efficient nucleation agents for the eventual preparation of nanocellular polymer foams with cell densities exceeding $10^{14}$ cell $\mathrm{cm}^{-3}$. Chapter 7 provides an outlook for future directions. In particular, suggestions for the improvement and exploitation of designer nanoparticles as nucleating agents in nanocellular polymer foaming are presented. The importance of obtaining a deeper understanding of foaming at the macromolecular length scale in general is underlined, as well. In this Thesis one type of PMMA was the "work horse" for the majority of all experiments. Recent results reported however pointed out that optimization of the polymer matrix is also required. ${ }^{20,40-41}$ It is anticipated that combining polymer foam matrices optimized for foaming with designer nucleating agents as presented in this Thesis eventually results in nanocellular foams with cell densities exceeding $10^{14}$ cells $\mathrm{cm}^{-3}$ that can be prepared in industrially relevant processes.

\section{References}

[1] Notario, B.; Pinto, J.; Solorzano, E.; De Saja, J. A.; Dumon, M.; Rodríguez-Pérez, M. A. Experimental validation of the Knudsen effect in nanocellular polymeric foams. Polymer 2015, 56, 57-67.

[2] Forest, C.; Chaumont, P.; Cassagnau, P.; Swoboda, B.; Sonntag, P. Polymer nano-foams for insulating applications prepared from $\mathrm{CO}_{2}$ foaming. Progress in Polymer Science 2015, 41, 122-145.

[3] Liu, S.; Duvigneau, J.; Vancso, G. J. Nanocellular polymer foams as promising high performance thermal insulation materials. European Polymer Journal 2015, 65, 33-45.

[4] Dai, X.; Liu, Z.; Wang, Y.; Yang, G.; Xu, J.; Han, B. High damping property of microcellular polymer prepared by friendly environmental approach. The Journal of Supercritical Fluids 2005, 33, 259-267. 
[5] Costeux, S. $\mathrm{CO}_{2}$-blown nanocellular foams. Journal of Applied Polymer Science 2014, 131, 41293-41308.

[6] Shastri, V. P.; Martin, I.; Langer, R. Macroporous polymer foams by hydrocarbon templating. Proceedings of the National Academy of Sciences 2000, 97, 1970-1975.

[7] Shen, B.; Zhai, W.; Tao, M.; Ling, J.; Zheng, W. Lightweight, multifunctional polyetherimide/graphene@ $\mathrm{Fe}_{3} \mathrm{O}_{4}$ composite foams for shielding of electromagnetic pollution. ACS Applied Materials \& Interfaces 2013, 5, 11383-11391.

[8] Liu, Z.; Bai, G.; Huang, Y.; Ma, Y.; Du, F.; Li, F.; Guo, T.; Chen, Y. Reflection and absorption contributions to the electromagnetic interference shielding of single-walled carbon nanotube/polyurethane composites. Carbon 2007, 45, 821-827.

[9] Rezwan, K.; Chen, Q.; Blaker, J.; Boccaccini, A. R. Biodegradable and bioactive porous polymer/inorganic composite scaffolds for bone tissue engineering. Biomaterials 2006, 27, 3413-3431.

[10] Ma, P. X.; Langer, R. Fabrication of biodegradable polymer foams for cell transplantation and tissue engineering. Tissue Engineering Methods and Protocols 1999, 18, 47-56.

[11] Berge, A.; Johansson, P. Literature review of high performance thermal insulation. Chalmers University of Technology, 2012.

[12] Image obtained from <Image from: http://www.aconcordcarpenter.com/evaluate-yourhomes-energy-efficiency.html $>$.

[13] P. NowakowskiLect Notes Comput Sci, 2009, 5615, p. 100.

[14] Papadopoulos, A. M. State of the art in thermal insulation materials and aims for future developments. Energy and Buildings 2005, 37, 77-86.

[15] Danowska, M.; Piszczyk, Ł.; Strankowski, M.; Gazda, M.; Haponiuk, J. T. Rigid polyurethane foams modified with selected layered silicate nanofillers. Journal of Applied Polymer Science 2013, 130, 2272-2281.

[16] Alam, M.; Singh, H.; Limbachiya, M. Vacuum Insulation Panels (VIPs) for building construction industry-A review of the contemporary developments and future directions. Applied Energy 2011, 88, 3592-3602.

[17] Baetens, R.; Jelle, B. P.; Gustavsen, A. Aerogel insulation for building applications: a stateof-the-art review. Energy and Buildings 2011, 43, 761-769.

[18] Baetens, R.; Jelle, B. P.; Thue, J. V.; Tenpierik, M. J.; Grynning, S.; Uvsløkk, S.; Gustavsen, A. Vacuum insulation panels for building applications: A review and beyond. Energy and Buildings 2010, 42, 147-172.

[19] https://simple.wikipedia.org/wiki/Aerogel\#/media/File:Aerogelflower_filtered.jpg.

[20] Guo, H.; Nicolae, A.; Kumar, V. Solid-state poly (methyl methacrylate)(PMMA) nanofoams. Part II: Low-temperature solid-state process space using $\mathrm{CO}_{2}$ and the resulting morphologies. Polymer 2015, 70, 231-241.

[21] Martín-de León, J.; Bernardo, V.; Rodríguez-Pérez, M. Á. Low density nanocellular polymers based on PMMA produced by gas dissolution foaming: fabrication and cellular structure characterization. Polymers 2016, 8, 265. 
[22] Lee, L. J.; Zeng, C.; Cao, X.; Han, X.; Shen, J.; Xu, G. Polymer nanocomposite foams. Composites Science and Technology 2005, 65, 2344-2363.

[23] Zeng, C.; Han, X.; Lee, L. J.; Koelling, K. W.; Tomasko, D. L. Polymer-clay nanocomposite foams prepared using carbon dioxide. Advanced Materials 2003, 15, 17431747.

[24] Zhang, H.-B.; Yan, Q.; Zheng, W.-G.; He, Z.; Yu, Z.-Z. Tough graphene polymer microcellular foams for electromagnetic interference shielding. ACS Applied Materials \& Interfaces 2011, 3, 918-924.

[25] Zhai, W.; Yu, J.; Wu, L.; Ma, W.; He, J. Heterogeneous nucleation uniformizing cell size distribution in microcellular nanocomposites foams. Polymer 2006, 47, 7580-7589.

[26] Shen, J.; Zeng, C.; Lee, L. J. Synthesis of polystyrene-carbon nanofibers nanocomposite foams. Polymer 2005, 46, 5218-5224.

[27] Yang, Y.; Gupta, M. C.; Dudley, K. L.; Lawrence, R. W. Novel carbon nanotubepolystyrene foam composites for electromagnetic interference shielding. Nano Letters $\mathbf{2 0 0 5}$, $5,2131-2134$.

[28] Costeux, S.; Zhu, L. Low density thermoplastic nanofoams nucleated by nanoparticles. Polymer 2013, 54, 2785-2795.

[29] Goren, K.; Chen, L.; Schadler, L. S.; Ozisik, R. Influence of nanoparticle surface chemistry and size on supercritical carbon dioxide processed nanocomposite foam morphology. The Journal of Supercritical Fluids 2010, 51, 420-427.

[30] Spitael, P.; Macosko, C. W.; McClurg, R. B. Block copolymer micelles for nucleation of microcellular thermoplastic foams. Macromolecules 2004, 37, 6874-6882.

[31] Ruiz, J. A. R.; Pedros, M.; Tallon, J.-M.; Dumon, M. Micro and nano cellular amorphous polymers (PMMA, PS) in supercritical $\mathrm{CO}_{2}$ assisted by nanostructured $\mathrm{CO}_{2}$-philic block copolymers-one step foaming process. The Journal of Supercritical Fluids 2011, 58, 168176.

[32] Li, L.; Nemoto, T.; Sugiyama, K.; Yokoyama, H. $\mathrm{CO}_{2}$ foaming in thin films of block copolymer containing fluorinated blocks. Macromolecules 2006, 39, 4746-4755.

[33] Shinkai, T.; Sugiyama, K.; Ito, K.; Yokoyama, H. Nanoporous fabrication of block copolymers via carbon dioxide swelling: difference between $\mathrm{CO}_{2}$-swollen and nanoporous block copolymers. Polymer 2016, 100, 19-27.

[34] Siripurapu, S.; DeSimone, J. M.; Khan, S. A.; Spontak, R. J. Low-temperature, surfacemediated foaming of polymer films. Advanced Materials 2004, 16, 989-994.

[35] Oxtoby, D. W. Density functional methods in the statistical mechanics of materials. Annual Review of Materials Research 2002, 32, 39-52.

[36] Siripurapu, S.; DeSimone, J. M.; Khan, S. A.; Spontak, R. J. Controlled foaming of polymer films through restricted surface diffusion and the addition of nanosilica particles or $\mathrm{CO}_{2-}$ philic surfactants. Macromolecules 2005, 38, 2271-2280.

[37] Shi, W.; Siefert, N. S.; Morreale, B. D. Molecular simulations of $\mathrm{CO}_{2}, \mathrm{H}_{2}, \mathrm{H}_{2} \mathrm{O}$, and $\mathrm{H}_{2} \mathrm{~S}$ gas absorption into hydrophobic poly(dimethylsiloxane) (PDMS) solvent: solubility and surface tension. The Journal of Physical Chemistry C 2015, 119, 19253-19265. 
[38] Yang, J.; Sang, Y.; Chen, F.; Fei, Z.; Zhong, M. Synthesis of silica particles grafted with poly (ionic liquid) and their nucleation effect on microcellular foaming of polystyrene using supercritical carbon dioxide. The Journal of Supercritical Fluids 2012, 62, 197-203.

[39] Nederkoorn, P. H. J.; Duvigneau, J.; Vancso, J.; Wassing, T., Polymer foam comprising a polymer and nanoparticles, and nanoparticles for the manufacture of such foam. Google Patents: 2013.

[40] Liao, Z. E.; Yeh, S. K.; Chu, C. C.; Tseng, T. W. In critical parameters of generating PMMA nanocellular foam. Annu. Tech. Conf.-Soc. Plast. Eng, 2016, 1773-1778.

[41] Notario, B.; Pinto, J.; Rodríguez-Pérez, M. Towards a new generation of polymeric foams: PMMA nanocellular foams with enhanced physical properties. Polymer 2015, 63, 116-126. 


\section{Chapter 2}

\section{Nanocellular Polymer Foams as Promising High Performance Thermal Insulation Materials}

Low density, nanocellular polymer nanocomposite foams are considered as a promising new class of materials with many potential applications, for example to passively enhance the energy efficiency of buildings. This Chapter reviews recent developments in this field of polymer materials science. Particular attention will be devoted to $\mathrm{CO}_{2}$ based foaming strategies. The emphasis of this Chapter is on new insights concerning heterogeneous nucleation at the macromolecular length scale and the thermal insulation performance of nanocellular polymer foams. Furthermore, this Chapter discusses the limitations and challenges that remain to be solved before these highly promising nanocomposites become available on a commercially viable scale. The shortcomings in the understanding of the fundamental principles involved in cell nucleation in polymer nanocomposites at the nanoscale are elucidated in this Chapter as well. Since hybrid core shell silica nanoparticles are successfully exploited as heterogeneous nucleating agent in this Thesis their synthesis is presented and discussed in detail.

\footnotetext{
*Part of this Chapter has been published in: Liu, S.; Duvigneau, J.; Vancso, G. J. Nanocellular polymer foams as promising high performance thermal insulation materials. European polymer journal 2015, 65, 33-45.
} 


\subsection{Preparation of nanocellular foams with $\mathrm{CO}_{2}$}

In the last decade an enhanced understanding of the reproducible nanocellular foam production has attracted great attention. ${ }^{1-6}$ In particular it is now evident that the addition of surface engineered inorganic nanoparticles with improved nucleation efficiencies to polymers is promising for driving the development towards cell nucleated and gas blown plastic aerogels with cell sizes close to the mean free path of gas molecules $(<100 \mathrm{~nm})$, while maintaining a sufficiently low foam density to ensure low thermal conduction through the matrix. ${ }^{5,20}$ In order for nanocellular materials to meet these criteria at least $10^{14}$ cells per $\mathrm{cm}^{3}$ of unfoamed material or more must be nucleated, expanded and stabilized. ${ }^{2}$ Expansion and stabilization of the cells can be achieved via e.g. control over viscosity or temperature as is demonstrated by numerous examples. ${ }^{21-30}$ It is of primary interest to understand foam cell nucleation at the macromolecular length scale as well as how the thermal conductivity of nanocellular polymer based materials is related to their morphology. Before these aspects of foaming will be presented and discussed in detail this section will first introduce batch foaming of polymers in general.

Foaming of polymers results in materials that feature trapped pockets of gas in a stable solid matrix phase. The solid typically consists of at least one polymer and potentially of multiple polymers and/or additives. ${ }^{31}$ The trapped gas can be confined to bubbles (closedcell foams) or to interconnected channels (open-cell foams). The gas is delivered by physical or chemical blowing agents. ${ }^{32-38}$ Commonly used blowing agents include hydrofluorocarbons (HFCs), e.g. HFC-245fa and hydrocarbons, e.g. pentane. ${ }^{39-40}$ The use of gases such as $\mathrm{CO}_{2}$ and nitrogen is receiving considerable attention from the early $90 \mathrm{~s} .{ }^{41}$ $\mathrm{CO}_{2}$ is proposed as a blowing agent to replace CFCs and HCFCs which are banned due to their contribution to ozone depletion and/or global warming. Despite the environmental and economic advantages of using $\mathrm{CO}_{2}$, the low solubility (i.e. typically a few wt $\%$ or less) of this gas in most conventional polymer melts is a problem. ${ }^{1}$ Thus the foaming process results in rather high foam densities. Utilization of co-blowing agents, $e$.g. ethanol or water, have been demonstrated to enhance the $\mathrm{CO}_{2}$ solubility and eventually provide a better foam morphology. ${ }^{42-45}$ However, co-blowing agents other than water are also often plagued by negative environmental impact such as the banned CFCs. In addition, $\mathrm{CO}_{2}$ has a high diffusivity, which means that after foaming rapid diffusion of $\mathrm{CO}_{2}$ out of the foam and relatively slow diffusion of air into the foam can cause foam instability and eventually cell collapse. ${ }^{46-47}$ Besides being 'greener', $\mathrm{CO}_{2}$ uptake by a polymer (melt) also alters its processability. For instance, $\mathrm{CO}_{2}$ dissolution in polystyrene (PS) was reported to lower the glass transition by over $50{ }^{\circ} \mathrm{C} .{ }^{48}$ This implies that using $\mathrm{CO}_{2}$ as a blowing agent yields different and often small processing windows. However $\mathrm{CO}_{2}$ is still favorable over the use of solvent based approaches that are frequently encountered to prepare nanocellular polymers, such as microemulsion templating ${ }^{49-51}$ or sol gel 
techniques, ${ }^{52}$ since these often require time consuming solvent exchange steps and supercritical or freeze drying to preserve the nanocellular structure. A particularly interesting processing window is observed for polymers that have retrograde vitrification behavior, i.e. for a certain pressure regime they have two glass transition temperatures. For a pressure in this regime the $\mathrm{CO}_{2}$ solubility is at low temperatures high enough to have a plasticizing effect, i.e. the polymer $\mathrm{CO}_{2}$ saturated system is in a viscoelastic state. Upon increasing the temperature (for the same pressure) the $\mathrm{CO}_{2}$ solubility decreases and the polymer exhibits a low temperature glass transition $\left(T_{g}\right.$, low $)$. Upon further heating a transition from the glassy state to a viscoelastic state is observed $\left(T_{g}\right.$, high), which is ascribed to the increased chain mobility at higher temperatures. For instance, Handa and Zhang reported ${ }^{53}$ on the batch $\mathrm{CO}_{2}$ foaming (see below) of poly(methyl methacrylate) (PMMA) exploiting the retrograde vitrification behavior to yield nanocellular PMMA foams.

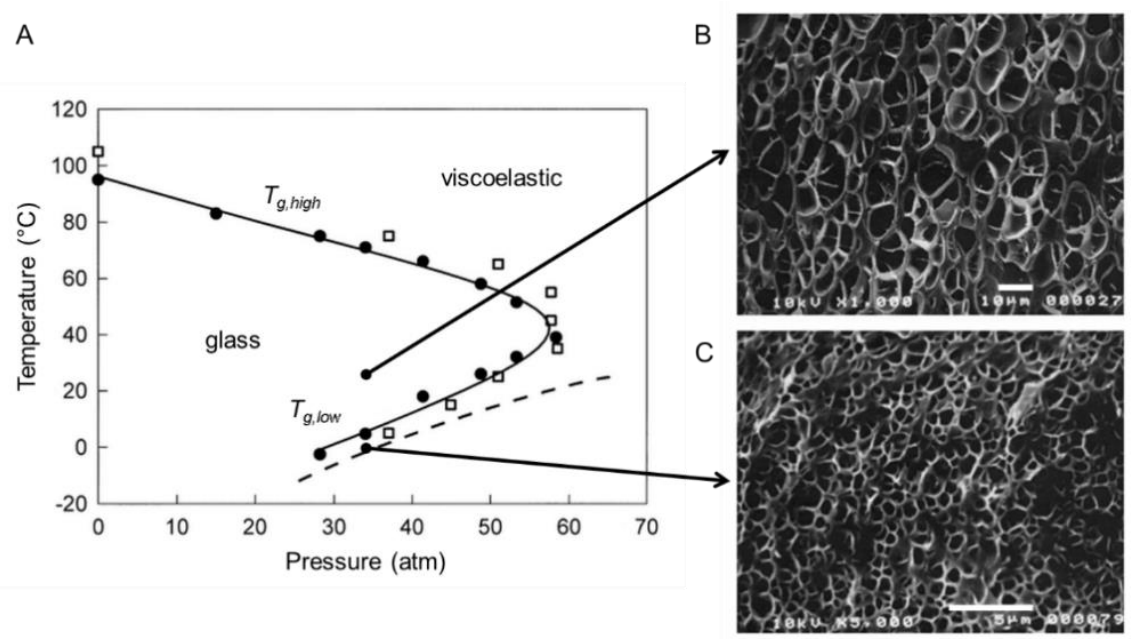

Figure 2.1 $\mathrm{T}_{\mathrm{g}}$ as a function of $\mathrm{CO}_{2}$ saturation pressure for PMMA as determined from DSC measurements (A). The solid line is a guide for the eye to clarify the $\mathrm{T}_{\mathrm{g}}$, low and $\mathrm{T}_{\mathrm{g}}$, high transitions. The dashed line is the $\mathrm{CO}_{2}$ liquid vapor equilibrium boundary. The images in (B) and (C) show cross sectional SEM images of foams prepared after saturation with $34 \mathrm{~atm} \mathrm{CO}_{2}$ for 24 hours at temperatures above $\left(24^{\circ} \mathrm{C}\right)$ and below $\left(-0.2^{\circ} \mathrm{C}\right) \mathrm{T}_{\mathrm{g}}$, low (indicated by the arrows), followed by rapid depressurization and foaming at $80^{\circ} \mathrm{C}$ for 2 minutes. The scale bars in (B) and (C) represent $10 \mu \mathrm{m}$ and $5 \mu \mathrm{m}$, respectively. Reprinted from reference [53], with permission from John Wiley and Sons.

Figure 2.1 shows both glass transition temperatures for PMMA as a function of the $\mathrm{CO}_{2}$ saturation pressure (A). Cross sectional SEM images are also displayed, showing PMMA foams obtained after saturating a PMMA film with 34 bar $\mathrm{CO}_{2}$ at $-0.2{ }^{\circ} \mathrm{C}(\mathrm{B})$ and $24^{\circ} \mathrm{C}(\mathrm{C})$, followed by a rapid pressure release and heating the films to $80{ }^{\circ} \mathrm{C}$ in a water 
bath. The foam prepared after saturation at $24{ }^{\circ} \mathrm{C}$ was microporous $(\approx 4.8 \mu \mathrm{m})$ while the foam prepared after saturation at $-0.2{ }^{\circ} \mathrm{C}$ was nanocellular $(\approx 350 \mathrm{~nm})$. It was observed that choosing the saturation conditions such that the pressure and temperature are in between the $T_{g}$, low and the vapor liquid equilibrium for $\mathrm{CO}_{2}$ results in interesting processing conditions.

Foaming processes are either non-continuous, e.g. batch foaming, injection molding foaming; or continuous, such as extrusion foaming. ${ }^{41}$ Currently, BASF has reported on the continuous extrusion of nanocellular PMMA with an extruder ${ }^{54}$ The gas injection to the polymer melt was realized at 480 bar and cooling of the $\mathrm{CO}_{2}$ saturated melt to approximately the glass transition temperature of the neat PMMA $\left(102{ }^{\circ} \mathrm{C}\right)$ was achieved via static mixers and melt pumps while maintaining a minimum pressure of $350 \mathrm{bar}$. The extruder die was $0.5 \mathrm{~mm}$ in diameter and about $1.8 \mathrm{~mm}$ in length resulting in a high pressure drop which favors nucleation (see section 2.4). The foams with about $100 \mathrm{~nm}$ pores and a density of approximately $200 \mathrm{~kg} / \mathrm{m}^{3}$ appeared bluish with incident light. Nanocellular foams have been prepared in semi continuous processes, as well. An early example of this was reported by Krause and coworkers. ${ }^{55}$ In their setup a PEI monofilament was saturated with $\mathrm{CO}_{2}$ at 50 bar for 8 hours at room temperature after which the saturated filament was pulled through a specially designed die and for certain conditions open nanocellular morphologies were obtained. In addition, more recently Costeux and coworkers ${ }^{56}$ reported on the production of nanocellular foams consisting of a PMMA copolymer and its silica nanocomposites with an extruder in a, what appears to be, batchwise operation. The PMMA melt, including about $0.25 \mathrm{wt} \%$ Aerosil 300, was oversaturated with $\mathrm{CO}_{2}$ at approximately $170{ }^{\circ} \mathrm{C}$ and 560 bar at which the $\mathrm{CO}_{2}$ solubility was around $15 \mathrm{wt} \%$. Subsequently, the extruder was allowed to cool in 30 minutes to $38{ }^{\circ} \mathrm{C}$ at which the $\mathrm{CO}_{2}$ solubility was approximately $33 \mathrm{wt} \%$ followed by extrusion of the saturated copolymer through a $1 \times 3 \mathrm{~mm}$ die. The resultant foam had relatively monodisperse pores with diameters of about $390 \mathrm{~nm}$ and a density of approximately 360 $\mathrm{kg} / \mathrm{m}^{3}$.

This is mainly ascribed to the difficult control of key physical parameters, e.g. viscosity, $\mathrm{CO}_{2}$ solubility, diffusivity and temperature. The presented (semi)continuous processes are still only capable of producing foams on a rather small scale and thus regardless of the quality of the foam morphology the scaling issue remains to be solved. In view of market demands however, it is anticipated that in the near future new strategies will be introduced to scale the production of nanocellular foams.

Presently the majority of the reported work on the preparation of nanocellular polymers is based on batch foaming processes. This approach has been used for the foaming of amorphous and semi-crystalline polymers, including engineering plastics, as well as for nanocomposites and nanostructured blends. In batch foaming the polymer is saturated with $\mathrm{CO}_{2}$ at a known pressure and temperature (see Figure 2.2). Foaming is 
induced upon releasing the pressure or by increasing the temperature such that the dissolved $\mathrm{CO}_{2}$ becomes oversaturated in the matrix and cell nucleation occurs. ${ }^{18}$ It is believed that generation of nanocellular polymers with high enough cell densities require the saturation of a polymer with $\mathrm{CO}_{2}$ at lower temperatures, facilitating a higher solubility of the $\mathrm{CO}_{2}$. In order for the foam to expand, often a subsequent thermal conditioning step is required. ${ }^{2}$

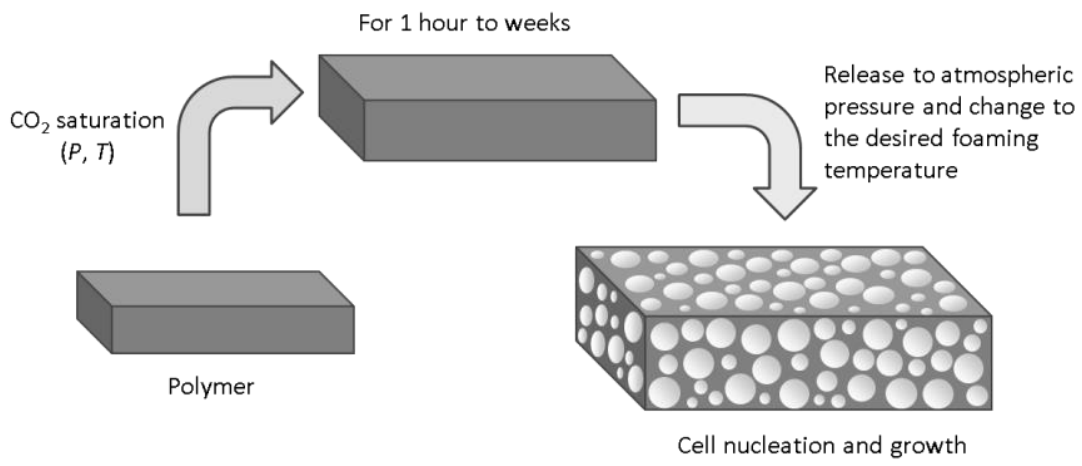

Figure 2.2 Schematic for batch foaming of a polymer with $\mathrm{CO}_{2}$.

The relatively high pressures (up to several hundreds of bars) and long saturation times (up to weeks) required for batch foaming render this process mainly applicable for research in which relatively small pieces of foams are produced. The amount of foam that is prepared in a batch is limited to the size of the autoclave used. Another drawback of this approach is that often only thin foams are obtained with a homogenous morphology. Typical foam thickness is well below $1 \mathrm{~mm}$, while for thermal insulation of buildings several $\mathrm{cm}$ thick foams are preferred. In addition, nanocellular polymer foams with a rather thick skin layer and/or additional microporous intermediate layers are frequently produced. Nonetheless, following the pioneering work of Krause and coworkers, ${ }^{57}$ batch foaming provided valuable insights in polymer foaming behavior, foaming conditions and morphology control. Recently the preparation of relatively thick, homogeneous nanocellular foams was also achieved (see section 3). ${ }^{58}$ Krause and coworkers reported on the foaming of poly(ether imide) (PEI) and poly(ether sulfone) (PES) ${ }^{59}$ with a nanocellular morphology via batch foaming with $\mathrm{CO}_{2}$ saturation pressures not higher than 50 bar. Rodríguez-Pérez and coworkers ${ }^{60}$ reported the successful fabrication of PMMA nanocellular foams following the saturation of PMMA films with 33 bar $\mathrm{CO}_{2}$ with a cell size between $200 \mathrm{~nm}$ and $250 \mathrm{~nm}$ and a cell density exceeding $10^{14}$ cells $\mathrm{cm}^{-3}$. Tseng and coworkers $^{61}$ reported the preparation of PMMA nanocellular foams following high pressure $\mathrm{CO}_{2}$ saturation (i.e. 138 bar), as well. The authors suggested that the viscosity of the $\mathrm{CO}_{2}$ swollen PMMA during foaming is one of the critical issues that affects the preparation of PMMA nanocellular foams. Kumar and coworkers ${ }^{62}$ reported nanocellular 
PMMA foams prepared after saturation with 50 bar $\mathrm{CO}_{2}$ at temperatures between $-30{ }^{\circ} \mathrm{C}$ and $100{ }^{\circ} \mathrm{C}$ and they argued that the $\mathrm{CO}_{2}$ solubility is a key parameter to control the foam morphology.

Oshima and coworkers ${ }^{63}$ reported on the foaming of PS/PMMA blends prepared by in situ polymerization of PMMA nano sized confined domains in PS. Foaming of $1 \mathrm{~mm}$ thick samples was performed by saturating with 82 bar $\mathrm{CO}_{2}$ at $40{ }^{\circ} \mathrm{C}$ followed by cooling to the desired foaming temperature, i.e. $20-40{ }^{\circ} \mathrm{C}$. Subsequently, foaming was initiated by releasing the pressure to atmospheric pressure at a controlled rate, i.e. 1 or 5 bar min 1. The effect of blend composition, foaming temperature and depressurization rate on the foam morphology was elucidated. The optimized foam had approximately $50 \mathrm{~nm}$ cells and a cell density of about $8.5 \times 10^{14}$ cells $/ \mathrm{cm}^{3}$. This in situ blend preparation approach offers an attractive alternative strategy that avoids the use of block copolymers ${ }^{64-68}$ to control the foam morphology via confined $\mathrm{CO}_{2}$-philic domains. Costeux and coworkers ${ }^{69}$ described that the batch foaming of poly(styrene-co-acrylonitrile) (SAN) to which poly(ethyl methacrylate) (PEMA) or poly(methyl methacrylate-co-ethyl acrylate) (PMMA-co-EA) was added resulted in the formation of foams with smaller cells and a narrower cell size distribution. It was shown that PMMA-co-EA blends with SAN resulted in general in foams with a cell size to below $100 \mathrm{~nm}$ and a cell density of up to 5 $\mathrm{x} 10^{15}$ cells $/ \mathrm{cm}^{3}$. The authors, interestingly, argued that the better foam morphology, i.e. higher cell density, smaller cells and higher porosity, of the blends with a smaller $\mathrm{CO}_{2}$ content points towards a new mechanism for the nucleation of cells in a polymer in which i) macromolecular elasticity driven restriction of initial nuclei growth or $i i$ ) the existence of a separate $\mathrm{CO}_{2}$ phase or $\mathrm{CO}_{2}$ concentration fluctuations play a dominant role for the formation of these high numbers of cells at the foaming conditions used.

In order to improve the foam morphology, the design of batch foaming equipment also received attention. For instance, Janani and Famili ${ }^{70}$ presented a batch foaming device that allowed the instantaneous pressure release $\left(\approx 3000 \mathrm{bar} \mathrm{sec}^{-1}\right)$ to facilitate high cell nucleation rates followed by a rapid temperature quench to stabilize the (nanocellular) foam. The authors demonstrated that with their setup the formation of a skin layer as typically observed after batch foaming was prevented due to the increased cell nucleation.

\subsection{Addition of heterogeneous nucleating particles}

The addition of (nano)fillers to serve as heterogeneous nucleation agents favoring a higher cell density is extensively researched and reported, as well. Colton and Suh ${ }^{71-73}$ were among the first to report on the addition of heterogeneous nucleation agents to a polymer matrix. They used zinc stearate below its solubility limit in PS foaming and 
proved that heterogeneous nucleation was favored over homogeneous nucleation in their case. They also observed that the nucleation efficiency was only affected by the concentration of zinc stearate. Subsequently, it has been widely recognized that the addition of a low weight percentage of well dispersed nanoparticles to polymers offers a large number of potential nucleation sites. An additional advantage of adding nanoparticles is that the large number of heterogeneous nucleated cells rapidly consume the available blowing agent, frequently resulting in a narrower cell size distribution for nanocomposite foams compared to their pristine counterparts. Successful examples in which the nucleation efficiency was increased upon the addition of nanoparticles include

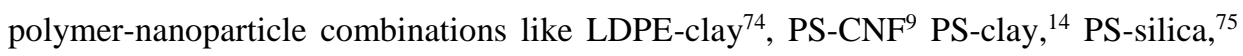
PMMA-clay, ${ }^{14}$ PMMA-MWCNT, ${ }^{76}$ PMMA-silica, ${ }^{16}$ SAN-clay ${ }^{77}$ and PU-clay. ${ }^{78}$ It is of key importance that the nucleation sites are evenly distributed in the unfoamed polymer, since a poor distribution results in the formation of inhomogeneous foams potentially with diminishing property enhancement (insulation). The preparation of well dispersed nanocomposites and the nucleation ability of nanoparticles in nanocomposite foams is since then widely investigated and reviewed. The interested reader is directed to the earlier recommended reviews. ${ }^{2,5,12,35,41}$

At this point it is noteworthy to refer to the recent work by Costeux and coworkers ${ }^{58}$ presenting the production of several millimeter thick nanocellular PMMA-co-EA nanocomposite foams via supercritical $\mathrm{CO}_{2}$ batch foaming. Silica nanoparticle or methacryl substituted POSS nanocomposite films were saturated with $\mathrm{CO}_{2}$ at pressures up to 330 bar for several hours. Following depressurization and foaming at an initial temperature the resulting structures were post treated at higher temperatures $\left(\approx 80{ }^{\circ} \mathrm{C}\right)$ in order to maximize the porosity and reduce internal stress. The resulting foams were less brittle after the post foaming treatment. Figure 2.3 shows a cross sectional SEM image of a PMMA-co-EA foam containing $0.5 \mathrm{wt} \%$ nanosilica. This particular sample had a pore size of $180 \mathrm{~nm}$ and a porosity of $\approx 82 \%$. Homogeneous cell sizes of $\approx 100 \mathrm{~nm}$ and cell densities of $10^{16}$ cells $/ \mathrm{cm}^{3}$ were achieved for similar nanocomposite systems. The porosity of these materials was as high as $85 \%$ and according to Costeux and coworkers these samples appeared bluish which is ascribed to their pore size of $100 \mathrm{~nm}$ and smaller. Following an introduction to the classical nucleation theory in the next section, more examples of nanocomposite nanocellular polymer foams, as well as silica nanoparticles synthesis and surface modification, will be presented and discussed, paying attention to the importance of nanoparticle size and surface chemistry with respect to their nucleation capability. 


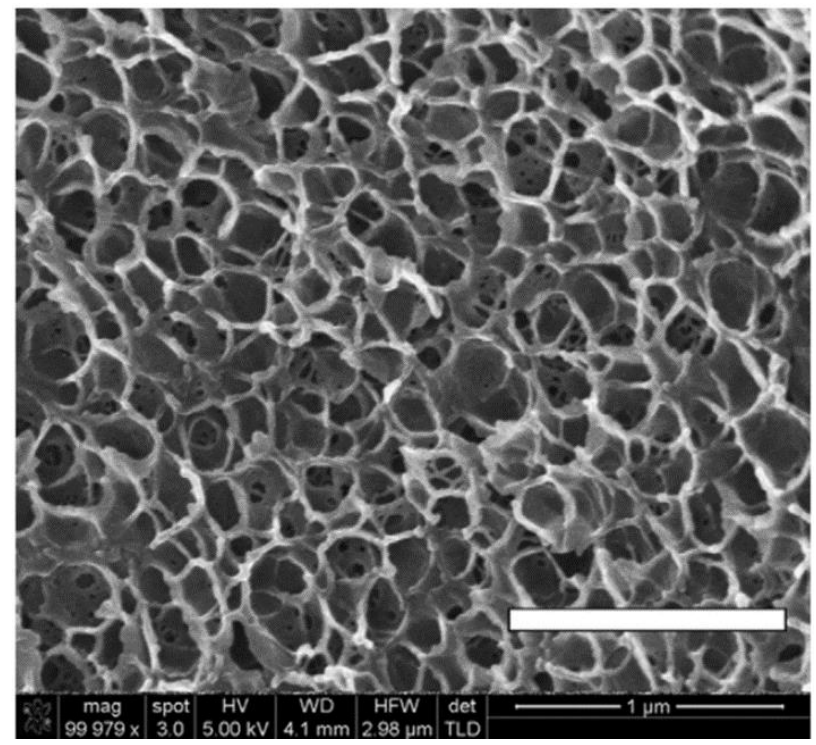

Figure 2.3 Cross sectional SEM image of a PMMA-co-EA nanocomposite foam containing $0.5 \mathrm{wt} \%$ nanosilica. The pore size and porosity were $180 \mathrm{~nm}$ and $82 \%$, respectively. Foams were prepared via the saturation of the nanocomposite polymer films with $\mathrm{CO}_{2}$ at 330 bar for 6 hours at $40{ }^{\circ} \mathrm{C}$, followed by a pressure quench ( 1 second) and post foaming at $80{ }^{\circ} \mathrm{C}$ for 25 seconds. The scale bar represents $1 \mu \mathrm{m}$. Reprinted from reference [58], with permission from Elsevier.

\subsection{The classical nucleation theory to describe cell nucleation}

Obtaining nanocellular polymer foams with low densities requires the nucleation of many cells in a polymer matrix that can be vitrified to eventually yield stable cellular morphologies. It is of fundamental interest to understand the nucleation of pores with sizes that are only 1-2 orders of magnitude smaller than their final cell size. The most frequently encountered model used to describe the observed nucleation behavior is based on the classical nucleation theory (CNT) ${ }^{79-80}$ The CNT describes the formation of bubbles (i.e. cells) in low boiling liquids as the formation of clusters of molecules based on the capillary approximation, i.e. continuum thermodynamics, which assumes that the small nuclei have the same properties as the bulk. In other words, the surface tension of the highly curved cluster is assumed to be that of a planar surface, while in reality it can substantially deviate from this value due to size effects. According to the CNT, the steady state homogeneous nucleation rate, $N_{0}$, is given by the following equation:

$N_{0}=C_{0} f_{0} e^{\left(-\frac{\Delta G_{\text {crit }}}{k_{B} T}\right)}$ eq. 1 
In which, $\Delta G_{\text {crit }}$ is the free energy of critical nucleus formation, $k_{B}$ is the Boltzmann constant, $T$ is the temperature in Kelvin, $C_{0}$ is the number of gas molecules dissolved per unit volume of polymer matrix and $f_{0}$ is a kinetic pre-exponential factor which is weakly temperature dependent. From equation 1 it is clear that changes in $\Delta G_{c r i t}$ have the largest impact on the nucleation rate. The free energy of critical nucleus formation can be written as a function of the surface free energy, $\sigma$ and the pressure difference between the saturation and foaming pressure, $\Delta P$.

$$
\Delta G_{c r i t}=\frac{16 \pi \sigma^{3}}{3 \Delta P^{2}}
$$

The nucleation rate for heterogeneous nucleation $\left(N_{l}\right)$ can be obtained by adapting equation 1 to the following equation:

$N_{1}=C_{1} f_{1} e^{\left(-\frac{\Delta G_{c r i t}}{k_{B} T}\right)}$

eq. 3

Here, $C_{l}$ is the concentration of heterogeneous nucleation sites and $f_{l}$ is the frequency factor of gas molecules joining the foam cell embryo. According to the CNT the free energy of heterogeneous critical nucleus formation scales with that of homogeneous nucleation by a factor $S$ which is a function of the contact angle $(\theta)$ between the gas, particle and polymer surface (see Figure 2.4 ) according to the following equations:

$$
\begin{array}{ll}
\Delta G_{\text {crit }}^{\text {het }}=\frac{16 \pi \sigma^{3}}{3 \Delta P^{2}} S(\theta) & \text { eq. } 4 \\
S(\theta)=\left(\frac{1}{4}\right)(2+\cos \theta)(1-\cos \theta)^{2} & \text { eq. } 5 \\
\Delta G_{\text {crit }}^{\text {het }}=\frac{16 \pi \sigma^{3}}{3 \Delta P^{2}} \frac{f(m, w)}{2} & \text { eq. } 6
\end{array}
$$




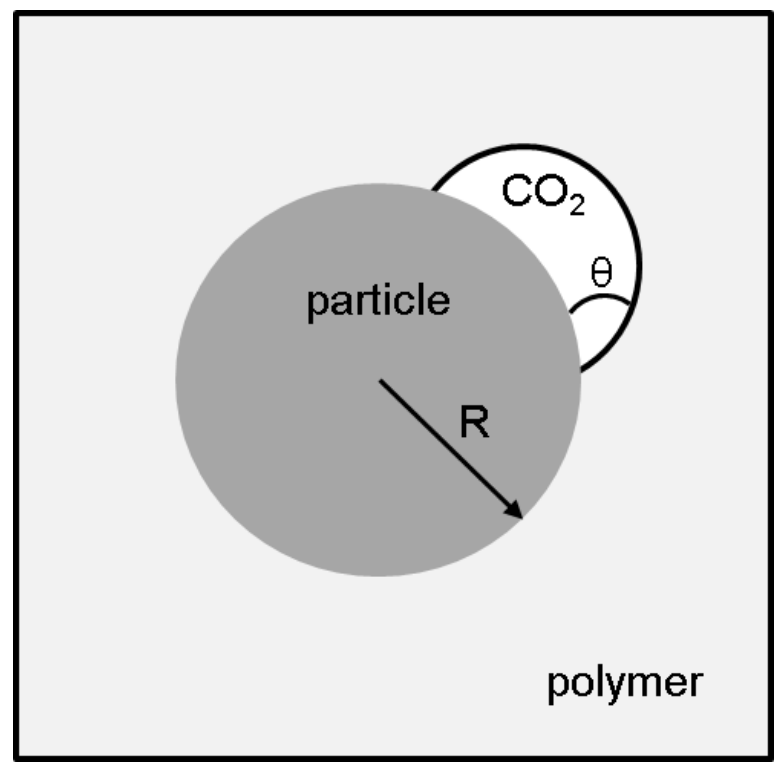

Figure 2.4 Scheme of a $\mathrm{CO}_{2}$ nucleus on a particle with radius $\mathrm{R}$.

Besides the contact angle, the surface curvature of the particles also plays an important role in the nucleation energy. The surface curvature dependence was added by Fletcher ${ }^{54}$ in the form of the so called critical energy reduction factor $(f(m, w))$ according to the following set of equations:

$f(m, w)=1+\left(\frac{1-m w}{g}\right)^{3}+w^{3}\left[2-3\left(\frac{w-m}{g}\right)+\left(\frac{w-m}{g}\right)^{3}\right]+3 m w^{2}\left(\frac{w-m}{g}-1\right)$ eq. 7

In which, $m, w$ and $g$ are:

$m=\cos \theta$

eq. 8

$w=\frac{R}{r_{\text {crit }}}$ eq. 9

$g=\sqrt{1+w^{2}-2 m w}$ eq. 10

With $R$ being the radius of the nucleating particle (see Figure 2.4) and $r_{c r i t}$ the critical radius of the nucleus according to:

$r_{\text {crit }}=\frac{2 \sigma}{\Delta P}$ eq. 11

The highest reduction of the free energy of critical nucleus formation $\left(\Delta G_{c r i t}\right)$ is obtained when the surface curvature is low i.e. a flat surface would be optimal. Furthermore, the contact angle of the gas bubble on the particle should be as low as possible to obtain the highest reduction of $\Delta G_{\text {crit. }}$ In other words the gas phase should prefer wetting of the 
heterogeneous particle surface instead of the polymer. The relation connecting the reduction factor, contact angle and relative radius, $R / r_{c r i t}$, is shown in Figure 2.5 . From Figure 2.5 it is obvious that all particles with a radius exceeding 10 times $r_{\text {crit }}(w=10)$ can be regarded as a flat surface and further increasing their radius does not influence the energy reduction factor. Furthermore the importance of controlling the contact angle for a given gas, polymer and nucleating particle surface combination is clearly visible, i.e. low contact angles give rise to the highest critical nucleation energy reduction, while for a contact angle of 90 degrees, there is no significant critical nucleation energy reduction, regardless the relative curvature of the particles.

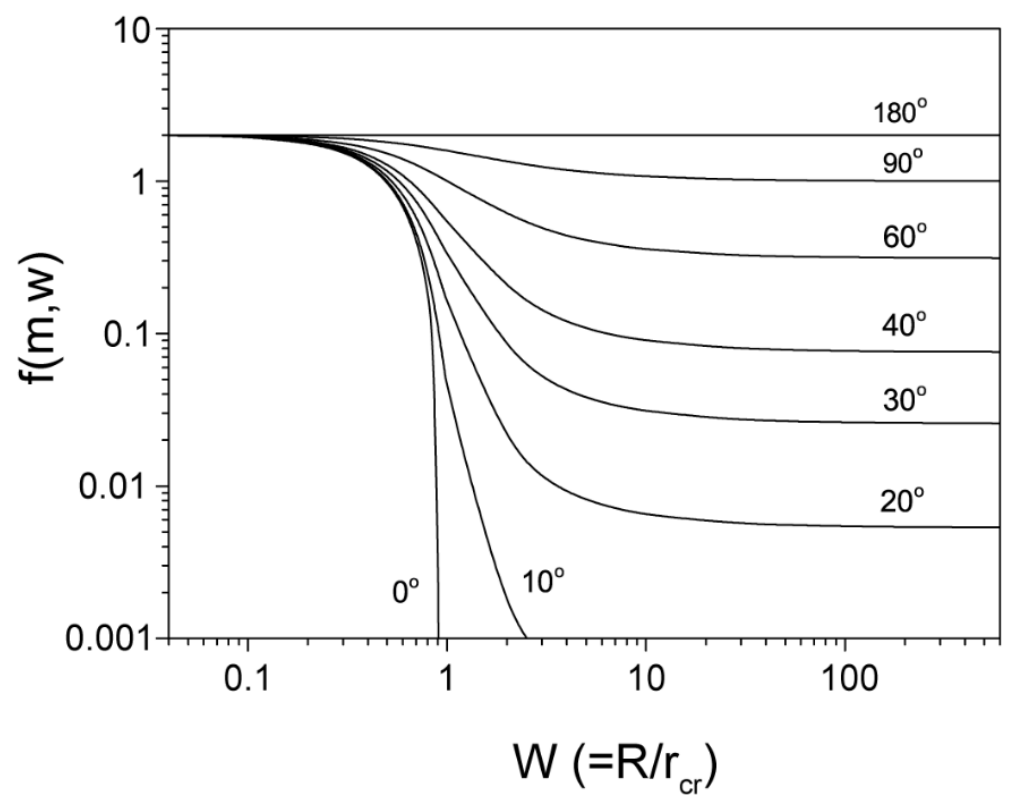

Figure 2.5 The critical nucleation energy reduction factor as a function of the contact angle $(\theta)$ and the relative particle radius (w). Reprinted from reference [16], with permission from Elsevier.

\subsection{Controlling particle surface chemistry to optimize heterogeneous nucleation}

It is anticipated that surface engineering of nucleating particles, which change the surface chemical composition and surface roughness, would have an effect on the particle's foam nucleating performance. For example, He and coworkers ${ }^{81}$ reported on the fabrication of silica polycarbonate nanocomposite foams via batch foaming with $\mathrm{CO}_{2}$ 
as the blowing agent. Following saturation with 200 bar $\mathrm{CO}_{2}$ at $50{ }^{\circ} \mathrm{C}$ the pressure was released and the nanocomposite films were transferred to a glycerol bath with temperatures between 100 to $150{ }^{\circ} \mathrm{C}$ for 30 seconds followed by quenching in an ice water bath. For this system it was calculated that the Gibbs free energy for heterogeneous nucleation was approximately $5 \times 10^{-3}$ times the energy required for homogenous nucleation. The cell size distribution of the nanocomposite foam containing $9.0 \mathrm{wt} \%$ of nanosilica ranged from 0.1 to $0.8 \mu \mathrm{m}$ while the pristine PC foam had cell sizes between 0.7 to $6 \mu \mathrm{m}$. The cell density increased from $10^{11}$ to $10^{13}$ cells $\mathrm{cm}^{-3}$ upon the addition of the silica nanoparticles. This observation is in line with the calculated decrease in nucleation energy upon the addition of nanoparticles. Interestingly, regardless of the nanoparticle loading, varying from 1.0 to $9.0 \mathrm{wt} \%$, the nucleation efficiency was in the order of $0.01-0.02 \%$. This means that, if particle aggregation and cell coalescence are ignored and if every particle corresponds to 1 theoretical nucleation site, for every 10.000 particles present only one cell is nucleated. Such relatively low nucleation efficiencies are frequently reported ${ }^{9}$, or can be extracted from experimental data reported, and imply that the used particles are often not energetically favorable. Hence nanoparticle surface engineering to optimize the surface energy of the nanoparticles offers a potential for improving the nucleation efficiency and is considered by us to be of key importance for the foaming of nanocellular materials.

\subsubsection{Nanoparticle surface engineering}

Ozisik and coworkers ${ }^{16}$ reported on a higher nucleation efficiency for $150 \mathrm{~nm}$ silica particles, compared to $15 \mathrm{~nm}$ silica particles, in $\mathrm{CO}_{2}$ blown PMMA foams containing $1.0 \mathrm{wt} \%$ silica particles. They suggested that the lower nucleation efficiency for smaller silica particles is caused by their larger surface curvature which increases the critical Gibbs free energy of nucleation; note that the critical cell radius for neat PMMA was calculated to be in between 4 to $10 \mathrm{~nm}$ for the conditions used. Furthermore they reported that changing the surface chemistry from bare silica to fluorinated silica the nucleation efficiency increased significantly. This is explained by the decrease in surface energy of fluorinated silica, as compared to bare silica, which should result in a reduced critical nucleus radius. The particle loading was constant in weight thus the number of smaller particles was significantly higher, even when corrected for the observed particle aggregation. To what extend this affects the nucleation efficiency, cell growth and cell coalescence and thus the final foam morphology remains to be seen. Enayati and coworkers ${ }^{75}$ prepared PS nanocomposite films with different types of silica nanoparticles i.e. $7 \mathrm{~nm}$ and $12 \mathrm{~nm}$ bare silica particles and $14 \mathrm{~nm}$ methyl functionalized silica. The 12 $\mathrm{nm}$ bare silica particles increased the cell density 66 times compared to neat PS foams and were the best performing nucleation agents. We calculated for these foams nucleation 
efficiencies in the order of 0.01 to $0.1 \%$. The difference in performance for the larger silica particles was again explained by the larger relative curvature $(w)$ of the larger silica particles which provides more favorable surfaces for the nucleation of cells at the same temperature and pressure conditions. The worse performance of the methyl functionalized silica particles was ascribed to their hydrophobic surface, which had a greater affinity for the PS compared to the bare silica particles. This yields a lower polymer-nanoparticle interfacial tension, increasing the contact angle between the polymer, gas, and particles, which results in an increase in the nucleation efficiency. Unfortunately, the authors did not take particle aggregation into account in their explanation, while for the nanoparticle types used it is well known that dispersion to the primary particle size is hard to achieve. Furthermore, the interfacial interactions between nanoparticles and polymer matrix is expected to influence particles nucleation performance as well. ${ }^{9,}$ 17, 82 For instance, Ohshima and coworkers demonstrated that a poor affinity between heterogeneous nucleation sites and the polymer matrix can decrease the free energy barrier for cell nucleation and as a consequence increase the cell density in polymer foaming. ${ }^{83} \mathrm{In}$ addition, examples exist where the nanoparticles have proven to be ineffective as nucleation agents. ${ }^{58,84-87}$ This brings forward the importance of having well defined, well dispersed nanocomposites in order to study, understand and optimize particle dependent nucleation relationships at the nanometer length scale.

\subsubsection{Towards a nucleation efficiency of $100 \%$}

Recently we have developed a series of silica core shell nanoparticles with shells consisting of surface grafted polymers in order to control the particle dispersion and simultaneously increase the nucleation efficiency with several orders of magnitude (see Chapters 3 and 4). For instance, silica poly(dimethylsiloxane) (PDMS) core shell nanoparticles were well dispersed in PS films. Following batch foaming of PS films containing about $4.0 \mathrm{wt} \%$ of these nanoparticles foams with cell sizes down to $600 \mathrm{~nm}$ cells and a cell density of up to $4.6 \times 10^{12}$ cells $/ \mathrm{cm}^{3}$ were obtained (see Figure 2.6). The nucleation efficiency for these designer silica nanoparticle nucleation agents was calculated to be as high as $0.3 .^{88}$ Following work was directed towards the foaming of PMMA for which eventually nucleating efficiencies of $\sim 0.5$ were achieved (see Chapter 4). These were at that time the highest nucleation efficiencies reported. It was found that the PDMS decorated nanoparticles have a significantly higher nucleation efficiency compared to their bare counterparts. This is ascribed to the high $\mathrm{CO}_{2}$ philicity and low surface energy of the thin PDMS shell around silica nanoparticles. ${ }^{89-93}$ Furthermore, the nucleation efficiency of nanoparticles was found to dependent on both particles size and saturation pressure. For instance, particles with diameters above $60 \mathrm{~nm}$ were found to be more efficient compared to the smaller ones, i.e. diameters, $<40 \mathrm{~nm}$, when the foaming 
pressure and temperature were $\sim 55$ bar and $40{ }^{\circ} \mathrm{C}$, respectively. This is ascribed to the presence of a positive line tension and its contribution to the free energy for cell nucleation (see section 2.6.3 and Chapter 4). Increasing the saturation pressure to $300 \mathrm{bar}$ resulted in a decrease of the cell nucleation efficiency for nanoparticles with a diameter of $80 \mathrm{~nm}$. This was ascribed to a more pronounced effect of line tension at these foaming conditions, while at the same time homogeneous cell nucleation became more favorable due to a lower nucleation energy barrier compared to low pressure foaming (e.g., 55 bar). Critical evaluation of our particle design and recent modeling work on cell nucleation from convex/concave surfaces pointed us in the direction of using raspberrylike nanoparticles to further enhance the nucleation efficiency of silica based nanoparticles. Combined with optimizing the surface chemistry by grafting a PDMS layer to these particles nucleation efficiencies exceeding unity have been obtained (see Chapter 6). The excellent cell nucleation performance for these core shell raspberry-like hybrid particles is ascribed to the combination of a high $\mathrm{CO}_{2}$ absorption close to the particle surface, the low surface energy and high $\mathrm{CO}_{2}$ philicity of the PDMS shell, as well as the energetically favorable nucleation in nanocavities. It is expected that utilization of surface engineered nanoparticles opens new processing windows that eventually allow the blowing of nanocellular materials with higher cell densities and narrower cell size distributions. 


\section{Nanoparticle surface engineering}

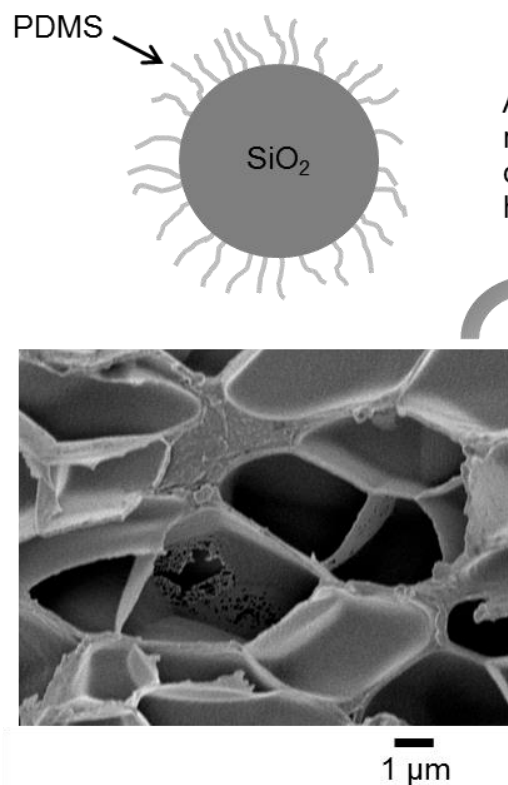

Add few weight percentage of nanoparticles with optimized surface chemistry to facilitate nucleation with high efficiency.

Figure 2.6 Cross sectional SEM images of a bare PS foam (left) and a PS nanocomposite foam (right) containing silica PDMS core shell nanoparticles. Foams were prepared via batch foaming, i.e. saturation with $\mathrm{CO}_{2}$ at 55 bar at room temperature followed by a rapid pressure release and immersing the $\mathrm{CO}_{2}$ saturated nanocomposite films in a glycerol bath thermostated at $100{ }^{\circ} \mathrm{C}$. Obviously every pore contains 1 to a few nanoparticles only, which is in agreement with the calculated nucleation efficiency of $\approx 30 \% .{ }^{88}$

\subsection{The classical nucleation theory challenged}

\subsubsection{Limitations of the classical nucleation theory}

As mentioned earlier, in order to prepare stable nanocellular polymer foams it is pivotal to understand and describe cell nucleation and growth at the macromolecular length scale. The fact that the use of the CNT to describe nucleation of cells in polymers is often accepted while the observed nucleation rates are frequently orders of magnitude underestimated (see below) underlines our deficiency in capturing nanoscale cell nucleation in polymers (i.e. viscoelastic liquids). The main shortcomings of the CNT are that $i$ ) the CNT assumes that the cells have bulk properties and a sharp interface and $i$ ) the CNT assumes that the nucleating cell has an infinite planar surface. Intuitively for 
nanometer sized cells in a macromolecular environment these assumptions are not correct. Thompson and coworkers ${ }^{94}$ explained that polymer chains on the outside of a curved (nano)cell interface can adapt more conformations compared to polymer chains near flat surfaces. Hence the free energy of the curved interface is significantly reduced which results in a decreased barrier for nucleation and thus in an increased nucleation rate. Furthermore the number of unfavorable energetic contacts between polymer chains and molecules in the cell near curved interfaces is also reduced, i.e. polymers in the vicinity of a curved interface are less likely to find a part of their chain in the interior of the energetically unfavorable cell. In addition, Thompson and coworkers mentioned that for small cells the diffuse walls collide causing increased mixing of polymer and fluid molecules, which results in a reduction of the interface energy, favoring lowering of the nucleation barrier energies and an increased nucleation rate. In the same report they compared homogeneous nucleation according to the CNT and a self-consistent field theory (SCFT), since the latter is not hindered by the previously mentioned limitations of the former. Interestingly, their SCFT calculations for the presented example revealed that the CNT predicts a critical radius that is more than $33 \%$ too large, a nucleation barrier that is six times too large and that the nucleation rate is underestimated by 5 orders of magnitude. They argued that based on their SCFT model these results point towards an underestimated competitive role of homogenous nucleation versus heterogeneous nucleation. Furthermore heterogeneous nucleation rates are often estimated based on modifications to calculations for homogenous nucleation rates, which implies that the rates of the former must be reconsidered, as well.

\subsubsection{Thought provoking models}

The CNT assumes a uniform pressure throughout the polymer-fluid system, while this is not necessarily the case during foaming. For instance, Park and coworkers ${ }^{95}$ have reported on the numerical analysis of the existence of growing cell flow induced pressure fluctuations near heterogeneous micrometer sized particles that decrease the free energy barrier for heterogeneous nucleation, as well as the critical radius, favoring a high heterogeneous nucleation rate. They have demonstrated that the pressure fluctuations depend on the configuration and dynamics of the nucleation sites. More recently, Park and coworkers ${ }^{96}$ reported on the batch foaming of intercalated and exfoliated clay HDPE composites. Surprisingly, the intercalated particles resulted in higher heterogeneous nucleation rates, despite their lower particle density and smaller interfacial area. This was mainly ascribed to the higher stress fields around the larger intercalated clay particles favoring stress induced cell nucleation as previously reported.

Costeux and coworkers ${ }^{97}$ recently developed a density functional theory (DFT) which can be used to quantitatively describe the thermodynamic bulk and interfacial properties 
of polymer- $\mathrm{CO}_{2}$ mixtures in a wide pressure and temperature range. They combined this DFT with the string method to calculate the minimum free energy path of cell nucleation and to make quantitative predictions for cell nucleation in poly(methyl methacrylate)$\mathrm{CO}_{2}$ mixtures. ${ }^{98}$ The authors reported that below a critical temperature there is a metastable transition from a $\mathrm{CO}_{2}$ rich vapor phase to a $\mathrm{CO}_{2}$ rich liquid phase for $\mathrm{CO}_{2}$ and as a consequence the phase that has the lowest free energy barrier for nucleation results in the formation of a cell that is either gas or liquid filled, respectively. This implies that nucleation of a $\mathrm{CO}_{2}$ gas filled cell in the metastable polymer $\mathrm{CO}_{2}$ mixture is a two-step process for certain conditions. Additionally, the calculation of the energy reduction factor according to the CNT is only valid for spherical nucleating agents, the effect of particle shape and roughness is not included. Park and coworkers ${ }^{99-100}$ developed a modified heterogeneous nucleation model that treated heterogeneous nucleation particles as a series of conical cavities with random conical angles $\left(0^{\circ}\right.$ to $\left.90^{\circ}\right)$ in order to create random surface geometries. The CNT was as such corrected for the assumption that the nucleating particles have the properties of flat surfaces. Comparison of experimental values and their simulated values for the nucleation site density were, after iteration of the contact angles used for the gas/particle/polymer system, in good quantitative agreement. The authors rightfully argued that the validity of the determined contact angles requires further investigation.

\subsubsection{The effect of line tension}

Although in equation 6 the heterogeneous nucleation rate is corrected for the ratio of the particle size to critical bubble ratio as proposed by Fletcher, ${ }^{84}$ it still does not take into account the particle size dependent surface energy, which causes a change in the contact angle for the polymer, gas, particle interface. For instance, the line tension $(\tau)$, defined as energy per unit length associated with the three phase contact line (TPCL) due to the excess energy caused by the imbalance of intermolecular forces at the TPCL, ${ }^{101}$ has been shown to influence the surface nucleation. ${ }^{102-104}$ Closer examine a particle during nucleation it is obvious that a TPCL exists and thus that a line tension in the order of $10^{-}$ 12 to $10^{-6} \mathrm{~N}$ needs to be considered when studying the cell nucleation. ${ }^{101-102,105-106}$ For example, McBride and $\mathrm{Law}^{101}$ reported on the determination of the particle size dependent contact angle of a modified silica PS three phase system. Based on their atomic force microscopy analysis the contact angle of individual particles was determined. The contact angle decreased from $\approx 58^{\circ}$ to $\approx 39^{\circ}$ upon decreasing the silica particle size from $\approx 200 \mathrm{~nm}$ to $\approx 88 \mathrm{~nm}$, respectively. Interestingly, it was shown that below a particle size of $\approx 78 \mathrm{~nm}\left(r_{\min }\right)$ no particle existed on the liquid vapor interface, which was ascribed to a line tension of $\approx 0.93 \mathrm{nN}$. Recently, Mi and coworkers ${ }^{107}$ presented a density functional approach, including line tension, to calculate the free energy barriers of bubble nucleation 
in polystyrene and poly(methyl methacrylate) nanocomposites. The authors demonstrated that the addition of nanoparticles can improve the nucleation rates up to 5 orders of magnitude, and the critical radii shrink down to approximately half of the homogeneous nuclei radii. However, detailed insights in the effect of line tension on cell nucleation were not discussed by the authors.

In our work of nanoparticle enhanced cell nucleation in PMMA foaming (see Chapter 4 ), the complete engulfment of particles with a (core) diameter below 40 nanometer at the cell wall interface points toward line tension values of approximately $0.42 \mathrm{nN}$ for the used foaming condition, i.e. the foaming pressure and temperature were 55 bar and $40{ }^{\circ} \mathrm{C}$, respectively. The cell nucleation energy barrier was found to be significantly increased by a line tension of this magnitude. A closer investigation of the adhesion behaviors for individual nanoparticles at $\mathrm{CO}_{2}$ swollen polymer surface found that the interfacial interactions between nanoparticles and polymer matrix, e.g., line tension and elastocapillarity, are particle size dependent indeed (see Chapter 5). We show by a developed thermodynamic model that line tension is responsible for the engulfment of nanoparticles with a small size. These findings imply that the influence of line tension on cell nucleation in $\mathrm{CO}_{2}$ assisted nanocomposite foaming should be considered and that the classical nucleation theory must be reevaluated for these systems.

\subsubsection{Nucleation from pre-existing voids}

Some researchers considered the presence of microvoids with radii larger than $r_{\text {crit }}$ so that after saturation with $\mathrm{CO}_{2}$ and depressurization these voids would grow without having to overcome the nucleation energy barrier. ${ }^{108-109}$ These voids could be present either in the polymer, on particle surfaces or in cavities of particles aggregates as well as at the surface of processing equipment. Harvey and coworkers ${ }^{110-111}$ were among the pioneers demonstrating that stable pre-existing cells (so called Harvey nuclei, see Figure 2.7) exist in conical pits on a heterogeneous nucleating site. This form of nucleation includes homogeneous and heterogeneous processes from pre-existing gas cavities at the surface of suspended particles or processing equipment as well as tiny metastable cells in the polymer melt. When the polymer-gas system is in a supersaturated state, the radius of these pre-existing gas cavities is still less than $r_{c}$ as determined by classical nucleation theory. During the continuous pressure drop, the pre-existing gas cavities will overcome the finite free energy barrier as the degree of super saturation increases and consequently these cells grow spontaneously. However, Ward and Levart ${ }^{112}$ proposed that the existence of Harvey nuclei requires an interface with a contact angle which is greater than $90^{\circ}$ and this rarely exists. They suggested that when the gas concentration is slightly higher than the saturation level, the existence of tiny cell nuclei in the bulk of the oversaturated 
mixture or in conical pits on the surfaces of suspended nucleating agent particles is possible. ${ }^{113}$

\section{Polymer/gas mixture}

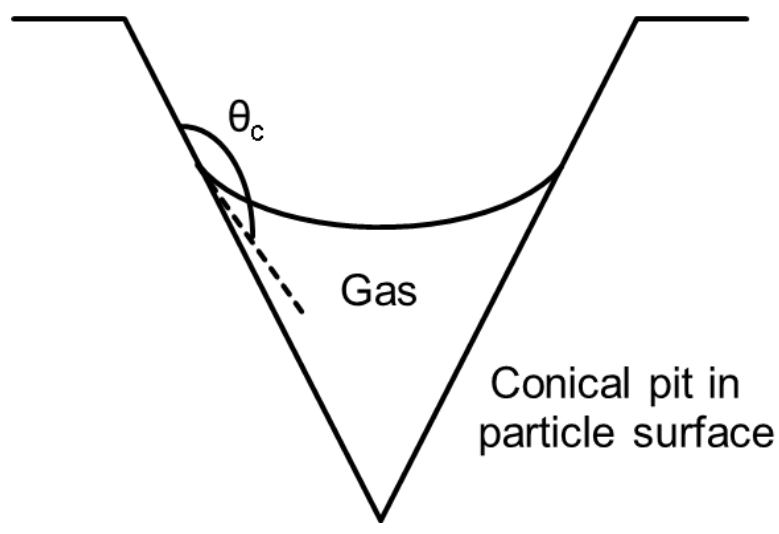

Figure 2.7 Scheme of a Harvey nucleus in a conical pit of a particle surface.

Lee ${ }^{114}$ extended the cavity model concept and developed a "shear-enhanced nucleation model". Lee suggested that nucleating particles tend to aggregate with each other to form a cluster of particles in the polymer matrix. The porous surfaces of the aggregates may not be completely wetted by the polymer melt, which results in the entrapment of gas molecules near the nucleating agent surface, forming gas cavities. Shear flow in the die during extrusion foaming is believed to enhance the detachment of these pre-existing gas cavities from the particle surfaces and following a pressure reduction these voids grow into cells. Han and $\operatorname{Han}^{115}$ also suggested that cell nucleation can be induced by shear force or flow due to the motion of gas clusters, even at thermodynamically unsaturated conditions, based on their in situ observation of bubble nucleation in concentrated PS toluene solutions. From these and other reports ${ }^{116-117}$ it is concluded that under shear homogenous nucleation is easily underestimated. None of the presented alternative mechanisms for cell nucleation is capable of quantitatively deriving the cell nucleation rate. Hence for the time being the CNT, with its various modifications, is still often employed as the basis for cell nucleation rate predictions or to explain experimental observations. 


\subsection{Thermal conductivity of nanocellular polymers}

\subsubsection{The Knudsen effect}

Considerable research has been devoted to the understanding of the development of nanocellular polymers as a new class of high performance thermal insulation materials. In this paragraph we will discuss in more detail why nanocellular materials are receiving this much attention.

Like for any other foam the thermal conductivity $(\lambda)$ consists of four contributions: ${ }^{118}$

$\lambda=\lambda_{s}+\lambda_{g}+\lambda_{r}+\lambda_{c}$ eq. 12

In which $\lambda_{s}, \lambda_{g}, \lambda_{r}$ and $\lambda_{c}$ are the contribution of solid phase conduction, gas phase conduction, radiation and convection to the overall thermal conductivity $(\lambda)$, respectively. For the small pore sizes, convective heat transfer can be ignored. ${ }^{119}$ The expected potential for nanocellular foams is based on the fact that when pore sizes are on the order of the mean free path of gas molecules, e.g. for air $\approx 70 \mathrm{~nm}$ at standard conditions, the gas molecules, instead of having many collisions with each other, enter the ballistic regime and as a consequence heat conduction by the gas phase is significantly reduced. This is also referred to as a Knudsen gas. In many reports one can find reference to the Knudsen equation:

$\lambda_{g}=\frac{\lambda_{g 0}}{1+\beta K n}$

eq. 13

In which $\lambda_{g 0}$ is the thermal conductivity of the gas at standard conditions $\left(\lambda_{\text {air }} \approx 26\right.$ $\mathrm{mW} /(\mathrm{m} \cdot \mathrm{K})), \beta$ is a factor for the energy transfer between gas molecules and the surrounding solid walls ( $\approx 2$ for air) and $K n$ is the Knudsen number, which is defined as the ratio of the mean free path of the gas molecules to the average pore diameter.

Obviously from decreasing the pore size from $\approx 1 \mu \mathrm{m}$ to below $100 \mathrm{~nm}$ the gas phase conduction is significantly reduced. Low density silica based aerogels are an outstanding example of the potential of nanocellular polymers. Due to their pore sizes well below 100 $\mathrm{nm}$ and to their extremely low densities, these materials are reported to have thermal conductivities below $15 \mathrm{~mW} /(\mathrm{m} \cdot \mathrm{K}){ }^{120-121}$ This is significantly lower compared to the conventional thermal insulation materials such as PUR foams $(20-30 \mathrm{~mW} /(\mathrm{m} \cdot \mathrm{K}))$, XPS/EPS (33-40 $\mathrm{mW} /(\mathrm{m} \cdot \mathrm{K}))$ and mineral wools $(37-40 \mathrm{~mW} /(\mathrm{m} \cdot \mathrm{K})) .{ }^{121}$ Like mentioned, their extremely high price and poor processability limit their wide spread application as thermal insulation material, although some aerogel based composites are gaining ground in niche applications. Hence polymers rendered nanocellular via e.g. $\mathrm{CO}_{2}$ foaming appear to be an attractive alternative from economic as well as processing points of view. Intriguing is that the vast majority of reports presenting the production of nanocellular 
polymer structures mentions the applicability of these materials as thermal insulators, however not many reports offer an experimental quantification of the thermal conductivity of the prepared nanocellular polymer foams. This is probably explained by assuming that $i$ ) the foams prepared have often a graded cross sectional structure with a varying foam morphology and the structure is only partly in the nanocellular regime, and that $i$ ) the foams obtained are often relatively small due to scaling issues in foam production.

\subsubsection{Thermal conductivity of nanocellular polymers}

Sundarram and $\mathrm{Li}^{122}$ recently reported on the thermal conductivity of PEI nanofoams with pore sizes of 86,240 and $260 \mathrm{~nm}$ and porosities of 80,77 and $74 \%$, respectively. The thermal conductivity of their relatively small samples was determined with a transient plane source analyzer and subsequently the thermal conductivity of the nanocellular foam part was obtained via correcting the overall thermal conductivity for the presence of a skin layer and a microcellular foam region. The obtained thermal conductivity values were 19,16 and $15 \mathrm{~mW} /(\mathrm{m} \cdot \mathrm{K})$ for the PEI foams with pore sizes of 260, 240 and $86 \mathrm{~nm}$, respectively. Molecular dynamics simulations were performed to model the thermal conductivity of nanocellular PEI (closed cells) and the resulting thermal conductivity values for PEI foams containing 1 or $5 \mathrm{~nm}$ pores were slightly lower compared to the experimentally determined values for the PEI foams. Due to computational limitations no PEI foams with larger pores were simulated. The MD simulations showed that besides capturing the effect of porosity, the pore size effect was also well described. This is an advantage compared to the more straightforward analytical models based on the rule of mixture for the gas and solid phase (i.e. porosity) ${ }^{123-124}$ including some modifications, that e.g. introduce an efficiency factor for the tortuous path of solid heat conduction through the cell walls ${ }^{124}$ or include radiation. ${ }^{125}$ Hence, the same MD simulations were carried out for a PMMA foam with various pore sizes and porosities. ${ }^{122}$ The thermal conductivity of a PMMA foam with $10 \mathrm{~nm}$ pores at $85 \%$ porosity was reported to be $8 \mathrm{~mW} /(\mathrm{m} \cdot \mathrm{K})$, while at $60 \%$ porosity it would be nearly equal to that of still standing air (i.e. $25 \mathrm{~mW} /(\mathrm{m} \cdot \mathrm{K})$ at atmospheric conditions).

The thermal conductivity of the PEI foams reported on by Sundarram and $\mathrm{Li}^{122}$ were compared by Sonntag and coworkers ${ }^{118}$ with a model that estimates the thermal conductivity of a PS based aerogel. The calculated thermal conductivity values for the PS foams were 20, 18 and $13 \mathrm{~mW} /(\mathrm{m} \cdot \mathrm{K})$ corresponding well to the PEI foams with thermal conductivities of 19,16 and $15 \mathrm{~mW} /(\mathrm{m} \cdot \mathrm{K})$, respectively. Despite the differences in matrix materials (PS vs PEI) the theoretical and experimental values are in fair agreement. 


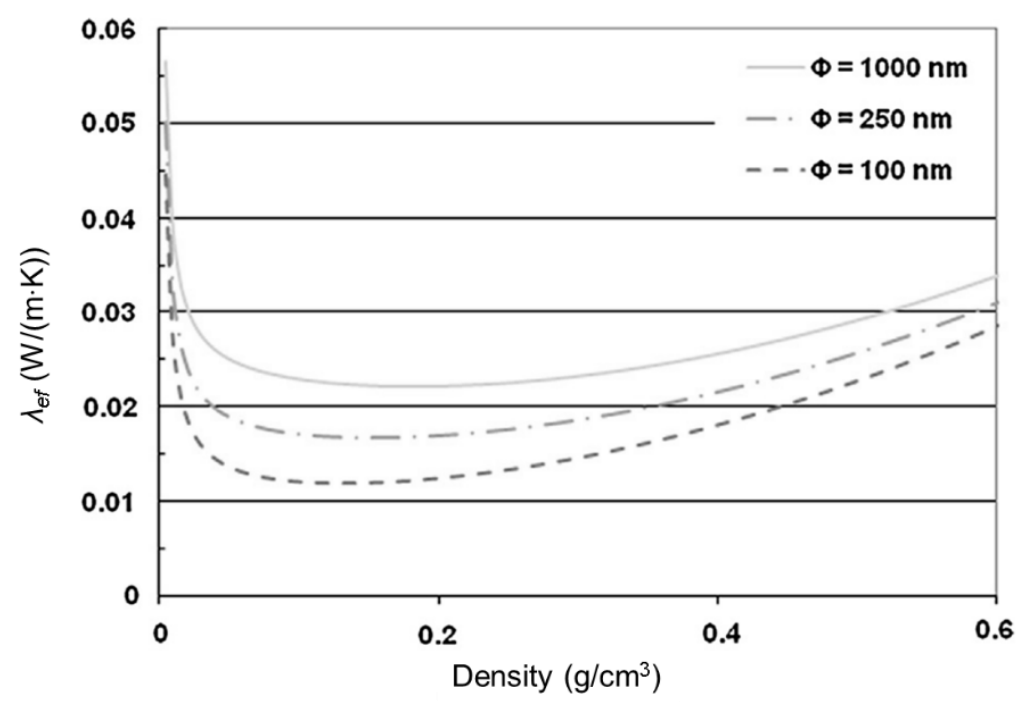

Figure 2.8 Calculated thermal conductivity of a nanocellular PS foam (aerogel model) as a function of the foam density and pore size. Reprinted from reference [118], with permission from Elsevier.

Figure 2.8 shows the theoretical derived thermal conductivity of the PS foam as a function of the foam density and cell size. Obviously there is an optimum foam density, i.e. $\approx 0.1-0.2 \mathrm{~g} \mathrm{~cm}^{-3}$, at which the thermal conductivity is minimized for nanocellular foams to below that of stagnant air. At densities lower than these optimum values the contribution of radiation becomes significant while at higher densities the contribution of solid phase conduction increases.

Zhao and coworkers have recently reported the fabrication of nanocellular PMMA/thermoplastic polyurethane (TPU) foams with nanostructured TPU domains as the heterogeneous nucleating agent. PMMA/TPU foams with an average cell size of 205 $\mathrm{nm}$ and a porosity of $\sim 0.88$ were obtained. The authors demonstrated that the obtained foams exhibited a thermal conductivity of $24.8 \mathrm{~mW} /(\mathrm{m} \cdot \mathrm{K})$ and a high compressive strength. ${ }^{126}$ Pinto and coworkers ${ }^{127}$ reported on the quantification of the gas phase thermal conductivity of PMMA/MAM blends that were foamed to open nanocellular foams with various pore sizes and densities ranging from approximately $320 \mathrm{~nm}$ to $10 \mu \mathrm{m}$ and 0.32 $\mathrm{g} / \mathrm{cm}^{3}$ to $0.71 \mathrm{~g} / \mathrm{cm}^{3}$, respectively. In fact these authors were the first to quantitatively report that the Knudsen effect for nanocellular polymer foams exists (see Figure 2.9). In Figure 2.9 the experimental data for $\lambda_{g}$ of the PMMA/MAM foams with various pore sizes agree very well with the solid line which is representing the Knudsen effect (i.e. equation 13). Furthermore it is obvious that when the pore size of the polymer foams is reduced to $\approx 200 \mathrm{~nm}$ the gas phase conduction is reduced to below $\approx 50 \%$. 


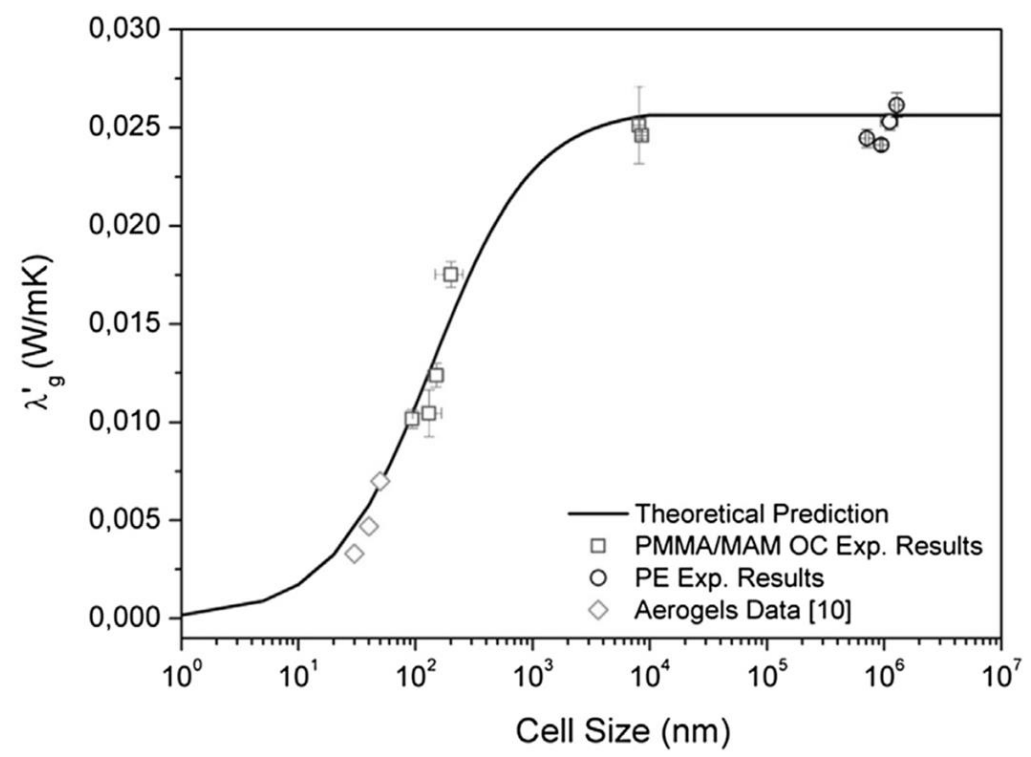

Figure 2.9 Gas phase conduction for PMMA/MAM foams as a function of their pore size (open squares) compared to the Knudsen equation (solid line). Reprinted from reference [127], with permission from Elsevier.

\subsubsection{Competing (nanocomposite) polymer systems}

The Knudsen effect is present in nanocellular polymer foams and based on the discussed theoretical models foams with a density of about $0.15 \mathrm{~g} \mathrm{~cm}^{-3}$ and a pore size in the order of $70 \mathrm{~nm}$ appear as promising candidates to become a new class of high performance thermal insulation materials. Costeux ${ }^{2}$ graphically organized existing nanocellular foams that were reported in the accessible literature as a function of their cell size, porosity and expansion ratio, see Figure 2.10. From Figure 2.10 it is obvious that acrylic copolymers and nanocomposites ${ }^{58,128}$ hold a great promise in terms of their cell size and porosity to classify as super insulating nanocellular materials. Unfortunately until today no thermal conductivity values for these foams have been reported in the open literature. If we take into account the penalty of up to a few $\mathrm{mW} /(\mathrm{m} \cdot \mathrm{K})$ in thermal conductivity for using acrylate copolymers compared to using PS or PEI, ${ }^{118,122}$ due to the higher solid phase thermal conductivity of the former, their expected thermal conductivity is still low. Hence, in agreement with what Costeux mentioned in his recent review paper, ${ }^{2}$ it seems reasonable to assume that low thermal conductivity materials can indeed be made from these (nanocomposite) polymers. 


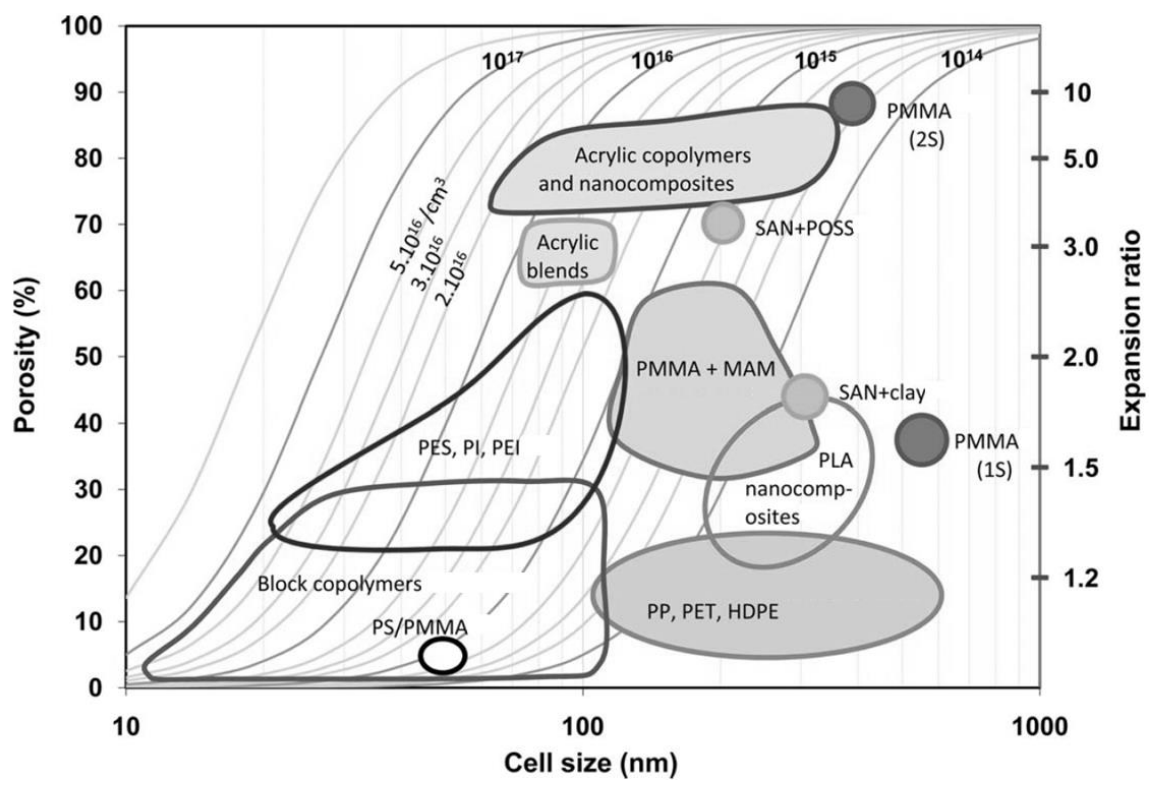

Figure 2.10 Graphical organization of various nanocellular polymer systems as a function of the average cell size, porosity, expansion ratio and cell nucleation density. Reprinted from reference [2], with permission from John Wiley and Sons.

\subsection{Silica nanoparticles synthesis and surface modification}

As discussed above (see section 2.4) silica nanoparticles are of particular interest as heterogeneous nucleation agents in polymer foaming. This is ascribed to its low cost, easy preparation, good size control, and the ease of employing various surface functionalization strategies. In the following sections the commonly used approaches for the synthesis and subsequent surface chemistry or topology engineering of silica nanoparticles are shown.

\subsubsection{Stöber nanoparticles synthesis}

The Stöber method is a well-known and frequently used strategy for the preparation of silica sols and gels via hydrolysis and condensation of silicon alkoxides (general formula $\left.\mathrm{Si}(\mathrm{OR})_{4}\right)$, resulting in spherical silica particles. ${ }^{129-133}$ The hydrolysis and condensation reactions involved are shown in Figure 2.11. 


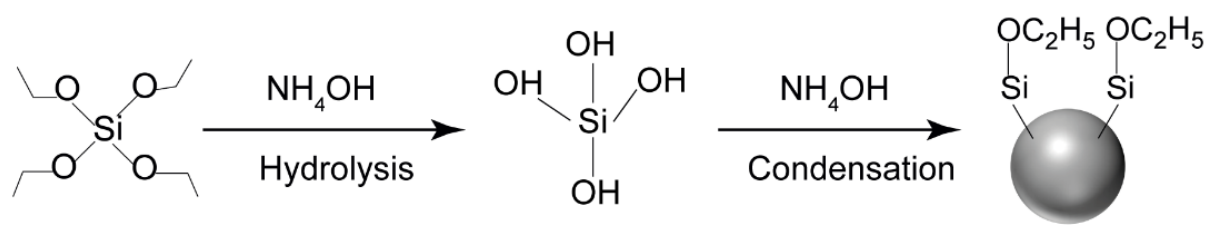

Figure 2.11 Hydrolysis and condensation reactions occurring in the Stöber method for the formation of silica nanoparticles.

The hydrolysis and condensation of silicon alkoxides is promoted through the introduction of hydroxide ions in the reaction mixture, by the addition of e.g. $\mathrm{NH}_{4} \mathrm{OH}$, or the hydrolysis is acid catalyzed. ${ }^{133}$ The latter method results in a slightly broader particle size distribution. ${ }^{129}$ The size of the prepared silica nanoparticles can be controlled from several nanometers up to a few micrometers by manipulating the $\mathrm{pH}$ of the reaction mixture, e.g., by varying the concentration of $\mathrm{NH}_{4} \mathrm{OH} .{ }^{134-135}$ Other important factors to control the particle size are the tetraethyl orthosilicate (TEOS) concentration and the type of alcohol used for the reaction. In a typical Stöber reaction with TEOS, water, $\mathrm{NH}_{4} \mathrm{OH}$ and either methanol or ethanol, the use of methanol will result in smaller particles compared to when using ethanol. ${ }^{135}$ Figure 2.12 shows SEM images of monodisperse silica nanoparticles with various diameters prepared with the Stöber method. ${ }^{136}$
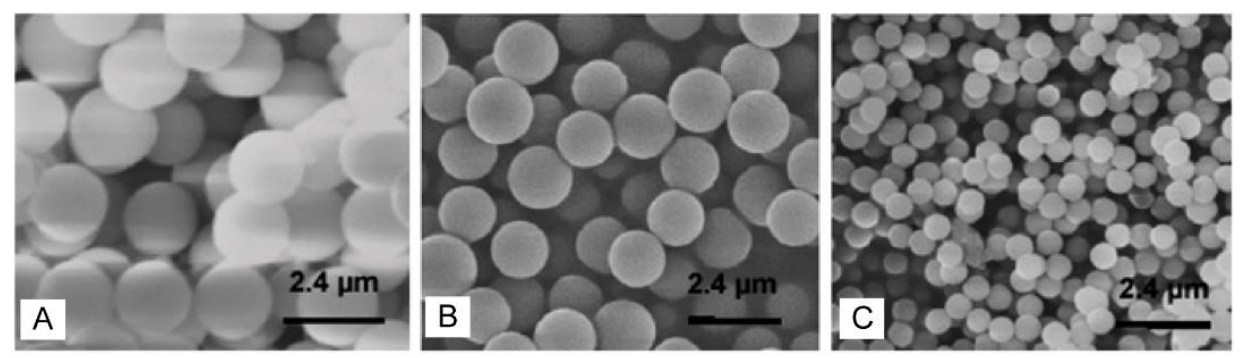

Figure 2.12 SEM images of solid silica nanoparticles synthesized by the Stöber method with a diameter of $\sim 1800 \mathrm{~nm}(\mathrm{~A}), \sim 1100 \mathrm{~nm}(\mathrm{~B})$ and $\sim 600 \mathrm{~nm}(\mathrm{C}) .{ }^{136}$

When using TEOS as silicon alkoxide in the preparation of silica nanoparticles, the hydrolysis of TEOS is sometimes not complete and a part of the ethoxy groups remain in the particles. These ethoxy groups are able to be removed by hydrolysis in slightly acidic water, resulting in the formation of silanol groups. ${ }^{133}$ These silanol groups can be used for subsequent surface modification reactions of the silica nanoparticles by using a wide variety of available silane compounds. ${ }^{137}$ This silane based chemistry can for example be used to tether an atom transfer radical polymerization (ATRP) initiator to the silica nanoparticle surface, to be able to polymerize a polymer shell around the particle, or to be used as reactive sites to couple polymers with functional groups by the grafting to 
method. ${ }^{11,138-143}$ The next section will focus on the formation of silica polymer core shell nanoparticles.

\subsubsection{Hybrid silica core shell nanoparticles}

Grafting polymers from/to silica nanoparticles surfaces is widely used to improve the compatibility between the particles and a polymer, resulting in the improved particle dispersion in the polymer matrix. ${ }^{144-145}$ In addition, it often leads to significant enhancement of the resulting nanocomposite properties, i.e. mechanical, optical or thermal. ${ }^{146-151}$

Among the possible surface derivatization strategies, surface initiated ATRP (SIATRP) is a frequently adopted reaction to graft polymers from silica nanoparticles. ${ }^{152-157}$ ATRP is a type of 'quasi' living controlled free polymerization mechanism. By using a transition metal compound with ligands and a proper initiator, the polymerization conditions can be adjusted to have a linear reaction rate during polymer growth ${ }^{151,158}$ and as a result a low polydispersity for the resulting polymers is achieved. ${ }^{159}$ For a general mechanism and further details of ATRP reactions the interested reader is directed towards the references 146, 147, 152 and 153.

A

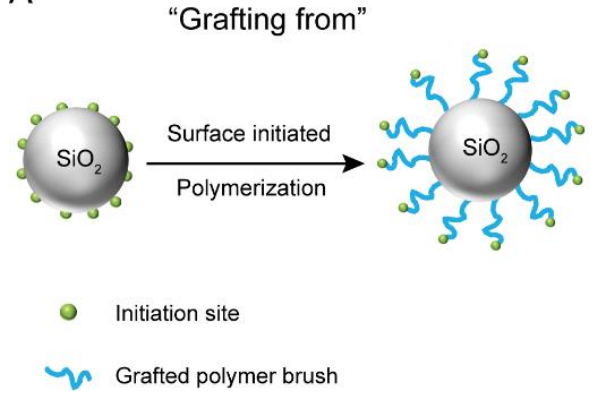

B

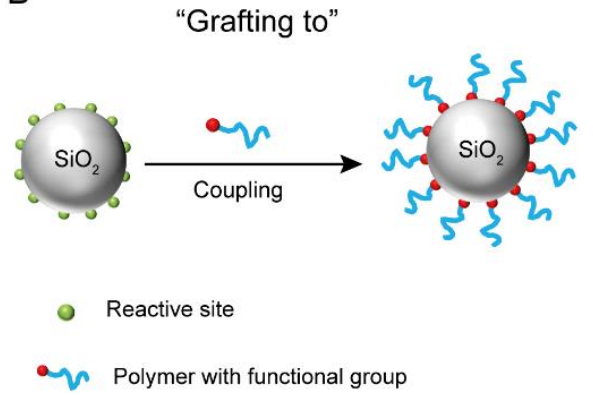

Figure 2.13 Schematic showing polymer brushes grafted from initiator tethered silica particles by SI-ATRP (A) and polymer brushes decorated to silica nanoparticles by the "grafting" to method (B).

With surface initiated SI-ATRP, (block) polymers can be grafted from surfaces by polymerization from surface tethered initiator molecules. ${ }^{152-153,160-166}$ The tolerance to a wide range of functional monomers makes this technique widely used. ${ }^{151-152,159,161,167-}$ 174 Due to the low concentration of active radicals, the risk of termination by the interaction between chain ends is reduced to a minimum. ${ }^{151-152,161,167,175-176}$ With this method, it is possible to get a high grafting density resulting in a polymer brush shell 
around the nanoparticles. For instance Matyjaszewski and coworkers ${ }^{177}$ reported the synthesis of styrene grafted hybrid silica nanoparticles by ATRP. The influence of the chain constraint on the glass-transition temperature of the grafted polystyrene (PS) was studied. The authors demonstrated that the glass transition of PS tethered to the curved particle surfaces was elevated compared to the glass transition temperature of bulk PS. This increase in glass transition temperature is attributed to the steric confinement of the grafted PS chains. Patten ${ }^{138}$ reported on the modification of silica particles with 2-(4 chloromethylphenyl) ethyldimethylethoxysilane for the preparation of a silica particle based ATRP macroinitiator. The subsequent ATRP of styrene resulted in a two times increase in particle diameter compared to the bare silica particles, as was measured with dynamic light scattering (DLS). Figure 2.13A shows a typical SI-ATRP for the grafting of polymer brushes from initiator tethered silica particles. In Chapter 3 the SI-ATRP of styrene from silica nanoparticles with a diameter of $80 \mathrm{~nm}$ is presented as well.

Another common strategy to decorate a particle surface with polymer chains is the 'grafting to' method. This method relies on the coupling of an end functional polymer to the surface of a particle by a chemical reaction or simply by adsorption. ${ }^{178-182}$ This method is shown in Figure 2.13B. Since PDMS is the grafted polymer of interest in this Thesis (See section 2.5.2) a few examples of the grafting to of PMDS are discussed here. Weis and coworkers ${ }^{183}$ reported the "grafting to" of poly(dimethylsiloxane) (PDMS) onto hydrophilic silica nanoparticles by adsorption of PDMS onto the silica surface from a PDMS solution, followed by a thermal treatment. The authors demonstrated that this procedure resulted in the formation of chain loops chemically attached to the silica surface with both chain ends. Liu and $\mathrm{Li}^{184}$ reported on the direct grafting of monoglycidyletherterminated PDMS (PDMS-G) to 10 - $15 \mathrm{~nm}$ silica nanoparticles with surface exposed hydroxyl groups in the presence of Tin Chloride dehydrate as a catalyst. The obtained silica/PDMS star type polymers, as they referred to the obtained silica core-shell materials, possessed a better thermal degradation stability compared to the bare PDMS. In addition, Yang and coworkers ${ }^{185}$ reported the preparation of a PDMS/silica nanoparticle latex by an ultrasonical modification process and miniemulsion polymerization in the presence of hydroxyl silicone oil pretreated silica sol nanoparticles. The authors demonstrated that approximately $5.0 \mathrm{wt} \%$ PDMS was grafted to the $\sim 79 \mathrm{~nm}$ silica nanoparticles.

Besides surface chemistry modification of silica nanoparticles another interesting surface engineering strategy is the manipulation of the surface texture of the particles, such as the synthesis of raspberry-like silica, ${ }^{186}{ }^{186-187}$ mesoporous silica, ${ }^{188-191}$ and hollow core shell silica. ${ }^{192-194}$ There are two primary strategies to fabricate raspberry-like nanoparticles, i.e., by self-templated etching of spherical silica nanoparticles ${ }^{195}$ and immobilization of small silica nanoparticles to the surface of the larger ones ${ }^{196}$ as shown in Figure 2.14. Compared to the attaching method synthesis of raspberry silica 
nanoparticles by the etching method is relatively easy. This is ascribed to its simple reaction procedure which consists of only two processes, i.e. the dissolution of $\mathrm{SiO}_{2}$ species and re-deposition (growth) of the roughened silica layer in a one pot reaction. For instance, $\mathrm{He}$ and coworkers ${ }^{195}$ reported the synthesis of surface-roughened silica nanoparticles by a self-templated etching route with $\mathrm{NaBH}_{4}$. The authors demonstrate that coating of glass surfaces with the obtained raspberry-like particles followed by a modification reaction with perfluorooctyltriethoxysilane resulted in the formation of superhydrophobic surfaces.

De With and coworkers ${ }^{197}$ reported the synthesis of raspberry-like nanoparticles via the dual size coupling strategy. Two different sizes of silica nanoparticles were prepared with each a specific chemical surface functionality. The smaller particles were aminofunctionalized, while the larger particles were epoxy-functionalized. Followed by the attachment of the smaller nanoparticles to the larger ones, raspberry-like particles were obtained. By adjusting the size of the larger and smaller particles it is possible to have precise control over the surface morphology. In Chapter 6 we employed raspberry-like silica nanoparticles prepared by the etching method, since those were stable during subsequent processing steps, i.e. sonication and melt blending. This we ascribe to the stronger neck formation during the redeposition step in the etching method compared to the available contact area for chemical bonding of smaller particles to the larger particles in the dual size coupling method.

A

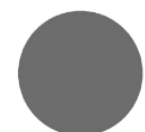

(a)

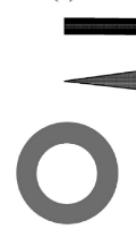

(f)

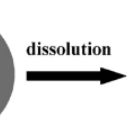

(b)

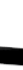

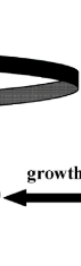

(e)

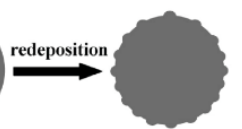

(c)

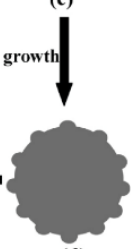

(d)
B<smiles>NC(N)N</smiles>

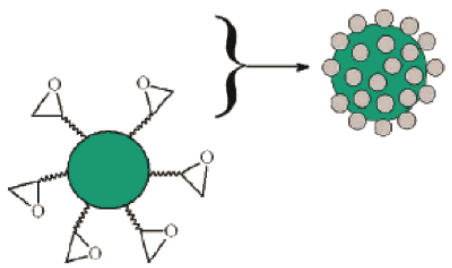

Figure 2.14 Scheme of the etching ${ }^{195}$ (A) and the dual size coupling ${ }^{197}$ (B) methods for the synthesis of raspberry-like silica nanoparticles.

The versatile production and surface engineering of silica nanoparticles with various surface chemistries and roughness provided us with a very promising starting point for the design of nanoparticles that can be used as potentially efficient nucleation agents in $\mathrm{CO}_{2}$ blown nanocellular polymer foams. 


\subsection{Conclusion}

For nanocellular polymer foams to become applicable in areas like thermal insulation their cell density needs to be increased to above $10^{14}$ cells $\mathrm{cm}^{-3}$, while their cell size remains in the order of a few tens of nanometers. This requires that at least an equal number of foam cells are nucleated during the initial stages of foaming. Therefore it is of great importance to improve our understanding of cell nucleation at this length scale. Existing models and remaining questions have been discussed in detail in this Chapter. Despite the apparent lack in fundamental insights and experimental validation, a growing number of reports describe the preparation of batch foamed nanocellular films. From these reports an enhanced understanding in the available processing windows has been obtained. Acrylic copolymers and their nanocomposites have been produced into relatively thick nanocellular samples with cell sizes, cell densities and porosities close to the targeted values. Parts of the contributions are described in this Thesis.

In particular the optimization of nanoparticle surface chemistry and roughness for the development of nucleation agents with high nucleation efficiencies, is considered promising for the preparation of blown polymers with e.g. high cell densities or narrower cell size distributions. 


\section{References}

[1] Liu, S.; Duvigneau, J.; Vancso, G. J., Nanocellular polymer foams as promising high performance thermal insulation materials. European polymer journal 2015, 65, 33-45.

[2] Costeux, S., $\mathrm{CO}_{2}$-blown nanocellular foams. Journal of Applied Polymer Science 2014, 131, 41293-41308.

[3] Reglero Ruiz, J. A.; Dumon, M.; Pinto, J.; Rodriguez-Pérez, M. A., Low-density nanocellular foams produced by high-pressure carbon dioxide. Macromolecular Materials and Engineering 2011, 296, 752-759.

[4] Notario, B.; Pinto, J.; Rodríguez-Pérez, M., Towards a new generation of polymeric foams: PMMA nanocellular foams with enhanced physical properties. Polymer 2015, 63, 116-126.

[5] Lee, L. J.; Zeng, C.; Cao, X.; Han, X.; Shen, J.; Xu, G., Polymer nanocomposite foams. Composites Science and Technology 2005, 65, 2344-2363.

[6] Okolieocha, C.; Raps, D.; Subramaniam, K.; Altstädt, V., Microcellular to nanocellular polymer foams: Progress (2004-2015) and future directions-A review. European Polymer Journal 2015, 73, 500-519.

[7] Wool, R.; Sun, X. S., Bio-based polymers and composites. Academic Press: 2011.

[8] Fu, J.; Naguib, H. E., Effect of nanoclay on the mechanical properties of PMMA/clay nanocomposite foams. Journal of Cellular Plastics 2006, 42, 325-342.

[9] Shen, J.; Zeng, C.; Lee, L. J., Synthesis of polystyrene-carbon nanofibers nanocomposite foams. Polymer 2005, 46, 5218-5224.

[10] Yang, Y.; Gupta, M. C.; Dudley, K. L.; Lawrence, R. W., Novel carbon nanotubepolystyrene foam composites for electromagnetic interference shielding. Nano Letters $\mathbf{2 0 0 5}$, 5, 2131-2134.

[11] Liu, S.; Zoetebier, B.; Hulsman, L.; Zhang, Y.; Duvigneau, J.; Vancso, G. J., Nanocellular polymer foams nucleated by core-shell nanoparticles. Polymer 2016, 104, 22-30.

[12] Ibeh, C. C.; Bubacz, M., Current trends in nanocomposite foams. Journal of Cellular Plastics 2008, 44, 493-515.

[13] Zheng, W.; Lee, Y.; Park, C., Use of nanoparticles for improving the foaming behaviors of linear PP. Journal of Applied Polymer Science 2010, 117, 2972-2979.

[14] Zeng, C.; Han, X.; Lee, L. J.; Koelling, K. W.; Tomasko, D. L., Polymer-clay nanocomposite foams prepared using carbon dioxide. Advanced Materials 2003, 15, 1743-1747.

[15] Cao, X.; Lee, L. J.; Widya, T.; Macosko, C., Polyurethane/clay nanocomposites foams: processing, structure and properties. Polymer 2005, 46, 775-783.

[16] Goren, K.; Chen, L.; Schadler, L. S.; Ozisik, R., Influence of nanoparticle surface chemistry and size on supercritical carbon dioxide processed nanocomposite foam morphology. The Journal of Supercritical Fluids 2010, 51, 420-427.

[17] Saha, M.; Kabir, M. E.; Jeelani, S., Enhancement in thermal and mechanical properties of polyurethane foam infused with nanoparticles. Materials Science and Engineering: A 2008, $479,213-222$. 
[18] Kresta, J. E.; Wu, J.; Crooker, R. M., Polymer foam containing nanoclay. Google Patents: 2003.

[19] Hussain, F.; Hojjati, M.; Okamoto, M.; Gorga, R. E., Polymer-matrix nanocomposites, processing, manufacturing, and application: an overview. Journal of Composite Materials 2006, 40, 1511-1575.

[20] Cai, L. F.; Huang, X. B.; Rong, M. Z.; Ruan, W. H.; Zhang, M. Q., Effect of grafted polymeric foaming agent on the structure and properties of nano-silica/polypropylene composites. Polymer 2006, 47, 7043-7050.

[21] Leung, S. N.; Wong, A.; Guo, Q.; Park, C. B.; Zong, J. H., Change in the critical nucleation radius and its impact on cell stability during polymeric foaming processes. Chemical Engineering Science 2009, 64, 4899-4907.

[22] Liao, R.; Yu, W.; Zhou, C., Rheological control in foaming polymeric materials: I. Amorphous polymers. Polymer 2010, 51, 568-580.

[23] Krause, B.; Diekmann, K.; Van der Vegt, N.; Wessling, M., Open nanoporous morphologies from polymeric blends by carbon dioxide foaming. Macromolecules 2002, 35, 1738-1745.

[24] Li, S.; Xiao, M.; Guan, Y.; Wei, D.; Xiao, H.; Zheng, A., A novel strategy for the preparation of long chain branching polypropylene and the investigation on foamability and rheology. European Polymer Journal 2012, 48, 362-371.

[25] Matuana, L. M.; Diaz, C. A., Study of cell nucleation in microcellular poly (lactic acid) foamed with supercritical $\mathrm{CO}_{2}$ through a continuous-extrusion process. Industrial \& Engineering Chemistry Research 2010, 49, 2186-2193.

[26] Stafford, C. M.; Russell, T. P.; McCarthy, T. J., Expansion of polystyrene using supercritical carbon dioxide: effects of molecular weight, polydispersity, and low molecular weight components. Macromolecules 1999, 32, 7610-7616.

[27] Zhai, W.; Wang, J.; Chen, N.; Naguib, H. E.; Park, C. B., The orientation of carbon nanotubes in poly (ethylene-co-octene) microcellular foaming and its suppression effect on cell coalescence. Polymer Engineering \& Science 2012, 52, 2078-2089.

[28] Liao, R.; Yu, W.; Zhou, C., Rheological control in foaming polymeric materials: II. Semicrystalline polymers. Polymer 2010, 51, 6334-6345.

[29] McCallum, T. J.; Kontopoulou, M.; Park, C. B.; Wong, A.; Kim, S. G., Effect of branched PP content on the physical properties and cell growth during foaming of TPOs. Journal of Applied Polymer Science 2008, 110, 817-824.

[30] Mihai, M.; Huneault, M. A.; Favis, B. D., Rheology and extrusion foaming of chain-branched poly (lactic acid). Polymer Engineering \& Science 2010, 50, 629-642.

[31] Chen, L.; Rende, D.; Schadler, L. S.; Ozisik, R., Polymer nanocomposite foams. Journal of Materials Chemistry A 2013, 1, 3837-3850.

[32] Klempner, D.; Frisch, K. C., Handbook of polymeric foams and foam technology. Hanser Munich etc.: 1991; Vol. 404.

[33] Shi, C.; Huang, Z.; Kilic, S.; Xu, J.; Enick, R.; Beckman, E.; Carr, A.; Melendez, R.; Hamilton, A., The gelation of $\mathrm{CO}_{2}$ : a sustainable route to the creation of microcellular materials. Science 1999, 286, 1540-1543. 
[34] Butler, R.; Hopkinson, I.; Cooper, A., Synthesis of porous emulsion-templated polymers using high internal phase $\mathrm{CO}_{2}$-in-water emulsions. Journal of the American Chemical Society 2003, 125, 14473-14481.

[35] Tomasko, D. L.; Li, H.; Liu, D.; Han, X.; Wingert, M. J.; Lee, L. J.; Koelling, K. W., A review of $\mathrm{CO}_{2}$ applications in the processing of polymers. Industrial \& Engineering Chemistry Research 2003, 42, 6431-6456.

[36] Park, C. B.; Behravesh, A. H.; Venter, R. D., Low density microcellular foam processing in extrusion using $\mathrm{CO}_{2}$. Polymer Engineering \& Science 1998, 38, 1812-1823.

[37] Bledzki, A. K.; Faruk, O., Effects of the chemical foaming agents, injection parameters, and melt-flow index on the microstructure and mechanical properties of microcellular injectionmolded wood-fiber/polypropylene composites. Journal of Applied Polymer Science 2005, 97, 1090-1096.

[38] Li, Q.; Matuana, L. M., Foam extrusion of high density polyethylene/wood-flour composites using chemical foaming agents. Journal of Applied Polymer Science 2003, 88, 3139-3150.

[39] Robin, M. L.; Iikubo, Y.; Register, W. D.; Rose, R. S., Hydrofluorocarbon compositions as blowing agents for cellular plastics. Google Patents: 1994.

[40] Singh, S. N.; Burns, S. B.; Jones, P. A., Flame resistant rigid polyurethane foams blown with hydrofluorocarbons. Google Patents: 2002.

[41] Jacobs, L. J.; Kemmere, M. F.; Keurentjes, J. T., Sustainable polymer foaming using high pressure carbon dioxide: a review on fundamentals, processes and applications. Green Chemistry 2008, 10, 731-738.

[42] Tsivintzelis, I.; Pavlidou, E.; Panayiotou, C., Biodegradable polymer foams prepared with supercritical $\mathrm{CO}_{2}-$ ethanol mixtures as blowing agents. The Journal of Supercritical Fluids 2007, 42, 265-272.

[43] Oksman, K.; Aitomäki, Y.; Mathew, A. P.; Siqueira, G.; Zhou, Q.; Butylina, S.; Tanpichai, S.; Zhou, X.; Hooshmand, S., Review of the recent developments in cellulose nanocomposite processing. Composites Part A: Applied Science and Manufacturing 2016, 83, 2-18.

[44] Zhao, N.; Zhu, C.; Howe Mark, L.; Park, C. B.; Li, Q., Batch foaming poly (vinyl alcohol)/microfibrillated cellulose composites with $\mathrm{CO}_{2}$ and water as co-blowing agents. Journal of Applied Polymer Science 2015, 132, 42551-42560.

[45] Zhao, N.; Mark, L. H.; Zhu, C.; Park, C. B.; Li, Q.; Glenn, R.; Thompson, T. R., Foaming poly (vinyl alcohol)/microfibrillated cellulose composites with $\mathrm{CO}_{2}$ and water as co-blowing agents. Industrial \& Engineering Chemistry Research 2014, 53, 11962-11972.

[46] Bouma, R.; Nauta, W.; Arnauts, J.; Boomgaard, T.; Steuten, J.; Strathmann, H., Foam stability related to polymer permeability. I. Low molecular weight additives. Journal of Applied Polymer Science 1997, 65, 2679-2689.

[47] Nauta, W. J., Stabilisation of low density, closed cell polyethylene foam. Universiteit Twente: 2000.

[48] Condo, P.; Sanchez, I.; Panayiotou, C.; Johnston, K., Glass transition behavior including retrograde vitrification of polymers with compressed fluid diluents. Macromolecules 1992, 25, 6119-6127. 
[49] Du Fresne Von Hohenesche, C.; Schmidt, D.; Schadler, V., Nanoporous melamineformaldehyde gels by microemulsion templating. Chemistry of Materials 2008, 20, 61246129 .

[50] Kailasam, K.; Jun, Y.-S.; Katekomol, P.; Epping, J. D.; Hong, W. H.; Thomas, A., Mesoporous melamine resins by soft templating of block-co-polymer mesophases. Chemistry of Materials 2009, 22, 428-434.

[51] Notario, B.; Pinto, J.; Rodriguez-Perez, M., Nanoporous polymeric materials: A new class of materials with enhanced properties. Progress in Materials Science 2016, 78, 93-139.

[52] Luo, Y.; Ye, C., Using nanocapsules as building blocks to fabricate organic polymer nanofoam with ultra low thermal conductivity and high mechanical strength. Polymer 2012, $53,5699-5705$.

[53] Handa, Y. P.; Zhang, Z., A new technique for measuring retrograde vitrification in polymergas systems and for making ultramicrocellular foams from the retrograde phase. Journal of Polymer Science Part B: Polymer Physics 2000, 38, 716-725.

[54] Sandler, J. K. W.; Francis, T.; Lopes, P. M. S., Nanoporous polymer foams. Google Patents: 2013.

[55] Krause, B.; Kloth, M.; Van der Vegt, N.; Wessling, M., Porous monofilaments by continuous solid-state foaming. Industrial \& Engineering Chemistry Research 2002, 41, 1195-1204.

[56] Costeux, S.; Lantz, D. R.; Beaudoin, D. A.; Barger, M. A., Continuous process for extruding nanoporous foam. Google Patents: 2015.

[57] Krause, B., Polymer nanofoams. PrintPartners Ipskamp: 2001.

[58] Costeux, S.; Zhu, L., Low density thermoplastic nanofoams nucleated by nanoparticles. Polymer 2013, 54, 2785-2795.

[59] Krause, B.; Sijbesma, H.; Münüklü, P.; Van der Vegt, N.; Wessling, M., Bicontinuous nanoporous polymers by carbon dioxide foaming. Macromolecules 2001, 34, 8792-8801.

[60] Martín-de León, J.; Bernardo, V.; Rodríguez-Pérez, M. Á., Low density nanocellular polymers based on PMMA produced by gas dissolution foaming: fabrication and cellular structure characterization. Polymers 2016, 8, 265.

[61] Liao, Z.-E.; Yeh, S.-K.; Chu, C.-C.; Tseng, T.-W., Critical Parameters of Generating PMMA Nanocellular Foam. Annual Technical Conference-ANTEC, Conference Proceedings, 2016.

[62] Guo, H.; Kumar, V., Solid-state poly (methyl methacrylate)(PMMA) nanofoams. Part I: lowtemperature $\mathrm{CO}_{2}$ sorption, diffusion, and the depression in PMMA glass transition. Polymer 2015, 57, 157-163.

[63] Otsuka, T.; Taki, K.; Ohshima, M., Nanocellular foams of PS/PMMA polymer blends. Macromolecular Materials and Engineering 2008, 293, 78-82.

[64] Yokoyama, B. H.; Li, L.; Nemoto, T.; Sugiyama, K., Tunable nanocellular polymeric monoliths using fluorinated block copolymer templates and supercritical carbon dioxide. Advanced Materials 2004, 16, 1542-1546.

[65] Li, L.; Nemoto, T.; Sugiyama, K.; Yokoyama, H., $\mathrm{CO}_{2}$ foaming in thin films of block copolymer containing fluorinated blocks. Macromolecules 2006, 39, 4746-4755. 
[66] Yokoyama, H.; Sugiyama, K., Nanocellular structures in block copolymers with $\mathrm{CO}_{2}$-philic blocks using $\mathrm{CO}_{2}$ as a blowing agent: crossover from micro-to nanocellular structures with depressurization temperature. Macromolecules 2005, 38, 10516-10522.

[67] Spitael, P.; Macosko, C. W.; McClurg, R. B., Block copolymer micelles for nucleation of microcellular thermoplastic foams. Macromolecules 2004, 37, 6874-6882.

[68] Ruiz, J. A. R.; Pedros, M.; Tallon, J.-M.; Dumon, M., Micro and nano cellular amorphous polymers (PMMA, PS) in supercritical $\mathrm{CO}_{2}$ assisted by nanostructured $\mathrm{CO}_{2}$-philic block copolymers-one step foaming process. The Journal of Supercritical Fluids 2011, 58, 168176.

[69] Costeux, S.; Bunker, S. P.; Jeon, H. K., Homogeneous nanocellular foams from styrenicacrylic polymer blends. Journal of Materials Research 2013, 28, 2351-2365.

[70] Janani, H.; Famili, M., Investigation of a strategy for well controlled inducement of microcellular and nanocellular morphologies in polymers. Polymer Engineering \& Science 2010, 50, 1558-1570.

[71] Cohon, J.; Suh, N., Nucleation of microcellular foam: theory and practice. Polymer Engineering and Science 1987, 27, 500-503.

[72] Colton, J.; Suh, N., The nucleation of microcellular thermoplastic foam with additives: Part II: Experimental results and discussion. Polymer Engineering \& Science 1987, 27, 493-499.

[73] Colton, J.; Suh, N., The nucleation of microcellular thermoplastic foam with additives: Part I: Theoretical considerations. Polymer Engineering \& Science 1987, 27, 485-492.

[74] Velasco, J.; Antunes, M.; Ayyad, O.; López-Cuesta, J.; Gaudon, P.; Saiz-Arroyo, C.; Rodríguez-Pérez, M.; De Saja, J., Foaming behaviour and cellular structure of LDPE/hectorite nanocomposites. Polymer 2007, 48, 2098-2108.

[75] Famili, M.; Janani, H.; Enayati, M., Foaming of a polymer-nanoparticle system: effect of the particle properties. Journal of Applied Polymer Science 2011, 119, 2847-2856.

[76] Chen, L.; Ozisik, R.; Schadler, L. S., The influence of carbon nanotube aspect ratio on the foam morphology of MWNT/PMMA nanocomposite foams. Polymer 2010, 51, 2368-2375.

[77] Urbanczyk, L.; Calberg, C.; Detrembleur, C.; Jérôme, C.; Alexandre, M., Batch foaming of SAN/clay nanocomposites with $\mathrm{scCO}_{2}$ : a very tunable way of controlling the cellular morphology. Polymer 2010, 51, 3520-3531.

[78] Harikrishnan, G.; Patro, T. U.; Unni, A. R.; Khakhar, D. V., Clay nanoplatelet induced morphological evolutions during polymeric foaming. Soft Matter 2011, 7, 6801-6804.

[79] Oxtoby, D. W., Density functional methods in the statistical mechanics of materials. Annual Review of Materials Research 2002, 32, 39-52.

[80] Zettlemoyer, A. C., Nucleation. 1969.

[81] Zhai, W.; Yu, J.; Wu, L.; Ma, W.; He, J., Heterogeneous nucleation uniformizing cell size distribution in microcellular nanocomposites foams. Polymer 2006, 47, 7580-7589.

[82] Bandarian, M.; Shojaei, A.; Rashidi, A. M., Thermal, mechanical and acoustic damping properties of flexible open-cell polyurethane/multi-walled carbon nanotube foams: Effect of surface functionality of nanotubes. Polymer International 2011, 60, 475-482. 
[83] Gong, P.; Ohshima, M., Effect of interfacial tension on the cell structure of poly (methyl methacrylate)/bisphenol A polycarbonate blends foamed with $\mathrm{CO}_{2}$. Journal of Applied Polymer Science 2014, 131, 39228-39239.

[84] Fletcher, N., Size effect in heterogeneous nucleation. The Journal of Chemical Physics 1958, $29,572-576$.

[85] Yang, J.; Sang, Y.; Chen, F.; Fei, Z.; Zhong, M., Synthesis of silica particles grafted with poly (ionic liquid) and their nucleation effect on microcellular foaming of polystyrene using supercritical carbon dioxide. The Journal of Supercritical Fluids 2012, 62, 197-203.

[86] Siripurapu, S.; DeSimone, J. M.; Khan, S. A.; Spontak, R. J., Controlled foaming of polymer films through restricted surface diffusion and the addition of nanosilica particles or $\mathrm{CO}_{2}$ philic surfactants. Macromolecules 2005, 38, 2271-2280.

[87] Yang, J.; Huang, L.; Zhang, Y.; Chen, F.; Zhong, M., Mesoporous silica particles grafted with polystyrene brushes as a nucleation agent for polystyrene supercritical carbon dioxide foaming. Journal of Applied Polymer Science 2013, 130, 4308-4317.

[88] Vancso, G.; Duvigneau, J.; Nederkoorn, P.; Wassing, T., Polymer foam comprising a polymer and nanoparticles, and nanoparticles for the manufacture of such foam. 2014.

[89] Shi, W.; Siefert, N. S.; Morreale, B. D., Molecular simulations of $\mathrm{CO}_{2}, \mathrm{H}_{2}, \mathrm{H}_{2} \mathrm{O}$, and $\mathrm{H}_{2} \mathrm{~S}$ gas absorption into hydrophobic poly (dimethylsiloxane)(PDMS) solvent: solubility and surface tension. The Journal of Physical Chemistry C 2015, 119, 19253-19265.

[90] Li, J.-L.; Chen, B.-H., Review of $\mathrm{CO}_{2}$ absorption using chemical solvents in hollow fiber membrane contactors. Separation and Purification Technology 2005, 41, 109-122.

[91] Miller, M. B.; Luebke, D. R.; Enick, R. M., $\mathrm{CO}_{2}$-philic oligomers as novel solvents for $\mathrm{CO}_{2}$ absorption. Energy \& Fuels 2010, 24, 6214-6219.

[92] Scholes, C. A.; Stevens, G. W.; Kentish, S. E., The effect of hydrogen sulfide, carbon monoxide and water on the performance of a PDMS membrane in carbon dioxide/nitrogen separation. Journal of Membrane Science 2010, 350, 189-199.

[93] Xiong, Y.; Kiran, E., Miscibility, density and viscosity of poly (dimethylsiloxane) in supercritical carbon dioxide. Polymer 1995, 36, 4817-4826.

[94] Kim, Y.; Park, C. B.; Chen, P.; Thompson, R. B., Origins of the failure of classical nucleation theory for nanocellular polymer foams. Soft Matter 2011, 7, 7351-7358.

[95] Wang, C.; Leung, S.; Bussmann, M.; Zhai, W.; Park, C., Numerical investigation of nucleating-agent-enhanced heterogeneous nucleation. Industrial \& Engineering Chemistry Research 2010, 49, 12783-12792.

[96] Wong, A.; Stephan, F.; Wijnands, L.; Kuboki, T.; Park, C. B., Mechanisms of nanoclayenhanced plastic foaming processes: effects of nanoclay intercalation and exfoliation. Journal of Nanoparticle Research 2013, 15, 1.

[97] Xu, X.; Cristancho, D. E.; Costeux, S.; Wang, Z.-G., Density-functional theory for polymercarbon dioxide mixtures: A perturbed-chain SAFT approach. The Journal of Chemical Physics 2012, 137, 054902. 
[98] Xu, X.; Cristancho, D. E.; Costeux, S. p.; Wang, Z., Discontinuous bubble nucleation due to a metastable condensation transition in polymer- $\mathrm{CO}_{2}$ mixtures. The Journal of Physical Chemistry Letters 2013, 4, 1639-1643.

[99] Leung, S.; Park, C.; Li, H., Numerical simulation of polymeric foaming processes using modified nucleation theory. Plastics, Rubber and Composites 2006, 35, 93-100.

[100] Leung, S. N.; Wong, A.; Park, C. B.; Zong, J. H., Ideal surface geometries of nucleating agents to enhance cell nucleation in polymeric foaming processes. Journal of Applied Polymer Science 2008, 108, 3997-4003.

[101] McBride, S. P.; Law, B. M., Influence of line tension on spherical colloidal particles at liquidvapor interfaces. Physical Review Letters 2012, 109, 196101.

[102] Navascues, G.; Tarazona, P., Line tension effects in heterogeneous nucleation theory. The Journal of Chemical Physics 1981, 75, 2441-2446.

[103] Hienola, A.; Winkler, P.; Wagner, P.; Vehkamäki, H.; Lauri, A.; Napari, I.; Kulmala, M., Estimation of line tension and contact angle from heterogeneous nucleation experimental data. The Journal of Chemical Physics 2007, 126, 094705.

[104] Law, B. M., Theory of nucleated wetting. Physical Review Letters 1994, 72, 1698-1701.

[105] Bresme, F.; Quirke, N., Computer simulation study of the wetting behavior and line tensions of nanometer size particulates at a liquid-vapor interface. Physical Review Letters 1998, 80, 3791 .

[106] Gretz, R., The line-tension effect in heterogeneous nucleation. Surface Science 1966, 5, 239251.

[107] Wang, L.; Zhou, H.; Wang, X.; Mi, J., Evaluation of nanoparticle effect on bubble nucleation in polymer foaming. The Journal of Physical Chemistry C 2016, 120, 26841-26851.

[108] Martini-Vvedensky, J. E.; Suh, N. P.; Waldman, F. A., Microcellular closed cell foams and their method of manufacture. Google Patents: 1984.

[109] Ramesh, N.; Rasmussen, D. H.; Campbell, G. A., The heterogeneous nucleation of microcellular foams assisted by the survival of microvoids in polymers containing low glass transition particles. Part I: Mathematical modeling and numerical simulation. Polymer Engineering \& Science 1994, 34, 1685-1697.

[110] Hervey, E. N.; Barnes, D.; McElroy, W.; Whiteley, A.; Pease, D., Removal of gas nuclei from liquids and surfaces. Journal of the American Chemical Society 1945, 67, 156-157.

[111] Harvey, E. N.; McElroy, W. D.; Whiteley, A., On cavity formation in water. Journal of Applied Physics 1947, 18, 162-172.

[112] Ward, C.; Levart, E., Conditions for stability of bubble nuclei in solid surfaces contacting a liquid-gas solution. Journal of Applied Physics 1984, 56, 491-500.

[113] Ward, C.; Tikuisis, P.; Venter, R., Stability of bubbles in a closed volume of liquid-gas solution. Journal of Applied Physics 1982, 53, 6076-6084.

[114] Lee, S. T., Shear effects on thermoplastic foam nucleation. Polymer Engineering \& Science 1993, 33, 418-422. 
[115] Han, J. H.; Dae Han, C., Bubble nucleation in polymeric liquids. II. Theoretical considerations. Journal of Polymer Science Part B: Polymer Physics 1990, 28, 743-761.

[116] Guo, M.; Peng, Y., Study of shear nucleation theory in continuous microcellular foam extrusion. Polymer testing 2003, 22, 705-709.

[117] Chen, L.; Sheth, H.; Wang, X., Effects of shear stress and pressure drop rate on microcellular foaming process. Journal of cellular plastics 2001, 37, 353-363.

[118] Forest, C.; Chaumont, P.; Cassagnau, P.; Swoboda, B.; Sonntag, P., Polymer nano-foams for insulating applications prepared from $\mathrm{CO}_{2}$ foaming. Progress in Polymer Science 2015, 41, 122-145.

[119] Kuhn, J.; Ebert, H.-P.; Arduini-Schuster, M.; Büttner, D.; Fricke, J., Thermal transport in polystyrene and polyurethane foam insulations. International Journal of Heat and Mass Transfer 1992, 35, 1795-1801.

[120] Baetens, R.; Jelle, B. P.; Gustavsen, A., Aerogel insulation for building applications: a stateof-the-art review. Energy and Buildings 2011, 43, 761-769.

[121] Jelle, B. P.; Gustavsen, A.; Baetens, R., The path to the high performance thermal building insulation materials and solutions of tomorrow. Journal of Building Physics 2010, 34, 99-123.

[122] Sundarram, S. S.; Li, W., On thermal conductivity of micro-and nanocellular polymer foams. Polymer Engineering \& Science 2013, 53, 1901-1909.

[123] Klasse, K. S. G. d. W. M.-P., Abhandlungen der Mathematisch-Physischen Klasse der Königlich-Sächsischen Gesellschaft der Wissenschaften. Hirzel: 1870; Vol. 12.

[124] Collishaw, P.; Evans, J., An assessment of expressions for the apparent thermal conductivity of cellular materials. Journal of Materials Science 1994, 29, 486-498.

[125] Alvarez-Lainez, M.; Rodriguez-Perez, M.; De Saja, J., Thermal conductivity of open-cell polyolefin foams. Journal of Polymer Science Part B: Polymer Physics 2008, 46, 212-221.

[126] Wang, G.; Zhao, J.; Mark, L. H.; Wang, G.; Yu, K.; Wang, C.; Park, C. B.; Zhao, G., Ultratough and super thermal-insulation nanocellular PMMA/TPU. Chemical Engineering Journal 2017, 325, 632-646.

[127] Notario, B.; Pinto, J.; Solorzano, E.; De Saja, J. A.; Dumon, M.; Rodríguez-Pérez, M. A., Experimental validation of the Knudsen effect in nanocellular polymeric foams. Polymer 2015, 56, 57-67.

[128] Pascault, J.-P.; Williams, R. J., Epoxy polymers: new materials and innovations. John Wiley \& Sons: 2009.

[129] Bredereck, K.; Effenberger, F.; Tretter, M., Preparation and characterization of silica aquasols. Journal of Colloid and Interface Science 2011, 360, 408-414.

[130] Rossi, L. M.; Shi, L.; Quina, F. H.; Rosenzweig, Z., Stöber synthesis of monodispersed luminescent silica nanoparticles for bioanalytical assays. Langmuir 2005, 21, 4277-4280.

[131] Lee, C. H.; Park, S. H.; Chung, W.; Kim, J. Y.; Kim, S. H., Preparation and characterization of surface modified silica nanoparticles with organo-silane compounds. Colloids and Surfaces A: Physicochemical and Engineering Aspects 2011, 384, 318-322. 
[132] Masalov, V.; Sukhinina, N.; Kudrenko, E.; Emelchenko, G., Mechanism of formation and nanostructure of Stöber silica particles. Nanotechnology 2011, 22, 275718.

[133] Chen, S.; Hayakawa, S.; Shirosaki, Y.; Fujii, E.; Kawabata, K.; Tsuru, K.; Osaka, A., SolGel Synthesis and Microstructure Analysis of Amino-Modified Hybrid Silica Nanoparticles from Aminopropyltriethoxysilane and Tetraethoxysilane. Journal of the American Ceramic Society 2009, 92, 2074-2082.

[134] Baudoin, M.; Thomas, J.-L.; Coulouvrat, F.; Chanéac, C., Scattering of ultrasonic shock waves in suspensions of silica nanoparticles. The Journal of the Acoustical Society of America 2011, 129, 1209-1220.

[135] Kim, J.; Kim, L.; Kim, C., Size control of silica nanoparticles and their surface treatment for fabrication of dental nanocomposites. Biomacromolecules 2007, 8, 215-222.

[136] Liberman, A.; Mendez, N.; Trogler, W. C.; Kummel, A. C., Synthesis and surface functionalization of silica nanoparticles for nanomedicine. Surface Science Reports 2014, 69 , 132-158.

[137] Lü, C.; Yang, B., High refractive index organic-inorganic nanocomposites: design, synthesis and application. Journal of Materials Chemistry 2009, 19, 2884-2901.

[138] Von Werne, T.; Patten, T. E., Preparation of structurally well-defined polymer- nanoparticle hybrids with controlled/living radical polymerizations. Journal of the American Chemical Society 1999, 121, 7409-7410.

[139] Pyun, J.; Matyjaszewski, K., Synthesis of nanocomposite organic/inorganic hybrid materials using controlled/“living” radical polymerization. Chemistry of Materials 2001, 13, 34363448 .

[140] McEwan, M.; Green, D., Rheological impacts of particle softness on wetted polymer-grafted silica nanoparticles in polymer melts. Soft Matter 2009, 5, 1705-1716.

[141] Wu, T.; Zhang, Y.; Wang, X.; Liu, S., Fabrication of hybrid silica nanoparticles densely grafted with thermoresponsive poly ( $\mathrm{N}$-isopropylacrylamide) brushes of controlled thickness via surface-initiated atom transfer radical polymerization. Chemistry of Materials 2007, 20, 101-109.

[142] Radhakrishnan, B.; Ranjan, R.; Brittain, W. J., Surface initiated polymerizations from silica nanoparticles. Soft Matter 2006, 2, 386-396.

[143] Huang, C.; Tassone, T.; Woodberry, K.; Sunday, D.; Green, D. L., Impact of ATRP initiator spacer length on grafting poly (methyl methacrylate) from silica nanoparticles. Langmuir 2009, 25, 13351-13360.

[144] Liu, P.; Tian, J.; Liu, W.; Xue, Q., Surface-initiated atom transfer radical polymerization (ATRP) of styrene from silica nanoparticles under UV irradiation. Polymer International 2004, 53, 127-130.

[145] El Harrak, A.; Carrot, G.; Oberdisse, J.; Jestin, J.; Boué, F., Atom transfer radical polymerization from silica nanoparticles using the 'grafting from'method and structural study via small-angle neutron scattering. Polymer 2005, 46, 1095-1104. 
[146] Choudhury, A.; Bhowmick, A. K.; Ong, C., Novel role of polymer-solvent and clay-solvent interaction parameters on the thermal, mechanical and optical properties of polymer nanocomposites. Polymer 2009, 50, 201-210.

[147] Tjong, S. C., Structural and mechanical properties of polymer nanocomposites. Materials Science and Engineering: R: Reports 2006, 53, 73-197.

[148] Guo, Z.; Wei, S.; Shedd, B.; Scaffaro, R.; Pereira, T.; Hahn, H. T., Particle surface engineering effect on the mechanical, optical and photoluminescent properties of $\mathrm{ZnO} /$ vinylester resin nanocomposites. Journal of Materials Chemistry 2007, 17, 806-813.

[149] Kuan, H.-C.; Ma, C.-C. M.; Chang, W.-P.; Yuen, S.-M.; Wu, H.-H.; Lee, T.-M., Synthesis, thermal, mechanical and rheological properties of multiwall carbon nanotube/waterborne polyurethane nanocomposite. Composites Science and Technology 2005, 65, 1703-1710.

[150] Agag, T.; Koga, T.; Takeichi, T., Studies on thermal and mechanical properties of polyimideclay nanocomposites. Polymer 2001, 42, 3399-3408.

[151] Wang, J.-S.; Matyjaszewski, K., Controlled/" living" radical polymerization. Halogen atom transfer radical polymerization promoted by a $\mathrm{Cu}$ (I)/Cu (II) redox process. Macromolecules 1995, 28, 7901-7910.

[152] Matyjaszewski, K., Atom transfer radical polymerization (ATRP): current status and future perspectives. Macromolecules 2012, 45, 4015-4039.

[153] Matyjaszewski, K.; Dong, H.; Jakubowski, W.; Pietrasik, J.; Kusumo, A., Grafting from Surfaces for "Everyone": ARGET ATRP in the Presence of Air. Langmuir 2007, 23, 45284531.

[154] Min, K.; Gao, H.; Matyjaszewski, K., Preparation of homopolymers and block copolymers in miniemulsion by ATRP using activators generated by electron transfer (AGET). Journal of the American Chemical Society 2005, 127, 3825-3830.

[155] Gao, H.; Matyjaszewski, K., Synthesis of star polymers by a combination of ATRP and the “click" coupling method. Macromolecules 2006, 39, 4960-4965.

[156] Tang, W.; Matyjaszewski, K., Effect of ligand structure on activation rate constants in ATRP. Macromolecules 2006, 39, 4953-4959.

[157] Neugebauer, D.; Zhang, Y.; Pakula, T.; Sheiko, S. S.; Matyjaszewski, K., Densely-grafted and double-grafted PEO brushes via ATRP. A route to soft elastomers. Macromolecules 2003, $36,6746-6755$.

[158] Matyjaszewski, K.; Patten, T. E.; Xia, J., Controlled/“living” radical polymerization. Kinetics of the homogeneous atom transfer radical polymerization of styrene. Journal of the American Chemical Society 1997, 119, 674-680.

[159] Braunecker, W. A.; Matyjaszewski, K., Controlled/living radical polymerization: features, developments, and perspectives. Progress in Polymer Science 2007, 32, 93-146.

[160] Matyjaszewski, K.; Miller, P. J.; Shukla, N.; Immaraporn, B.; Gelman, A.; Luokala, B. B.; Siclovan, T. M.; Kickelbick, G.; Vallant, T.; Hoffmann, H., Polymers at interfaces: using atom transfer radical polymerization in the controlled growth of homopolymers and block copolymers from silicon surfaces in the absence of untethered sacrificial initiator. Macromolecules 1999, 32, 8716-8724. 
[161] Wang, J.-S.; Matyjaszewski, K., Controlled/" living" radical polymerization. Atom transfer radical polymerization in the presence of transition-metal complexes. Journal of the American Chemical Society 1995, 117, 5614-5615.

[162] Edmondson, S.; Osborne, V. L.; Huck, W. T., Polymer brushes via surface-initiated polymerizations. Chemical Society Reviews 2004, 33, 14-22.

[163] Matyjaszewski, K.; Tsarevsky, N. V., Nanostructured functional materials prepared by atom transfer radical polymerization. Nature Chemistry 2009, 1, 276-288.

[164] Pyun, J.; Kowalewski, T.; Matyjaszewski, K., Synthesis of polymer brushes using atom transfer radical polymerization. Macromolecular Rapid Communications 2003, 24, 1043 1059.

[165] Saleh, N.; Sirk, K.; Liu, Y.; Phenrat, T.; Dufour, B.; Matyjaszewski, K.; Tilton, R. D.; Lowry, G. V., Surface modifications enhance nanoiron transport and NAPL targeting in saturated porous media. Environmental Engineering Science 2007, 24, 45-57.

[166] Siegwart, D. J.; Oh, J. K.; Matyjaszewski, K., ATRP in the design of functional materials for biomedical applications. Progress in polymer science 2012, 37, 18-37.

[167] Patten, T. E.; Xia, J.; Abernathy, T.; Matyjaszewski, K., Polymers with very low polydispersities from atom transfer radical polymerization. Science 1996, 272, 866.

[168] Gao, H.; Matyjaszewski, K., Synthesis of functional polymers with controlled architecture by CRP of monomers in the presence of cross-linkers: from stars to gels. Progress in Polymer Science 2009, 34, 317-350.

[169] Averick, S.; Simakova, A.; Park, S.; Konkolewicz, D.; Magenau, A. J.; Mehl, R. A.; Matyjaszewski, K., ATRP under biologically relevant conditions: grafting from a protein. ACS Macro Letters 2011, 1, 6-10.

[170] Oh, J. K.; Min, K.; Matyjaszewski, K., Preparation of poly (oligo (ethylene glycol) monomethyl ether methacrylate) by homogeneous aqueous AGET ATRP. Macromolecules 2006, 39, 3161-3167.

[171] Matyjaszewski, K.; Xia, J., Atom transfer radical polymerization. Chemical reviews 2001, 101, 2921-2990.

[172] Shipp, D. A.; Wang, J.-L.; Matyjaszewski, K., Synthesis of acrylate and methacrylate block copolymers using atom transfer radical polymerization. Macromolecules 1998, 31, 80058008 .

[173] Xia, J.; Gaynor, S. G.; Matyjaszewski, K., Controlled/“living” radical polymerization. Atom transfer radical polymerization of acrylates at ambient temperature. Macromolecules 1998, $31,5958-5959$.

[174] Kwak, Y.; Matyjaszewski, K., ARGET ATRP of methyl methacrylate in the presence of nitrogen-based ligands as reducing agents. Polymer International 2009, 58, 242-247.

[175] Dong, H.; Tang, W.; Matyjaszewski, K., Well-defined high-molecular-weight polyacrylonitrile via activators regenerated by electron transfer ATRP. Macromolecules 2007, 40, 2974-2977. 
[176] Gao, H.; Ohno, S.; Matyjaszewski, K., Low polydispersity star polymers via cross-linking macromonomers by ATRP. Journal of the American Chemical Society 2006, 128, 1511115113.

[177] Savin, D. A.; Pyun, J.; Patterson, G. D.; Kowalewski, T.; Matyjaszewski, K., Synthesis and characterization of silica-graft-polystyrene hybrid nanoparticles: Effect of constraint on the glass-transition temperature of spherical polymer brushes. Journal of Polymer Science Part B: Polymer Physics 2002, 40, 2667-2676.

[178] Karim, A.; Satija, S.; Douglas, J.; Ankner, J.; Fetters, L., Neutron reflectivity study of the density profile of a model end-grafted polymer brush: influence of solvent quality. Physical Review Letters 1994, 73, 3407.

[179] Choi, E.-Y.; Han, T. H.; Hong, J.; Kim, J. E.; Lee, S. H.; Kim, H. W.; Kim, S. O., Noncovalent functionalization of graphene with end-functional polymers. Journal of Materials Chemistry 2010, 20, 1907-1912.

[180] Kramer, E. J., Grafting Kinetics of End-Functional Polymers at Melt Interfaces. Israel Journal of Chemistry 1995, 35, 49-54.

[181] Minko, S.; Patil, S.; Datsyuk, V.; Simon, F.; Eichhorn, K.-J.; Motornov, M.; Usov, D.; Tokarev, I.; Stamm, M., Synthesis of adaptive polymer brushes via "grafting to" approach from melt. Langmuir 2002, 18, 289-296.

[182] Zdyrko, B.; Luzinov, I., Polymer brushes by the "grafting to" method. Macromolecular Rapid Communications 2011, 32, 859-869.

[183] Litvinov, V.; Barthel, H.; Weis, J., Structure of a PDMS layer grafted onto a silica surface studied by means of DSC and solid-state NMR. Macromolecules 2002, 35, 4356-4364.

[184] Liu, Y. L.; Li, S. H., Poly (dimethylsiloxane) star polymers having nanosized silica cores. Macromolecular Rapid Communications 2004, 25, 1392-1395.

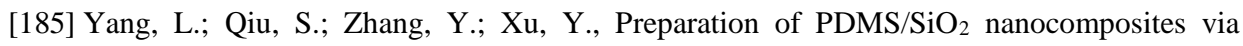
ultrasonical modification and miniemulsion polymerization. Journal of Polymer Research 2013, $20,1$.

[186] Liu, X.; He, J., Hierarchically structured superhydrophilic coatings fabricated by selfassembling raspberry-like silica nanospheres. Journal of Colloid and Interface Science 2007, $314,341-345$.

[187] Du, X.; Liu, X.; Chen, H.; He, J., Facile fabrication of raspberry-like composite nanoparticles and their application as building blocks for constructing superhydrophilic coatings. The Journal of Physical Chemistry C 2009, 113, 9063-9070.

[188] Gustafsson, H.; Isaksson, S.; Altskär, A.; Holmberg, K., Mesoporous silica nanoparticles with controllable morphology prepared from oil-in-water emulsions. Journal of Colloid and Interface Science 2016, 467, 253-260.

[189] Du, X.; He, J., Facile fabrication of hollow mesoporous silica nanospheres for superhydrophilic and visible/Near-IR antireflection coatings. Chemistry-A European Journal 2011, 17, 8165-8174. 
[190] Slowing, I. I.; Vivero-Escoto, J. L.; Wu, C.-W.; Lin, V. S.-Y., Mesoporous silica nanoparticles as controlled release drug delivery and gene transfection carriers. Advanced Drug Delivery Reviews 2008, 60, 1278-1288.

[191] Li, Z.; Barnes, J. C.; Bosoy, A.; Stoddart, J. F.; Zink, J. I., Mesoporous silica nanoparticles in biomedical applications. Chemical Society Reviews 2012, 41, 2590-2605.

[192] Zhang, T.; Zhang, Q.; Ge, J.; Goebl, J.; Sun, M.; Yan, Y.; Liu, Y.-s.; Chang, C.; Guo, J.; Yin, Y., A self-templated route to hollow silica microspheres. The Journal of Physical Chemistry C 2009, 113, 3168-3175.

[193] Li, Z.-Z.; Wen, L.-X.; Shao, L.; Chen, J.-F., Fabrication of porous hollow silica nanoparticles and their applications in drug release control. Journal of Controlled Release 2004, 98, 245254.

[194] Chen, J.-F.; Ding, H.-M.; Wang, J.-X.; Shao, L., Preparation and characterization of porous hollow silica nanoparticles for drug delivery application. Biomaterials 2004, 25, 723-727.

[195] Du, X.; He, J., A self-templated etching route to surface-rough silica nanoparticles for superhydrophobic coatings. ACS Applied Materials \& Interfaces 2011, 3, 1269-1276.

[196] Puretskiy, N.; Ionov, L., Synthesis of robust raspberry-like particles using polymer brushes. Langmuir 2011, 27, 3006-3011.

[197] Ming, W.; Wu, D.; van Benthem, R.; De With, G., Superhydrophobic films from raspberrylike particles. Nano Letters 2005, 5, 2298-2301. 


\section{Chapter 3}

\section{Nanocellular Polymer Foams Nucleated by Core-shell Nanoparticles}

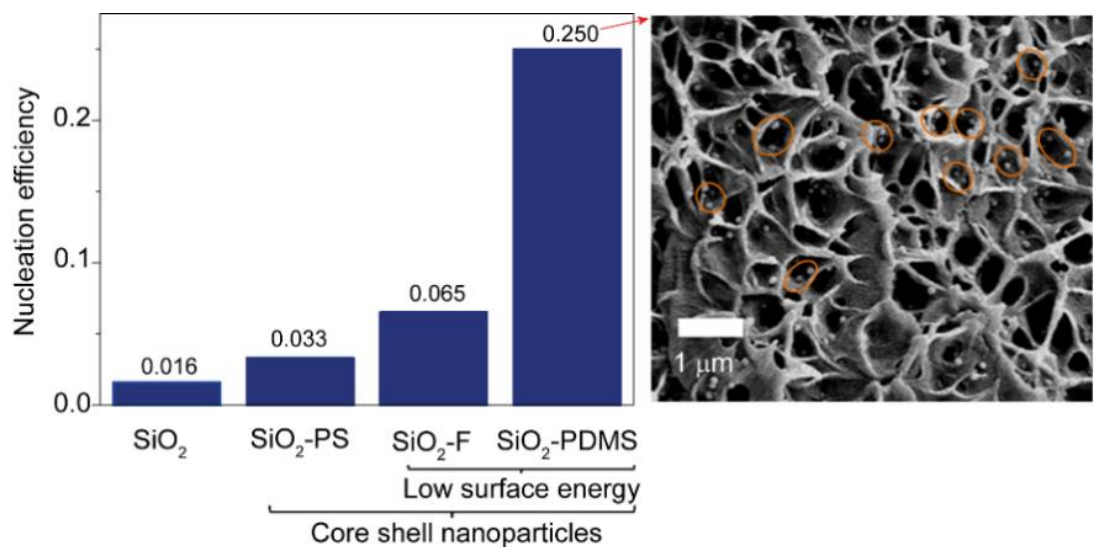

This Chapter describes the synthesis of low surface energy polymer grafted silica nanoparticles for utilization as highly efficient cell nucleation agents to obtain nanocellular, $\mathrm{CO}_{2}$ blown polystyrene (PS) and poly(methyl methacrylate) (PMMA) films in a batch process. For nanoparticle surface functionalization Fluorolink E10 and poly(dimethylsiloxane) (PDMS) were used. Their successful grafting to silica nanoparticles was confirmed by Fourier transform infrared (FTIR) spectroscopy, thermogravimetric analysis (TGA) and transmission electron microscopy (TEM). Following melt blending of the modified silica nanoparticles with PS or PMMA their dispersion was evaluated by scanning electron microscopy (SEM) analysis. Our results show that proper selection of the polymer grafts results in achieving nucleation efficiencies of up to approximately 0.5 (i.e. 1 foam cell per 2 particles on average), which is the highest value achieved so far for nanofillers as nucleation agents. This number was confirmed by the presence of only 2 to 4 nanoparticles per cell in nanocellular PS and PMMA foams containing $\mathrm{SiO}_{2}$ nanoparticles with a PDMS shell as was observed in cross sectional SEM images. The lowest density foam we obtained $\left(\sim 0.32 \mathrm{~g} \mathrm{~cm}^{-3}\right)$ had a nanocellular morphology with a cell size and cell density of $\sim 440 \mathrm{~nm}$ and $1.85 \times 10^{13}$ 
cells $\mathrm{cm}^{-3}$, respectively. It is shown that the use of a low surface energy thin shell around silica nanoparticles is beneficial for cell nucleation compared to untreated particles.

*Part of this Chapter has been published in: Liu, S.; Zoetebier, B.; Hulsman, L.; Zhang, Y.; Duvigneau, J.; Vancso, G. J. Nanocellular polymer foams nucleated by core-shell nanoparticles. Polymer 2016, 104, 22-30. 


\subsection{Introduction}

Low density polymer foams with cell sizes of several hundreds of nanometers or smaller comprise a relatively new class of materials that is considered to be of interest for numerous applications, e.g. in lightweight structural supports ${ }^{1}$, catalysis ${ }^{2}$, thermal insulation $^{3}$, sound insulation ${ }^{4}$, electromagnetic shielding ${ }^{5-6}$ and tissue engineering ${ }^{7}$. For instance, Miller and coworkers ${ }^{8}$ reported that the confinement of polymer chains in cell walls of nanocellular polyetherimide (PEI) foams leads to a significant increase of toughness and strain at break compared to the microporous material. This enables utilization as lightweight structural support. In addition, when cell diameters are close to, or smaller than, the collision mean free path of molecules making up air between successive impacts ( $70 \mathrm{~nm}$ at standard conditions $),{ }^{9}$ the gas phase thermal conduction is minimized. This so called Knudsen effect renders nanoporous polymer foams very promising candidates as high performance thermal insulation materials ${ }^{10-11}$. For instance, Sundarram and coworkers reported a value of $15 \mathrm{~mW} \mathrm{~m}^{-1} \mathrm{~K}^{-1}$ for the thermal conductivity of a nanocellular polyetherimide foam with a cell size and porosity of $86 \mathrm{~nm}$ and $80 \%$, respectively. Despite the rather high polyetherimide foam density the thermal conductivity value for the nanocellular foam reported is significantly lower compared to that of conventional polyurethane based foams $\left(20-22 \mathrm{~mW} \mathrm{~m}^{-1} \mathrm{~K}^{-1}\right)^{12}$.

For the applications described, control over the foam bulk density is as important as having a nanocellular morphology ${ }^{13}$. Among the possible foaming strategies usually employed, $\mathrm{CO}_{2}$ assisted batch foaming is frequently used for the preparation of nanoporous foams ${ }^{14-19}$. This is mainly ascribed to $\mathrm{CO}_{2}$ being considered as a green alternative to other blowing agents. A further advantage is the easy adaption of batch foaming conditions over a wide pressure and temperature range ${ }^{20}$. Unfortunately, due to its size limitations, batch foaming still remains a laboratory scale approach ${ }^{21}$. It is foreseen that in the near future novel foaming concepts will be developed that will allow the upscaling of nanocellular foam production to technologically relevant levels.

The majority of the batch foamed nanocellular materials reported in the open literature had foam thicknesses restricted to below a millimeter. In addition, the foams typically had relatively low porosities, i.e. below $80 \%$. It was only recently that Costeux and coworkers $^{13}$ reported the batch foaming of polymethyl methacrylate (PMMA) copolymers with thicknesses exceeding a few millimeters and a maximum porosity of $85 \%$. However, the production of low density nanocellular polymer foams remains a challenge due to $i$ ) low cell nucleation numbers, $i$ ) fast diffusion of $\mathrm{CO}_{2}$ out of the foaming polymer and $\mathrm{iii}$ ) coalescence of cells during foaming.

In order to enhance cell nucleation to levels exceeding $10^{14}$ cells $\mathrm{cm}^{-3}$ the introduction of nanostructured phases to polymers prior to foaming is considered a promising approach. According to the classical nucleation theory $(\mathrm{CNT})^{22-23}$ heterogeneous nucleation is 
preferred over homogeneous nucleation once the interfacial energy and domain size of the heterogeneous phase are properly selected. For instance, foaming of block copolymer blends ${ }^{24-26}$ and nanocomposites ${ }^{13}, 17,27-35$ has been reported.

Table 3.1 Overview of the (calculated) nucleation efficiency of different nanofiller/ polymer systems selected from the literature.

\begin{tabular}{|c|c|}
\hline Nanocomposites & Nucleation efficiency \\
\hline Polypropylene/nanoclay ${ }^{27}$ & $<1.0 \times 10^{-4}$ \\
\hline PMMA/nanoclay ${ }^{17}$ & $<1.0 \times 10^{-4}$ \\
\hline PS/nanoclay ${ }^{17}$ & $<1.0 \times 10^{-4}$ \\
\hline PS/nanoclay ${ }^{34}$ & $7.4 \times 10^{-4}$ \\
\hline PMMA-co-EA/SiO ${ }_{2}{ }^{13}$ & 0.1 \\
\hline $\mathrm{PMMA} / \mathrm{SiO}_{2}{ }^{13}$ & $4.8 \times 10^{-3}$ \\
\hline $\mathrm{PMMA} / \mathrm{SiO}_{2}{ }^{30}$ & $2.8 \times 10^{-4}$ \\
\hline PMMA/fluorinated silane modified $\mathrm{SiO}_{2}{ }^{33}$ & $1.5 \times 10^{-4}$ \\
\hline PMMA/hydroxyl-terminated $\mathrm{SiO}_{2}{ }^{34}$ & $8.6 \times 10^{-6}$ \\
\hline Polycarbonate $/ \mathrm{SiO}_{2}{ }^{32}$ & $1.8 \times 10^{-2}$ \\
\hline PS/carbon nanofibers ${ }^{28}$ & $2.0 \times 10^{-2}$ \\
\hline PS/carbon nanotubes ${ }^{28}$ & $9.1 \times 10^{-5}$ \\
\hline PS/amino-terminated $\mathrm{SiO}_{2}{ }^{37}$ & $<3 \times 10^{-4}$ \\
\hline $\mathrm{PS} / \mathrm{SiO}_{2}$ with poly(ionic liquid) grafts ${ }^{37}$ & $<1.7 \times 10^{-3}$ \\
\hline $\mathrm{PS} / \mathrm{SiO}_{2}$ with PS grafts ${ }^{38}$ & $<2.0 \times 10^{-2}$ \\
\hline
\end{tabular}

Nano-clay and silica nanoparticles are among the most widely used heterogeneous nucleation agents ${ }^{32-33,36}$. He and coworkers ${ }^{32}$ reported that the addition of nanosilica to polycarbonate prior to batch foaming significantly decreases the foam cell size and increases the cell density compared to neat polycarbonate foams. Ozisik and coworkers ${ }^{33}$ described that fluorinated silane modified silica nanoparticles reduced the nucleation free energy barrier and increased the cell density of PMMA foams compared to foams containing pristine silica nanoparticles. 
Despite effectively increasing the cell density of polymer foams upon the addition of (modified) nanoparticles, a closer examination of their nucleation efficiency shows that nanoparticles are still poor nucleation agents. The nucleation efficiency is defined as the ratio of the number of cells per $\mathrm{cm}^{3}$ of unfoamed material to the number of nanoparticles per $\mathrm{cm}^{3}$ unfoamed material ${ }^{28}$. This definition, as it is obvious, incorporates cell coalescence and cell collapse. Table 3.1 shows for a number of selected polymer nanoparticle systems the calculated nucleation efficiencies. Obviously the nucleation efficiency is often orders of magnitude below unity. In the best case the nucleation efficiency was 0.1 , meaning that for every 10 particles added 1 cell was nucleated.

In order to enhance the nucleation efficiency of silica nanoparticles Yang and coworkers ${ }^{37}$ reported on the grafting of highly $\mathrm{CO}_{2}$-philic poly(ionic liquid) from silica nanoparticles as nucleation agents for the foaming of microcellular polystyrene foams. Surface initiated atom-transfer radical polymerization (SI-ATRP) was used to graft poly[2-(methacryloyloxy)ethyl]trimethylammonium tetrafluoroborate $\left(\mathrm{P}[\mathrm{MATMA}]\left[\mathrm{BF}_{4}\right]\right)$ from silica nanoparticle surfaces. Grafted layers with thicknesses of several tens of nanometer were achieved. The authors demonstrated that the $\mathrm{CO}_{2}$ solubility was slightly enhanced due to the presence of the surface confined $\mathrm{P}[\mathrm{MATMA}]\left[\mathrm{BF}_{4}\right]$ phase. Compared to microcellular polystyrene foams prepared with bare silica nanoparticles the cell density increased (factor $\sim 5$ ) and the cell size decreased (factor $\sim 2$ ). However, the overall nucleation efficiency of these polymer decorated nanoparticles remained poor $\left(<1.7 \times 10^{-3}\right)$.

In this Chapter, a simple "grafting to" approach of $\mathrm{CO}_{2}$-philic and low surface energy polymers was employed to decorate silica nanoparticles in order to have a thin, low surface energy shell around the silica nanoparticles. The nucleation efficiency and foam morphology of the resulting materials are explored. Poly(dimethylsiloxane) $\left(19.8 \mathrm{~mJ} \cdot \mathrm{m}^{-}\right.$ 2) (PDMS) and Fluorolink E10, i.e. a hydroxyl-terminated perfluoropolyether, (18.0 $\mathrm{mJ} \cdot \mathrm{m}^{-2}$ ) were selected as the matrix polymers due to their known low surface energy and good wetting property with $\mathrm{CO}_{2}{ }^{33,40-41}$. For comparison, PS grafted nanoparticles were also synthesized. The core-shell nanoparticles obtained were used as highly efficient heterogeneous nucleation agents for the $\mathrm{CO}_{2}$ batch foaming of PS and PMMA. 


\subsection{Results and discussion}

\subsubsection{Preparation and characterization of nanoparticles}

Stöber silica nanoparticles were synthesized, followed by their surface grafting with polystyrene, PDMS or Fluorolink E10, respectively. The reaction scheme is depicted in Figure 3.1 Silica nanoparticles with a diameter of $\sim 80 \mathrm{~nm}$ were prepared via a Stöber reaction (step 3.1a), followed by the hydrolysis of the surface exposed ethoxy groups to silanol moieties (step 3.1b). Subsequently the hydrolyzed particles were modified with APTES, resulting in the formation of amine functionalized nanoparticles (step 3.1c). Following the reaction with $\alpha$-bromoisobutyryl bromide a macroinitiator nanoparticle (step 3.1d) for the subsequent SI-ATRP of styrene (step 3.1e) was obtained. PDMS and Fluorolink E10 grafted core-shell structure nanoparticles were synthesized by the grafting to of PDMS-G (step 3.1d') and Fluorolink E10 (step 3.1c') to the amine functionalized and hydrolyzed silica nanoparticles, respectively.

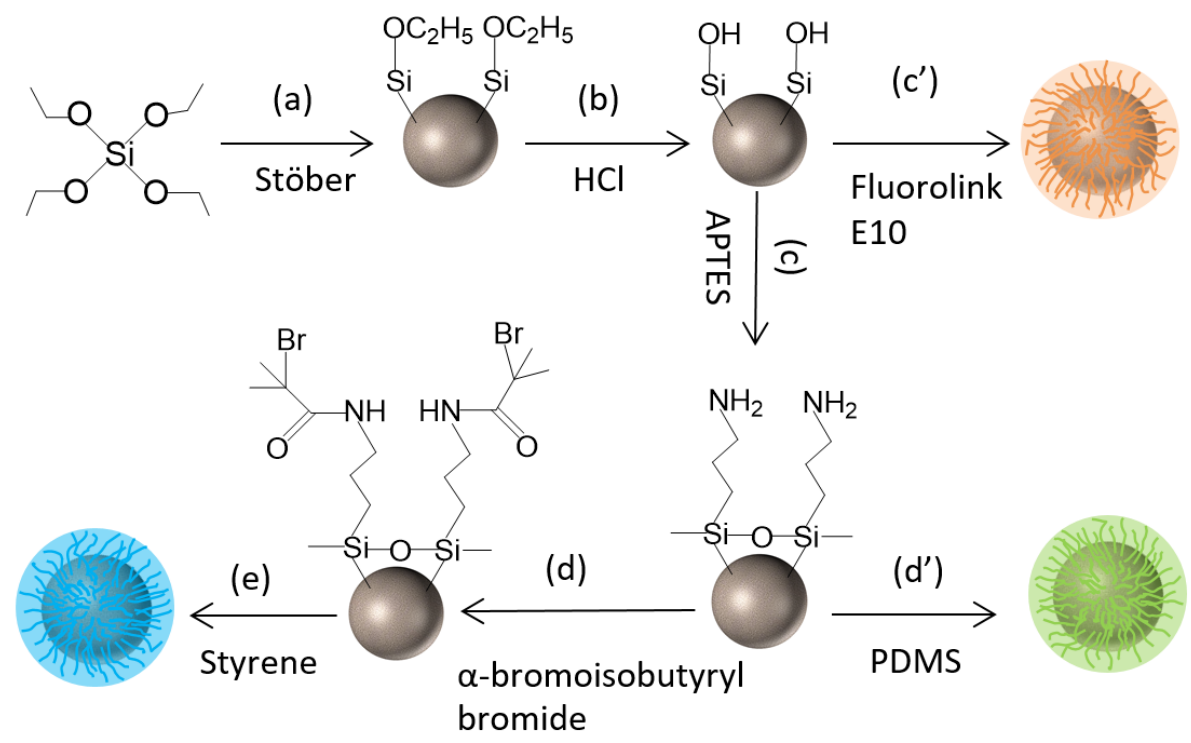

Figure 3.1 Particle preparation strategies: Stöber silica nanoparticles were prepared (a) followed by the hydrolysis of surface exposed ethoxy group in diluted $\mathrm{HCl}$ (b). Subsequently, amine groups were introduced to the surface of the nanoparticles (c) followed by modification with a bromine terminated ATRP initiator (d) for the SI-ATRP of styrene (e). The grafting to of PDMS and Fluorolink E10 are shown in Figure 3.1d' and c', respectively.

Figure 3.2a shows FTIR absorbance spectra of the (modified) silica nanoparticles. The remaining ethoxy groups after the Stöber reaction of TEOS are clearly observed in the FTIR spectra of the $\mathrm{SiO}_{2}$ particles, i.e. the $\mathrm{CH}_{2} / \mathrm{CH}_{3}$ bending absorption band at 1452 60 
$\mathrm{cm}^{-1}$ and $\mathrm{CH}_{2} / \mathrm{CH}_{3}$ absorption band at $2980 \mathrm{~cm}^{-1} .{ }^{43}$ After hydrolysis these absorbance bands disappeared (data not shown). The absorption bands at $1452 \mathrm{~cm}^{-1}$ (ascribed to $\mathrm{C}=\mathrm{C}$ stretching vibrations) and near $3000 \mathrm{~cm}^{-1}$ (ascribed to aromatic and aliphatic $\mathrm{C}-\mathrm{H}$ stretching) indicate the successful grafting of PS from silica nanoparticles ${ }^{38}$. The absorption bands for $\mathrm{CH}_{3}$ stretching at $2967 \mathrm{~cm}^{-1}$ and for $\mathrm{C}-\mathrm{H}$ bending at $1263 \mathrm{~cm}^{-1}$ confirm the successful grafting of PDMS to silica nanoparticles ${ }^{44}$. The absorption band at $1180 \mathrm{~cm}^{-1}$, which is ascribed to C-F stretching modes, indicates the successful grafting of Fluorolink E10 to the silica nanoparticles ${ }^{45}$.
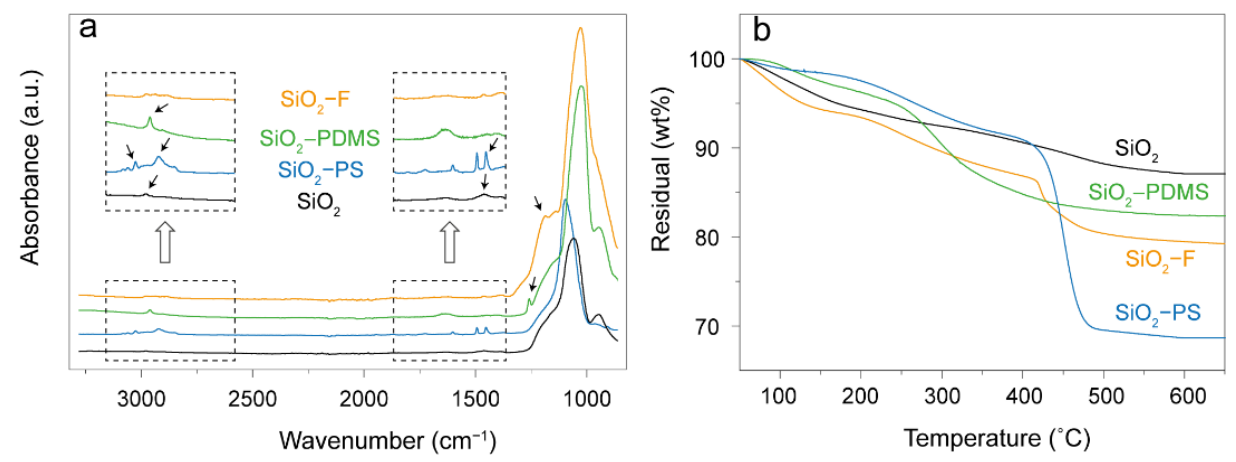

Figure 3.2 ATR-FTIR absorbance spectra (a) and non-isothermal TGA thermograms (b) of $\mathrm{SiO}_{2}$, $\mathrm{SiO}_{2}-\mathrm{PS}, \mathrm{SiO}_{2}-\mathrm{F}$ and $\mathrm{SiO}_{2}$-PDMS nanoparticles. In Figure 3.2a the black arrows indicate characteristic FTIR absorption bands of the bare and core-shell silica nanoparticles.

TGA was used to determine the amount of polymer grafted from/to the $\mathrm{SiO}_{2}$ nanoparticles. Figure $3.2 \mathrm{~b}$ shows the weight loss versus temperature curves for nonisothermal TGA measurements of $\mathrm{SiO}_{2}, \mathrm{SiO}_{2}-\mathrm{PS}, \mathrm{SiO}_{2}-\mathrm{F}$ and $\mathrm{SiO}_{2}-\mathrm{PDMS}$. The weight percentage of PS, Fluorolink E10 and PDMS covalently bound to $\mathrm{SiO}_{2}$ nanoparticles was determined to be $18.4 \mathrm{wt} \%, 7.8 \mathrm{wt} \%$ and $5.0 \mathrm{wt} \%$, respectively from mass loss values. Based on the TGA results, the molar mass of grafted polymer chains (i.e. $9061 \mathrm{~g} \mathrm{~mol}^{-1}$, $1700 \mathrm{~g} \mathrm{~mol}^{-1}$ and $1000 \mathrm{~g} \mathrm{~mol}^{-1}$ for PS, Fluorolink E10 and PDMS, respectively) and the surface area of the used $\mathrm{SiO}_{2}$ nanoparticles $\left(33 \mathrm{~m}^{2} \mathrm{~g}^{-1}\right)$, the PS, Fluorolink E10 and PDMS grafting densities were calculated to be $0.45 \mathrm{~nm}^{-2}, 0.90 \mathrm{~nm}^{-2}$ and $0.91 \mathrm{~nm}^{-2}$, respectively.

TEM was used to confirm the core-shell structure of the nanoparticles (see Figure 3.3). The value of the bare silica nanoparticle diameter was determined to be $79.0 \pm 9.0 \mathrm{~nm}$. A clear core-shell structure is observed for the $\mathrm{SiO}_{2}-\mathrm{PS}, \mathrm{SiO}_{2}-\mathrm{F}$ and $\mathrm{SiO}_{2}-\mathrm{PDMS}$ nanoparticles (see Figure 3.3b-d) and the shell thickness was estimated to be $12.5 \pm 1.2$ $\mathrm{nm}, 8.0 \pm 1.4 \mathrm{~nm}$ and $6.0 \pm 1.3 \mathrm{~nm}$, respectively. Hence, bare and core-shell nanoparticles were successfully synthesized, and the prepared nanoparticles were used as nucleation agents for nanocomposite foaming (see section 3.2.2). 

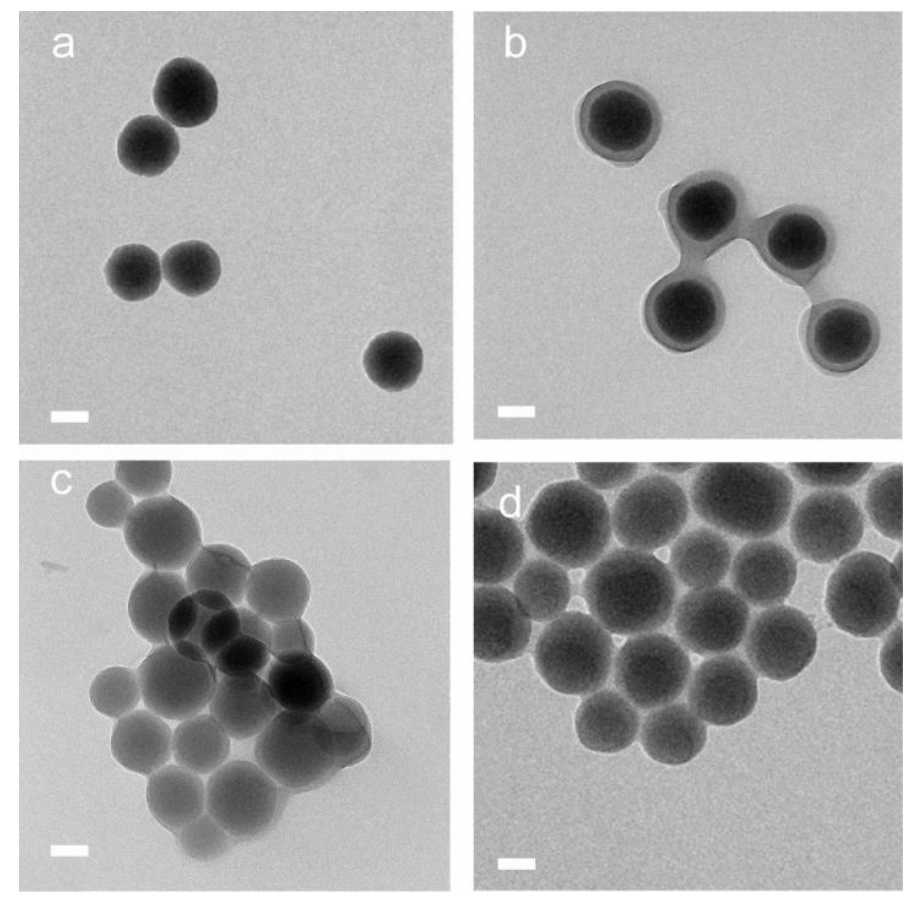

Figure 3.3 TEM images of $\mathrm{SiO}_{2}(\mathrm{a}), \mathrm{SiO}_{2}-\mathrm{PS}(\mathrm{b}), \mathrm{SiO}_{2}-\mathrm{F}$ (c) and $\mathrm{SiO}_{2}-\mathrm{PDMS}$ (d) nanoparticles. The scale bars represent $50 \mathrm{~nm}$.

\subsubsection{Nanocomposite foams}

Prior to foaming the prepared nanoparticles were melt blended in a PS matrix and pressed to films with a thickness of $\sim 200$ micrometer. The nanoparticle concentration was $4 \mathrm{wt} \%$ based on the silica core content. Hence all nanocomposite films had the same particle density prior to foaming (assuming a good particle dispersion). SEM was used to investigate the dispersion of nanoparticles in the respective PS nanocomposites.

Figure 3.4 shows SEM images of sections of freeze fractured PS nanocomposite films. It is obvious that $\mathrm{SiO}_{2}-\mathrm{PS}$ and $\mathrm{SiO}_{2}-\mathrm{PDMS}$ nanoparticles were well dispersed in PS, while some aggregates for $\mathrm{SiO}_{2}$ and $\mathrm{SiO}_{2}-\mathrm{F}$ nanoparticles melt blended in PS were observed. For Fluorolink E10 modified nanoparticles the observed aggregation is ascribed to the bifunctionality of the polymer used in the bulk grafting reaction i.e. potentially one chain end reacts with one particle while the other chain end may react with the same, or with a different particle. Hence, although undesirable, some particle aggregation could not be prevented for this type of core-shell nanoparticle. 

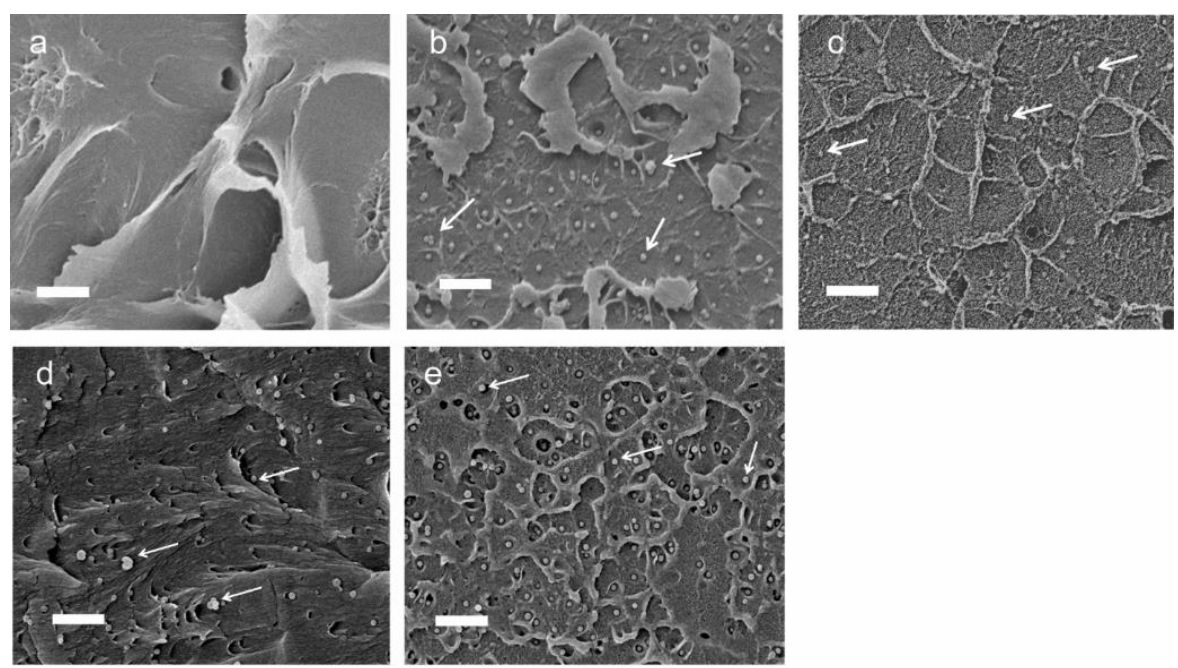

Figure 3.4 SEM images of freeze fractured polystyrene films containing no $\mathrm{SiO}_{2}$ (a), $\mathrm{SiO}_{2}$ (b), $\mathrm{SiO}_{2}-\mathrm{PS}(\mathrm{c}), \mathrm{SiO}_{2}-\mathrm{F}(\mathrm{d})$ and $\mathrm{SiO}_{2}-\mathrm{PDMS}$ (e) nanoparticles. The white arrows point towards selected nanoparticles. The scale bars represent $1 \mu \mathrm{m}$.

Table 3.2 Expansion ratio $(f)$ and foam density $(\rho)$ of the obtained PS (nanocomposite) foams.

\begin{tabular}{l|c|c|c|c|c}
\hline & Neat PS & PS with $\mathrm{SiO}_{2}$ & $\begin{array}{c}\text { PS with } \\
\mathrm{SiO}_{2}-\mathrm{PS}\end{array}$ & $\begin{array}{c}\text { PS with } \\
\mathrm{SiO}_{2}-\mathrm{F}\end{array}$ & $\begin{array}{c}\text { PS with } \\
\mathrm{SiO}_{2}-\mathrm{PDMS}\end{array}$ \\
\hline \hline$f$ & 2.5 & 2.3 & 3.1 & 2.9 & 3.3 \\
\hline$\rho\left(\mathrm{g} \mathrm{cm}^{-3}\right)$ & 0.42 & 0.46 & 0.34 & 0.36 & 0.32 \\
\hline
\end{tabular}

The PS nanocomposites with different core-shell structured nanoparticles were foamed after saturation with $\mathrm{CO}_{2}$ at 55 bar. The volume expansion ratio and densities of the obtained PS foams are shown in table 3.2.

Figure 3.5 shows SEM images of sectioned PS foams without and with nanoparticles. From Figure 3.5 it is obvious that the incorporation of (modified) silica nanoparticles significantly decreases the cell size and increases the cell density. For a good comparison the cell size and cell density of the respective PS foams were determined. The results obtained are shown in Figure 3.6.

The average cell size and cell density of neat polystyrene foams were $\sim 2.4 \mu \mathrm{m}$ and $1.0 \times 10^{11}$ cells $\mathrm{cm}^{-3}$, respectively (Figure 3.6a and b). Upon the addition of $4 \mathrm{wt} \%$ bare $\mathrm{SiO}_{2}$ nanoparticles to PS the cell size decreased to $\sim 1.1 \mu \mathrm{m}$ and the cell density increased to $1.2 \times 10^{12}$ cells $\mathrm{cm}^{-3}$ (Figure $3.6 \mathrm{a}$ and $\mathrm{b}$ ). This is ascribed to heterogeneous cell 
nucleation at the silica nanoparticle-polymer interface. The cell size and cell density of composites containing $\mathrm{SiO}_{2}$-PS nanoparticles were $\sim 0.7 \mu \mathrm{m}$ and $2.5 \times 10^{12}$ cells $\mathrm{cm}^{-3}$, respectively (Figure 3.6a and b). This improvement in foam morphology compared to the bare $\mathrm{SiO}_{2}$ nanoparticle containing PS foam is explained by the better particle dispersion for the PS grafted $\mathrm{SiO}_{2}$ particles (compare Figure 3.4b and c). This observation is in agreement with results reported by Jingtao and coworkers ${ }^{38}$. They showed that the grafting of PS on mesoporous silica nanoparticles improved the dispersion of the particles as well as the polystyrene foam morphology.
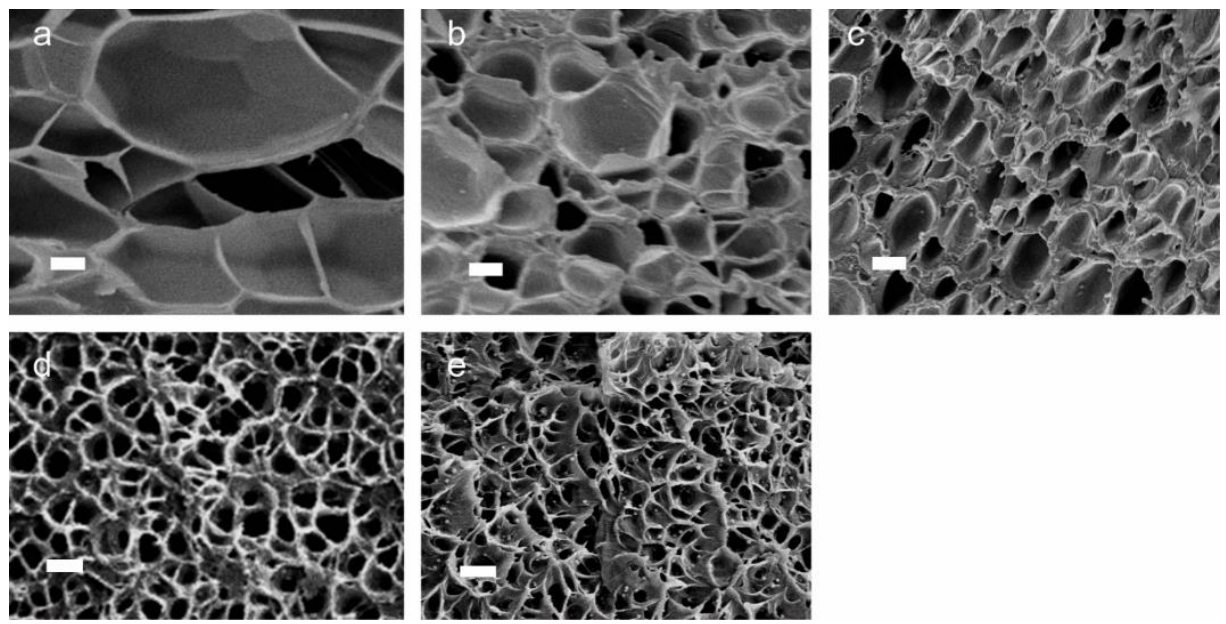

Figure 3.5 SEM images of sectioned PS foams containing no $\mathrm{SiO}_{2}$ (a), $\mathrm{SiO}_{2}$ (b), $\mathrm{SiO}_{2}-\mathrm{PS}$ (c), $\mathrm{SiO}_{2}-$ $\mathrm{F}(\mathrm{d})$ and $\mathrm{SiO}_{2}$-PDMS (e) nanoparticles. The scale bars represent $1 \mu \mathrm{m}$. The saturation pressure and foaming temperature were 55 bar and $100^{\circ} \mathrm{C}$, respectively.

Upon the addition of $\mathrm{SiO}_{2}$ particles grafted with low surface energy polymers the cell size was further reduced to $\sim 440$ nanometers and the cell density increased to $1.85 \times 10^{13}$ cells $\mathrm{cm}^{-3}$ (Figure 3.6a and b). The effect on cell size and cell density was less pronounced for the Fluorolink E10 modified nanoparticles, which we ascribe to the observed particle clustering that reduces the effective number of nucleation sites (see Figure 3.4d).

Figure 3.6c shows the calculated nucleation efficiencies of the nanoparticles used. Since $4 \mathrm{wt} \%$ of nanoparticles was added to the nanocomposites based on their respective silica content, the number of theoretical nucleation sites, i.e. $7.5 \times 10^{13}$ particles per $\mathrm{cm}^{3}$ of unfoamed material, was the same for all nanocomposites. Hence, this number was used to calculate the nucleation efficiency for each type of particles. The expansion ratios of the obtained foams as shown in table 3.2 are used to calculate the number of cells per unit volume of unfoamed material with equation 2 . 

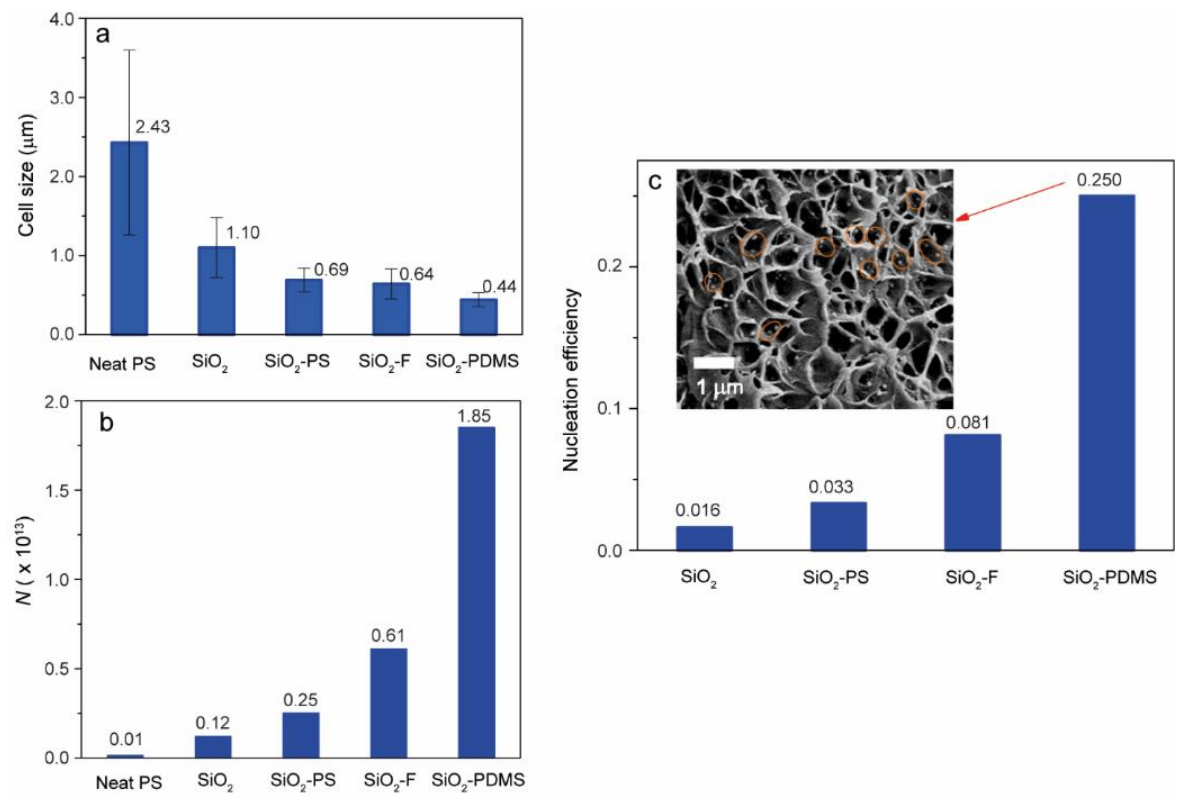

Figure 3.6 Cell size (a), cell density (b) and nucleation efficiency (c) of neat polystyrene and polystyrene nanocomposite foams containing $\mathrm{SiO}_{2}, \mathrm{SiO}_{2}-\mathrm{PS}, \mathrm{SiO}_{2}-\mathrm{F}$ and $\mathrm{SiO}_{2}-\mathrm{PDMS}$ nanoparticles.

Obviously, the nucleation efficiency of polymer decorated particles is better compared to the bare silica nanoparticles. The highest nucleation efficiency, i.e. 0.25, was obtained for the PDMS grafted $\mathrm{SiO}_{2}$ nanoparticles. The SEM image in the inset in Figure $3.6 \mathrm{c}$ shows that for this foam every cell cross section contains about 2 particles. If we assume that on average every cell was cut in half this number is in good agreement with the observed nucleation efficiency, i.e. 4 particles result in the formation of 1 cell. The nucleation efficiency of the PDMS coated nanoparticles is 15 times higher compared to the bare silica nanoparticles. In fact, to the best of our knowledge the nucleation efficiency obtained for these particles is the highest compared to data available in the open literature (see also table 1). In particular these particles perform significantly better compared to the $\mathrm{CO}_{2}$-philic polyionic liquid grafted nanoparticles reported on by Yang and coworkers ${ }^{37}$. However direct comparison is not trivial since it is known that the foaming conditions (i.e., foaming temperature and saturation pressure) used influence the performance of the added nanoparticles. Despite this, the high nucleation efficiency for the $\mathrm{SiO}_{2}$-PDMS nanoparticles is ascribed to $i$ ) the low surface energy of the PDMS shell, ii) the higher local $\mathrm{CO}_{2}$ concentration in the PDMS shell compared to the PS matrix and iii) their good dispersion in the PS matrix. In addition, the interfacial interactions between the nanoparticle shell and polymer matrix is expected to affect cell nucleation as well. In fact, it has been reported that for a poor polymer shell matrix interaction the nucleation energy barrier is reduced ${ }^{39}$. Studying cell nucleation at the nanometer length scale is 
highly challenging and currently we are working on establishing methods to quantify the role of the low surface energy shell and the polymer interphase on cell nucleation.

In order to further elucidate the impact of the grafted PDMS coating on nucleation, silica nanoparticles with a diameter of 120 nanometers and PDMS shells were prepared and melt blended with PMMA at a concentration of $4 \mathrm{wt} \%$. Following $\mathrm{CO}_{2}$ sorption (55 bar, room temperature, $4 \mathrm{~h}$ ) the $\mathrm{CO}_{2}$ saturated films were foamed at $40{ }^{\circ} \mathrm{C}$ for $3 \mathrm{~min}$. The obtained foam (with a density of $\sim 0.38 \mathrm{~g} \cdot \mathrm{cm}^{-3}$ ) had an average cell size of $\sim 400 \mathrm{~nm}$ and a nucleation efficiency of $\sim 0.5$, while for the bare nanoparticles $(120 \mathrm{~nm})$ it was only 0.09, as shown in Figure 3.7. Hence PDMS grafting to nanoparticles seems to be a very promising strategy for enhancing the nucleation efficiency of nanoparticles in polymer foaming.
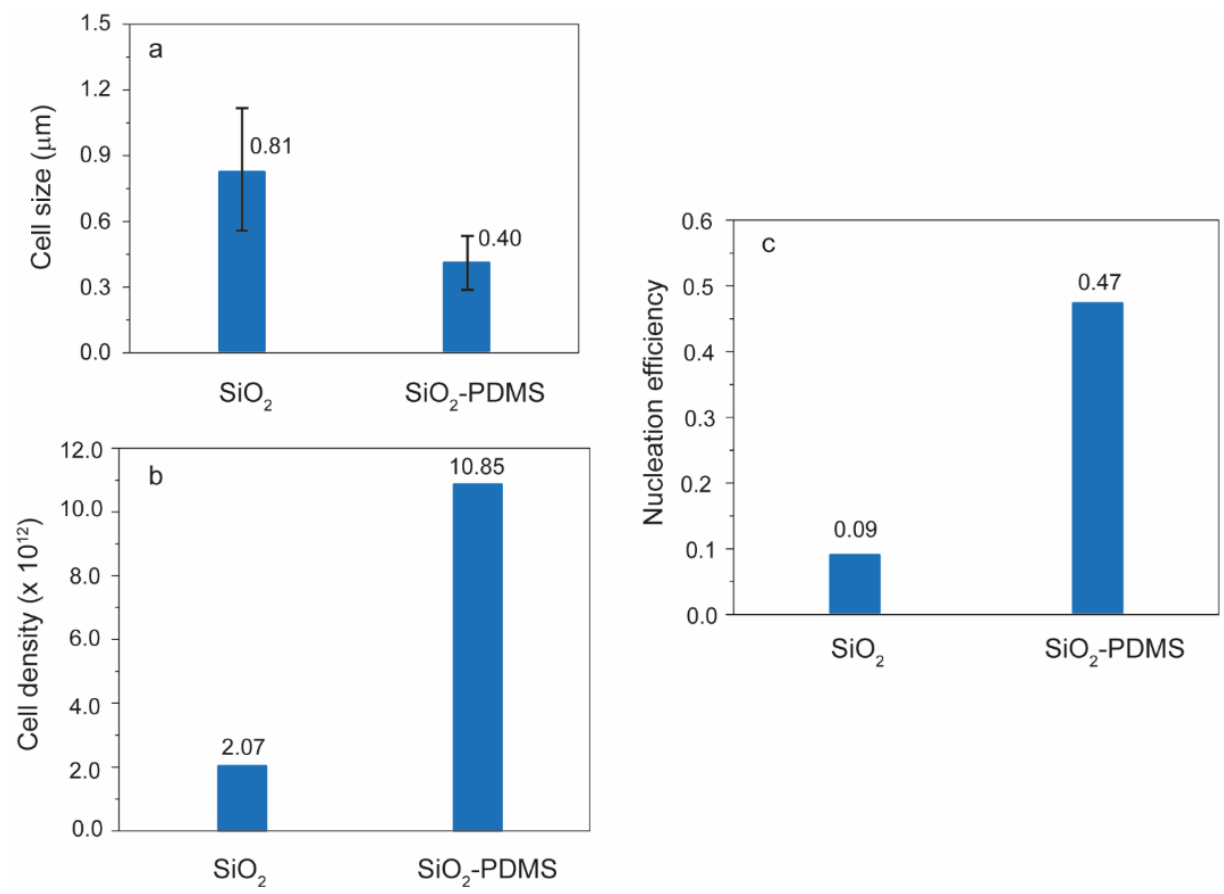

Figure 3.7 Cell size (a), cell density (b) and nucleation efficiency (c) of PMMA nanocomposite foams containing $\mathrm{SiO}_{2}$ and $\mathrm{SiO}_{2}$-PDMS nanoparticles. The number density of $120 \mathrm{~nm}$ nanoparticles per $\mathrm{cm}^{3}$ unfoamed PMMA is $2.3 \times 10^{13}$ particles $\mathrm{cm}^{-3}$.

In fact, upon the addition of PDMS grafted nanoparticles, foam morphologies with relevant properties are within reach via batch foaming at relatively low $\mathrm{CO}_{2}$ saturation pressures. For instance, the theoretical thermal conductivity $(\lambda)$ of the nanocomposite PS and PMMA foams obtained in this study can be determined using a model established by Sonntag and coworkers ${ }^{9}$ for the thermal conductivity of nanocellular PS foams. Based on 
this model the $\lambda$ for the PS and PMMA foams containing PDMS grafted silica nanoparticles was estimated to be $\sim 22.0 \mathrm{~mW} \mathrm{~m}^{-1} \mathrm{~K}^{-1}$ and $24.0 \mathrm{~mW} \mathrm{~m}^{-1} \mathrm{~K}^{-1}$, respectively (see Figure 3.8). These numbers are lower compared to commercially available EPS and XPS (31.0-45.0 $\mathrm{mW} \mathrm{m}^{-1} \mathrm{~K}^{-1}$ ) foams and can compete with existing polyurethane based foams (20.0-22.0 $\left.\mathrm{mW} \mathrm{m}^{-1} \mathrm{~K}^{-1}\right)$. We note that the used model was in good agreement with reported thermal conductivity values for nanocellular polyimide foams. However, more recent work reported by Rodríguez-Pérez and coworkers ${ }^{11}$ points towards and underestimation of the thermal conductivity upon increasing cell wall thicknesses. In addition, the used model does not take into account the presence of nanoparticles in the cell walls and its effect on the solid phase thermal conductivity.

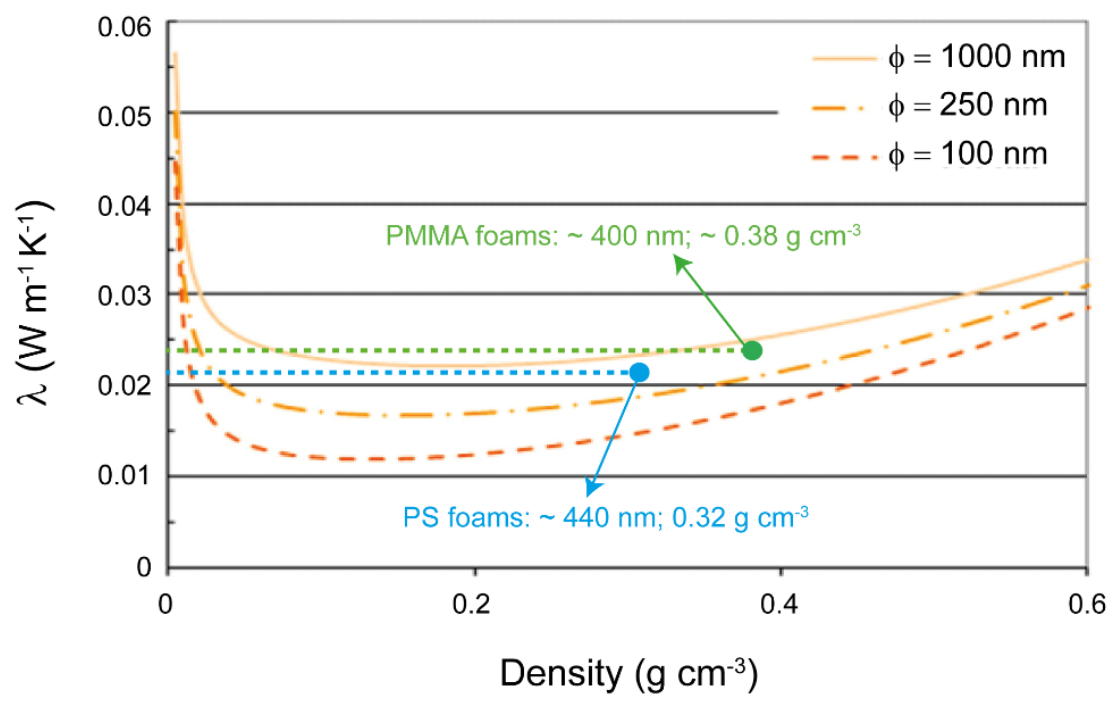

Figure 3.8 Estimation of the thermal conductivity of PS and PMMA nanocomposite foams with $\mathrm{SiO}_{2}$-PDMS nanoparticles as nucleation agents. This image was adapted from reference [9]. The curved solid and dashed lines represent the thermal conductivity for a PS foam as a function of the cell size and foam density. We note that for the calculation of the thermal conductivity of our PMMA nanocomposite foam the model has been corrected for the thermal conductivity of PMMA.

Since (meth)acrylate based polymers saturated at $\mathrm{CO}_{2}$ pressures exceeding 250 bar provided the lowest density nanocellular foams reported until today ${ }^{13}$ our future efforts are directed towards understanding and improving the nucleation behavior of polymer grafted nanoparticles in (meth)acrylate based polymer/ $\mathrm{CO}_{2}$ systems. In particular the effect of particle size (i.e. curvature), surface roughness and the composition of the interface/interphase have our attention, since there is a lack in a quantitative understanding of the role of these parameters on cell nucleation at the macromolecular length scale. We believe that an enhanced understanding of these issues is of pivotal 
importance for advancing nanocellular foaming to industrially relevant foaming conditions and levels.

\subsection{Conclusion}

In this Chapter silica nanoparticles grafted with low surface energy polymers were exploited as highly efficient nucleation agents in the $\mathrm{CO}_{2}$ batch foaming of PS and PMMA. Following the synthesis of $\mathrm{SiO}_{2}, \mathrm{SiO}_{2},-\mathrm{PS}, \mathrm{SiO}_{2}-\mathrm{F}$ and $\mathrm{SiO}_{2}-\mathrm{PDMS}$ nanoparticles with a core diameter of $80 \mathrm{~nm}$ they were melt blended with the respective matrix polymers. Batch foaming was used to produce micro- and nanocellular foams. The obtained nanocomposite foams showed that $i$ ) the addition of nanoparticles was favorable for cell nucleation and that $i$ ) the grafting of a thin PDMS shell to the silica nanoparticles increased the nucleation efficiency to 0.5 . The obtained nucleation efficiency of PDMS grafted nanoparticles is significantly higher compared to that of other nanofillers reported so far in the open literature. Hence, PDMS grafted silica nanoparticles are very promising to be used as highly efficient nucleation agents for nanocellular polymer foaming. Future work should be directed towards optimization of the particle size (see Chapter 4) and surface roughness (see Chapter 6) as well as the thickness and composition of the low surface energy shell next to increasing our understanding of the role of these parameters on cell nucleation and foam morphology.

\subsection{Materials and methods}

Materials. Tetraethyl orthosilicate (TEOS) $\geq 99.0 \%$, (3-aminopropyl)-triethoxysilane (APTES) 97\%, 2-propanol 99.5\%, copper(I) bromide 98\% and polystyrene $\left(\mathrm{M}_{\mathrm{w}}=230000\right.$ $\mathrm{g} \cdot \mathrm{mol}^{-1}, \rho=1.05 \mathrm{~g} \cdot \mathrm{cm}^{-3}$ ) were purchased from Aldrich (Milwaukee, WI, USA). Ammonium hydroxide solution 28-30\%, triethylamine (TEA) 99.5\%, copper(II) bromide $99 \%, \alpha$-bromoisobutyryl bromide $\geq 99 \%$, hydrocholoric acid $37 \%$, aluminum oxide (for chromatography), nonafluorobutyl methyl ether $\geq 99 \%$, hydrofluoric acid (48\%) and poly(dimethylsiloxane) monoglycidyl ether terminated (PDMS-G) $\left(\mathrm{M}_{\mathrm{w}}=1000 \mathrm{~g} \cdot \mathrm{mol}^{-1}\right)$ were purchased from Sigma-Aldrich (St. Louis, MO, USA). PMMA was a gift from Arkema (VM100, i.e. a PMMA-co-EA polymer, $\left.\rho=1.18 \mathrm{~g} \cdot \mathrm{cm}^{-3}\right)($ La Garenne-Colombes, France). Absolute N,N-dimethylformamide (DMF) and tetrahydrofuran (THF) were purchased from Biosolve (Valkenswaard, the Netherlands). Ethanol absolute for analysis was purchased from Merck (Darmstadt, Germany). Hydroxyl-terminated 68 
perfluoropolyether (Fluorolink E10, $\mathrm{M}_{\mathrm{w}}=1700 \mathrm{~g} \cdot \mathrm{mol}^{-1}$ ) was a gift from Solvay Solexis (Milan, Italy). N,N,N',N',N''-pentamethyldiethylenetriamine (PMDETA) 98\% was purchased from Acros Organics (Geel, Belgium). Styrene was passed through an aluminum oxide column to remove the inhibitor. Copper(I) bromide was purified by stirring appropriate amounts in water free acetic acid for 24 hours, followed by filtration, washing with ethanol for three times and subsequent vacuum drying for at least 12 hours. Milli-Q water was produced by a Millipore Synergy system (Billerica, MA, USA). Unless otherwise mentioned all other chemicals were used as received.

Stöber silica nanoparticles synthesis. To prepare Stöber silica nanoparticles $\left(\mathrm{SiO}_{2}\right)$ with a diameter of $\sim 80 \mathrm{~nm}, 168 \mathrm{ml}$ ethanol was mixed with $28 \mathrm{ml}$ Milli-Q water and 30 $\mathrm{ml}$ TEOS in the presence of $2 \mathrm{ml}$ ammonium hydroxide while stirring at $500 \mathrm{rpm}$ at room temperature. After 1.5 hours the obtained $\mathrm{SiO}_{2}$ dispersion was centrifuged at $10,000 \mathrm{rpm}$ for $30 \mathrm{~min}$. Subsequently the collected $\mathrm{SiO}_{2}$ were redispersed in 2-propanol and centrifuged again. This washing step was repeated 2 more times followed by vacuum drying the collected $\mathrm{SiO}_{2}$ nanoparticles at room temperature for 12 hours. To prepare silica particles with a diameter of 120 nanometers $87.5 \mathrm{~g}$ ethanol was mixed with $4.4 \mathrm{~g}$ Milli-Q water and $8.6 \mathrm{~g}$ TEOS in the presence of $4.2 \mathrm{~g}$ ammonium hydroxide while stirring at $500 \mathrm{rpm}$ at room temperature for $12 \mathrm{~h}$. The washing, collection and drying step are the same as described above for $80 \mathrm{~nm}$ particles.

Hydrolysis. To introduce silanol groups on the surface of the prepared $\mathrm{SiO}_{2}$ nanoparticles, the particles were redispersed in Milli-Q water by sonication (BRANSON 2510, Canada) for 1 hour. Subsequently, hydrochloric acid was added to the dispersion while stirring at $500 \mathrm{rpm}$ until the $\mathrm{pH}$ of the solution reached a value of approximately 1 . After 4 hours the dispersion was centrifuged at 10,000 rpm for $30 \mathrm{~min}$. The collected nanoparticles were redispersed in Milli-Q water and centrifuged again. This washing step was repeated 2 more times followed by drying the silanol functional nanoparticles $\left(\mathrm{SiO}_{2}-\right.$ $\mathrm{OH})$ in vacuum at room temperature for 12 hours.

APTES modification. $3.0 \mathrm{~g} \mathrm{SiO}_{2}-\mathrm{OH}$ nanoparticles were redispersed in $100 \mathrm{ml}$ ethanol followed by the addition of $15 \mathrm{ml}$ APTES. The dispersion was left to stir at $500 \mathrm{rpm}$ at room temperature for 17 hours. The APTES functionalized nanoparticles $\left(\mathrm{SiO}_{2}-\mathrm{NH}_{2}\right)$ were collected by centrifugation at 10,000 rpm for $30 \mathrm{~min}$ and redispersed in ethanol and centrifuged again. This washing step was repeated 2 more times followed by drying the collected $\mathrm{SiO}_{2}-\mathrm{NH}_{2}$ nanoparticles in vacuum at room temperature for 12 hours.

Grafting to of Fluorolink E10. $1.0 \mathrm{~g}$ of $\mathrm{SiO}_{2}-\mathrm{OH}$ nanoparticles were redispersed in 15 $\mathrm{ml}$ Fluorolink E10 followed by heating the resulting dispersion to $150{ }^{\circ} \mathrm{C}$ for 17 hours while stirring at $500 \mathrm{rpm}$. Subsequently, the Fluorolink E10 modified nanoparticles $\left(\mathrm{SiO}_{2}-\mathrm{F}\right)$ were cooled to room temperature and washed with nonafluorobutyl methyl ether 
for 1.5 hour followed by centrifuged for $30 \mathrm{~min}$ at $10000 \mathrm{rpm}$. This washing step was repeated 2 more times, followed by vacuum drying the $\mathrm{SiO}_{2}-\mathrm{F}$ nanoparticles at $100{ }^{\circ} \mathrm{C}$ for 12 hours.

Grafting to of PDMS-G. $1.0 \mathrm{~g}$ of $\mathrm{SiO}_{2}-\mathrm{NH}_{2}$ nanoparticles were redispersed in $20.5 \mathrm{ml}$ THF and $15 \mathrm{~g}$ PDMS-G while stirring at $500 \mathrm{rpm}$ for 1 hour followed by sonication for 1 hour. Subsequently, THF was removed by rotary evaporation and the resulting silica nanoparticle dispersion in PDMS-G was immersed in an oil bath thermostated at $80{ }^{\circ} \mathrm{C}$ for $17 \mathrm{~h}$. Following cooling to room temperature the reaction mixture was washed with THF and centrifuged at 10,000 rpm for $30 \mathrm{~min}$. This washing step was repeated 2 more times, followed by vacuum drying the PDMS-G grafted silica nanoparticles at room temperature for 12 hours.

ATRP Initiator immobilization. $1.5 \mathrm{~g} \mathrm{SiO}_{2}-\mathrm{NH}_{2}$ were redispersed in $75 \mathrm{ml} \mathrm{DMF}$ by 30 minutes of sonication. The mixture was cooled down to $0{ }^{\circ} \mathrm{C}$ with an ice bath, followed by dropwise addition of $15 \mathrm{ml}$ TEA and $5 \mathrm{ml} \alpha$-bromoisobutyryl bromide within $30 \mathrm{~min}$ while stirring at $700 \mathrm{rpm}$. The mixture was left to stir for 17 hours at room temperature, followed by centrifugation at 10,000 rpm for 30 minutes. The collected particles were redispersed in ethanol and centrifuged again to remove unreacted TEA, $\alpha$ Bromoisobutyryl bromide and the salt formed by TEA and $\mathrm{HBr}$. This washing step was repeated 2 more times, followed by vacuum drying the ATRP initiator functional nanoparticles $\left(\mathrm{SiO}_{2}-\mathrm{Br}\right)$ at room temperature for $12 \mathrm{~h}$.

SI-ATRP of styrene. $1.0 \mathrm{~g}$ of the $\mathrm{SiO}_{2}$ - $\mathrm{Br}$ nanoparticles were redispersed in $10 \mathrm{ml} \mathrm{DMF}$ by 30 minutes of sonication. Two other flasks were prepared, one with $156 \mathrm{mg} \mathrm{CuBr}$ and $24.3 \mathrm{mg} \mathrm{CuBr}_{2}$ and another one with $16.87 \mathrm{ml} \mathrm{DMF}, 12.5 \mathrm{ml}$ styrene and $459 \mu \mathrm{l}$ PMDETA. All three flasks were equipped with magnetic stirrers and sealed with a rubber septum. The flasks were purged with argon for 1 hour. Subsequently, the styrene solution was added to the $\mathrm{CuBr} / \mathrm{CuBr}_{2}$ mixture, followed by the addition of $\mathrm{SiO}_{2}-\mathrm{Br}$ nanoparticle dispersion to the resulting mixture. Subsequently, the reaction flask was submerged into an $90{ }^{\circ} \mathrm{C}$ thermostated oil bath and stirred at $500 \mathrm{rpm}$ for 17 hours under Argon atmosphere. To purify the core-shell nanoparticles, the reaction mixture was washed with DMF and centrifuged at 10,000 rpm for 30min. This washing step was repeated 2 more times after which the collected $\mathrm{SiO}_{2}$-PS was vacuum dried at room temperature for $12 \mathrm{~h}$. In order to determine the molar mass of the PS brushes the $\mathrm{SiO}_{2}$ core of a $\sim 100 \mathrm{mg}$ sample dispersed in $2 \mathrm{ml} \mathrm{THF}$ was etched with HF for overnight followed by drying the residual polymer. Subsequently the molar mass was measured with GPC to be $9061 \mathrm{~g}$ $\mathrm{mol}^{-1}$.

Nanocomposite preparation. Nanocomposites were prepared by dispersing $4 \mathrm{wt} \%$, based on the bare silica nanoparticle weight, (functional) silica nanoparticles in PS or 
PMMA with a mini extruder (DSM). In a typical procedure a dry blend of nanoparticles and polystyrene was fed to the extruder followed by internal mixing for 3 minutes. The barrel temperature was set to $155^{\circ} \mathrm{C}$ and the screw speed was $100 \mathrm{rpm}$. Subsequently the polystyrene nanocomposite was collected and left to cool to room temperature.

Film preparation. A hot press (Fortijne, the Netherlands) was used to press $\sim 0.2 \mathrm{~mm}$ thick nanocomposite films in a mold $(4 \times 3 \mathrm{~cm})$. The press temperature, applied load and press time were $130{ }^{\circ} \mathrm{C}, 250 \mathrm{KN}$ and 10 minutes, respectively.

Batch foaming of nanocomposite films. The obtained nanocomposite PS films were saturated with carbon dioxide (55 bar) in an autoclave for 3 hours at room temperature followed by rapid depressurization. Subsequently the PS films were foamed by immersion in a glycerol bath, which was thermostated at $100{ }^{\circ} \mathrm{C}$ for 30 seconds. Next, the samples were quenched to room temperature in a 50:50 water- ethanol bath followed by immersion in ethanol for 1 hour. Finally the foams were left to dry in air for at least 12 hours prior to further analysis. For the foaming of PMMA nanocomposite films a $\mathrm{CO}_{2}$ saturation pressure and time of 55 bar and 3 hours were used, respectively. Following quick depressurization the polymer films were foamed by immersion in a water bath thermostated at $40{ }^{\circ} \mathrm{C}$ for 3 minutes after which the samples were quenched in an ice bath for 30 minutes. Finally the samples were left to dry in air for at least 12 hours prior to further analysis. A scheme of the used foaming setup is shown in Figure 3.9. We note that the used foaming conditions provided the lowest cell size and highest cell density within a range of foaming temperatures $\left(0{ }^{\circ} \mathrm{C}\right.$ to $110{ }^{\circ} \mathrm{C}$ and times ( few seconds to 5 minutes) and thus they were selected as our standard conditions throughout this Chapter.

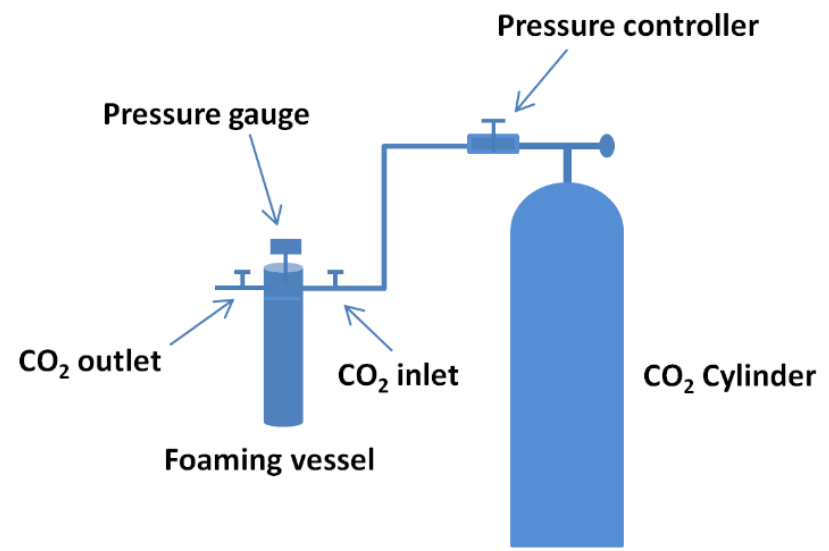

Figure 3.9 Scheme of the $\mathrm{CO}_{2}$ batch foaming setup. The maximum operation pressure of this setup is $\sim 60$ bar. 
Fourier transform infrared (FTIR) spectroscopy. FTIR spectra were collected with a Bruker ALPHA single attenuated total reflection (ATR) FTIR Spectrometer equipped with an ATR single reflection crystal (Bruker Optic GmbH, Ettlingen, Germany). The spectra were collected in the range of $400-4000 \mathrm{~cm}^{-1}$ (spectral solution of $4 \mathrm{~cm}^{-1}, 1280$ scans). Background spectra were recorded against air.

Thermo gravimetric analysis (TGA). The weight loss of the (modified) particles as a function of temperature was measured with a TGA400 (PerkinElmer, Inc., Waltham, MA, USA). A sample weighing 3 to $6 \mathrm{mg}$ was loaded into the platinum pan and set to $50{ }^{\circ} \mathrm{C}$ to stabilize. Subsequently the sample was heated to $900{ }^{\circ} \mathrm{C}$ at a heating rate of $20{ }^{\circ} \mathrm{C} \mathrm{min}$

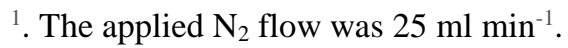

Transmission electron microscopy (TEM). To investigate the core-shell structure of the functionalized nanoparticles a FEI/Philips CM300 transmission electron microscope (Eindhoven, the Netherlands) was used. Diluted particle dispersions in THF were deposited on the carbon side of a carbon/copper grid (HC200-Cu) (EMS, Germany). Images were obtained in the bright field mode with a $300 \mathrm{kV}$ acceleration voltage.

Scanning electron microscopy (SEM). To investigate the morphology of the unfoamed/foamed nanocomposite films a high resolution scanning electron microscope (JEOL Field Emission JSM-633OF, JEOL Benelux, Nieuw-Vennep, the Netherlands) was used. The typically used electron acceleration voltage was $5 \mathrm{keV}$. Prior to analysis the nanocomposite films and foams were freeze fractured after cooling in liquid nitrogen for 5 minutes and the obtain cross sections were sputter coated (JEOL JFC-1300 Auto Fine Coater, JEOL Benelux, Nieuw-Vennep, the Netherlands) with gold under argon atmospheres for $40 \mathrm{~s}$ at a current of $30 \mathrm{~mA}$.

Calculation of cell density. The cell size and cell density were obtained by analyzing the SEM cross sections. Cell density $\left(N_{v}\right)$ of the foams was calculated by Kumar's theoretical approximation ${ }^{42}$. No direct measurements of cell dimensions over the micrograph are required in this method, only the micrograph area $(A)$ and the total number of cells $(n)$ contained therein are measured. Together with the magnification factor of the micrograph $(M), N_{v}$ can be calculated according to equation 1.

$$
N_{v}=\left[\frac{\left(n M^{2}\right)}{A}\right]^{3 / 2}
$$

By combining $N_{V}$ with the volume expansion ratio $(B)$ of nanocomposite films after foaming, the cell numbers per $\mathrm{cm}^{3}$ of unfoamed materials $(N)$ can be calculated according to equation 2 .

$$
N=N_{v} * B
$$




\section{References}

[1] Costeux, S. $\mathrm{CO}_{2}$-blown nanocellular foams. Journal of Applied Polymer Science 2014, 131, 41293-41208.

[2] Shastri, V. P.; Martin, I.; Langer, R. Macroporous polymer foams by hydrocarbon templating. Proceedings of the National Academy of Sciences 2000, 97, 1970-1975.

[3] Kim, Y. H.; Choi, S. J.; Kim, J. M.; Han, M. S.; Kim, W. N.; Bang, K. T. Effects of organoclay on the thermal insulating properties of rigid polyurethane poams blown by environmentally friendly blowing agents. Macromolecular Research 2007, 15, 676-681.

[4] Dai, X.; Liu, Z.; Wang, Y.; Yang, G.; Xu, J.; Han, B. High damping property of microcellular polymer prepared by friendly environmental approach. The Journal of Supercritical Fluids 2005, 33, 259-267.

[5] Shen, B.; Zhai, W.; Tao, M.; Ling, J.; Zheng, W. Lightweight, multifunctional polyetherimide/graphene@ $\mathrm{Fe}_{3} \mathrm{O}_{4}$ composite foams for shielding of electromagnetic pollution. ACS applied materials \& interfaces 2013, 5, 11383-11391.

[6] Ling, J.; Zhai, W.; Feng, W.; Shen, B.; Zhang, J.; Zheng, W. g. Facile preparation of lightweight microcellular polyetherimide/graphene composite foams for electromagnetic interference shielding. ACS Applied Materials \& Interfaces 2013, 5, 2677-2684.

[7] Rezwan, K.; Chen, Q.; Blaker, J.; Boccaccini, A. R. Biodegradable and bioactive porous polymer/inorganic composite scaffolds for bone tissue engineering. Biomaterials 2006, 27, 3413-3431.

[8] Miller, D.; Kumar, V. Microcellular and nanocellular solid-state polyetherimide (PEI) foams using sub-critical carbon dioxide II. Tensile and impact properties. Polymer 2011, 52, 2910 2919.

[9] Forest, C.; Chaumont, P.; Cassagnau, P.; Swoboda, B.; Sonntag, P. Polymer nano-foams for insulating applications prepared from $\mathrm{CO}_{2}$ foaming. Progress in Polymer Science 2015, 41 , 122-145.

[10] Hrubesh, L. W.; Pekala, R. W. Thermal properties of organic and inorganic aerogels. Journal of Materials Research 1994, 9, 731-738.

[11] Notario, B.; Pinto, J.; Solorzano, E.; De Saja, J. A.; Dumon, M.; Rodríguez-Pérez, M. A. Experimental validation of the Knudsen effect in nanocellular polymeric foams. Polymer 2015, 56, 57-67.

[12] Sundarram, S. S.; Li, W. On thermal conductivity of micro-and nanocellular polymer foams. Polymer Engineering \& Science 2013, 53, 1901-1909.

[13] Costeux, S.; Zhu, L. Low density thermoplastic nanofoams nucleated by nanoparticles. Polymer 2013, 54, 2785-2795.

[14] Yokoyama, H.; Sugiyama, K. Nanocellular structures in block copolymers with $\mathrm{CO}_{2}$-philic blocks using $\mathrm{CO}_{2}$ as a blowing agent: Crossover from micro-to nanocellular structures with depressurization temperature. Macromolecules 2005, 38, 10516-10522. 
[15] Handa, Y. P.; Zhang, Z. A new technique for measuring retrograde vitrification in polymergas systems and for making ultramicrocellular foams from the retrograde phase. Journal of Polymer Science Part B: Polymer Physics 2000, 38, 716-725.

[16] Ruiz, J. A. R.; Pedros, M.; Tallon, J.-M.; Dumon, M. Micro and nano cellular amorphous polymers (PMMA, PS) in supercritical $\mathrm{CO}_{2}$ assisted by nanostructured $\mathrm{CO}_{2}$-philic block copolymers-one step foaming process. The Journal of Supercritical Fluids 2011, 58, 168176.

[17] Zeng, C.; Han, X.; Lee, L. J.; Koelling, K. W.; Tomasko, D. L. Polymer-clay nanocomposite foams prepared using carbon dioxide. Advanced Materials 2003, 15, 1743-1747.

[18] Krause, B.; Mettinkhof, R.; Van der Vegt, N.; Wessling, M. Microcellular foaming of amorphous high-Tg polymers using carbon dioxide. Macromolecules 2001, 34, 874-884.

[19] Krause, B.; Diekmann, K.; Van der Vegt, N.; Wessling, M. Open nanoporous morphologies from polymeric blends by carbon dioxide foaming. Macromolecules 2002, 35, 1738-1745.

[20] Chen, L.; Rende, D.; Schadler, L. S.; Ozisik, R. Polymer nanocomposite foams. Journal of Materials Chemistry A 2013, 1, 3837-3850.

[21] Liu, S.; Duvigneau, J.; Vancso, G. J. Nanocellular polymer foams as promising high performance thermal insulation materials. European Polymer Journal 2015, 65, 33-45.

[22] Lothe, J.; Pound, G. Statistical mechanics of nucleation. Nucleation, Marcel Dekker, Inc, New York 1969, 112.

[23] Oxtoby, D. W. Density functional methods in the statistical mechanics of materials. Annual Review of Materials Research 2002, 32, 39-52.

[24] Spitael, P.; Macosko, C. W.; McClurg, R. B. Block copolymer micelles for nucleation of microcellular thermoplastic foams. Macromolecules 2004, 37, 6874-6882.

[25] Li, L.; Nemoto, T.; Sugiyama, K.; Yokoyama, H. $\mathrm{CO}_{2}$ foaming in thin films of block copolymer containing fluorinated blocks. Macromolecules 2006, 39, 4746-4755.

[26] Pinto, J.; Dumon, M.; Pedros, M.; Reglero, J.; Rodriguez-Perez, M. A. Nanocellular $\mathrm{CO}_{2}$ foaming of PMMA assisted by block copolymer nanostructuration. Chemical Engineering Journal 2014, 243, 428-435.

[27] Okamoto, M.; Nam, P. H.; Maiti, P.; Kotaka, T.; Nakayama, T.; Takada, M.; Ohshima, M.; Usuki, A.; Hasegawa, N.; Okamoto, H. Biaxial flow-induced alignment of silicate layers in polypropylene/clay nanocomposite foam. Nano letters 2001, 1, 503-505.

[28] Shen, J.; Zeng, C.; Lee, L. J. Synthesis of polystyrene-carbon nanofibers nanocomposite foams. Polymer 2005, 46, 5218-5224.

[29] Cao, X.; Lee, L. J.; Widya, T.; Macosko, C. Polyurethane/clay nanocomposites foams: processing, structure and properties. Polymer 2005, 46, 775-783.

[30] Siripurapu, S.; DeSimone, J. M.; Khan, S. A.; Spontak, R. J. Controlled foaming of polymer films through restricted surface diffusion and the addition of nanosilica particles or $\mathrm{CO}_{2}$ philic surfactants. Macromolecules 2005, 38, 2271-2280.

[31] Lee, L. J.; Zeng, C.; Cao, X.; Han, X.; Shen, J.; Xu, G. Polymer nanocomposite foams. Composites Science and Technology 2005, 65, 2344-2363. 
[32] Zhai, W.; Yu, J.; Wu, L.; Ma, W.; He, J. Heterogeneous nucleation uniformizing cell size distribution in microcellular nanocomposites foams. Polymer 2006, 47, 7580-7589.

[33] Goren, K.; Chen, L.; Schadler, L. S.; Ozisik, R. Influence of nanoparticle surface chemistry and size on supercritical carbon dioxide processed nanocomposite foam morphology. The Journal of Supercritical Fluids 2010, 51, 420-427.

[34] Siripurapu, S.; DeSimone, J. M.; Khan, S. A.; Spontak, R. J. Low-temperature, surfacemediated foaming of polymer films. Advanced Materials 2004, 16, 989-994.

[35] Chen, L.; Ozisik, R.; Schadler, L. S. The influence of carbon nanotube aspect ratio on the foam morphology of MWNT/PMMA nanocomposite foams. Polymer 2010, 51, 2368-2375.

[36] Harikrishnan, G.; Lindsay, C. I.; Arunagirinathan, M.; Macosko, C. W. Probing nanodispersions of clays for reactive foaming. ACS Applied Materials \& Interfaces 2009, 1, 1913-1918.

[37] Yang, J.; Sang, Y.; Chen, F.; Fei, Z.; Zhong, M. Synthesis of silica particles grafted with poly (ionic liquid) and their nucleation effect on microcellular foaming of polystyrene using supercritical carbon dioxide. The Journal of Supercritical Fluids 2012, 62, 197-203.

[38] Yang, J.; Huang, L.; Zhang, Y.; Chen, F.; Zhong, M. Mesoporous silica particles grafted with polystyrene brushes as a nucleation agent for polystyrene supercritical carbon dioxide foaming. Journal of Applied Polymer Science 2013, 130, 4308-4317.

[39] Bärwinkel, S.; Bahrami, R.; Löbling, T. I.; Schmalz, H.; Müller, A. H.; Altstädt, V. Polymer foams made of immiscible polymer blends compatibilized by Janus particles-effect of compatibilization on foam morphology. Advanced Engineering Materials 2016, 18, 814-825.

[40] Dann, J. Forces involved in the adhesive process: I. Critical surface tensions of polymeric solids as determined with polar liquids. Journal of Colloid and Interface Science 1970, 32, 302-320.

[41] Wu, S. In Calculation of interfacial tension in polymer systems. Journal of Polymer Science: Polymer Symposia, Wiley Online Library: 1971; pp 19-30.

[42] Kumar, V.; Suh, N. P. A process for making microcellular thermoplastic parts. Polymer Engineering \& Science 1990, 30, 1323-1329.

[43] Musić, S.; Filipović-Vinceković, N.; Sekovanić, L. Precipitation of amorphous SiO2 particles and their properties. Brazilian Journal of Chemical Engineering 2011, 28, 89-94.

[44] Kim, H.; Kim, H. G.; Kim, S.; Kim, S. S. PDMS-silica composite membranes with silane coupling for propylene separation. Journal of Membrane Science 2009, 344, 211-218.

[45] Radice, S.; Di Dedda, E.; Tonelli, C.; Della Pergola, R.; Milani, A.; Castiglioni, C. FT-IR Spectroscopy and DFT Calculations on Fluorinated Macromer Diols: IR Intensity and Association Properties. The Journal of Physical Chemistry B 2010, 114, 6332-6336. 
Chapter 4

\section{Silica Assisted Nucleation of Polymer} Foam Cells with Nanoscopic Dimensions: Impact of Particle Size and Surface Functionality

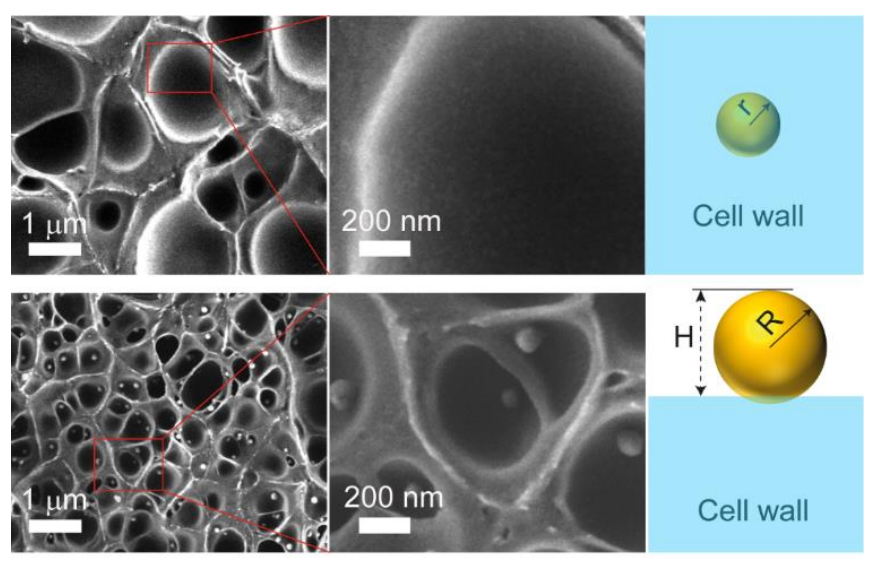

In this Chapter core-shell nanoparticles using silica as core and polydimethylsiloxane (PDMS) as shell with different diameters were prepared and used as heterogeneous nucleation agents to obtain $\mathrm{CO}_{2}$ blown poly(methyl methacrylate) (PMMA) nanocomposite foams. PDMS was selected as shell material as it possesses a low surface energy and high $\mathrm{CO}_{2}$-philicity. The successful synthesis of core-shell nanoparticles was confirmed by Fourier transform infrared (FTIR) spectroscopy, thermogravimetric analysis (TGA) and transmission electron microscopy (TEM). The cell size and cell density of the PMMA micro- and nanocellular foams obtained were determined with scanning electron microscopy (SEM). The results show that cell nucleation by the coreshell nanoparticles was significantly enhanced compared to unmodified silica. The highest nucleation efficiency obtained had an value of $\sim 0.5$ for nanoparticles with a core diameter of $80 \mathrm{~nm}$. The particle size dependence of nucleation efficiency is discussed 
taking into account line tension effects. The complete engulfment of particles with a core diameter below $40 \mathrm{~nm}$ at the cell wall interface corresponds to line tension values of approximately $0.42 \mathrm{nN}$. This line tension significantly increases the heterogeneous nucleation energy barrier and as a consequence reduces the nucleation efficiency. The increase of the $\mathrm{CO}_{2}$ saturation pressure to 300 bar prior to batch foaming resulted in an increased line tension length. A decrease of the heterogeneous nucleation efficiency was observed for such foaming conditions, which we attribute to homogenous nucleation becoming more favorable at the expense of heterogeneous nucleation. Overall it is shown that the contribution of line tension to the free energy barrier of heterogeneous foam cell nucleation needs to be considered to understand foaming of viscoelastic materials. This finding emphasizes the need for new strategies and for the design of nucleating particles to enhance the foam cell nucleation efficiency.

*Part of this Chapter will be published as: Shanqiu Liu, Rik Eijkelenkamp, Joost Duvigneau and G. Julius Vancso. Silica Assisted Nucleation of Polymer Foam Cells with Nanoscopic Dimensions: Impact of Particle Size and Surface Functionality. ACS Applied Materials \& Interfaces. Accepted. 


\subsection{Introduction}

Polymer foams are materials with numerous applications, and are used e.g., in the field of energy absorption, thermal insulation and as catalyst carriers. ${ }^{1-3}$ When the cell size in closed cell foams is smaller than the collision mean free path of gas molecules ( $70 \mathrm{~nm}$ at standard conditions), the thermal conduction by the gas phase encapsulated in the foam cells is significantly decreased due to the so called Knudsen effect. ${ }^{4-5}$ This makes nanocellular polymer foams very promising candidates as high performance thermal insulation materials. ${ }^{2}$ However, to fabricate foams with such small cells and with a high cell density remains a scientific and technological challenge. ${ }^{2-3}$

Among the possible foaming strategies $\mathrm{CO}_{2}$ batch foaming is one of the most widely used approaches to prepare nanocellular foams. ${ }^{6-14}$ This is ascribed to the easy control of the foaming conditions and the use of $\mathrm{CO}_{2}$ as an environmentally benign blowing agent. Disadvantages of the technique are that $i$ ) it is limited to relatively small specimen sizes, and $i$ ) it has a lower production efficiency when compared to continuous processes and as a consequence its industrial utilization has not been established.

Tuning the foam cell morphology, defined by the cell size, cell density, cell size distribution and cell structure (e.g., open or closed cells), is an issue of great practical interest that will eventually allow one to determine the optimum foam structure for the targeted application. ${ }^{15-16}$ For instance, polymer foams with cell sizes of $100 \mathrm{~nm}$ or less and a cell density of $10^{15}-10^{16}$ cells $\mathrm{cm}^{-3}$ show high thermal insulation performances ascribed to the already introduced Knudsen effect. ${ }^{3}$ However, nanocellular polymer foams with small cell sizes $(<100 \mathrm{~nm})$ and with high cell densities $\left(>10^{15}\right.$ cells $\left.\cdot \mathrm{cm}^{-3}\right)$ are still rarely reported. ${ }^{17-19}$ Besides optimization of the foaming conditions, another common strategy to enhance cell morphology control is to introduce nanostructured heterogeneous phases to the foamed matrix to act as heterogeneous nucleation cites during foaming. ${ }^{2,} 12$ In general, according to the classical nucleation theory, heterogeneous cell nucleation would be preferable due to the related lower nucleation energy barrier compared to homogeneous nucleation. ${ }^{20}$ For instance, (nano)particulate (fillers) $)^{17,21-27}$ and block polymers ${ }^{28-31}$ have been widely reported in the open literature as heterogeneous nucleation agents.

Silica nanoparticles are of particular interest as heterogeneous nucleation agents in polymer foaming due to their low cost, easy preparation, size control, and the ease of employing various surface functionalization strategies for their surface decoration. For instance, $\mathrm{He}$ and coworkers $^{24}$ reported that the addition of silica nanoparticles in polycarbonate prior to foaming resulted in a more uniform cell size distribution and higher cell density due to heterogeneous nucleation compared to the pristine polycarbonate foams. Spontak and coworkers ${ }^{10}$ described the influence of nanoparticle concentration on cell morphology in $\mathrm{CO}_{2}$ assisted PMMA foaming. The authors 
demonstrated that below a certain concentration of the nucleating silica nanoparticles, the cell size decreased and the cell density increased with increasing particle concentration. Zhong and coworkers ${ }^{32}$ as well as Ozisik and coworkers ${ }^{27}$ have shown that the surface derivatization of silica nanoparticles with $\mathrm{CO}_{2}$-philic surfactants can decrease the nucleation energy and significantly enhance the cell nucleation efficiency in $\mathrm{CO}_{2}$ polymer foaming compared to pristine particles. In addition, in Chapter 3 we presented the synthesis of PDMS grafted silica nanoparticles with a core diameter of $80 \mathrm{~nm}$ as highly efficient cell nucleation agents in $\mathrm{CO}_{2}$ blown batch foaming of polystyrene and poly(methyl methacrylate) films. ${ }^{13}$ Nucleation efficiencies of up to $\sim 0.5$ (i.e. 1 foam cell per 2 particles on average) were achieved for the foaming conditions we used. This is the highest nucleation efficiency value achieved so far for nanoparticles used as heterogeneous nucleation agents. We note that in this Chapter we used a custom build batch foaming device that allows the saturation of polymers with $\mathrm{CO}_{2}$ at pressures up to 300 bar.

To further study the influence of interfacial interactions and particle curvature on cell nucleation, in this Chapter bare hydroxyl terminated $\mathrm{SiO}_{2}$ nanoparticles and PDMS grafted core-shell nanoparticles $\left(\mathrm{SiO}_{2}\right.$-PDMS) with different silica core diameters (from $12 \mathrm{~nm}$ to $120 \mathrm{~nm}$ ) were prepared and subsequently incorporated in PMMA to act as heterogeneous nucleation agents. We selected a $\mathrm{CO}_{2}$ saturation pressure of 55 bar and a foaming temperature of $40{ }^{\circ} \mathrm{C}$ based on our previously experimental results (see Chapter 3 ) as this ensures highly efficient nucleation of PDMS grafted core-shell nanoparticles. ${ }^{13}$ Under these conditions heterogeneous nucleation is still favorable compared to homogenous nucleation and the effect of particle size and surface chemistry is thus expected to determine the foam morphologies. In addition, this pressure (i.e. 55 bar) is still significantly lower than pressures used during the frequently exploited supercritical foaming conditions in batch foaming, e.g., using pressures up to 330 bar. ${ }^{33-34} \mathrm{We}$ expect that an enhanced understanding of heterogeneous nucleation and foaming at relatively low saturation pressures would eventually result in the development of industrially relevant processes.

We considered it of particular interest to decrease the PDMS grafted core-shell particle size to below the previously reported silica core diameter of $\sim 80$ nanometer (see Chapter 3$),{ }^{13}$ since a decreased particle size allows the introduction of more potential foam cell nucleation sites at the same weight percentage of particle loading. Provided that the smaller particles nucleate foam cells as efficient as larger ones, the use of smaller particles is expected to yield foams with a higher cell density and a lower overall foam density, without the need for adding additional solid mass (i.e. silica). For instance, foams for thermal insulation applications are expected to benefit from as low as possible silica weight concentrations as silica is a good thermal conductor. As we will show in this Chapter, nanoparticles with a high surface curvature, i.e. small diameters, especially 80 
below $40 \mathrm{~nm}$, were found to be less efficient for heterogeneous nucleation compared to particles with larger size. We show here that the less efficient nucleation for the smaller particles is ascribed to a positive line tension acting at the three phase contact line between the nanoparticle, $\mathrm{CO}_{2}$ nucleus and $\mathrm{CO}_{2}$ swollen polymer. Although the length scale over which line tension effects become relevant for viscoelastic polymer/particle systems used in nucleated foam production is not yet fully understood, it is generally accepted that line tension effects become significant at diminishing dimensions. ${ }^{35-37}$ In fact, we show that at the length scales relevant for our foaming process, line tension must be included in the models for quantitatively describing the free energy of cell nucleation in polymer foaming.

Interestingly, morphology imaging of cellular materials, and in particular, capturing the position of the nucleating particles with respect to the matrix-cell gas interface, provides information about the influence of line tension effects on cell nucleation. For example, SEM micrographs reveal the absence of the smallest nanoparticles at the surface of the foam cell walls which supports the impact of a positive line tension and thus confirms that its contribution to the free energy of cell nucleation must be included in the models describing foaming. These results further underline the importance of obtaining an enhanced understanding of the interactions between highly curved particles with viscoelastic polymers when sizes approach the macromolecular length scale. This understanding would allow one to fully exploit the potential of nanoparticles as highly efficient nucleation agents in nanocellular foaming, as well as in numerous other applications, such as in electronics, ${ }^{38}$ sensors, ${ }^{39-40}$ adhesives $^{41}$ and templated porous materials. $^{42}$

\subsection{Results and discussion}

\subsubsection{Preparation and characterization of silica nanoparticles}

Stöber silica nanoparticles (hereinafter we abbreviate "nanoparticle" with NP) with different diameters were synthesized, followed by their surface grafting with PDMS. The reaction scheme of the process we used is depicted in Figure 4.1A. Typically, silica NPs $\left(\mathrm{SiO}_{2}\right)$ were prepared via a Stöber reaction ${ }^{43}$ (step a), followed by the hydrolysis of the surface-exposed ethoxy groups to silanol moieties (step b). The hydrolyzed particles $\left(\mathrm{SiO}_{2}-\mathrm{OH}\right)$ were derivatized with (3-aminopropyl)-triethoxysilane (APTES), resulting in the formation of amine functionalized $\mathrm{NPs}\left(\mathrm{SiO}_{2}-\mathrm{NH}_{2}\right)$ (step c). Subsequently, PDMS grafted core-shell NPs ( $\mathrm{SiO}_{2}$-PDMS) were prepared by the grafting to of monoglycidyl ether terminated PDMS (step d). When commercially available silica core particles were 
used, their surface was directly modified with N-(2-aminoethyl-3aminopropyl)methyldimethoxysilane to yield $\mathrm{SiO}_{2}-\mathrm{NH}_{2}$ followed by the grafting of PDMS to the particles. (We note that the diameter of the silica (core) NPs is depicted as round numbers while information about the corresponding average particle sizes and size distibutions is shown in Table 4.1).
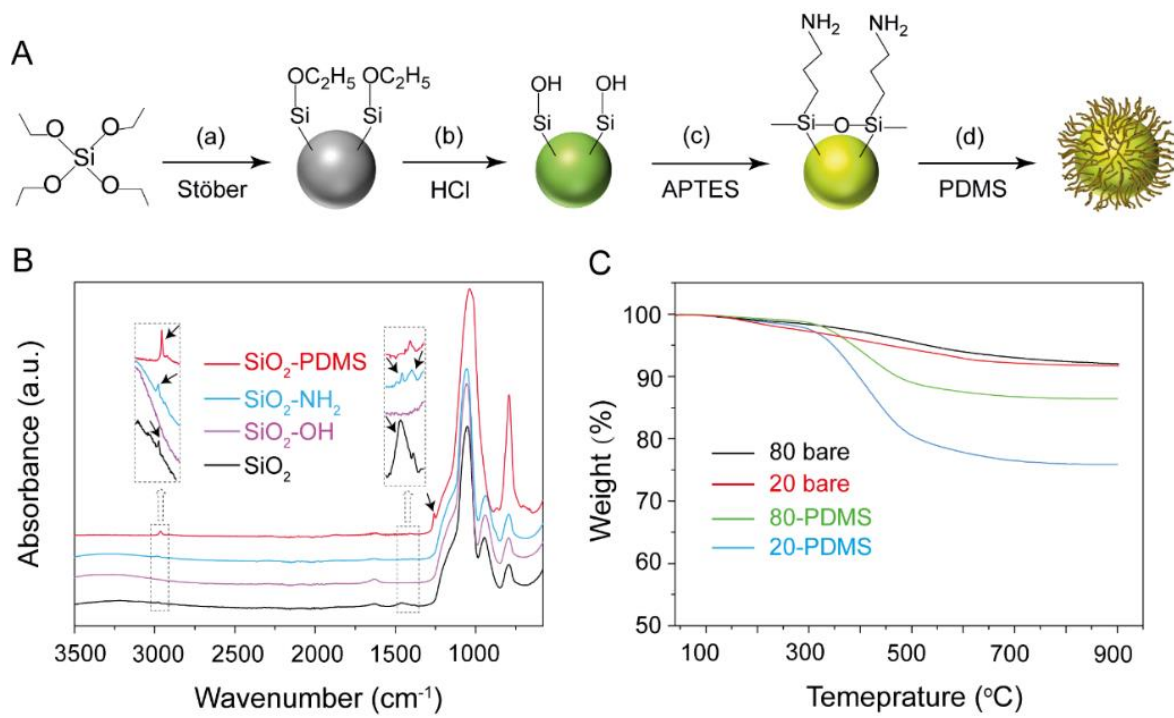

Figure 4.1 Schematic of the NP preparation process (A). Single reflection ATR-FTIR absorbance spectra of $\mathrm{SiO}_{2}, \mathrm{SiO}_{2}-\mathrm{OH}, \mathrm{SiO}_{2}-\mathrm{NH}_{2}$ and $\mathrm{SiO}_{2}-\mathrm{PDMS} \mathrm{NPs}$ with a silica (core) diameter of $80 \mathrm{~nm}$ (B). The black arrows in the FTIR spectra indicate characteristic FTIR absorbances of the (modified) NPs. Non-isothermal TGA thermograms of $\mathrm{SiO}_{2}-\mathrm{NH}_{2}$ and $\mathrm{SiO}_{2}-\mathrm{PDMS}$ NPs with a silica (core) diameter of $20 \mathrm{~nm}$ and $80 \mathrm{~nm}(\mathrm{C})$.

Figure 4.1B shows the FTIR absorbance spectra of the (modified) NPs. The remaining ethoxy groups after the Stöber reaction of tetraethyl orthosilicate (TEOS) are clearly observed in the FTIR spectra of the $\mathrm{SiO}_{2}$ particles, i.e. the $\mathrm{CH}_{2} / \mathrm{CH}_{3}$ bending absorbance band at $1452 \mathrm{~cm}^{-1}$ and the $\mathrm{CH}_{2} / \mathrm{CH}_{3}$ absorbance band at $2980 \mathrm{~cm}^{-1} \cdot{ }^{44}$ Following hydrolysis to obtain $\mathrm{SiO}_{2} \mathrm{NPs}$ with surface $-\mathrm{OH}$ functionalities $\left(\mathrm{SiO}_{2}-\mathrm{OH}\right)$, these absorbance bands disappeared, which indicates quantitative hydrolysis of the remaining ethoxy groups. ${ }^{45}$ The reappearance of absorbances at $2980 \mathrm{~cm}^{-1}, 1450 \mathrm{~cm}^{-1}$ and $1380 \mathrm{~cm}^{-1}$ in the FTIR spectrum of amino-functionalized NPs $\left(\mathrm{SiO}_{2}-\mathrm{NH}_{2}\right)$ are assigned to $\mathrm{CH}_{2}$ groups of the propyl spacer of surface tethered APTES. The absorption bands for $\mathrm{CH}_{3}$ stretching at $2967 \mathrm{~cm}^{-1}$ and for C-H bending at $1263 \mathrm{~cm}^{-1}$ confirm the successful grafting of PDMS to silica NPs. ${ }^{46}$ 
Table 4.1 Determined NP diameters.

\begin{tabular}{l|c|c|c|c|c|c}
\hline Depicted NP diameter (nm) & 12 & 20 & 40 & 60 & 80 & 120 \\
\hline \hline Average NP diameter (nm) & 11.8 & 21.8 & 41.2 & 57.3 & 82.7 & 123.7 \\
\hline STDEV (N > 150) & 2.2 & 3.9 & 4.7 & 6.9 & 11.1 & 11.5 \\
\hline
\end{tabular}

TGA analyses was employed to determine the amount of grafted polymer. Figure 4.1C shows an example of the weight loss versus temperature curves for non-isothermal TGA measurements of $\mathrm{SiO}_{2}-\mathrm{NH}_{2}$ and PDMS grafted NPs with silica (core) diameters of $20 \mathrm{~nm}$ and $80 \mathrm{~nm}$, respectively. The weight percentage of PDMS covalently bound to the $\mathrm{SiO}_{2}$ NPs was calculated from the TGA charts (see Table 4.2). The results show that the amount of grafted PDMS increases from $~ 3.1 \mathrm{wt} \%$ to $\sim 24.2 \mathrm{wt} \%$ with a decrease in the NP diameter from $120 \mathrm{~nm}$ to $12 \mathrm{~nm}$. This is ascribed to the increased specific surface area for the smaller particles. Based on the TGA results, the molar mass of the grafted PDMS chains used (i.e. 1,000 $\left.\mathrm{g} \mathrm{mol}^{-1}\right)$ and the surface area of the NPs $\left(e . g .33 \mathrm{~m}^{2} \mathrm{~g}^{-1}\right.$ for $80 \mathrm{~nm}$ NPs), the PDMS grafting densities were estimated to be approximately $\sim 0.9$ chains $\mathrm{nm}^{-}$ ${ }^{2}$ for particles with a diameter between 12 and $120 \mathrm{~nm}$ (see Table 4.2). Thus the variations in silica NP surface curvature did not affect the obtained PDMS grafting densities.

Table 4.2 Weight of grafted PDMS to silica NPs and the corresponding calculated PDMS grafting density as a function of the silica particle diameter.

\begin{tabular}{l|c|c|c|c|c|c}
\hline NP diameter (nm) & 12 & 20 & 40 & 60 & 80 & 120 \\
\hline \hline Percentage of grafted PDMS (wt\%) & 24.2 & 15.9 & 8.7 & 6.3 & 4.8 & 3.1 \\
\hline Grafting density (chains $\mathrm{nm}^{-2}$ ) & 0.87 & 0.88 & 0.87 & 0.92 & 0.91 & 0.89 \\
\hline
\end{tabular}



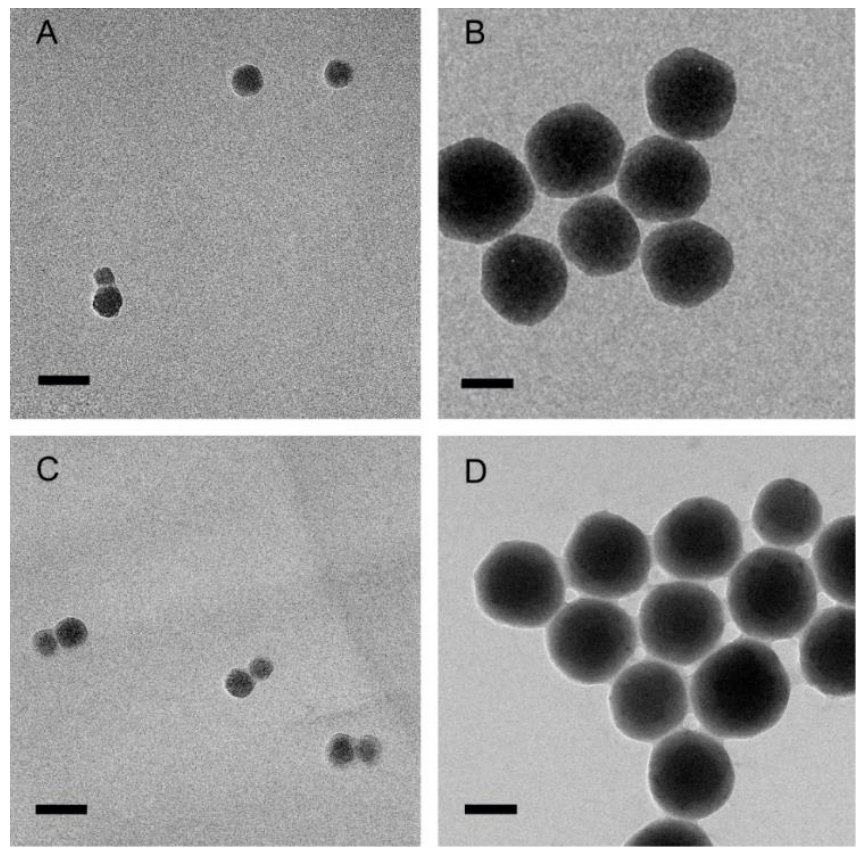

Figure 4.2 TEM images of $\mathrm{SiO}_{2}-\mathrm{OH}$ NPs with a diameter of $20 \mathrm{~nm}$ (A) and $80 \mathrm{~nm}$ (B) as well as $\mathrm{SiO}_{2}$-PDMS NPs with a silica core diameter of $20 \mathrm{~nm}$ (C) and $80 \mathrm{~nm}$ (D). The scale bars represent $50 \mathrm{~nm}$.

TEM was used to confirm the core-shell structure of the hybrid NPs. Figure 4.2 shows TEM images of bare and PDMS grafted NPs with a silica core diameter of 20 and 80 nanometer, respectively. A clear PDMS shell structure around the NPs is observed (see Figure $4.2 \mathrm{C}$ and D). From the TEM images the shell thickness value was estimated to be in the range of $6.0 \pm 1.3 \mathrm{~nm}$. The NPs obtained were subsequently used as heterogeneous nucleation agents for PMMA nanocomposite foaming.

\subsubsection{Nanocomposite foams}

Prior to foaming the NPs were melt-blended to PMMA and pressed to films with a thickness of approximately $200 \mu \mathrm{m}$. For comparison we kept the volume number density of the particles with different diameters constant at the value of $2.3 \times 10^{13}$ particles $\mathrm{cm}^{-3}$. Thus, assuming a good particle dispersion, all nanocomposite films had the same particle number density per volume prior to foaming. 

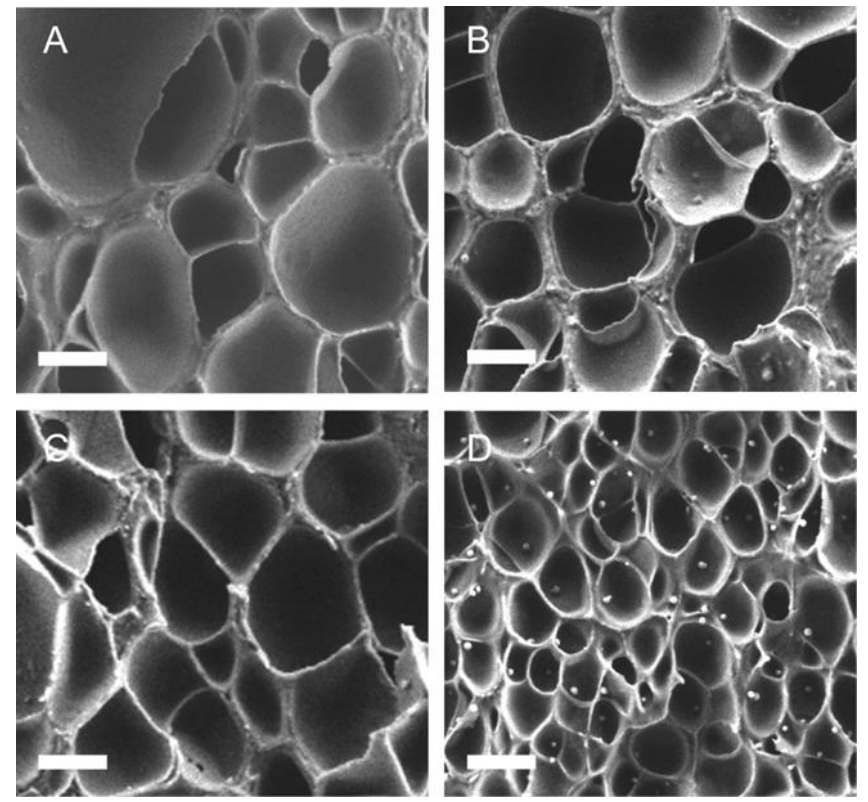

Figure 4.3 SEM images of cross sectioned PMMA foams containing $\mathrm{SiO}_{2}-\mathrm{OH}$ NPs with a diameter of $20 \mathrm{~nm}(\mathrm{~A})$ and $80 \mathrm{~nm}(\mathrm{~B})$ as well as PMMA foams containing $\mathrm{SiO}_{2}$-PDMS NPs with a silica core diameter of $20 \mathrm{~nm}(\mathrm{C})$ and $80 \mathrm{~nm}$ (D). The scale bars represent $1 \mu \mathrm{m}$. The saturation pressure, foaming temperature and foaming time were $55 \mathrm{bar}, 40^{\circ} \mathrm{C}$ and $180 \mathrm{~s}$, respectively.

PMMA nanocomposites with bare and core-shell NPs were foamed after saturation with $\mathrm{CO}_{2}$ at 55 bar. Figure 4.3 shows SEM images of cross sectioned PMMA foams containing $20 \mathrm{~nm}$ and $80 \mathrm{~nm}$ diameter particles, respectively, after $180 \mathrm{~s}$ of foaming. From Figure 4.3 it is obvious that the incorporation of PDMS grafted NPs can significantly decrease the cell size and increase the cell density compared to untreated silica. For quantitative comparison, the cell size and cell density of the respective PMMA foams were determined. The results are shown in Figure 4.4. 

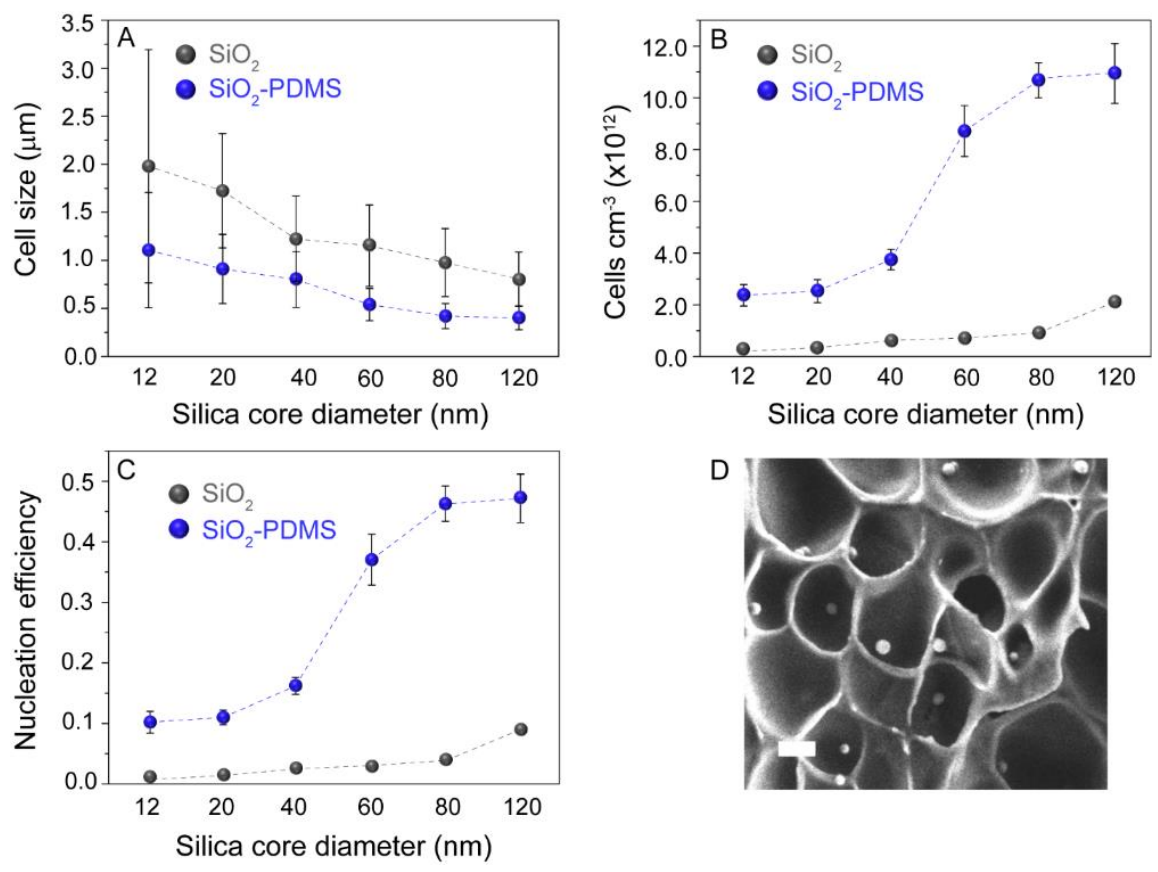

Figure 4.4 Cell size (A), cell density (B) and nucleation efficiency (C) of PMMA nanocomposite foams containing $\mathrm{SiO}_{2}-\mathrm{OH}$ and $\mathrm{SiO}_{2}$-PDMS NPs as a function of the silica (core) diameter. In (D) Cross sectional SEM images of PMMA foams containing PDMS grafted NPs with a silica core diameter of $80 \mathrm{~nm}$ foamed for $180 \mathrm{~s}$ are shown. The scale bars represent $200 \mathrm{~nm}$. (Note: The error bars for the measurements involving bare silica in panel B and C are too small to be seen.)

PMMA foams without added nucleating agents had a cell size and cell density of approximately $13 \mu \mathrm{m}$ and $3 \times 10^{8}$ cells cm${ }^{-3}$, respectively. Compared to these numbers the addition of the prepared (hybrid) silica NPs to PMMA as nucleating agents seems very effective. As is obvious from Figures $4.4 \mathrm{~A}$ and $\mathrm{B}$ the cell size and cell size distribution both decrease while the cell density increases upon increasing the NP size. The cell size and cell density of PMMA foams containing $120 \mathrm{~nm}$ bare silica are $\sim 810 \mathrm{~nm}$ and $2.1 \times$ $10^{12}$ cells $\mathrm{cm}^{-3}$, respectively, which is a significant enhancement compared to the structure of the foam obtained by incorporation of $12 \mathrm{~nm}$ bare silica. After the incorporation of core-shell NPs, the cell sizes are further decreased and the cell densities are significantly increased compared to the PMMA foams featuring bare silica. For instance, for PMMA foams nucleated by $120 \mathrm{~nm} \mathrm{SiO}_{2}$-PDMS NPs the cell size decreased to $\sim 410 \mathrm{~nm}$ and the cell density increased to $1.09 \times 10^{13} \mathrm{cells} \mathrm{cm}^{-3}$.

Strikingly, there is a sharp increase in the cell density for the $\mathrm{SiO}_{2}-\mathrm{PDMS}$ NPs starting at a particle diameter of $\sim 40 \mathrm{~nm}$ and reaching a plateau value at $\sim 80 \mathrm{~nm}$. Regarding this observation we provide an explanation later. 
The nucleation efficiencies of the NPs in our foaming experiments were calculated as the ratio of the number of cells per $\mathrm{cm}^{3}$ unfoamed polymer to the number of NPs per $\mathrm{cm}^{3}$ unfoamed polymer (i.e. $2.3 \times 10^{13}$, see also the experimental section). It is assumed that i) there is no cell coalescence and $i$ ) that every particle provides one potential nucleation site. However, we note that the number of nucleation sites per particles is not limited to one. In principle there are no physical restrictions that prevent the occurrence of more than one nucleation event per particle, i.e. nucleation efficiencies exceeding unity are possible.

The nucleation efficiency of NPs with a PDMS shell is significantly higher compared to that of the bare silica. For instance, a nucleation efficiency of 0.47 was obtained for the PDMS decorated silica with a core diameter of $80 \mathrm{~nm}$, which is 12 folds higher compared to the value observed for the corresponding untreated NPs (which had a nucleation efficiency of 0.04). The SEM images shown in Figure 4.4D reveal that every cell cross section contains approximately one particle. If we assume that on average every cell was cut in half this would correspond to two particles to nucleate one foam cell. This is in excellent agreement with the determined nucleation efficiency of $\sim 0.5$.

We note that our NPs perform significantly better as foam nucleating agents compared to typical values, i.e. $<0.01$, obtained for other nucleating agents, e.g. nano-clay, ${ }^{12,}{ }^{22}$ nanotubes ${ }^{47}$ and $\mathrm{CO}_{2}$-philic polyionic liquid grafted particles. ${ }^{32}$ Direct comparison of nucleation efficiencies is not a trivial task since it also depends on the used foam matrix as well as on the foaming parameters. Nevertheless, we ascribe the increase in cell density and high nucleation efficiency observed in our experiments to $i$ ) the good NP dispersion in the polymer matrix, ii) the low surface energy of the PDMS shell which reduces the nucleation energy barrier, and iii) the higher local $\mathrm{CO}_{2}$ concentration in the PDMS shell $(\sim 75 \mathrm{wt} \%)^{48}$ compared to the PMMA ( $\left.18 \mathrm{wt} \%\right)$ matrix. ${ }^{49}$ The higher $\mathrm{CO}_{2}$ concentration in the PDMS shell ensures that upon decreasing the pressure and increasing the temperature during foaming the amount of $\mathrm{CO}_{2}$ available for foaming is higher closer to the heterogeneous nucleation sites compared to the bulk of the matrix. ${ }^{13}$ This is expected to result in a higher nucleation rate at the energetically favorable particle interphases. In addition, it was reported that for weak polymer shell matrix interaction the height of the nucleation energy barrier is reduced, as well. ${ }^{50-51}$

We attempted to prepare hybrid NPs with a higher PDMS grafting length in order to enhance the $\mathrm{CO}_{2}$ adsorption in the nucleating interphase. Upon increasing the grafting length by using a $5,000 \mathrm{~g} \mathrm{~mol}^{-1}$ PDMS, NPs with a core diameter of $80 \mathrm{~nm}$ had similar grafting percentages compared to the shorter PDMS grafts. For this size of core-shell NPs similar nucleation efficiencies were obtained. On the contrary the smallest particles (diameters below $40 \mathrm{~nm}$ ) had a significant increase in grafting percentages for the longer PDMS chains. Surprisingly, this did not result in a significant increase in the cell 
nucleation efficiency for these NPs. This is ascribed to the inefficient cell nucleation of NPs with (core) diameters below $40 \mathrm{~nm}$ as we will discuss hereafter.
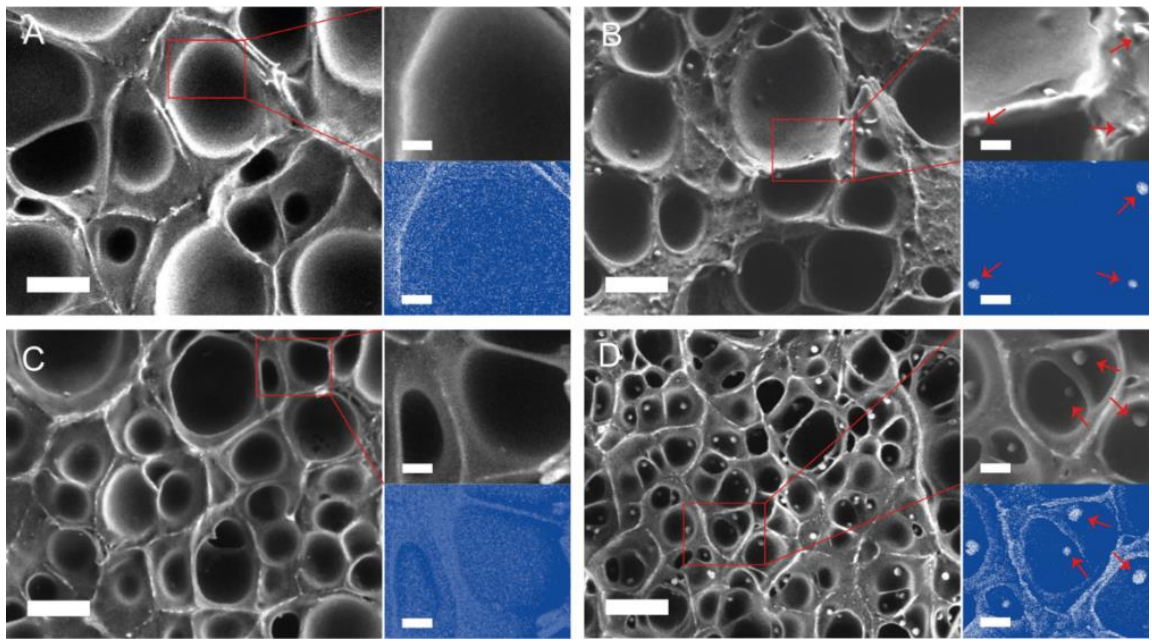

Figure 4.5 SEM images of $0.3 \mathrm{~s}$ foamed PMMA containing $\mathrm{SiO}_{2}-\mathrm{OH}$ with diameters of $20 \mathrm{~nm}$ (A) and $80 \mathrm{~nm}$ (B) as well as $\mathrm{SiO}_{2}$-PDMS with core diameters of $20 \mathrm{~nm}$ (C) and $80 \mathrm{~nm}$ (D). The scale bars represent $1 \mu \mathrm{m}$. The inserts are SEM/EDS images of the magnified parts and the scale bars in these inserts represent $200 \mathrm{~nm}$.

In order to further elucidate the cell nucleation process at the interface of the NPs, we foamed PMMA over a very short period of time, i.e. 0.3 seconds. (We note, that this was the shortest foaming time we could experimentally achieve.) Figure 4.5 shows cross sectional SEM images of PMMA foam cells containing bare and PDMS grafted silica with core diameters of $20 \mathrm{~nm}$ and $80 \mathrm{~nm}$, respectively after foaming for 0.3 seconds. From Figure 4.5 it is clear that these foams have on average a smaller cell size and a thicker cell wall compared to the foams obtained over $180 \mathrm{~s}$ (see Figure 4.3). This we attribute to the limited time for cell growth. For instance, PMMA foams containing $80 \mathrm{~nm}$ PDMS grafted NPs foamed for $0.3 \mathrm{~s}$ and $180 \mathrm{~s}$ have average cell sizes of approximately $290 \mathrm{~nm}$ and $430 \mathrm{~nm}$, respectively. Clearly, in the foaming process nucleation is followed by rapid cell growth. Unfortunately, the experimental limitations do not allow us to capture the cell morphology right after nucleation, i.e. on a time scale faster than 0.3 seconds.

While most of the reports discussing heterogeneous nucleation with spherical particles ignore the position of the nucleating particles in the final foam morphology, we actually obtained valuable information from the position of the NPs after foaming. Namely, a striking difference in the morphologies captured in Figure 5 is the absence of NPs with $20 \mathrm{~nm}$ diameter at the polymer wall cell interface, while the 80 nanometer particles are clearly visible. In addition, the 12 and 40 nanometer $\mathrm{SiO}_{2}-\mathrm{OH}$ and $\mathrm{SiO}_{2}-\mathrm{PDMS}$ NPs were 
not visible at the cell wall surface either. Particles with a core diameter of $60 \mathrm{~nm}$ and larger at the cell wall were observed for both $\mathrm{SiO}_{2}-\mathrm{OH}$ and $\mathrm{SiO}_{2}-\mathrm{PDMS}$ NPs.

\subsubsection{Line tension effects on heterogeneous nucleation}

In this section we turn our attention to line tension effects to elucidate the observed differences and clarify its contribution to the free energy of cell nucleation. In Figures 4.6 and 4.7 we provide schematics of a proposed $\mathrm{CO}_{2}-\mathrm{NP}$ cell embryo and proposed steps of cell growth for different NP sizes.

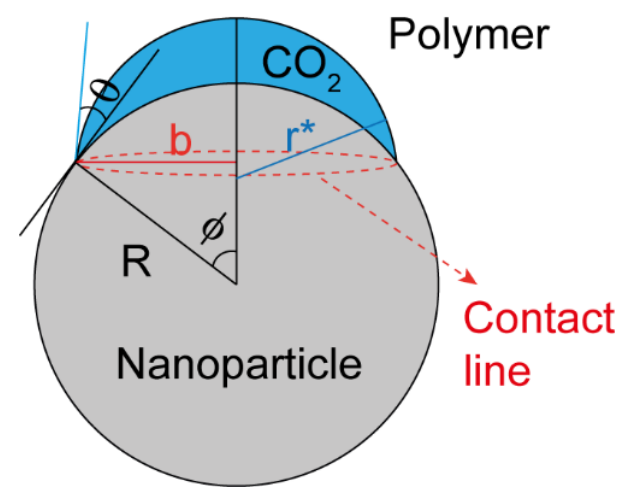

Figure 4.6 Sketch of the cross section of a proposed $\mathrm{CO}_{2}$ embryo with radius $\mathrm{r} *$ in equilibrium with the $\mathrm{CO}_{2}$ swollen polymer shell on a spherical seed particle with a radius $\mathrm{R}$. 


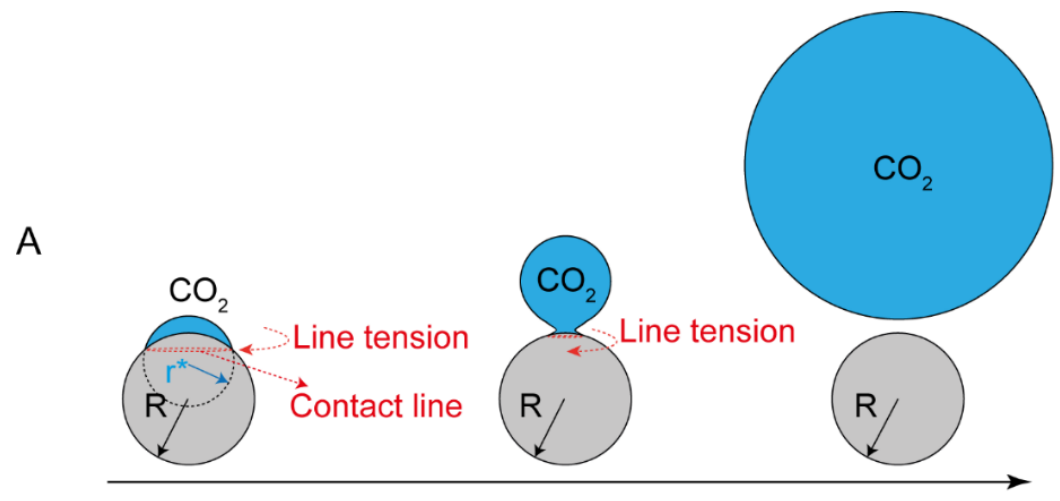

Cell nucleation

Cell growth and particle engulfment

B

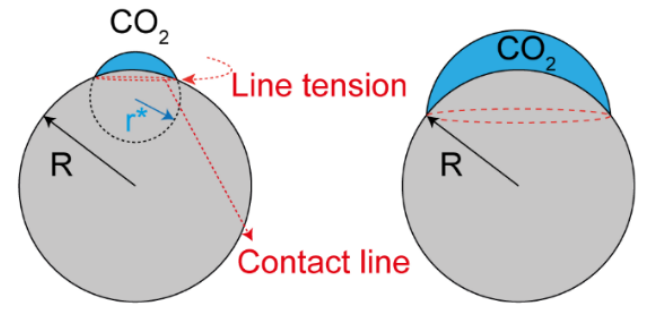

Cell nucleation

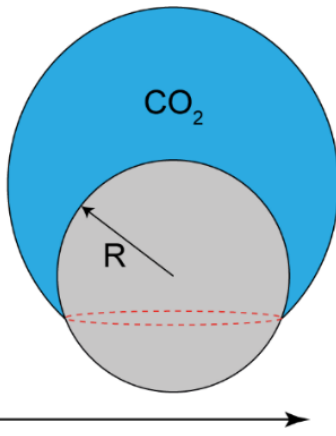

Cell growth

Figure 4.7 Scheme of cell nucleation and initial cell growth from NPs with a diameter below 40 $\mathrm{nm}$ (A) and above $60 \mathrm{~nm}(\mathrm{~B}) . \mathrm{R}$ and $\mathrm{r}^{*}$ denote the radius of NPs and critical $\mathrm{CO}_{2}$ embryo, respectively. The line tension of a curved three phase contact line acts along the tangents of the contact line circle.

When closer examining a particle during nucleation it is obvious that a three phase contact line exists (see Figure 4.6) and thus that a line tension $(\tau)$ in the order of $10^{-12}$ to $10^{-6} \mathrm{~N} \mathrm{~m}^{-1}$ needs to be considered as part of the nucleation free energy barrier. ${ }^{35,52}$ Following nucleation of a capped nucleus on a highly curved particle, ${ }^{53}$ a positive line tension eventually results in the engulfment of the NP in the polymer foam cell walls (see Figure 4.7A). Although the frequently used classical nucleation theory for foam cell nucleation considers particle curvature effects to some extent, ${ }^{54}$ it does not include line tension effects in the nucleation energy barrier. When considering line tension effects the nucleation energy barrier can be written according to equation $1.53,55$

$\Delta G^{*}=\frac{2 \pi r^{* 2} \sigma}{3} f(m, w)-\frac{\tau}{R \tan \varnothing} S+2 \pi R \tau \sin \emptyset$ 
Where $\Delta G^{*}$ is the nucleation energy barrier, $r^{*}$ is the critical radius of a $\mathrm{CO}_{2}$ embryo, $\sigma$ is the surface free energy between polymer and $\mathrm{CO}_{2}, \mathrm{R}$ is NP radius, $S$ is the surface area between the critical $\mathrm{CO}_{2}$ embryo and NP and $\tau$ is the three phase contact line tension. The surface area $S$ can be obtained from Eq. (2): ${ }^{.5}$

$S=2 \pi R^{2}(1-\cos \emptyset)$

The angle $\emptyset$ (see Figure 4.6) is given by ${ }^{56}$

$\tan \emptyset=r \sin \theta /(R-r \cos \theta)$

Where $\theta$ is the contact angle (see Figure 4.6).

$f(m, w)$ is the energy reduction factor according to the classical nucleation theory: ${ }^{27}$

$f(m, w)=1+\left(\frac{1-m w}{g}\right)^{3}+w^{3}\left[2-3\left(\frac{w-m}{g}\right)+\left(\frac{w-m}{g}\right)^{3}\right]+3 m w^{2}\left(\frac{w-m}{g}-1\right)$ Eq. (4)

In which,

$m=\cos \theta$

$\mathrm{w}=\mathrm{R} / r^{*}$

$r^{*}=\frac{2 \sigma}{\Delta P}$

$\mathrm{g}=\sqrt{1+w^{2}-2 m w}$

Here $\Delta \mathrm{P}$ is the pressure difference between the blowing agent saturation pressure and atmospheric pressure. ${ }^{27}$

Although the magnitude of the line tension is for numerous systems still under debate, it is agreed that for a positive line tension particles engulf when their size is smaller than the line tension length (i.e., $\mathrm{L}=\tau / \sigma$ ). Hence the engulfment of the smaller particles (i.e. a diameter below $40 \mathrm{~nm}$ ) following bubble nucleation as depicted in Figure 4.7A is in agreement with $\mathrm{L}$ being approximately $20 \mathrm{~nm}$ and a positive line tension of $\sim 0.42 \mathrm{nN}$ ( $\tau=\mathrm{L} \times \sigma$ and $\sigma$ is $\sim 21 \mathrm{mN} \mathrm{m}^{-1}$ for the foaming conditions used ${ }^{57}$ ). The critical bubble radius for our system is on the order of $3 \mathrm{~nm}$ to below $1 \mathrm{~nm}$ (see also equation 7). ${ }^{58}$ Figure 4.8 shows the calculated nucleation energy barrier as a function of the contact angle $(\theta)$ (Figure 4.8A), line tension (Figure 4.8B) and critical radius $\left(r^{*}\right)$ (Figure 4.8C) according to equation 1. 

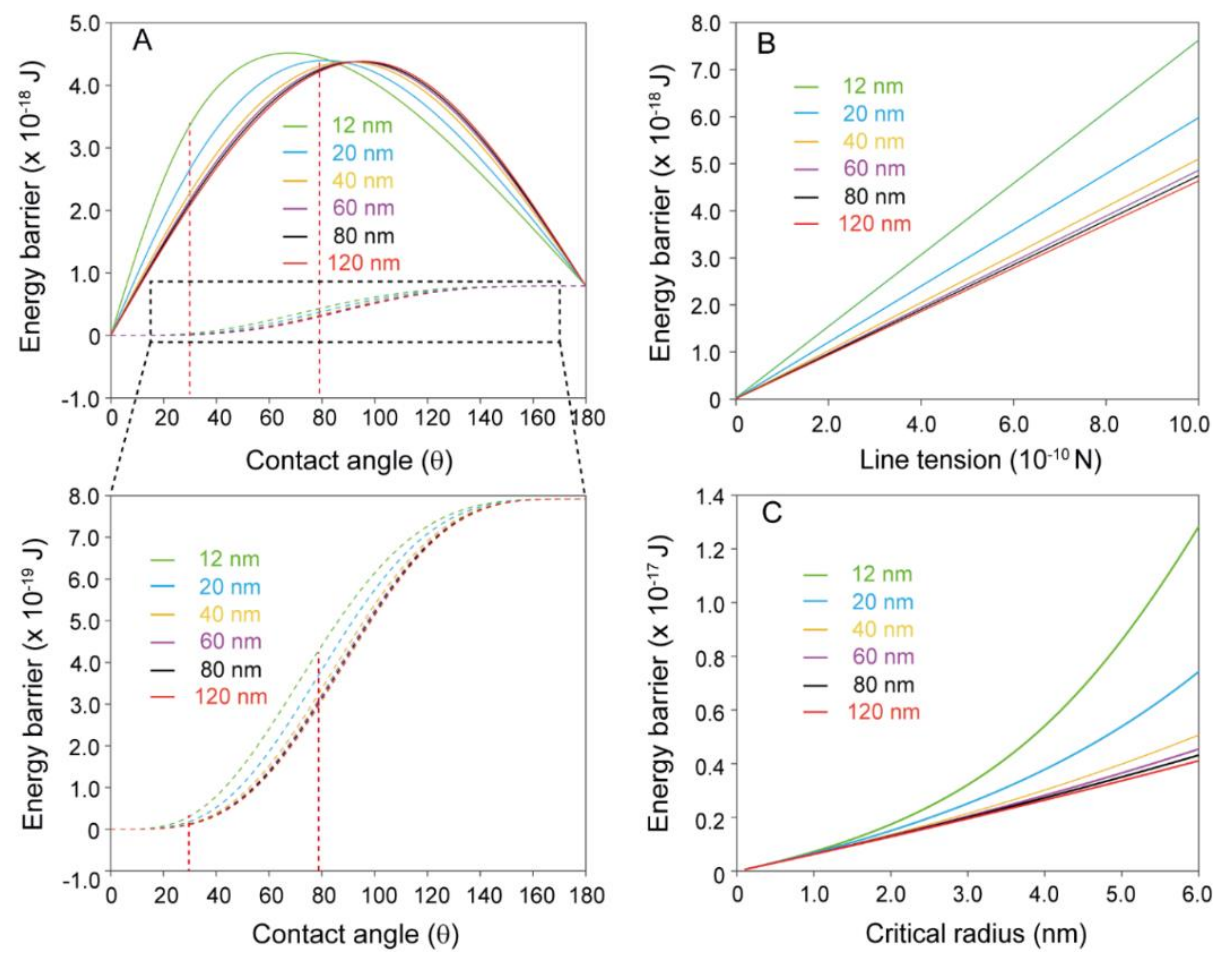

Figure 4.8 Nucleation energy barrier of the formation of a critical $\mathrm{CO}_{2}$ embryo on NPs as a function of the contact angle for a line tension of $0.42 \mathrm{nN}$ (solid lines) as well as without the contribution of line tension (dashed lines) (A). Nucleation energy barrier as a function of line tension for a contact angle of $28^{\circ}$ (B). The critical cell nucleation radius is $3 \mathrm{~nm}$ in (A and $\mathrm{B}$ ). The nucleation energy barrier as a function of the critical $\mathrm{CO}_{2}$ embryo radius for a line tension of $0.42 \mathrm{nN}$ and a contact angle of $28^{\circ}(\mathrm{C})$.

From Figure 4.8A it is clear that for a positive line tension of $0.42 \mathrm{nN}$, the nucleation energy barrier (shown by solid lines) is significantly increased compared to the barrier calculated according to the classical nucleation theory (shown by dashed lines). In addition, from high resolution SEM images, the $\mathrm{CO}_{2}$ swollen polymer - particle contact angles of bare and PDMS grafted particles as shown in Figure 4.9 were calculated according to: ${ }^{59}$

$\theta=\arccos \left(\frac{(H-R)}{R}\right)$

Where $\mathrm{R}$ is the NP radius and $\mathrm{H}$ is the height of NPs above the cell wall after foaming (see Figure 4.9).

The average apparent height of $80 \mathrm{~nm} \mathrm{SiO} 2-\mathrm{OH}$ and $\mathrm{SiO}_{2}-\mathrm{PDMS}$ above the cell wall were determined to be $\sim 47.6 \mathrm{~nm}$ and $\sim 75.4 \mathrm{~nm}$, respectively (without considering the 
PDMS shell thickness). Hence, according to Eq. (9) the contact angles were $\sim 28^{\circ}$ and $\sim$ $79^{\circ}$ for the $80 \mathrm{~nm}$ PDMS grafted NPs and bare NPs, respectively. We note that these contact angles are an approximation, since in situ determination of the contact angle during nucleation is not experimentally possible for our system. Thus we assume that these contact angles are representative. The lower contact angle for the 80 nanometer $\mathrm{SiO}_{2}$-PDMS particles compared to the bare NPs is ascribed to the energetically favorable interaction with the $\mathrm{CO}_{2}$ phase of the former, and explains also the higher nucleation efficiency. (We note that here identical contact angle values are assumed for NPs with the same surface chemistry.)
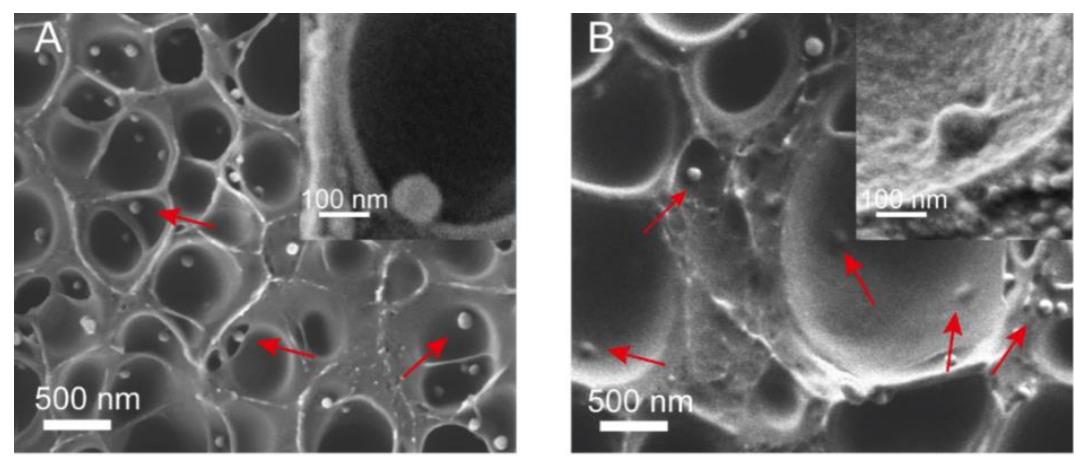

C

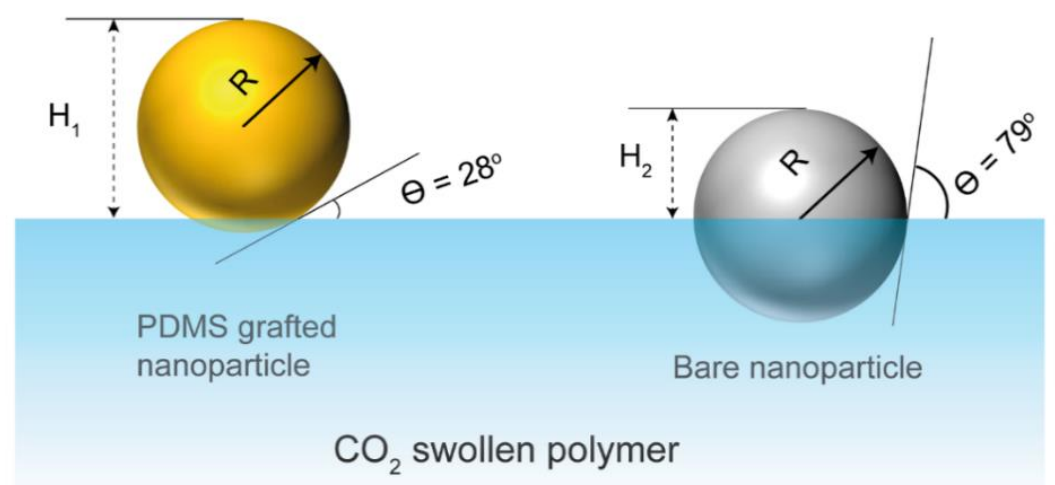

Figure 4.9 SEM images of $80 \mathrm{~nm} \mathrm{SiO}_{2}$-PDMS (A) and $\mathrm{SiO}_{2}-\mathrm{OH}$ (B) visible at the foam cell walls after $0.3 \mathrm{~s}$ foaming. The saturation pressure and foaming temperature are 55 bar and $40{ }^{\circ} \mathrm{C}$, respectively. The red arrows point at some NPs. In (C) a scheme for the position of the $80 \mathrm{~nm}$ particles at the cell wall after $0.3 \mathrm{~s}$ foaming is shown.

Thus from Figure 4.8 it is obvious that for the PDMS grafted NPs the nucleation energy is significantly affected by the contribution of line tension for the 12, 20 and 40 $\mathrm{nm}$ particles. For the smaller bare silica NPs this effect is less pronounced. The larger 
particles (> $60 \mathrm{~nm}$ ) have nearly identical nucleation energy barriers for a given contact angle. Overall, bare silica particles have a higher nucleation energy barrier compared to the grafted ones. These results are in good agreement with the nucleation efficiencies presented in Figure 4.4, which shows a sudden increase in nucleation efficiency for particles larger than 40 nanometer when the contact angle for nucleation is low (PDMS shell) while for the bare silica particles there is a more steady increase in the nucleation efficiency. We note that the $40 \mathrm{~nm}$ value used in equation (1) is a well-defined size, while in the foamed systems the particles have a size distribution (see Table 4.1). This may imply that for a given particle size distribution with a mean value on the order of few tens of nanometers the smaller particles are not that efficient for nucleation when compared with the larger ones. The model used to calculate the free energy barrier for cell nucleation (i.e. equation 1) does not take this effect into account. In addition, it is not difficult to imagine that for increasing line tension values and increasing critical nucleation radii the nucleation energy barrier increases, as well (shown in Figure 4.8B and C). Interesting to mention here is that $\mathrm{CO}_{2}$ philic block copolymer based heterogeneous phases belong to promising nucleation agents, as well. ${ }^{8,60-61}$ In fact it was reported by Rodriguez-Perez and coworkers $^{61}$, for poly(methylmethacrylate)-co-poly(butyl acrylate)-copoly(methylmethacrylate) block copolymer domains in PMMA a nucleation efficiency close to unity was obtained. This high nucleation efficiency could be explained by the fact that depending on the nucleation point in these phase separated morphologies and subsequent cell growth these block copolymer domains do not experience a line tension.

The smallest PDMS grafted particles were still favorable compared to their bare counterparts, showing once more the effectiveness of a $\mathrm{CO}_{2}$ philic, low surface energy shell grafted to a heterogeneous nucleation agent. Moreover, it is demonstrated that particle size is an important parameter to control and optimize foaming when heterogeneous nucleation is favorable over homogenous nucleation. For instance, if one would increase the $\mathrm{CO}_{2}$ saturation pressure, the surface energy of the $\mathrm{CO}_{2}$ swollen PMMA would decrease ${ }^{58}$ resulting in a larger line tension length. In fact, following $\mathrm{CO}_{2}$ saturation at 300 bar and subsequent foaming for 0.3 seconds at $40{ }^{\circ} \mathrm{C}$ resulted in the nearly complete engulfment of the $60 \mathrm{~nm}$ and $80 \mathrm{~nm}$ bare and PDMS grafted NPs as is shown in Figure 4.10, indicating an increased line tension length. This is in line with the observed decreased nucleation efficiency, i.e. $<<0.1$, for particles with a silica (core) diameter below $80 \mathrm{~nm}$ at foaming conditions utilizing a $\mathrm{CO}_{2}$ saturation pressure of 300 bar. 
Silica Assisted Nucleation of Polymer Foam Cells with Nanoscopic Dimensions: Impact of Particle Size and Surface Functionality
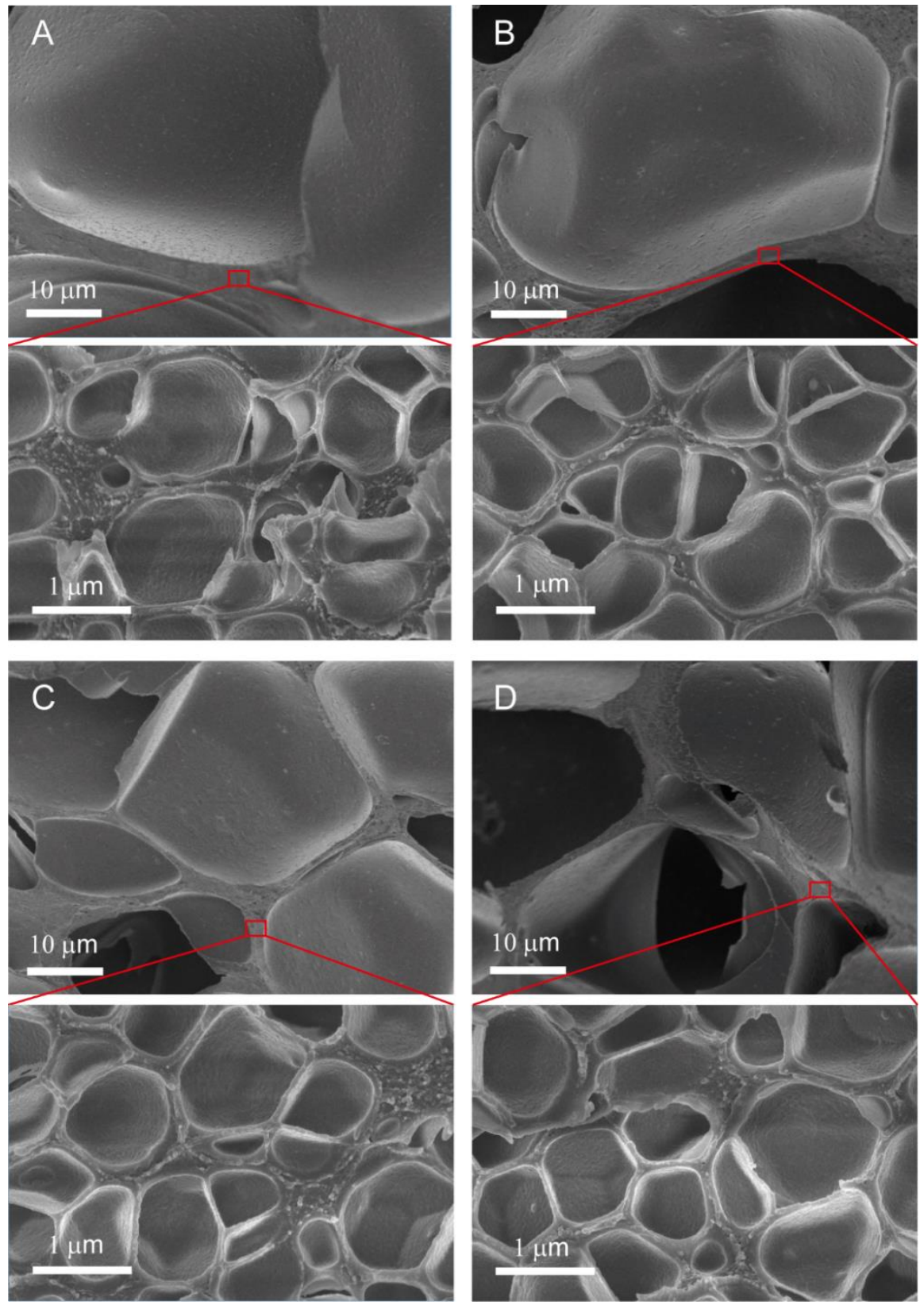

Figure 4.10 SEM images of cross sectioned PMMA foams containing untreated and core shell silica naoparticles prepared after saturation with 300 bar $\mathrm{CO}_{2}$. The foaming time and temperature were 0.3 seconds and $40{ }^{\circ} \mathrm{C}$, respectively. From figure 4.10 it is obvious that a bimodal cell size distrubtion was obtained, this points towards the presence of homogenous nucleation. 
To what extend line tension contributes to the reduced nucleation efficiency at these foaming conditions remains to be seen. The critical bubble radius for PMMA films saturated with 300 bar $\mathrm{CO}_{2}$ is reduced to values below $1 \mathrm{~nm} .{ }^{58}$ This means that for these smaller capped nuclei on the surface of the NPs (diameter $>12 \mathrm{~nm}$ ) the three phase contact line is diminished and as a consequence its contribution to the heterogeneous nucleation energy barrier is reduced as well. In addition, the higher the pressure drop the more favorable homogenous nucleation is compared to the heterogeneous process. ${ }^{14}$ Interestingly, we observed evidence for homogenous nucleation in parts of the cell walls of PMMA foams prepared with a saturation pressure of 300 bar, which is in agreement with the observed reduced nucleation efficiency, as well. This means that following foaming from higher saturation pressures the resulting smaller critical bubble radius decreases the energy penalty of the line tension for nucleation while homogenous nucleation becomes more favorable. ${ }^{54}$ This limits the foam processing window where particles are effective as nucleation agents. Under such conditions relatively large particles are needed compared to the targeted foam cell sizes. This means that new strategies and particle designs must be developed that increase the nucleation efficiency and result in foaming of nanocellular PMMA foams with cell densities exceeding $10^{15}$ cells $\mathrm{cm}^{-3}$.

\subsection{Conclusion}

PDMS decorated and bare silica NPs with (core) diameters between 12 to 120 nanometer were exploited as heterogeneous nucleation sites in $\mathrm{CO}_{2}$ blown PMMA nanocellular batch foaming. NPs grafted with a $\sim 6 \mathrm{~nm}$ thick PDMS shell were found to be more efficient as nucleation agents compared to their bare counterparts. The highest nucleation efficiency obtained was $\sim 0.5$ and the optimum core diameter of PDMS grafted NPs for cell nucleation is around $80 \mathrm{~nm}$. The complete engulfment of particles with a (core) diameter below 40 nanometer in the cell wall corresponds to a line tension of $0.42 \mathrm{nN}$. It is shown that line tensions of this order of magnitude results in a significant increase in the heterogeneous nucleation free energy barrier. As a consequence the smallest NPs used were not as effective as expected. At higher $\mathrm{CO}_{2}$ saturation pressures (300 bar) the line tension length increased such that particles up to 80 nanometer were nearly entirely engulfed as well. The smaller critical bubble radii for these foaming conditions results in a significant decreased contribution of line tension to the nucleation free energy. Thus the observed decreased nucleation efficiency for these foaming conditions is ascribed to homogenous nucleation becoming more favorable at the expense of heterogeneous nucleation. Overall it is shown that line tension contributes to the 
nucleation energy barrier in foaming of viscoelastic media and that as a consequence it affects the nucleation efficiency of highly curved NPs in the foam processing window where heterogeneous nucleation is favorable. The deeper fundamental insight obtained emphasizes the need for the development of new foaming strategies and particle designs that are expected to further enhance the nucleation efficiency of NPs in polymer nanocellular foaming.

\subsection{Materials and methods}

Materials. Tetraethyl orthosilicate (TEOS) $\geq 99.0 \%$, 2-propanol $99.5 \%$ were purchased from Aldrich (Milwaukee, WI, USA). (3-Aminopropyl)-triethoxysilane (APTES) 99\%, hydrocholoric acid 37\% and ammonium hydroxide solution 28 - 30\% were purchased from Sigma-Aldrich (St. Louis, MO, USA). Poly(dimethylsiloxane) monoglycidyl ether terminated (PDMS-G) $\left(\mathrm{Mw}=1,000 \mathrm{~g} \cdot \mathrm{mol}^{-1}\right.$ and 5,000 $\left.\mathrm{g} \cdot \mathrm{mol}^{-1}\right)$ were purchased from Gelest (Morrisville, PA, USA). N-(2-aminoethyl-3aminopropyl)methyldimethoxysilane (Dynasylan 1411) $\geq 99.0 \%$ was purchased from Evonik (Marl, Germany). PMMA was bought from Arkema (VM100, i.e. a PMMA-coEA polymer, $\rho=1.18 \mathrm{~g} \mathrm{~cm}^{-3}$ ) (La Garenne-Colombes, France). NPs with diameters of 12 nm (Bindzil 40/220), $20 \mathrm{~nm}$ (Bindzil 40/130) and $60 \mathrm{~nm}$ (Levasil 50/50) were a gift from AkzoNobel (Bohus, Sweden). These particles were dispersed in aqueous solution and have surface exposed hydroxyl groups on the surface as received. Absolute Tetrahydrofuran (THF) was purchased from Biosolve (Valkenswaard, the Netherlands). Ethanol absolute for analysis was purchased from Merck (Darmstadt, Germany). Milli-Q water was produced by a Millipore Synergy system (Billerica, MA, USA). Unless otherwise mentioned all other chemicals were used as received.

Stöber silica NPs preparation. To prepare Stöber silica NPs $\left(\mathrm{SiO}_{2}\right)$ with a diameter of $\sim 80 \mathrm{~nm}, 168 \mathrm{ml}$ ethanol was mixed with $28 \mathrm{ml}$ Milli-Q water and $30 \mathrm{ml}$ TEOS in the presence of $2 \mathrm{ml}$ ammonium hydroxide while stirring at $500 \mathrm{rpm}$ at room temperature. After 1.5 hours the $\mathrm{SiO}_{2}$ dispersion was centrifuged at $10,000 \mathrm{rpm}$ for $30 \mathrm{~min}$. Subsequently the collected $\mathrm{SiO}_{2}$ was redispersed in ethanol and centrifuged again. This washing step was repeated 2 more times followed by vacuum drying the collected $\mathrm{SiO}_{2}$ NPs at room temperature for 12 hours. To synthesize the $40 \mathrm{~nm}$ particles $84 \mathrm{ml}$ of ethanol was mixed with $14 \mathrm{ml}$ Milli-Q water and $15 \mathrm{ml}$ TEOS in the presence of $0.75 \mathrm{ml}$ ammonium hydroxide in a $250 \mathrm{ml}$ round bottom flask while stirring at $500 \mathrm{rpm}$. The reaction was conducted for 1.5 hours at room temperature. To synthesize the $120 \mathrm{~nm}$ particles $100 \mathrm{ml}$ ethanol was mixed with $8 \mathrm{ml}$ Milli-Q water and $5 \mathrm{ml}$ TEOS in a round 
bottom flask stirring at $500 \mathrm{rpm}$ and subsequently $5 \mathrm{ml}$ of ammonium hydroxide was added and reacted for 3 hours at $50{ }^{\circ} \mathrm{C}$. The collecting, washing and drying step of NPs were the same as described for NPs of $80 \mathrm{~nm}$.

Hydrolysis. To introduce silanol groups on the surface of the prepared $\mathrm{SiO}_{2} \mathrm{NPs}$, the particles were redispersed in Milli-Q water by sonication (BRANSON 2510, Canada) for 1 hour. Subsequently, hydrochloric acid was added to the dispersion while stirring at 500 rpm until the $\mathrm{pH}$ of the solution reached a value of approximately 1 . After 4 hours the dispersion was centrifuged at 10,000 rpm for $30 \mathrm{~min}$. The collected NPs were redispersed in Milli-Q water and centrifuged again. This washing step was repeated 2 more times followed by drying the silanol functional $\mathrm{NPs}\left(\mathrm{SiO}_{2}-\mathrm{OH}\right)$ in vacuum at room temperature for 12 hours.

Amino-functionalization. $3.0 \mathrm{~g} \mathrm{SiO}_{2}-\mathrm{OH}$ NPs were redispersed in $100 \mathrm{ml}$ ethanol followed by the addition of $15 \mathrm{ml}$ APTES. The dispersion was left to stir at $500 \mathrm{rpm}$ at room temperature for 17 hours. The APTES functionalized NPs $\left(\mathrm{SiO}_{2}-\mathrm{NH}_{2}\right)$ were collected by centrifugation at 10,000 rpm for $30 \mathrm{~min}$ and redispersed in ethanol and centrifuged again. This washing step was repeated 2 more times followed by drying the collected $\mathrm{SiO}_{2}-\mathrm{NH}_{2} \mathrm{NPs}$ in vacuum at room temperature for 12 hours.

The Bindzil 40/220, Bindzil 40/130 and Levasil 50/50 particles with diameters of 12, 20 and 60 nanometer, respectively, were functionalized with Dynasylan 1411 in order to render their surface amino functional. Derivatization with APTES resulted in irreversible gelation. In a typical procedure $7 \mathrm{ml}$ Dynasylan 1411 was added to $10 \mathrm{ml}$ NP suspension. The dispersion was left to stir at $500 \mathrm{rpm}$ at room temperature for 17 hours. The aminofunctionalized NPs $\left(\mathrm{SiO}_{2}-\mathrm{NH}_{2}\right)$ with a diameter of $12 \mathrm{~nm}$ and $20 \mathrm{~nm}$ were collected by the addition of $5 \mathrm{ml}$ calcium chloride $\left(1 \mathrm{~mol} \mathrm{~L}^{-1}\right)$ that induces reversible aggregation of the NPs followed by centrifugation at $10,000 \mathrm{rpm}$ for $30 \mathrm{~min}$. The particles were redispersed in ethanol. This washing step was repeated 2 more times followed by drying the collected $\mathrm{SiO}_{2}-\mathrm{NH}_{2}$ NPs in vacuum at room temperature for 12 hours. The Levasil 50/50 NPs were collected by repeated centrifugation as earlier described.

Grafting to of PDMS-G to silica NPs. $1.0 \mathrm{~g}$ of $\mathrm{SiO}_{2}-\mathrm{NH}_{2}$ NPs were redispersed in 20.5 $\mathrm{ml}$ THF and $15 \mathrm{~g}$ PDMS-G while stirring at $500 \mathrm{rpm}$ for 1 hour followed by sonication for 1 hour. Subsequently, THF was removed by rotary evaporation and the resulting silica NP dispersion in PDMS-G was immersed in an oil bath thermostated at $80{ }^{\circ} \mathrm{C}$ for $17 \mathrm{~h}$. Following cooling to room temperature the reaction mixture was washed with THF and centrifuged at 10,000 rpm for $30 \mathrm{~min}$. This washing step was repeated 2 more times, followed by vacuum drying the $\mathrm{SiO}_{2}$-PDMS at room temperature for 12 hours.

Nanocomposite preparation. Nanocomposites were prepared by dispersing the same amount (functional) silica NPs $\left(2.3 \times 10^{13} \mathrm{~cm}^{-3}\right)$ in PMMA with a mini extruder (DSM 
Xplore, the Netherlands). In a typical procedure a dry blend of NPs and PMMA was fed to the extruder followed by internal mixing for 3 minutes. The barrel temperature was set to $155^{\circ} \mathrm{C}$ and the screw speed was $100 \mathrm{rpm}$. Subsequently the PMMA nanocomposite was collected and left to cool to room temperature.

Film preparation. A hot press (Fortijne, the Netherlands) was used to press $\sim 0.2 \mathrm{~mm}$ thick nanocomposite films in a mold $(4 \times 3 \mathrm{~cm})$. The press temperature, applied load and press time were $180^{\circ} \mathrm{C}, 250 \mathrm{KN}$ and 10 minutes, respectively.

Batch foaming of nanocomposite films. The nanocomposite PMMA films were saturated with $\mathrm{CO}_{2}$ (55 bar) in an autoclave for 4 hours at room temperature followed by rapid depressurization. Subsequently, the PMMA nanocomposite films were immersed in a water bath thermostated at $40{ }^{\circ} \mathrm{C}$ for different foaming time $(0.3 \mathrm{~s}$ and $180 \mathrm{~s})$ after which the samples were quenched in an ice bath for 30 minutes. The samples were left to dry in air for at least 12 hours prior to further analysis. For a scheme of the used foaming setup see Chapter 3 .

Fourier transform infrared (FTIR) spectroscopy. FTIR spectra were collected with a Bruker ALPHA single attenuated total reflection (ATR) FTIR Spectrometer equipped with an ATR single reflection crystal (Bruker Optic GmbH, Ettlingen, Germany). The spectra were collected in the range of $400-4000 \mathrm{~cm}^{-1}$ (spectral solution of $4 \mathrm{~cm}^{-1}, 128$ scans). Background spectra were recorded against air.

Thermo gravimetric analysis (TGA). The weight loss of the (modified) particles as a function of temperature was measured with a TGA400 (PerkinElmer, Inc., Waltham, MA, USA). A sample weighing $\sim 5$ to $10 \mathrm{mg}$ was loaded into the platinum pan and the temperature was set to $50{ }^{\circ} \mathrm{C}$ to stabilize. Subsequently the sample was heated to $900{ }^{\circ} \mathrm{C}$ at a heating rate of $20{ }^{\circ} \mathrm{C} \mathrm{min}^{-1}$. The applied air flow was $20 \mathrm{ml} \mathrm{min}$.

Transmission electron microscopy (TEM). To investigate the core-shell structure of the functionalized NPs a FEI/Philips CM300 transmission electron microscope (Eindhoven, the Netherlands) was used. Diluted particle dispersions in THF were deposited on the carbon side of a carbon/copper grid (HC200-Cu) (EMS, Germany). Images were obtained in the bright field mode with a $300 \mathrm{kV}$ acceleration voltage.

Scanning electron microscopy (SEM). To investigate the morphology of the foamed nanocomposite films a high resolution scanning electron microscope (JEOL Field Emission JSM-633OF, JEOL Benelux, Nieuw-Vennep, the Netherlands) was used. The typically used electron acceleration voltage was $5 \mathrm{keV}$. Prior to analysis the nanocomposite foams were freeze fractured after cooling in liquid nitrogen for 10 minutes. 
Calculation of cell density and nucleation efficiency. The cell size and cell density were obtained by analyzing the SEM cross sectional images. Cell density $\left(N_{v}\right)$ of the foams was calculated according to Kumar's theoretical approximation. ${ }^{62}$ No direct measurements of cell dimensions over the micrograph are required in this method, only the micrograph area $(A)$ and the total number of cells $(n)$ contained therein are measured. Together with the magnification factor of the micrograph $(M), N_{v}$ can be calculated according to equation 10 .

$N_{v}=\left[\frac{\left(n M^{2}\right)}{A}\right]^{3 / 2}$

Eq. (10)

By combining $N_{V}$ with the volume expansion ratio $(B)$ of nanocomposite films after foaming, the cell numbers per $\mathrm{cm}^{3}$ of unfoamed materials $(N)$ can be calculated according to equation 2 .

$N=N_{v} * B$

Eq. (11)

The mentioned cell density in the main text are all refer to $N$. In addition, the nucleation efficiency $(f)$ of NPs during foaming can be calculated as:

$f=N / C$

Eq. (12)

Where $C$ is the number of NPs per $\mathrm{cm}^{3}$ (i.e., $2.3 \times 10^{13}$ ) used for foaming.

\section{References}

[1] Eaves, D. Handbook of polymer foams. David E., Ed 2004, 1-8.

[2] Liu, S.; Duvigneau, J.; Vancso, G. J. Nanocellular polymer foams as promising high performance thermal insulation materials. European polymer journal 2015, 65, 33-45.

[3] Costeux, S. $\mathrm{CO}_{2}$-blown nanocellular foams. Journal of Applied Polymer Science 2014, 131, 41293-41308.

[4] Notario, B.; Pinto, J.; Solorzano, E.; de Saja, J. A.; Dumon, M.; Rodríguez-Pérez, M. A. Experimental validation of the Knudsen effect in nanocellular polymeric foams. Polymer 2015, 56, 57-67.

[5] Forest, C.; Chaumont, P.; Cassagnau, P.; Swoboda, B.; Sonntag, P. Polymer nano-foams for insulating applications prepared from $\mathrm{CO}_{2}$ foaming. Progress in Polymer Science 2015, 41, 122-145. 
[6] Ji, G.; Zhai, W.; Lin, D.; Ren, Q.; Zheng, W.; Jung, D. W. Microcellular Foaming of Poly(lactic acid)/Silica Nanocomposites in Compressed $\mathrm{CO}_{2}$ : Critical Influence of Crystallite Size on Cell Morphology and Foam Expansion. Industrial \& Engineering Chemistry Research 2013, 52, 6390-6398.

[7] Yu, J.; Song, L.; Chen, F.; Fan, P.; Sun, L.; Zhong, M.; Yang, J. Preparation of polymer foams with a gradient of cell size: further exploring the nucleation effect of porous inorganic materials in polymer foaming. Materials Today Communications 2016, 9, 1-6.

[8] Yokoyama, H.; Sugiyama, K. Nanocellular structures in block copolymers with $\mathrm{CO}_{2}$-philic blocks using $\mathrm{CO}_{2}$ as a blowing agent: crossover from micro- to nanocellular structures with depressurization temperature. Macromolecules 2005, 38, 10516-10522.

[9] Tomasko, D. L.; Li, H.; Liu, D.; Han, X.; Wingert, M. J.; Lee, L. J.; Koelling, K. W. A review of $\mathrm{CO}_{2}$ applications in the processing of polymers. Industrial \& Engineering Chemistry Research 2003, 42, 6431-6456.

[10] Siripurapu, S.; DeSimone, J. M.; Khan, S. A.; Spontak, R. J. Controlled foaming of polymer films through restricted surface diffusion and the addition of nanosilica particles or $\mathrm{CO}_{2}$ philic surfactants. Macromolecules 2005, 38, 2271-2280.

[11] Krause, B.; Mettinkhof, R.; van der Vegt, N. F. A.; Wessling, M. Microcellular foaming of amorphous high-Tg polymers using carbon dioxide. Macromolecules 2001, 34, 874-884.

[12] Siripurapu, S.; DeSimone, J. M.; Khan, S. A.; Spontak, R. J. Low-temperature, surfacemediated foaming of polymer films. Advanced Materials 2004, 16, 989-994.

[13] Liu, S.; Zoetebier, B.; Hulsman, L.; Zhang, Y.; Duvigneau, J.; Vancso, G. J. Nanocellular polymer foams nucleated by core-shell nanoparticles. Polymer 2016, 104, 22-30.

[14] Tammaro, D.; Astarita, A.; Di Maio, E.; Iannace, S. Polystyrene foaming at high pressure drop rates. Industrial \& Engineering Chemistry Research 2016, 55, 5696-5701.

[15] Lee, Y. S.; Park, N. H.; Yoon, H. S. Dynamic mechanical characteristics of expanded polypropylene foams. Journal of Cellular Plastics 2010, 46, 43-55.

[16] Notario, B.; Pinto, J.; Rodriguez-Perez, M. Nanoporous polymeric materials: a new class of materials with enhanced properties. Progress in Materials Science 2016, 78, 93-139.

[17] Costeux, S.; Zhu, L. Low density thermoplastic nanofoams nucleated by nanoparticles. Polymer 2013, 54, 2785-2795.

[18] Costeux, S.; Bunker, S. P.; Jeon, H. K. Homogeneous nanocellular foams from styrenicacrylic polymer blends. Journal of Materials Research 2013, 28, 2351-2365.

[19] Liao, Z.-E.; Yeh, S.-K.; Chu, C.-C.; Tseng, T.-W. Critical parameters of generating PMMA nanocellular foam, Annu. Tech. Conf.-Soc. Plast. Eng, 2016, 1773-1778.

[20] Oxtoby, D. W. Density functional methods in the statistical mechanics of materials. Annual Review of Materials Research 2002, 32, 39-52.

[21] Lee, L. J.; Zeng, C.; Cao, X.; Han, X.; Shen, J.; Xu, G. Polymer nanocomposite foams. Composites Science and Technology 2005, 65, 2344-2363.

[22] Zeng, C.; Han, X.; Lee, L. J.; Koelling, K. W.; Tomasko, D. L. Polymer-clay nanocomposite foams prepared using carbon dioxide. Advanced Materials 2003, 15, 1743-1747. 
[23] Zhang, H.; Yan, Q.; Zheng, W.; He, Z.; Yu, Z. Tough graphene polymer microcellular foams for electromagnetic interference shielding. ACS Applied Materials \& Interfaces 2011, 3, 918 924.

[24] Zhai, W.; Yu, J.; Wu, L.; Ma, W.; He, J. Heterogeneous nucleation uniformizing cell size distribution in microcellular nanocomposites foams. Polymer 2006, 47, 7580-7589.

[25] Shen, J.; Zeng, C.; Lee, L. J. Synthesis of polystyrene-carbon nanofibers nanocomposite foams. Polymer 2005, 46, 5218-5224.

[26] Yang, Y.; Gupta, M. C.; Dudley, K. L.; Lawrence, R. W. Novel carbon nanotube-polystyrene foam composites for electromagnetic interference shielding. Nano Letters 2005, 5, 21312134.

[27] Goren, K.; Chen, L.; Schadler, L. S.; Ozisik, R. Influence of nanoparticle surface chemistry and size on supercritical carbon dioxide processed nanocomposite foam morphology. The Journal of Supercritical Fluids 2010, 51, 420-427.

[28] Spitael, P.; Macosko, C. W.; McClurg, R. B. Block copolymer micelles for nucleation of microcellular thermoplastic foams. Macromolecules 2004, 37, 6874-6882.

[29] Ruiz, J. A. R.; Pedros, M.; Tallon, J.-M.; Dumon, M. Micro and nano cellular amorphous polymers (PMMA, PS) in supercritical $\mathrm{CO}_{2}$ assisted by nanostructured $\mathrm{CO}_{2}$-philic block copolymers-one step foaming process. The Journal of Supercritical Fluids 2011, 58, 168 176.

[30] Li, L.; Nemoto, T.; Sugiyama, K.; Yokoyama, $\mathrm{H} . \mathrm{CO}_{2}$ foaming in thin films of block copolymer containing fluorinated blocks. Macromolecules 2006, 39, 4746-4755.

[31] Shinkai, T.; Sugiyama, K.; Ito, K.; Yokoyama, H. Nanoporous fabrication of block copolymers via carbon dioxide swelling: difference between $\mathrm{CO}_{2}$-swollen and nanoporous block copolymers. Polymer 2016, 100, 19-27.

[32] Yang, J.; Sang, Y.; Chen, F.; Fei, Z.; Zhong, M. Synthesis of silica particles grafted with poly (ionic liquid) and their nucleation effect on microcellular foaming of polystyrene using supercritical carbon dioxide. The Journal of Supercritical Fluids 2012, 62, 197-203.

[33] Guo, H.; Nicolae, A.; Kumar, V. Solid-state poly (methyl methacrylate)(PMMA) nanofoams. Part II: low-temperature solid-state process space using $\mathrm{CO}_{2}$ and the resulting morphologies. Polymer 2015, 70, 231-241.

[34] Notario, B.; Pinto, J.; Rodríguez-Pérez, M. Towards a new generation of polymeric foams: PMMA nanocellular foams with enhanced physical properties. Polymer 2015, 63, 116-126.

[35] McBride, S. P.; Law, B. M. Influence of Line Tension on Spherical Colloidal Particles at Liquid-Vapor Interfaces. Physical Review Letters 2012, 109, 196101.

[36] Style, R. W.; Hyland, C.; Boltyanskiy, R.; Wettlaufer, J. S.; Dufresne, E. R. Surface tension and contact with soft elastic solids. Nature Communications 2013, 4, 2728.

[37] Winkler, P.; McGraw, R.; Bauer, P.; Rentenberger, C.; Wagner, P. Direct determination of three-phase contact line properties on nearly molecular scale. Scientific Reports 2016, 6, 26111.

[38] Asawapirom, U.; Bulut, F.; Farrell, T.; Gadermaier, C.; Gamerith, S.; Güntner, R.; Kietzke, T.; Patil, S.; Piok, T.; Montenegro, R. Materials for polymer electronics applications 
semiconducting polymer thin films and nanoparticles. Macromolecular Symposia 2004, 212, 83-91.

[39] Shipway, A. N.; Katz, E.; Willner, I. Nanoparticle arrays on surfaces for electronic, optical, and sensor applications. ChemPhysChem 2000, 1, 18-52.

[40] Sierra-Martin, B.; Fernandez-Barbero, A. Inorganic/polymer hybrid nanoparticles for sensing applications. Advances in Colloid and Interface Science 2016, 233, 25-37.

[41] Rose, S.; Prevoteau, A.; Elzière, P.; Hourdet, D.; Marcellan, A.; Leibler, L. Nanoparticle solutions as adhesives for gels and biological tissues. Nature 2014, 505, 382-385.

[42] Tan, W. S.; Du, Y.; Luna, L. E.; Khitass, Y.; Cohen, R. E.; Rubner, M. F. Templated nanopores for robust functional surface porosity in poly (methyl methacrylate). Langmuir 2012, 28, 13496-13502.

[43] Stöber, W.; Fink, A.; Bohn, E. Controlled growth of monodisperse silica spheres in the micron size range. Journal of Colloid and Interface Science 1968, 26, 62-69.

[44] Musić, S.; Filipović-Vinceković, N.; Sekovanić, L. Precipitation of amorphous $\mathrm{SiO}_{2}$ particles and their properties. Brazilian Journal of Chemical Engineering 2011, 28, 89-94.

[45] Alesker, M.; Heller, A.; Malik, Z.; Makarovsky, I.; Lellouche, J.-P. Hybrid silica nanoparticles traceable by fluorescence and FT-IR spectroscopy: preparation, characterization and preliminary biological studies. Journal of Materials Chemistry 2011, 21, 10883-10893.

[46] Kim, H.; Kim, H.-G.; Kim, S.; Kim, S. S. PDMS-silica composite membranes with silane coupling for propylene separation. Journal of Membrane Science 2009, 344, 211-218.

[47] Chen, L.; Ozisik, R.; Schadler, L. S. The influence of carbon nanotube aspect ratio on the foam morphology of MWNT/PMMA nanocomposite foams. Polymer 2010, 51, 2368-2375.

[48] Miller, M. B.; Luebke, D. R.; Enick, R. M. $\mathrm{CO}_{2}$-philic oligomers as novel solvents for $\mathrm{CO}_{2}$ absorption. Energy \& Fuels 2010, 24, 6214-6219.

[49] Wang, H.; Li, W. Selective ultrasonic foaming of polymer for biomedical applications. Journal of Manufacturing Science and Engineering 2008, 130, 0210041-0210049.

[50] Bärwinkel, S.; Bahrami, R.; Löbling, T. I.; Schmalz, H.; Müller, A. H. E.; Altstädt, V. Polymer foams made of immiscible polymer blends compatibilized by Janus particles - Effect of compatibilization on foam morphology. Advanced Engineering Materials 2016, 18, 814825 .

[51] Gong, P.; Ohshima, M. Effect of interfacial tension on the cell structure of poly (methyl methacrylate)/bisphenol A polycarbonate blends foamed with $\mathrm{CO}_{2}$. Journal of Applied Polymer Science 2014, 131,39228.

[52] Bresme, F.; Quirke, N. Computer simulation study of the wetting behavior and line tensions of nanometer size particulates at a liquid-vapor interface. Physical Review Letters 1998, 80, 3791-3794.

[53] Hienola, A. I.; Winkler, P. M.; Wagner, P. E.; Vehkamäki, H.; Lauri, A.; Napari, I.; Kulmala, M. Estimation of line tension and contact angle from heterogeneous nucleation experimental data. The Journal of Chemical Physics 2007, 126, 094705. 
[54] Fletcher, N. Size effect in heterogeneous nucleation. The Journal of Chemical Physics 1958, $29,572-576$.

[55] Lazaridis, M. The effects of surface diffusion and line tension on the mechanism of heterogeneous nucleation. Journal of Colloid and Interface Science 1993, 155, 386-391.

[56] Iwamatsu, M. Line-tension-induced scenario of heterogeneous nucleation on a spherical substrate and in a spherical cavity. The Journal of Chemical Physics 2015, 143, 014701.

[57] Goel, S. K.; Beckman, E. J. Generation of microcellular polymeric foams using supercritical carbon dioxide. I: effect of pressure and temperature on nucleation. Polymer Engineering \& Science 1994, 34, 1137-1147.

[58] Wang, L.; Zhou, H.; Wang, X.; Mi, J. Evaluation of nanoparticle effect on bubble nucleation in polymer foaming. The Journal of Physical Chemistry C 2016, 120, 26841-26851.

[59] Arnaudov, L. N.; Cayre, O. J.; Stuart, M. A. C.; Stoyanov, S. D.; Paunov, V. N. Measuring the three-phase contact angle of nanoparticles at fluid interfaces. Physical Chemistry Chemical Physics 2010, 12, 328-331.

[60] Ruiz, J. A. R.; Cloutet, E.; Dumon, M. Investigation of the nanocellular foaming of polystyrene in supercritical $\mathrm{CO}_{2}$ by adding a $\mathrm{CO}_{2}$-philic perfluorinated block copolymer. Journal of Applied Polymer Science 2012, 126, 38-45.

[61] Pinto, J.; Dumon, M.; Pedros, M.; Reglero, J.; Rodriguez-Perez, M. A. Nanocellular $\mathrm{CO}_{2}$ foaming of PMMA assisted by block copolymer nanostructuration. Chemical Engineering Journal 2014, 243, 428-435.

[62] Kumar, V.; Suh, N. P. A process for making microcellular thermoplastic parts. Polymer Engineering \& Science 1990, 30, 1323-1329. 


\section{Transition from Adhesion to Engulfment of Nanoparticles at the Melt-polymer Interface}
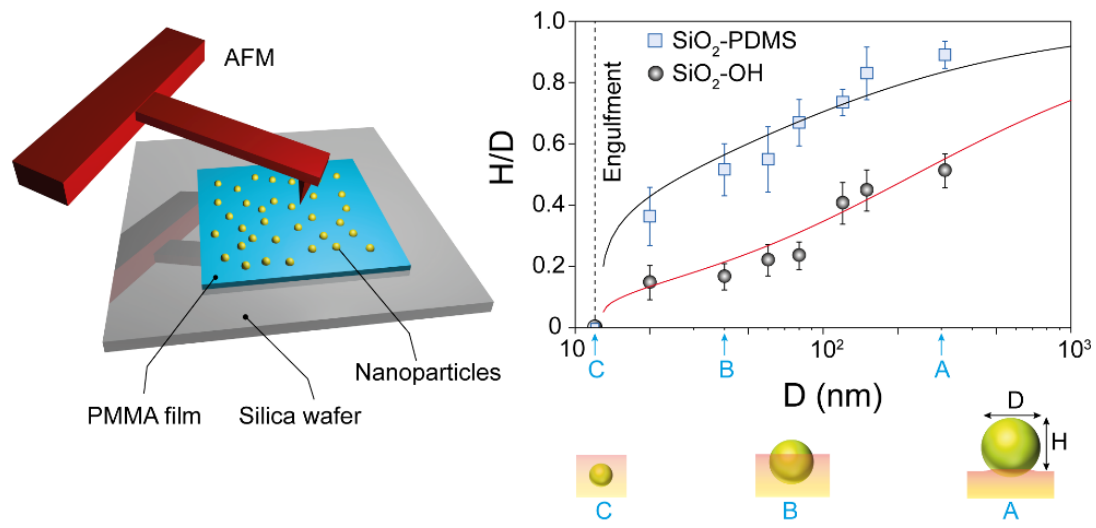

The adhesion of nanoparticles to polymer films plays a key role in various polymer technologies. In this Chapter we show experiments that reveal how silica nanoparticles adhere to an elastic PMMA film above the glass transition point. The polymer was swollen with $\mathrm{CO}_{2}$, closely matching the conditions of nanoparticle-enhanced polymer foaming. It is found that the degree by which the particles sink into the substrate is strongly size-dependent, and even leads to complete engulfment for particles below 12 $\mathrm{nm}$. These findings are explained quantitatively by a thermodynamic analysis, combining elasticity, capillary adhesion and line tension. We argue that line tension, here proposed for the first time in elastic media, is responsible for the nanoparticle engulfment.

*Part of this Chapter will be published as: Shanqiu Liu, Anupam Pandey (co-first author), Joost Duvigneau, Julius Vancso and Jacco H. Snoeijer. Transition from Adhesion to Engulfment of Nanoparticles at the Melt-polymer Interface. Submitted. 


\section{$5.1 \quad$ Introduction}

The diminishing size of nanoparticles results in a tremendous increase in their surface to volume ratio, leading to unexpected but exiting properties. ${ }^{1-3}$ In polymer technology, the interface between added nanoparticles and a surrounding matrix can indeed dominate the properties of the hybrid material. ${ }^{4-10}$ With the growing interest in nanoparticles as fillers and/or active component in polymers, it is of key importance to develop a detailed understanding of the role of this interface on the resulting material properties.

Recent studies have focussed on the adhesion of nanoparticles present at polymer/gas interfaces. ${ }^{11-18}$ Nanoparticles for example serve as highly efficient nucleation agents in $\mathrm{CO}_{2}$ blown polymer foams, ${ }^{19}$ or to prepare templated surfaces with controlled porosities and antireflective properties. ${ }^{20}$ However, the process of adhesion or embedding of nanoparticles presents a great challenge. Rubner and coworkers ${ }^{20}$ reported the controlled thermally assisted particle embedding of surface deposited silica nanoparticles on polymethylmethacrylate (PMMA) polymer films. Particle embedding was controlled by varying the thermal treatment temperature and time, and similar results were obtained for surface modified silica nanoparticles in films of PMMA and poly(methyl methacrylateco-methacrylic acid). ${ }^{17}$ As alternative to thermal annealing, Loos and coworkers ${ }^{18}$ reported the embedding of gold nanoparticles in polystyrene (PS) films via $\mathrm{CO}_{2}$ saturation of the polymer substrate at relatively low temperatures. The $\mathrm{CO}_{2}$ saturated polystyrene surface exhibits an increased polymer mobility causing the particles to sink in the surface. Surprisingly, we find that reducing the particle size to macromolecular length scale even leads to complete engulfment of the nanoparticle into a polymer film.. ${ }^{16}$

From a theoretical perspective, the adhesion of nanoparticles requires a revision of the classical JKR theory, ${ }^{21-22}$ as it does not account for capillary effects at small scale. Recent studies showed that particle adhesion is governed by the elasto-capillary length $\gamma_{s} / E,{ }^{23-25}$ where $\gamma_{s}$ is the "solid surface tension" of the elastic polymer film. While particles much larger than $\gamma_{s} / E$ follow the JKR-law, smaller particles are dominated by capillary forces. In the latter case the film's bulk elasticity is negligible, and the adhesion was proposed to be equivalent to particle adsorption at a liquid interface. However, these proposed descriptions do not predict any engulfment, nor have they been compared directly to experiments on nanoparticles.

In this Chapter we reveal a transition from adhesion, to wetting, to complete engulfment of silica nanoparticles on a PMMA film above the glass transition. Using atomic force microscopy (AFM), it is found that the relative degree by which the particles sink into the substrate is strongly size-dependent, and leads to complete engulfment for particles below $12 \mathrm{~nm}$. These findings are explained quantitatively by a thermodynamic analysis, combining elasticity, capillary adhesion and line tension. We argue that line 
tension, here proposed for the first time in elastic media, is responsible for the nanoparticle engulfment.

\section{A - deposition}

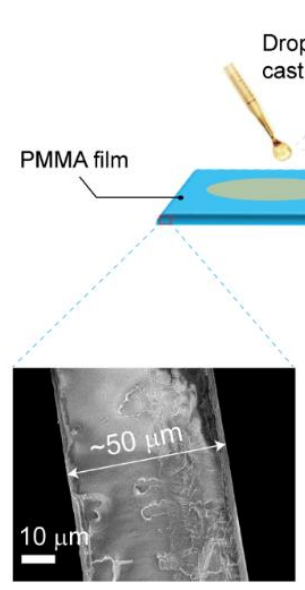

Cross sectional SEM image of PMMA film

\section{C - AFM measurement}

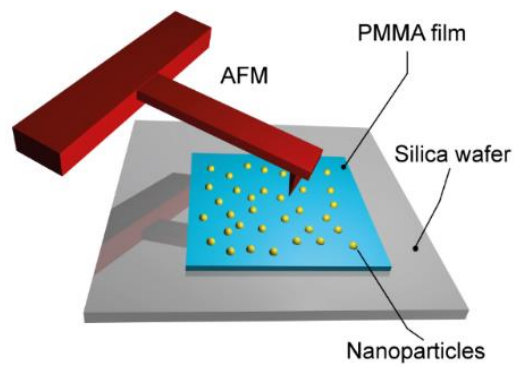

B - embedding

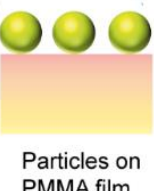

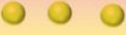

small particles

Figure 5.1 Schematic showing deposition (A) and embedding (B) of nanoparticles on a PMMA film. $\mathrm{CO}_{2}$ treatment of the particle laden PMMA layer leads to embedding and even engulfment of the nanoparticles by the polymer film. The degree by which the particles sink into the PMMA is quantified by measuring the height of nanoparticles above the polymer layer using an AFM (C).

\subsection{Results and discussion}

\subsubsection{Experiment results}

Here we show the adhesion of two types of silica nanoparticles, i.e. bare $\left(\mathrm{SiO}_{2}-\mathrm{OH}\right)$ and PDMS coated core shell particles ( $\mathrm{SiO}_{2}$-PDMS), with different silica (core) diameters on the surface of $\mathrm{CO}_{2}$ swollen PMMA films. The schematic drawings of sample preparation as well as AFM measurement for the prepared samples are shown in Figure 5.1. Silica nanoparticles were deposited by drop casting the particle solution diluted with 2-propanol on PMMA films (see Figure 5.1A). Upon saturating the PMMA samples with 58 bar $\mathrm{CO}_{2}$ at $40{ }^{\circ} \mathrm{C}$ the PMMA reaches a viscoelastic state. ${ }^{26-28}$ This allows the particles residing at its surface to (partly) sink into the polymer. 

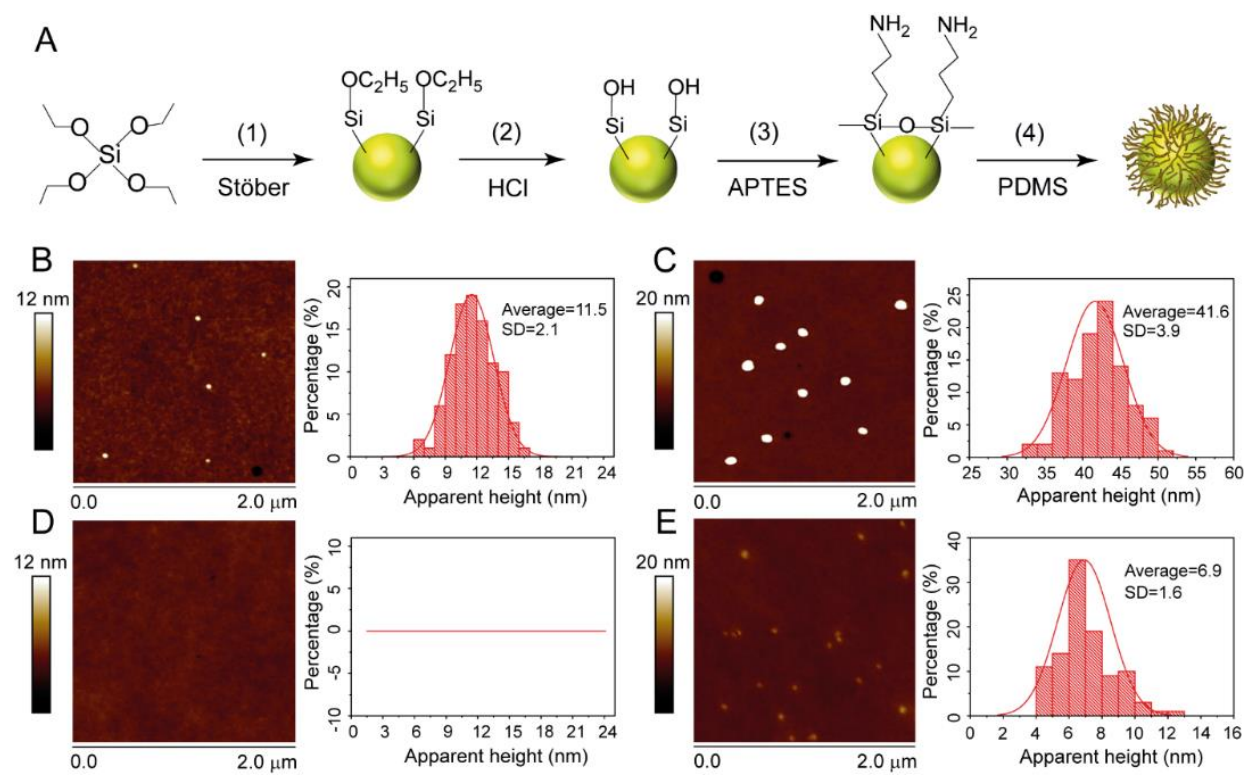

Figure 5.2 Stöber nanoparticle synthesis and subsequent derivation of PDMS grafted nanoparticles (A). AFM images of as deposited $\sim 12 \mathrm{~nm}$ (B) and $\sim 40 \mathrm{~nm}$ (C) bare particles $\left(\mathrm{SiO}_{2}-\mathrm{OH}\right)$ on glassy PMMA surfaces. In (D) and (E) the respective AFM images of the PMMA surfaces after embedding are shown. For a clear showing of the embedded nanoparticles the maximum $\mathrm{Z}$-scale for figure $\mathrm{C}$ and $\mathrm{E}$ was set to be $20 \mathrm{~nm}$.

The equilibrium position of the particles is determined from the residual particle height $(\mathrm{H})$ by AFM tapping mode imaging (see Figure 5.1B and $\mathrm{C}$ ). The key point to note here is that the polymer has a finite storage modulus $\left(\mathrm{G}^{\prime}\right)$ at zero frequency, called the shear modulus $\mathrm{G}\left(\mathrm{G}^{\prime}(w=0)\right)$, which governs the equilibrium particle height $\mathrm{H}$. Experimental details can be found in the method section. Figure 5.2A shows the synthesis of nanoparticles via a Stöber reaction (step 1), followed by the hydrolysis of the surface exposed ethoxy groups to silanol moieties (step 2). The hydrolyzed particles $\left(\mathrm{SiO}_{2}-\mathrm{OH}\right)$ were modified with APTES, which results in the formation of amine functionalized nanoparticles $\left(\mathrm{SiO}_{2}-\mathrm{NH}_{2}\right.$ ) (step 3). Subsequently, PDMS-G was covalently attached to the surface of the nanoparticles via the grafting to method (step 4) to yield $\mathrm{SiO}_{2}-\mathrm{PDMS}$ core shell nanoparticles. The successful modification of the nanoparticles was confirmed by FTIR (see Chapter 4).

The key parameter of interest is the apparent height $\mathrm{H}$ of nanoparticles deposited on PMMA film surfaces, before and after $\mathrm{CO}_{2}$-assisted embedding. The height profiles of the nanoparticles were obtained via tapping mode AFM measurements. All the obtained height values presented in this paper are the Gauss-averaged values for over more than 100 individual isolated particles. We first discuss results on the stiff, glassy PMMA substrate, where no particle sinking is expected. Figures 5.2B and C show AFM height 
images for bare particles on the glassy PMMA, respectively for particle diameters of 12 $\mathrm{nm}$ and $40 \mathrm{~nm}$. The average apparent heights of the as deposited silica particles prior to $\mathrm{CO}_{2}$ treatment of the PMMA surfaces agree well with the diameter of these nanoparticles determined by scanning electron microscopy (SEM). As expected, there is no embedding of nanoparticles in the polymer surfaces prior to $\mathrm{CO}_{2}$ treatment. In addition, decreasing the tapping mode setpoint values did not alter the obtained height values as well. Thus the agreement of the height values obtained with AFM and diameters obtained with scanning electron microscopy for the used nanoparticles confirms that the used tapping mode AFM imaging conditions are suitable to accurately determine the apparent height of the nanoparticles on the polymer films.

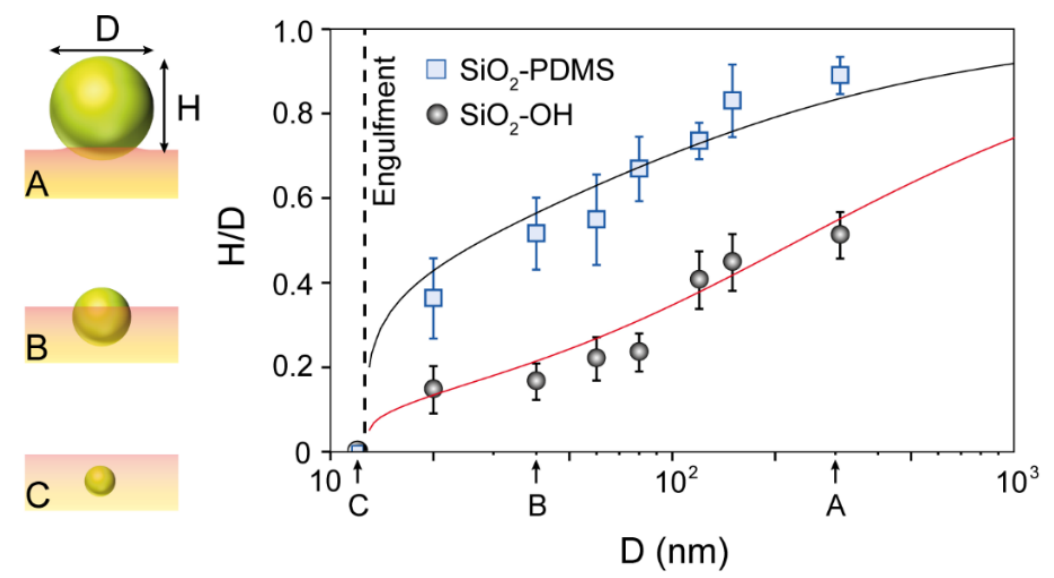

Figure 5.3 Engulfment of silica nanoparticles in a rubbery PMMA film. The nanoparticle embedding exhibits a double transition upon reducing the size, from adhesion (A), to wetting (B), and engulfment $(\mathrm{C})$. The plot shows measurements of the relative degree of embedding of the nanoparticles: the apparent height $\mathrm{H}$ normalized by the particle diameter $\mathrm{D}$ is shown for different particles sizes (circles for bare silica particles, squares for PDMS coated particles). Solid lines corresponds to the combined minimization of bulk energy, surface energy and line tension, given by equation (4).

The main interest of this Chapter is to present the size-dependent degree of particle embedding in the $\mathrm{CO}_{2}$ saturated and softened polymer films. Remarkably, Figure 5.2D shows that the $12 \mathrm{~nm}$ particles are completely engulfed into the substrate, as they are no longer visible in the AFM measurement. By contrast, the $40 \mathrm{~nm}$ particles bare particles are still partly visible (see Figure 5.2E). For these nanoparticles we determined that the average height $\mathrm{H}$ was $6.9 \mathrm{~nm}$, which corresponds to a ratio $\mathrm{H} / \mathrm{D}$ of 0.17 . Hence, the particle attachment and embedding to the softened PMMA film is strongly sizedependent. 
The relative degree of particle embedding is quantified in Figure 5.3, where we report the ratio H/D for different particle diameters D. The PDMS-coated particles (squares) are systematically less embedded than the bare particles (circles). This is due to the low surface energy and high $\mathrm{CO}_{2}$-philicity of the grafted PDMS that changes the interfacial interactions between the nanoparticles and the $\mathrm{CO}_{2}$ softened polymer. Another clear trend from Figure 5.3 is that large particles do not sink very deeply into the polymer films. Finally, regardless the surface chemistry of the particles, complete engulfment is observed for particles with a diameter of approximately $12 \mathrm{~nm}$ and less. These behaviors are explained below in detail.

\subsubsection{Thermodynamic model}

While size-dependent adhesion of nanoparticles has been predicted in theory and simulations, ${ }^{29-30}$ these do not capture the present experiments in particular they do not predict the engulfment phenomenon. Here we propose a thermodynamic model, by splitting the free energy in bulk contributions, surface contributions and a contribution due to the formation of a contact line. The latter term, referred to as line tension, is commonly used for wetting of nanodroplets. Here it is introduced for an elastic interface, motivated by recent studies on the equivalence between elastic and liquid contact lines and wetting. ${ }^{25}$

The free energy can thus be written as:

$$
F=F_{e l}+\left(\gamma_{s p}-\gamma_{p}\right) A_{c}-\gamma_{s} \pi a^{2}+2 \pi a \tau
$$

The first term represents the elastic energy due to the indentation, for which we below will use the Hertz scaling law $F_{e l} \sim h^{5 / 2}$, where $\mathrm{h}=\mathrm{D}-\mathrm{H}$ is the indentation (see Figure 5.5). The second term represent the exchange of particle-vapor surface with PMMAparticle surface, which gives a change in surface energy $\left(\gamma_{s p}-\gamma_{p}\right)$ times the relevant area $A_{c}$. Creating the contact also removes part of the solid-vapor energy. The associated solid surface energy is denoted as $\gamma_{s}$, while the area is approximated as $\pi a^{2}$ where $a$ is the radius of the contact. Up to this point, the free energy is identical to that posed in, ${ }^{24}$ which does not lead to engulfment. The key addition is the final term in (1) containing the line tension $\tau$, representing the energy necessary to create a contact line of perimeter $2 \pi a$.

The ratios of bulk-to-surface energy and of surface-to-line energy naturally introduces two length scales in the problem, to which the particle diameter D needs to be compared. The first is the elasto-capillary length, $l_{e c}=\gamma_{s} / E$, where $\mathrm{E}$ is the Young's modulus of the polymer. We treat the polymer to be incompressible for which $\mathrm{E}=3 \mathrm{G}$. The Young's modulus of the swollen PMMA film is estimated to be approximately $E \sim 10^{6} \mathrm{~Pa}$ based on the rheology measurements as shown in Figure 5.4, while $\gamma_{s}$ is approximately 21 
$\mathrm{mN} / \mathrm{m}^{31}$ This gives $l_{e c} \sim 20 \mathrm{~nm}$, which is indeed a relevant scale for the particles considered here. The second scale is the so-called tension length, $l_{\tau}=\tau / \gamma_{s}$, which is known in the context of nanodroplets. ${ }^{32-33}$ It is commonly accepted that $l_{\tau}$ should be of molecular scale,$^{34}$ though much larger values are often claimed in the literature. The ratio $l_{\tau} / l_{e c}$ is thus expected to be much smaller than unity and will appear as a parameter in the model. Another dimensionless parameter can be obtained from the work of adhesion

$$
W=\gamma_{s}+\gamma_{p}-\gamma_{s p}=\gamma_{s}\left(1+\cos \theta_{y}\right)
$$

which quantifies the energy per unit area required to separate two surfaces. Here we wrote it directly in terms of Young's angle $\theta_{y}$, which will be used as a model parameter. To explicitly perform the minimization we express the free energy in terms of the indentation depth $\mathrm{h}=\mathrm{D}-\mathrm{H}$. For a spherical particle, one find the geometric relations $A_{c}=$ $\pi D h$ and $a=\sqrt{D h-h^{2}}$. Based on this we rewrite the free energy as

$$
F=\frac{c E D^{1 / 2} h^{5 / 2}}{\sqrt{2}\left(1-v^{2}\right)}-\pi D h W+\pi \gamma_{s} h^{2}+\pi \tau \sqrt{D h-h^{2}}
$$

Here we closely followed, ${ }^{24}$ by approximating the elastic energy by the small deformation expression and use $c=8 / 5 \sqrt{3}$ to recover the JKR result for large particles. The equilibrium position is obtained from $\frac{d F}{d h}=0$, which, upon writing $\bar{h}=h / D$ and setting the Poisson ratio $v=1 / 2$, can be rearranged to

$$
\frac{8 \sqrt{2}}{3^{3 / 2} \pi}\left(\frac{D}{l_{e c}}\right) \bar{h}^{3 / 2}-\left(1+\cos \theta_{y}\right)+2 \bar{h}+\left(\frac{l_{\tau}}{D}\right) \frac{1-2 \bar{h}}{\sqrt{\bar{h}-\bar{h}^{2}}}=0
$$

As anticipated, the contact angle $\theta_{y}$ and the two length scales, $l_{e c}$ and $l_{\tau}$, appear as the relevant parameters. By solving $\bar{h}$ from (4), we can determine the sought-for equilibrium position $\mathrm{H} / \mathrm{D}=1-\bar{h}$. 


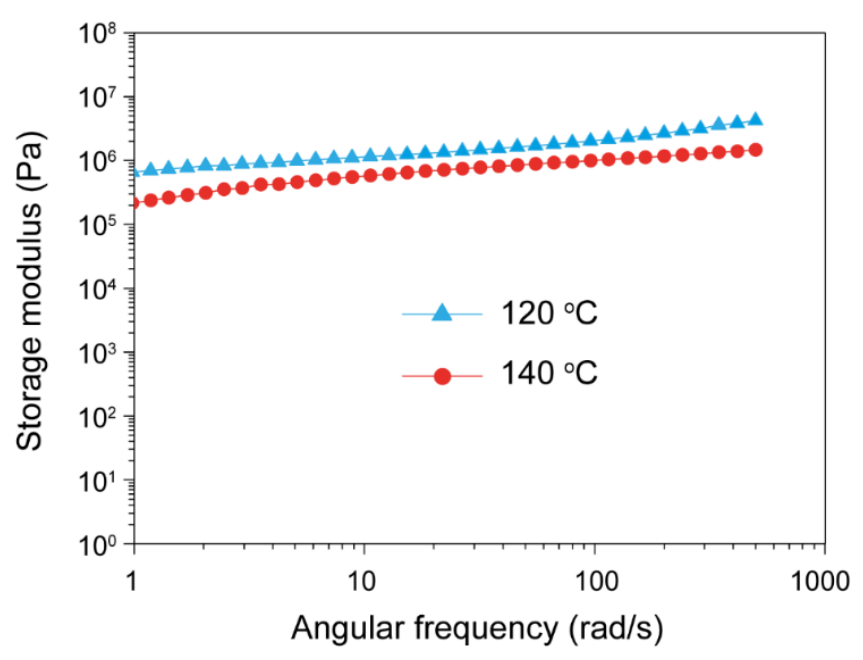

Figure 5.4 Storage modulus of PMMA at $120^{\circ} \mathrm{C}$ and $140{ }^{\circ} \mathrm{C}$.

\subsubsection{Results from the thermodynamic model}

The typical predictions of (4) are illustrated in Figure 5.5, showing H/D as function of the particle diameter normalized by the elasto-capillary length, $D / l_{e c}$. One indeed finds a monotonic dependence on the particle size. At large $D / l_{e c}$, there is barely any indentation and the result coincides with the classical JKR-law. For $D / l_{e c} \leq 1$, however, one observes that the particles tend towards a preferred position that is governed by the Young's angle $\theta_{y}$. This is because for smaller particles the surface energies start to dominate over the bulk elastic term. The red dashed line is the result without line tension, for which the particle position indeed approaches this wetting condition as previously found for elasto-capillary adhesion. ${ }^{24}$ Formally, this corresponds to $l_{\tau}=0$ in the limit $l_{e c} \gg 1$, and gives $\mathrm{H} / \mathrm{D}=\left(1-\cos \theta_{y}\right) / 2$.

The addition of line tension dramatically changes the behavior for small particle sizes, and leads to engulfment. This can be inferred from the solid lines of Figure 5.5, which were obtained for different strengths of the line tension, namely $\frac{l_{\tau}}{l_{e c}}=10^{-5}, 10^{-4}$, and $10^{-3}$. The line tension introduces a critical particle diameter below which stable solutions cease to exist. Instead, one observes a bifurcation where the lowest free energy is achieved by completely engulfing the particle inside the elastic layer. The critical diameter for engulfment increases with $l_{\tau}$. For the largest tension length shown in Figure 5.5, the plateau due to the wetting regime is no longer visible. 


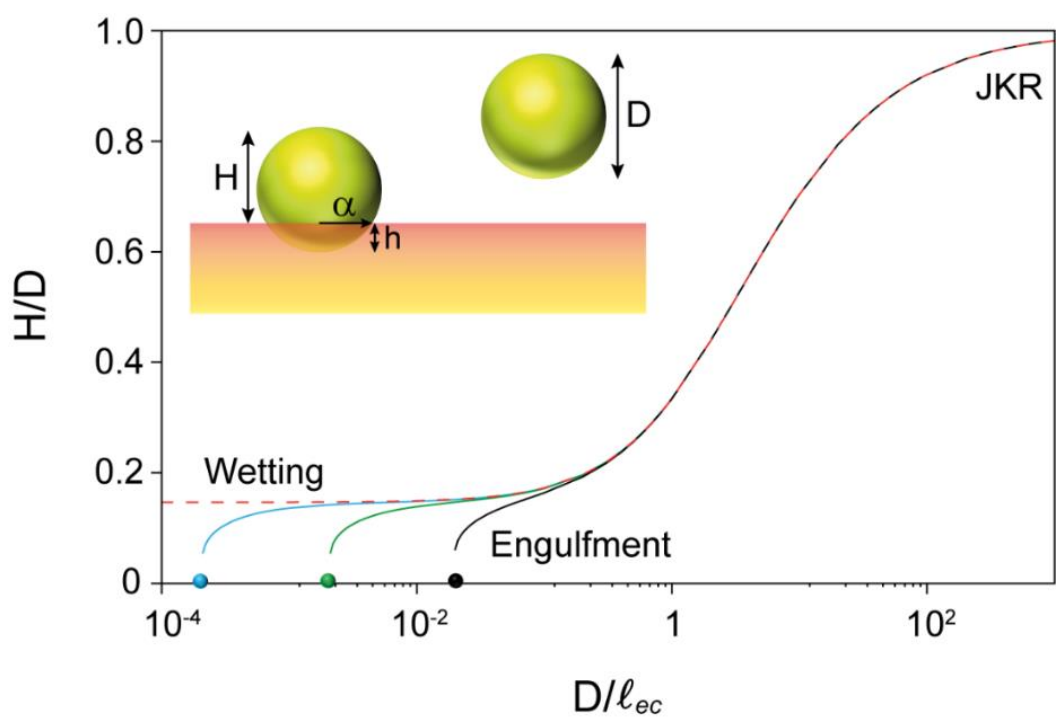

Figure 5.5 Thermodynamic model: Transition from adhesion to wetting to engulfment of nanoparticles, based on equation (4). The red dashed line represents the adhesion to wetting transition for $\theta_{y}=45^{\circ}$, for the case without line tension $\left(l_{\tau}=0\right)$. The gray solid lines incorporate line tension effects for $\frac{l_{\tau}}{l_{e c}}=10^{-5}, 10^{-4}$, and $10^{-3}$ from left to right. The corresponding circles represent the critical nanoparticle diameter for engulfment given by equation (6). The inset shows a nanoparticle in and out of contact with a polymer film and relevant geometric variables. The difference in energy between the two states leads to equation (1).

Such a line-tension induced bifurcation was previously observed for nanoparticles at liquid interfaces, ${ }^{35}$ and the same mechanism appears to be at play here. In the model, the critical diameter $D_{c}$ for engulfment is due to the disappearance of the energy minimum. The disappearance of the minimum can be found by the combined condition $\frac{d F}{d h}=0$, written as (4), and $\frac{d^{2} F}{d h^{2}}=0$. A closed form analytical expression for $D_{c}$ is obtained in the physically relevant limit $l_{\tau} \ll l_{e c}$, for which the elastic term can be treated upon expansion. This gives the critical diameter below which nanoparticles are unstable at the polymer interface:

$\frac{D_{c}}{l_{\tau}} \simeq \frac{2}{\left[1-\cos \theta_{y}{ }^{2 / 3}\right]^{3 / 2}}-f\left(\cos \theta_{y}\right)\left(\frac{l_{\tau}}{l_{e c}}\right)+O\left(\left(\frac{l_{\tau}}{l_{e c}}\right)^{2}\right)$

where $f(x)=(16 / 3 \sqrt{3} \pi) x^{-1 / 3}\left(x^{1 / 3}-1\right)^{-4}\left(x^{1 / 3}+1\right)^{-5 / 2}$. Indeed, the critical diameter is directly proportional to the tension length $l_{\tau}$. However, there is an intricate 
dependence on the contact angle. In particular, we find for $\theta_{y} \ll 1$ that (neglecting elasticity)

$D_{c} \simeq 2 \times 3^{3 / 2} \frac{l_{\tau}}{\theta_{y}^{3}}$

The dependence $\sim 1 / \theta_{y}{ }^{3}$ shows that for small contact angles, the critical diameter for engulfment can be orders of magnitude larger than the tension length. This pushes the engulfment diameter to the range of tens of nanometers. This effect is due to a geometric amplification of the influence of line tension, arising since contact lines with small $\theta_{y}$ only probe the "flat" part of the top of the particle.

\subsubsection{Comparison to experiments}

Finally, we compare the theoretical prediction to our experiments. The results are shown as the solid lines in Figure 5.3, capturing the full range of data including the engulfment. Importantly, the model contains three parameters, one of which is eliminated by setting the critical diameter to $12 \mathrm{~nm}$. Using the two remaining parameters to fit the experiment, we obtained for the coated particles (blue line) $\theta_{y}=55^{\circ}, l_{\tau}=5 \mathrm{~nm}, l_{e c}=$ $12 \mathrm{~nm}$, while for the bare particles (red line) $\theta_{y}=34^{\circ}, l_{\tau}=0.6 \mathrm{~nm}, l_{e c}=70 \mathrm{~nm}$. We note that variations of approximately $\pm 20 \%$ could be found when trying a good match of the data.

A few observations can be made. Most importantly, the obtained values for the tension lengths are of the expected scale. This makes a strong case that even relatively large particles, possibly tens of nanometers, can be engulfed by line tension when $\theta_{y}$ is sufficiently small. When comparing the fitted values of the bare particles and the PDMScoated particles, we find that the PDMS induces a higher contact angle, as to be expected. However, the fitting requires an elasto-capillary length $l_{e c}$ that is substantially smaller for the coated particle. A possible explanation is the rather crude approximation of the elastic energy, which is based on the result of linear elasticity and only holds for H/D not too far from unity. Still, the relatively simple thermodynamic model proposed here provides a very good description of the experimental data, and in particular explains the engulfment. 


\subsection{Conclusion}

In this Chapter we experimentally showed how nanoparticle adhere to soft PMMA films. Upon decreasing the size of the particles, we found a gradual transition from a classical adhesion regime to a complete engulfment of the particle into the PMMA. These observations were explained from simple thermodynamic considerations, but only when a line tension contribution is incorporated. Even though the PMMA has a nonzero elastic modulus, the contact line behaves very much like that of a liquid at the nanoscale. Of course, the modeling presented here is crude in the sense that all molecular interactions are effectively described by effective free energies. An important direction for future work is to reveal further details near the contact line by molecular simulation, and make the explicit link between molecular aspects and thermodynamics of nanoparticle adhesion.

Despite this, it is now anticipated that for instance in heterogeneous nanocellular polymer foaming the contribution of line tension to the free energy of cell nucleation needs to be considered. ${ }^{36-38}$ In particular when nucleating particle dimensions are at the macromolecular length scale for which we have shown that line tension can severely influence the three phase contact line its effect can probably not be ignored. In addition it demonstrates that when interested in obtaining surface topology effects the use of the smallest nanoparticles on viscoelastic surface/interfaces may provide unexpected results due to line tension effects. Thus a deeper and better quantified understanding of the effect of line tension on nanoparticles is needed from both a physical as well as a practical point of view in order to fully exploit their potential at the nanometer length scales.

\subsection{Materials and methods}

Materials. Tetraethyl orthosilicate (TEOS) $\geq 99.0 \%$, 2-propanol $99.5 \%$ were purchased from Aldrich (Milwaukee, WI, USA). (3-Aminopropyl)-triethoxysilane (APTES) 99\%, hydrocholoric acid 37\%, and poly(dimethylsiloxane) monoglycidyl ether terminated (PDMS-G) $\left(\mathrm{M}_{\mathrm{w}}=1000 \mathrm{~g} \cdot \mathrm{mol}^{-1}\right)$ were purchased from Sigma-Aldrich (St. Louis, MO, USA). Calcium chloride $\left(\mathrm{CaCl}_{2}\right)$ was purchased from Aldrich Chemical Company Ltd (Gillingham, England). PMMA was a gift from Arkema (VM100, i.e. a PMMA-co-EA polymer) (La Garenne-Colombes, France). Absolute Tetrahydrofuran (THF) were purchased from Biosolve (Valkenswaard, the Netherlands). Ethanol absolute for analysis was purchased from Merck (Darmstadt, Germany). Milli-Q water was produced by a Millipore Synergy system (Billerica, MA, USA). Nanoparticles with diameters of $\sim 12 \mathrm{~nm}$ (B220), 20 nm (B130) and $\sim 60 \mathrm{~nm}$ (Levasil 50/50) were purchased 
from AkzoNobel (Bohus, Sweden). These particles were dispersed in aqueous solution and have surface exposed hydroxyl groups on the surface as received. Unless otherwise mentioned all other chemicals were used as received.

Stöber nanoparticle preparation. To prepare Stöber silica nanoparticles $\left(\mathrm{SiO}_{2}\right)$ with a diameter of $\sim 80 \mathrm{~nm}, 168 \mathrm{ml}$ ethanol was mixed with $28 \mathrm{ml}$ Milli-Q water and $30 \mathrm{ml}$ TEOS in the presence of $2 \mathrm{ml}$ ammonium hydroxide while stirring at $500 \mathrm{rpm}$ at room temperature. After 1.5 hours the obtained $\mathrm{SiO}_{2}$ dispersion was centrifuged at $10,000 \mathrm{rpm}$ for 30 min. Subsequently, the collected $\mathrm{SiO}_{2}$ was redispersed in ethanol and centrifuged again. This washing step was repeated 2 more times followed by vacuum drying the collected $\mathrm{SiO}_{2}$ nanoparticles at room temperature for 12 hours. To synthesize the $40 \mathrm{~nm}$ particles $84 \mathrm{ml}$ of ethanol was mixed with $14 \mathrm{ml}$ Milli-Q water and $15 \mathrm{ml}$ TEOS in the presence of $0.75 \mathrm{ml}$ ammonium hydroxide in a $250 \mathrm{ml}$ round bottom flask while stirring at $500 \mathrm{rpm}$. The reaction was conducted for 1.5 hours at room temperature. To synthesize the $120 \mathrm{~nm}$ particles $100 \mathrm{ml}$ ethanol was mixed with $8 \mathrm{ml}$ Milli-Q water and $5 \mathrm{ml}$ TEOS in a round bottom flask stirring at $500 \mathrm{rpm}$ and subsequently $5 \mathrm{ml}$ of ammonium hydroxide was added and reacted for 3 hours at $50{ }^{\circ} \mathrm{C}$. To synthesize $\sim 150 \mathrm{~nm} \mathrm{SiO} \mathrm{Si}_{2}, 8$ $\mathrm{mL}$ Milli-Q water, $10 \mathrm{~mL}$ TEOS and $5 \mathrm{~mL}$ ammonia hydroxide solution were added to $100 \mathrm{~mL}$ ethanol, followed by stirring at $50{ }^{\circ} \mathrm{C}$ for $4.5 \mathrm{~h}$. To synthesis nanoparticles of $310 \mathrm{~nm} 100 \mathrm{ml}$ Ethanol was mixed with $8 \mathrm{ml} \mathrm{H}_{2} \mathrm{O}$ and $10 \mathrm{ml}$ TEOS, followed by the addition of $7 \mathrm{ml}$ ammonium hydroxide and the reaction mixture was left at $50{ }^{\circ} \mathrm{C}$ for 4.5 $\mathrm{h}$. The collection, washing and drying steps for these nanoparticles were the same as described for the $80 \mathrm{~nm}$ nanoparticles.

Hydrolysis. To introduce silanol groups on the surface of the prepared $\mathrm{SiO}_{2}$ nanoparticles, the particles were redispersed in Milli-Q water by sonication (BRANSON 2510, Canada) for 1 hour. Subsequently, hydrochloric acid was added to the dispersion while stirring at $500 \mathrm{rpm}$ until the $\mathrm{pH}$ of the solution reached a value of approximately 1 . After 4 hours the dispersion was centrifuged at 10,000 rpm for $30 \mathrm{~min}$. The collected nanoparticles were redispersed in Milli-Q water and centrifuged again. This washing step was repeated 2 more times followed by drying the silanol functional nanoparticles $\left(\mathrm{SiO}_{2}-\right.$ $\mathrm{OH})$ in vacuum at room temperature for 12 hours.

Amino-functionalization. $1.5 \mathrm{~g} \mathrm{SiO}_{2}-\mathrm{OH}$ nanoparticles were redispersed in $50 \mathrm{ml}$ ethanol followed by the addition of $7.5 \mathrm{ml}$ APTES. The dispersion was left to stir at 500 $\mathrm{rpm}$ at room temperature for 17 hours. The APTES functionalized nanoparticles $\left(\mathrm{SiO}_{2}-\right.$ $\mathrm{NH}_{2}$ ) were collected by centrifugation at $10,000 \mathrm{rpm}$ for $30 \mathrm{~min}$ and redispersed in ethanol and centrifuged again. This washing step was repeated 2 more times followed by drying the collected $\mathrm{SiO}_{2}-\mathrm{NH}_{2}$ nanoparticles in vacuum at room temperature for 12 hours. Due to the small size of B220 (12 nm) and B130 (20 nm), the nanoparticles could not be 
collected by centrifugation. After amino-functionalization $1 \mathrm{ml} \mathrm{CaCl} 2(1 \mathrm{M})$ was added to $15 \mathrm{ml}$ of the reaction mixture of B130 and B220 to change the surface zeta potential of the nanoparticles. This caused reversible agglomeration of the nanoparticles and made it possible to separate them from the ethanol during centrifugation.

Grafting to of PDMS-G to silica nanoparticles. $1.0 \mathrm{~g}$ of $\mathrm{SiO}_{2}-\mathrm{NH}_{2}$ nanoparticles were redispersed in $20.5 \mathrm{ml}$ THF and $15 \mathrm{~g}$ PDMS-G while stirring at $500 \mathrm{rpm}$ for 1 hour followed by sonication for 1 hour. Subsequently, THF was removed by rotary evaporation and the resulting silica nanoparticle dispersion in PDMS-G was immersed in an oil bath thermostated at $80{ }^{\circ} \mathrm{C}$ for $17 \mathrm{~h}$. Following cooling to room temperature the reaction mixture was washed with THF and centrifuged at 10,000 rpm for $30 \mathrm{~min}$. This washing step was repeated 2 more times, followed by vacuum drying the PDMS-G grafted silica nanoparticles $\left(\mathrm{SiO}_{2}-\mathrm{PDMS}\right)$ at room temperature for 12 hours.

Sample preparation for embedding treatment. PMMA films of approximately $50 \mu \mathrm{m}$ thick were prepared by drop casting a polymer-chloroform solution $(0.1 \mathrm{~g} / \mathrm{ml})$ onto silica wafers $(1 \mathrm{~cm} \times 1 \mathrm{~cm})$. Subsequently, the substrates were dried in air for 16 hours followed by annealing at $135^{\circ} \mathrm{C}$ for 12 hours to relieve any potentially present residual stresses in the film before being slowly cooled to room temperature. Prior to particle deposition, the prepared nanoparticles $\left(\mathrm{SiO}_{2}-\mathrm{OH}\right.$ and $\left.\mathrm{SiO}_{2}-\mathrm{PDMS}\right)$ were redispersed in 2-propanol by sonication and diluted to a concentration of $0.005 \mathrm{wt} \%$. Subsequently, a drop of the diluted nanoparticle solution was placed on the PMMA film, followed by drying the samples in a nitrogen box at room temperature for $12 \mathrm{~h}$. The particles did not sink in into the glassy polymer surfaces as a result of this preparation method as was confirmed by AFM height measurements.

Once prepared, the samples were placed inside a pressure vessel (Julabo, Seelbach, Germany). The temperature of the set-up was set to $40{ }^{\circ} \mathrm{C}$ and the set-up was flushed with $\mathrm{CO}_{2}$ for $20 \mathrm{~s}$. Subsequently, the $\mathrm{CO}_{2}$ pressure was set to 58 bar. To ensure that the nanoparticles obtain an equilibrium state at the interface of the polymer matrix the samples were saturated in $\mathrm{CO}_{2}$ for 7 hours, subsequently, the pressure was slowly released and the samples were quenched to room temperature for further analysis.

Atomic force microscopy $(A F M)$ characterization. The apparent height of the nanoparticles before and after embedding was determined by AFM (MFP-3D, Asylum Research, Santa Barbara, CA, USA) analysis in tapping mode (amplitude set-point 250 $\mathrm{mv}$ ) using a silicon cantilever (Nano Word) with a resonance frequency of $320 \mathrm{kHz}$ and a spring constant of $42 \mathrm{~N} \mathrm{~m}^{-1}$. The substrates were scanned at a minimum of three different positions and the obtained height images were analyzed. The height of more than 100 individual isolated particles were analyzed for each data point. 
Scanning electron microscopy (SEM). A high resolution SEM (JEOL Field Emission JSM-633OF, JEOL Benelux, Nieuw-Vennep, the Netherlands) was used to determine the diameter of of the prepared nanoparticles. The typically used electron acceleration voltage was $5 \mathrm{keV}$. To prepare samples for SEM measurement the nanoparticles were redispersed in 2-propanol at a very low concentration followed by dropping the solution on silica wafers. Prior to analysis the prepared samples were dried in a nitrogen box at room temperature for $12 \mathrm{~h}$. The SEM images were analyzed with Image J(NIH). To determine the particle diameter more than 100 nanoparticles were analyzed.

Fourier transform infrared (FTIR) spectroscopy. FTIR absorbance spectra were collected with a Bruker ALPHA single attenuated total reflection (ATR) FTIR Spectrometer equipped with an ATR single reflection crystal (Bruker Optic GmbH, Ettlingen, Germany). The spectra were collected in the range of 400-4000 $\mathrm{cm}^{-1}$ (spectral solution of $4 \mathrm{~cm}^{-1}, 128$ scans). Background spectra were recorded against air.

Rheological experiments. The rheological experiments were carried out with an UDS 200 rheometer (Anton Paar) using parallel plates $(25 \mathrm{~mm}$ diameter, gap $0.8 \mathrm{~mm}$ ) configuration at $120^{\circ} \mathrm{C}$ and $140{ }^{\circ} \mathrm{C}$ in the oscillatory mode.

\section{References:}

[1] Basiuk, V. A.; Basiuk, E. V., Green processes for nanotechnology: from inorganic to bioinspired nanomaterials. Springer: 2015.

[2] Gan, Y.; Sun, L.; Banhart, F. One-and two-dimensional diffusion of metal atoms in graphene. Small 2008, 4, 587-591.

[3] Cheng, S.; Xie, S.; Carrillo, J. Y.; Carroll, B.; Martin, H.; Cao, P.; Dadmun, M.; Sumpter, B. G.; Novikov, V. N.; Schweizer, K. S. Big effect of small nanoparticles: a shift in paradigm for polymer nanocomposites. ACS nano 2017, 11, 752-759.

[4] Schadler, L. Nanocomposites: model interfaces. Nature materials 2007, 6, 257-258.

[5] Smith, S. J.; Lau, C. H.; Mardel, J. I.; Kitchin, M.; Konstas, K.; Ladewig, B. P.; Hill, M. R. Physical aging in glassy mixed matrix membranes; tuning particle interaction for mechanically robust nanocomposite films. Journal of Materials Chemistry A 2016, 4, 1062710634.

[6] Fu, S.; Feng, X.; Lauke, B.; Mai, Y. Effects of particle size, particle/matrix interface adhesion and particle loading on mechanical properties of particulate-polymer composites. Composites Part B: Engineering 2008, 39, 933-961.

[7] Balazs, A. C.; Emrick, T.; Russell, T. P. Nanoparticle polymer composites: where two small worlds meet. Science 2006, 314, 1107-1110. 
[8] Siqueira, G.; Bras, J.; Dufresne, A. Cellulose whiskers versus microfibrils: influence of the nature of the nanoparticle and its surface functionalization on the thermal and mechanical properties of nanocomposites. Biomacromolecules 2008, 10, 425-432.

[9] Li, Q.; Barrett, D. G.; Messersmith, P. B.; Holten-Andersen, N. Controlling hydrogel mechanics via bio-inspired polymer-nanoparticle bond dynamics. ACS nano 2016, 10, 1317 1324 .

[10] Bansal, A.; Yang, H.; Li, C.; Benicewicz, B. C.; Kumar, S. K.; Schadler, L. S. Controlling the thermomechanical properties of polymer nanocomposites by tailoring the polymerparticle interface. Journal of Polymer Science Part B: Polymer Physics 2006, 44, 2944-2950.

[11] Fakhraai, Z.; Forrest, J. Measuring the surface dynamics of glassy polymers. Science 2008, $319,600-604$.

[12] Teichroeb, J.; Forrest, J. Direct imaging of nanoparticle embedding to probe viscoelasticity of polymer surfaces. Physical Review Letters 2003, 91, 016104.

[13] Karim, T. B.; McKenna, G. B. Evidence of surface softening in polymers and their nanocomposites as determined by spontaneous particle embedment. Polymer 2011, 52, 61346145 .

[14] Sharp, J.; Teichroeb, J.; Forrest, J. The properties of free polymer surfaces and their influence on the glass transition temperature of thin polystyrene films. The European Physical Journal E: Soft Matter and Biological Physics 2004, 15, 473-487.

[15] Rudoy, V.; Dement'eva, O.; Yaminskii, I.; Sukhov, V.; Kartseva, M.; Ogarev, V. Metal nanoparticles on polymer surfaces: a new method of determining glass transition temperature of the surface layer. Colloid Journal 2002, 64, 746-754.

[16] Deshmukh, R. D.; Composto, R. J. Direct observation of nanoparticle embedding into the surface of a polymer melt. Langmuir 2007, 23, 13169-13173.

[17] Qu, M.; Meth, J.; Blackman, G.; Cohen, G.; Sharp, K.; Van Vliet, K. Tailoring and probing particle-polymer interactions in PMMA/silica nanocomposites. Soft Matter 2011, 7, 84018408 .

[18] Yang, Q.; Xu, Q.; Loos, K. Enhanced polystyrene surface mobility under carbon dioxide at low temperature for nanoparticle embedding control. Macromolecules 2015, 48, 1786-1794.

[19] Liu, S.; Zoetebier, B.; Hulsman, L.; Zhang, Y.; Duvigneau, J.; Vancso, G. J. Nanocellular polymer foams nucleated by core-shell nanoparticles. Polymer 2016, 104, 22-30.

[20] Tan, W. S.; Du, Y.; Luna, L. E.; Khitass, Y.; Cohen, R. E.; Rubner, M. F. Templated nanopores for robust functional surface porosity in poly (methyl methacrylate). Langmuir 2012, 28, 13496-13502.

[21] Johnson, K.; Kendall, K.; Roberts, A. In Surface energy and the contact of elastic solids. Proceedings of the Royal Society of London A: Mathematical, Physical and Engineering Sciences, The Royal Society 1971, 301-313.

[22] Kendall, K. The adhesion and surface energy of elastic solids. Journal of Physics D: Applied Physics 1971, 4, 1186. 
[23] Hui, C.; Liu, T.; Salez, T.; Raphael, E.; Jagota, A. In Indentation of a rigid sphere into an elastic substrate with surface tension and adhesion, Proc. R. Soc. A, The Royal Society. 2015, 20140727.

[24] Style, R. W.; Hyland, C.; Boltyanskiy, R.; Wettlaufer, J. S.; Dufresne, E. R. Surface tension and contact with soft elastic solids. Nature Communications 2013, 4, 2728.

[25] Karpitschka, S.; van Wijngaarden, L.; Snoeijer, J. H. Surface tension regularizes the crack singularity of adhesion. Soft matter 2016, 12, 4463-4471.

[26] Handa, Y. P.; Kruus, P.; O'Neill, M. High-pressure calorimetric study of plasticization of poly (methyl methacrylate) by methane, ethylene, and carbon dioxide. Journal of Polymer Science-B-Polymer Physics Edition 1996, 34, 2635-2640.

[27] Kasturirangan, A.; Koh, C. A.; Teja, A. S. Glass-transition temperatures in $\mathrm{CO}_{2}$ polymer systems: modeling and experiment. Industrial \& Engineering Chemistry Research 2010, 50, 158-162.

[28] Handa, Y. P.; Zhang, Z. A new technique for measuring retrograde vitrification in polymergas systems and for making ultramicrocellular foams from the retrograde phase. Journal of Polymer Science Part B: Polymer Physics 2000, 38, 716-725.

[29] Cao, Z.; Stevens, M. J.; Dobrynin, A. V. Adhesion and wetting of nanoparticles on soft surfaces. Macromolecules 2014, 47, 3203-3209.

[30] Carrillo, J.-M. Y.; Raphael, E.; Dobrynin, A. V. Adhesion of nanoparticles. Langmuir 2010, 26, 12973-12979.

[31] Goel, S. K.; Beckman, E. J. Generation of microcellular polymeric foams using supercritical carbon dioxide. I: Effect of pressure and temperature on nucleation. Polymer Engineering \& Science 1994, 34, 1137-1147.

[32] Schimmele, L.; Dietrich, S. Line tension and the shape of nanodroplets. The European Physical Journal E: Soft Matter and Biological Physics 2009, 30, 427-430.

[33] Weijs, J. H.; Marchand, A.; Andreotti, B.; Lohse, D.; Snoeijer, J. H. Origin of line tension for a Lennard-Jones nanodroplet. Physics of fluids 2011, 23, 022001.

[34] De Gennes, P. G.; Brochard-Wyart, F.; Quéré, D. Capillarity and wetting phenomena: drops, bubbles, pearls, waves. Springer Science \& Business Media: 2013.

[35] McBride, S. P.; Law, B. M. Influence of line tension on spherical colloidal particles at liquidvapor interfaces. Physical Review Letters 2012, 109, 196101.

[36] Hienola, A.; Winkler, P.; Wagner, P.; Vehkamäki, H.; Lauri, A.; Napari, I.; Kulmala, M. Estimation of line tension and contact angle from heterogeneous nucleation experimental data. The Journal of Chemical Physics 2007, 126, 094705.

[37] Lazaridis, M. The effects of surface diffusion and line tension on the mechanism of heterogeneous nucleation. Journal of Colloid and Interface Science 1993, 155, 386-391.

[38] Iwamatsu, M. Line-tension-induced scenario of heterogeneous nucleation on a spherical substrate and in a spherical cavity. The Journal of Chemical Physics 2015, 143, 014701. 


\section{Chapter 6}

\section{Multiple Polymer Foam Cell Nucleation Events from PDMS Grafted Raspberry- like Silica Nanoparticles}

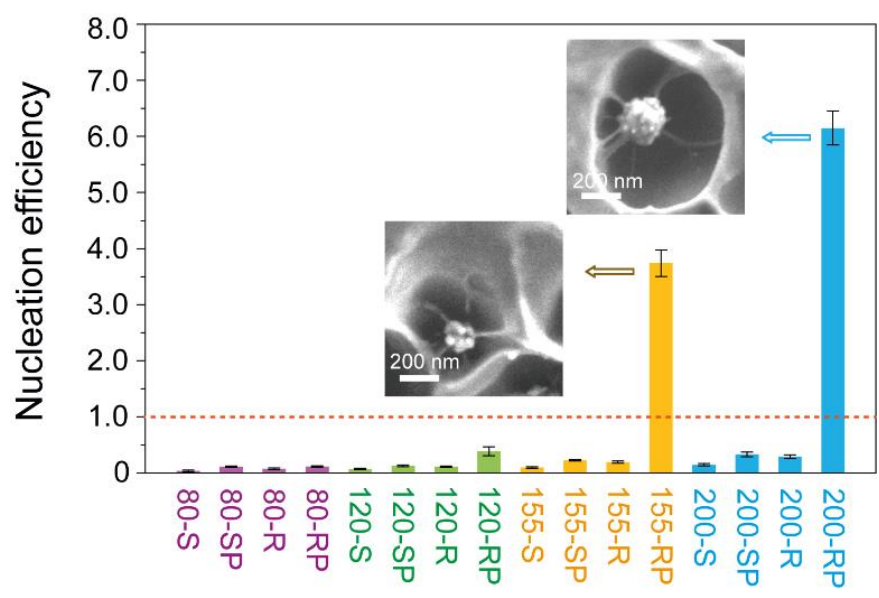

Bare and PDMS grafted raspberry-like silica nanoparticles with diameters from $\sim 80$ $\mathrm{nm}$ to $\sim 200 \mathrm{~nm}$ were synthesized and exploited as highly efficient nucleation agents in $\mathrm{CO}_{2}$ blown nanocellular PMMA foaming. The successful synthesis of core-shell nanoparticles was confirmed by Fourier transform infrared (FTIR) spectroscopy, thermogravimetric analysis (TGA), Brunauer-Emmet-Teller (BET) measurements and transmission electron microscopy (TEM). The cell size and cell density of the PMMA micro- and nanocellular foams obtained were determined by scanning electron microscopy (SEM). The results show qualitatively that an increased surface roughness increases the nucleation efficiency of the nucleating silica particles. This is ascribed to a decreased nucleation free energy for foam cell nucleation in nanocavities. For PDMS grafted raspberry-like silica nanoparticles with a diameter of $155 \mathrm{~nm}$ and $200 \mathrm{~nm}$ multiple cell nucleation events were observed. These hybrid particles had nucleation efficiencies of 3.7 and 6.2, respectively, which are the highest values reported so far for nanofillers as nucleation agents. The unexpected increase in nucleation efficiency to 
above unity is ascribed to the significant increase in $\mathrm{CO}_{2}$ absorption for the corresponding PMMA nanocomposite films during saturation. This results in the presence of large amounts of physical blowing agent close to energetically favorable nucleating points. Furthermore, it is shown that as a consequence of cell coalescence the increased number of foam cells is rapidly reduced during the first seconds of foaming. Hence, in addition to the design of highly efficient nucleating particles, careful selection of foam matrix materials seem to be of pivotal importance as well. These findings are expected to open new avenues for the fabrication of super-efficient cell nucleation agents for nanocellular polymer foaming.

*Part of this Chapter will be published as: Shanqiu Liu, Sida Yin, Joost Duvigneau and Julius Vancso. Multiple polymer foam cell nucleation events from PDMS grafted raspberry-like silica nanoparticles. To be submitted. 


\subsection{Introduction}

Nanocellular polymer foams are receiving considerable attention from the scientific and industrial communities. ${ }^{1-6}$ This is ascribed to the unexpected but sometimes exciting foam properties when their cells have diameters in the order of a few tens to hundreds of nanometers. For instance, the thermal conductivity of nanocellular foams is significantly reduced as a result of the Knudsen effect provided that the foam density is sufficiently low. ${ }^{2,7}$ In addition, the mechanical performance in terms of e.g. the Young's modulus, impact properties and shore hardness is significantly improved compared to microcellular foams with similar densities. ${ }^{8-10}$ These enhanced structure property relationships render nanocellular polymer foams of pivotal importance when considering new classes of materials for instance to achieve reductions in fuel consumption and $\mathrm{CO}_{2}$ emissions in transportation as well as for the thermal energy management of buildings.

Nanocellular polymer foam structures can be obtained by various strategies, e.g. selective extraction/decomposition, ${ }^{11-12}$ templating/imprinting, ${ }^{13-15}$ chemical/physical foaming, ${ }^{8,16-20}$ etc. Among these methods, $\mathrm{CO}_{2}$ assisted batch foaming is of particular interest, which is ascribed to its good control over the foaming conditions as well as the low cost and environmental friendliness of $\mathrm{CO}_{2}$ as a physical blowing agent. ${ }^{9}$ In batch foaming the polymer is first saturated with $\mathrm{CO}_{2}$ at a few to several hundreds of bars for a given time (order of hours to days). Subsequently, foaming is induced by a quick depressurization step followed by an increase in temperature. This results in an oversaturation of the dissolved $\mathrm{CO}_{2}$ in the polymer gas mixture leading to cell nucleation followed by rapid cell expansion. ${ }^{21}$ Disadvantage of batch foaming is that its relatively small batch size (i.e. scale of liters) limits the industrial relevance of this process. On the other hand, nanocellular foam extrusion, i.e. a continuous process, remains challenging, which is ascribed to the difficult control over key physical foaming parameters, e.g. polymer viscosity, $\mathrm{CO}_{2}$ solubility, $\mathrm{CO}_{2}$ diffusivity and foaming temperature. ${ }^{22-24}$

In addition to the nanocellular foam production challenges that have to be solved, nanocellular polymer foams with high porosities $(>85 \%)$ and cell densities $\left(>10^{14}\right.$ cells $\mathrm{cm}^{-3}$ ) are rarely reported on. ${ }^{4,25}$ This is ascribed to the fact that it is difficult to nucleate such high cell densities in the early stages of foaming as well as that on the time scale of foaming cell coalesce is hard to avoid. Frequently used strategies to increase the nucleated cell density rely on increasing the physical blowing agent saturation pressure and/or increasing the pressure release rate. ${ }^{3,25,28}$

The introduction of nanostructured heterogeneous phases to polymers as heterogeneous nucleation sites prior to foaming has been considered a promising 
approach, as well. Examples are the use of block copolymer domains ${ }^{29-32}$ and inorganic nanofillers. ${ }^{18,33-38}$

For instance, Rodríguez-Pérez and coworkers ${ }^{29}$ reported the $\mathrm{CO}_{2}$ assisted batch foaming of PMMA and poly(methyl methacrylate-block-butyl acrylate-block methyl methacrylate) (MAM) blends. The authors demonstrated that foams produced from these PMMA/MAM blends nucleated in the nanostructured MAM micellar phase, which is ascribed to the high $\mathrm{CO}_{2}$-philicity of poly(butyl acrylate) phase compared to the PMMA matrix. McClurg and coworkers ${ }^{31}$ demonstrated that the incorporation of AB diblock copolymers containing poly(dimethylsiloxane) as the core block into polystyrene prior to foaming increases the cell density of polystyrene foams. The nanostructured PDMS domains were considered as efficient nucleation sites because of their high $\mathrm{CO}_{2}$ philicity as well as to the low surface energy of PDMS.

Compared to the incorporation of block copolymer micelles, silica nanoparticles are of particular interest to be employed as heterogeneous nucleation agents in polymer foaming because of their low cost, easy preparation and the simplicity of employing various surface decoration strategies. ${ }^{39-40}$ For instance, Zhai and coworkers ${ }^{37}$ demonstrated that the incorporation of silica nanoparticles in polycarbonate prior to foaming resulted in a higher cell density and more uniform cell size distribution compared to the polycarbonate foams containing no silica nanoparticles as nucleating agents. Yang and coworkers ${ }^{41}$ reported that the decoration of silica nanoparticles with $\mathrm{CO}_{2}$-philic poly(ionic liquid) significantly enhances the cell nucleation in $\mathrm{CO}_{2}$ assisted polystyrene foaming compared to the polystyrene foams prepared with bare silica nanoparticles as nucleating agents. Despite these promising results we noted that the nanoparticles utilized so far suffered from very poor nucleation efficiencies, i.e. the number of foam cells obtained per number of nanoparticles per $\mathrm{cm}^{3}$ added to the polymer matrix prior to foaming. Nucleation efficiencies for these inorganic particle based nanofillers are typically far below 0.01. ${ }^{18,41-43}$ Meaning that hundreds of added particles result in the formation of 1 foam cell during foaming. In these calculations it is assumed that homogenous nucleation and cell coalescence can be neglected. ${ }^{3}$ We have reported the successful utilization of PDMS grafted silica nanoparticles with a silica core diameter of $80 \mathrm{~nm}$ with a nucleation efficiency of approximately 0.5 for the preparation of $\mathrm{CO}_{2}$ batch blown PMMA foams (see Chapter 3 and 4). ${ }^{33}$ The good efficiency of these particles is ascribed to $i$ ) the low surface energy of the PDMS shell, which reduces the nucleation energy barrier, and $i$ ) the higher local $\mathrm{CO}_{2}$ concentration in the PDMS shell $(\sim 75 \mathrm{wt} \%)^{44}$ compared to the PMMA matrix ( $\left.18 \mathrm{wt} \%\right) .{ }^{45}$ Furthermore we demonstrated that the presence of line tension significantly reduces the nucleation efficiency of PDMS grafted nanoparticles with a silica core diameter below $40 \mathrm{~nm}$ for the used foaming conditions (i.e. $\mathrm{CO}_{2}$ saturation pressure of 55 bar and foaming at $40{ }^{\circ} \mathrm{C}$ ). In addition for higher saturation pressures (e.g. 300 bar) 
homogenous nucleation is more and more favorable compared to heterogeneous nucleation and as a consequence the nucleation efficiency of particles up to 80 nanometer was significantly reduced (see Chapter 4 ). Thus the use of smaller particles, e.g. 10 nanometer in diameter is considered unfavorable while it would allow the addition of the required high number of potential nucleation sites $\left(>10^{15} \mathrm{~cm}^{-3}\right)$ at relatively low weight percentages of particle loading. As a consequence we concluded that new particle designs were needed to increase the nucleation efficiency to unity and if possible to even higher values.

The effect of surface roughness on the free energy of foam cell nucleation was not included in the particle design so far. Yang and coworkers reported ${ }^{46}$ a thermodynamic model and analytical solution for the free energy of cell nucleation at the nanometer length scale in nanocavities. It was shown that cells nucleated from a concave surface have a lower nucleation free energy compared to the free energy of nucleation from flat of convex surfaces (e.g. spherical particles). ${ }^{47-48}$ Based on these results we included surface roughness as a parameter for new nucleating hybrid particles designs.

Since the preparation of raspberry-like silica nanoparticles is fairly easy and well described in the literature, ${ }^{49-53}$ we considered these surface roughened nanoparticles as ideal candidates to explore the effect of nanocavities on nanocellular foam cell nucleation. He and coworkers ${ }^{51}$ reported on a method to produce raspberry-like nanoparticles by a self-templated etching route. This method limits the particle diameter to 60 nanometer or larger. In fact for the purpose of this work it is acceptable since it allows to study the effect of particle surface roughness on foam cell nucleation without other effects, like particle curvature dominating the nucleation efficiencies obtained (see Chapter 4). ${ }^{54-55}$

In this Chapter we will show that raspberry-like silica nanoparticles are efficient foam cell nucleators with nucleation efficiencies that are comparable to their PDMS grafted nearly spherical counterparts. Upon decorating the raspberry-like silica nanoparticles with a few nanometer thick PDMS shell the highest nucleation efficiency obtained was 6.2 for particles with an overall core diameter of $\sim 200 \mathrm{~nm}$. This nucleation efficiency is nearly 40 times higher compared to that of a pristine nearly spherical silica nanoparticle with a similar diameter. In addition in this Chapter it is reported for the first time that smart particle design allows the nucleation of multiple cells per particle in nanocellular foaming. We will show qualitatively that the high nucleation efficiency obtained for PDMS grafted raspberry-like silica nanoparticles is ascribed to a significant increased absorption of $\mathrm{CO}_{2}$ during saturation. This results in a higher $\mathrm{CO}_{2}$ concentration close to the PDMS decorated energetically favorable nanocavities at the nucleating surface. The utilization of surface cavities combined with optimized surface chemistry for efficient heterogeneous nucleation at the 
macromolecular length scale is expected to open new avenues for the production of nanocellular foams with high cell densities.

\subsection{Results and discussion}

\subsubsection{Nanoparticles synthesis and characterization}

Raspberry-like silica nanoparticles $\left(\mathrm{SiO}_{2}-\mathrm{R}\right)$ were synthesized by the reaction of Stöber silica nanoparticles with $\mathrm{NaBH}_{4}$, followed by the surface grafting of PDMS to yield rough silica core PDMS shell hybrid nanoparticles $\left(\mathrm{SiO}_{2}-\mathrm{RP}\right)$. The reaction scheme is depicted in Figure 6.1A. (Hereinafter we abbreviate "nanoparticle" with NP.) During the reaction of nearly smooth Stöber $\mathrm{SiO}_{2}\left(\mathrm{SiO}_{2}-\mathrm{S}\right) \mathrm{NPs}$ with $\mathrm{NaBH}_{4}$ the high basicity of the dissolved $\mathrm{NaBH}_{4}$ results in the dissociation of $\mathrm{Si}-\mathrm{O}$ bonds and subsequently in the formation of soluble mono- and polysilicate species. Eventually the dissolved silicate species in the solution become supersaturated which leads to the formation of small $\mathrm{SiO}_{2}$ domains on the surface of the remaining silica NPs (Figure 6.1A, step 1). ${ }^{51,56-57}$

SEM images of $\mathrm{SiO}_{2}-\mathrm{S}$ and $\mathrm{SiO}_{2}-\mathrm{R}$ NPs with a diameter of approximately $155 \mathrm{~nm}$ are shown in Figure $6.1 \mathrm{~B}$ and $\mathrm{C}$, respectively. The diameter of the $\mathrm{SiO}_{2}-\mathrm{R}$ NPs is defined as the diameter of a circle just large enough to enclose the $\mathrm{SiO}_{2}-\mathrm{R}$ NPs outer surface. Particles with diameters between $80 \mathrm{~nm}$ and $200 \mathrm{~nm}$ were prepared. Table 6.1 shows the particle size as determined by SEM image analysis for each particle type. The numbers prior to $\mathrm{SiO}_{2}$ refer to the appeared particle diameter. For instance $155 \mathrm{SiO}_{2}-\mathrm{S}$ refers to a Stöber silica NP with an average diameter of $155 \mathrm{~nm}$.

Table 6.1 Average NP diameter (D) and size distribution (StDev, N>150) as determined by SEM image analysis. (Note that for reasons of clarification $\mathrm{SiO}_{2}$ is removed from the abbreviations used in the Table)

\begin{tabular}{l|c|c|c|c|c|c|c|c}
\hline & $80-\mathrm{S}$ & $80-\mathrm{R}$ & $120-\mathrm{S}$ & $120-\mathrm{R}$ & $155-\mathrm{S}$ & $155-\mathrm{R}$ & $200-\mathrm{S}$ & $200-\mathrm{R}$ \\
\hline $\begin{array}{l}\mathrm{D} \\
(\mathrm{nm})\end{array}$ & 83 & 75 & 124 & 117 & 156 & 153 & 195 & 204 \\
\hline StDev & 11 & 13 & 12 & 14 & 11 & 20 & 23 & 24 \\
\hline
\end{tabular}


From Figure 6.1C it is obvious that small silica domains (with diameters of $\sim 20$ to $30 \mathrm{~nm}$ ) are present at the surface of the NPs after treatment with $\mathrm{NaBH}_{4}$, which is in agreement with the assumed deposition of silicate species at the silica particle surface during the reaction. ${ }^{51}$ Following the successful synthesis of $\mathrm{SiO}_{2}-\mathrm{R}$ NPs with diameters of $\sim 200 \mathrm{~nm}, \sim 155 \mathrm{~nm}, \sim 120 \mathrm{~nm}$ and $\sim 80 \mathrm{~nm}$, a PDMS shell was grafted to yield the corresponding hybrid $\left(\mathrm{SiO}_{2}-\mathrm{RP}\right) \mathrm{NPs}$ (Figure 6.1A). In brief, $\mathrm{SiO}_{2}-\mathrm{R}$ were derivatized with (3-aminopropyl)-triethoxysilane (APTES), resulting in the formation of amine functionalized NPs $\left(\mathrm{SiO}_{2}-\mathrm{R}-\mathrm{NH}_{2}\right)$ (step 2). Subsequently, PDMS grafted core-shell NPs were prepared by the grafting to of monoglycidyl ether terminated PDMS (step 3).

We note here that prolonged sonication or even melt blending did not destroy the surface roughness of the (hybrid) raspberry-like NPs. Meaning that they are stable enough for utilization as nucleating particles in nanocellular foaming.

A

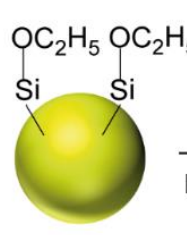

$\underset{\mathrm{NaBH}_{4}}{\stackrel{(1)}{\longrightarrow}}$

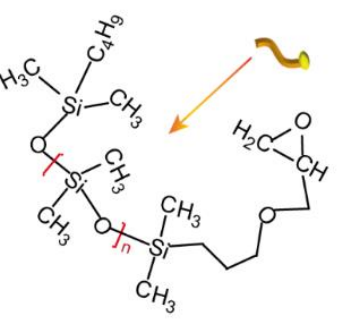

(2)
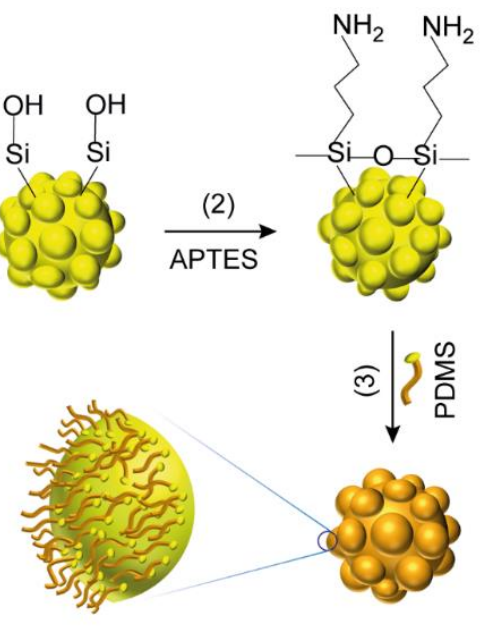

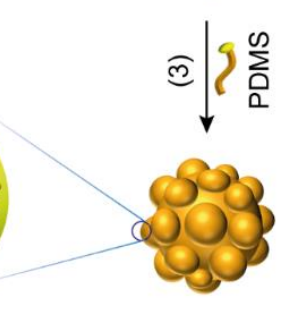

$\overrightarrow{\text { APTES }}$

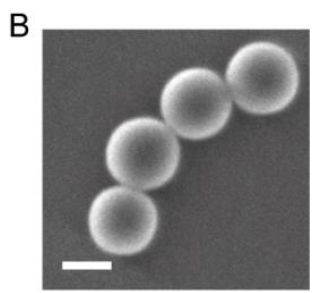

C

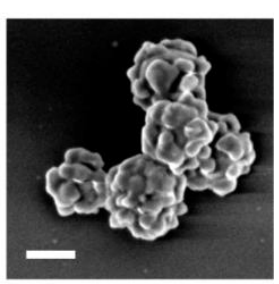

Figure 6.1 (A) Schematic of the $\mathrm{SiO}_{2}$-RP NPs preparation process. In (B) and (C) SEM images of $\mathrm{SiO}_{2}-\mathrm{S}$ and $\mathrm{SiO}_{2}-\mathrm{R}$ NPs with a silica particle diameter of $\sim 155 \mathrm{~nm}$ are shown, respectively. The scale bars in (B) and (C) represent $100 \mathrm{~nm}$.

Figure 6.2A shows FTIR absorbance spectra of $\mathrm{SiO}_{2}, \mathrm{SiO}_{2}-\mathrm{R}$, amino-functionalized $\mathrm{SiO}_{2}-\mathrm{R}\left(\mathrm{SiO}_{2}-\mathrm{R}-\mathrm{NH}_{2}\right), \mathrm{SiO}_{2}-\mathrm{RP}$ and $\mathrm{SiO}_{2}-\mathrm{SP}$ NPs with a (silica core ) diameter of $\sim 155$ $\mathrm{nm}$. The remaining ethoxy groups after the Stöber reaction of tetraethyl orthosilicate (TEOS) are clearly observed in the FTIR spectra of the $155 \mathrm{SiO}_{2}-\mathrm{S}$ particles, i.e. the $\mathrm{CH}_{2} / \mathrm{CH}_{3}$ bending absorbance band at $1452 \mathrm{~cm}^{-1}$ and the $\mathrm{CH}_{2} / \mathrm{CH}_{3}$ absorbance band at $2980 \mathrm{~cm}^{-1}{ }^{58}$ After $\mathrm{NaBH}_{4}$ etching to yield surface roughened NPs these absorbance bands disappeared, which indicates quantitative hydrolysis of the remaining ethoxy groups of the $155 \mathrm{SiO}_{2}-\mathrm{R} \mathrm{NPs}{ }^{51}$ The reappearance of absorbances at $2980 \mathrm{~cm}^{-1}, 1450$ 
$\mathrm{cm}^{-1}$ and $1380 \mathrm{~cm}^{-1}$ in the FTIR spectrum of $155 \mathrm{SiO}_{2}-\mathrm{R}-\mathrm{NH}_{2}$ are assigned to absorbances of the $\mathrm{CH}_{2}$ groups of the propyl spacer of surface tethered APTES. The presence of absorption bands ascribed to $\mathrm{CH}_{3}$ stretching at $2967 \mathrm{~cm}^{-1}$ and to $\mathrm{C}-\mathrm{H}$ bending at $1263 \mathrm{~cm}^{-1}$ in the FTIR spectrum of $155 \mathrm{SiO}_{2}-\mathrm{RP}$ NPs confirm the successful grafting of PDMS. ${ }^{59}$ The same absorbances are observed in the FTIR spectrum of nearly smooth PDMS grafted $\mathrm{SiO}_{2} \mathrm{NPs}\left(\mathrm{SiO}_{2}-\mathrm{SP}\right)$; their synthesis is well described in Chapters 3 and 4 as well as in the experimental section of this Chapter. ${ }^{33}$

To determine the amount of PDMS grafted to the silica NPs TGA was employed. Figure 6.2B shows the weight loss versus temperature curves for non-isothermal TGA measurements of nearly spherical and raspberry-like, amino-functionalized and PDMS grafted NPs with silica (core) diameters of approximately $155 \mathrm{~nm}$. The results clearly show that the amount of PDMS covalently bound to the $\mathrm{SiO}_{2} \mathrm{NPs}$ with a rough surface is significantly higher, i.e. $10.3 \mathrm{wt} \%$, compared to that of its spherical counterparts, i.e. $~ 3.0 \mathrm{wt} \%$. This nearly 3.4 fold increase in PDMS grafted weight is ascribed to the increased specific surface area for the raspberry-like NPs. Brunauer-Emmet-Teller (BET) measurements were used to determine the surface area of the prepared silica NPs. The results are shown in Figure 6.2C. It is obvious from Figure 6.2C that the surface area of the silica NPs was significantly increased after $\mathrm{NaBH}_{4}$ treatment. For the NPs with a diameter of $155 \mathrm{~nm}$ the surface area increased from $32.4 \mathrm{~m}^{2} \mathrm{~g}^{-1}$ to $116.0 \mathrm{~m}^{2} \mathrm{~g}^{-1}$ for the spherical and raspberry-like NPs, respectively. Nearly 3.6 fold increase in surface area is in good agreement with the 3.4 times higher grafted amount of PDMS to these particles. For the raspberry-like silica NPs with diameters of $200 \mathrm{~nm}$ and $120 \mathrm{~nm}$ the increase in PDMS grafting wt\% were in good agreement with the corresponding increase in surface area as well.

Based on the grafted PDMS mass obtained by TGA measurements, the molar mass of the grafted PDMS chains (i.e. 1,000 $\mathrm{g} \mathrm{mol}^{-1}$ ) and the BET surface area of the NPs the PDMS grafting densities were calculated to be $\sim 0.6$ chains $\mathrm{nm}^{-2}$ for the $155 \mathrm{SiO}_{2}-\mathrm{SP}$ and $155-\mathrm{SiO}_{2}$-RP NPs. This number is lower compared to the earlier reported value of 0.9 for $\mathrm{SiO}_{2}-\mathrm{SP}$ NPs with diameters of $12 \mathrm{~nm}$ to $120 \mathrm{~nm}$ (see Chapter 4). This difference is ascribed to the known over estimation of the surface area of Stöber silica NPs determined by BET measurements ${ }^{60-62}$ compared to the used simple arimetric estimation of the NP surface area based on the determined particle diameters in earlier Chapters. When using this simple arimetric method for the determination of the grafting density of the $\mathrm{SiO}_{2}$-SP NPs with a particle diameter from $80 \mathrm{~nm}$ to $200 \mathrm{~nm}$ graftng density values close to 0.9 chains $\mathrm{nm}^{-2}$ were obtained. This is in good agreement with values for $\mathrm{SiO}_{2}$-SP NPs reported in Chapters 3 and 4. Based on these results we note that BET analysis is used here only to qualitatively show the significant differences in surface area of the particles before and after roughening their surface. 

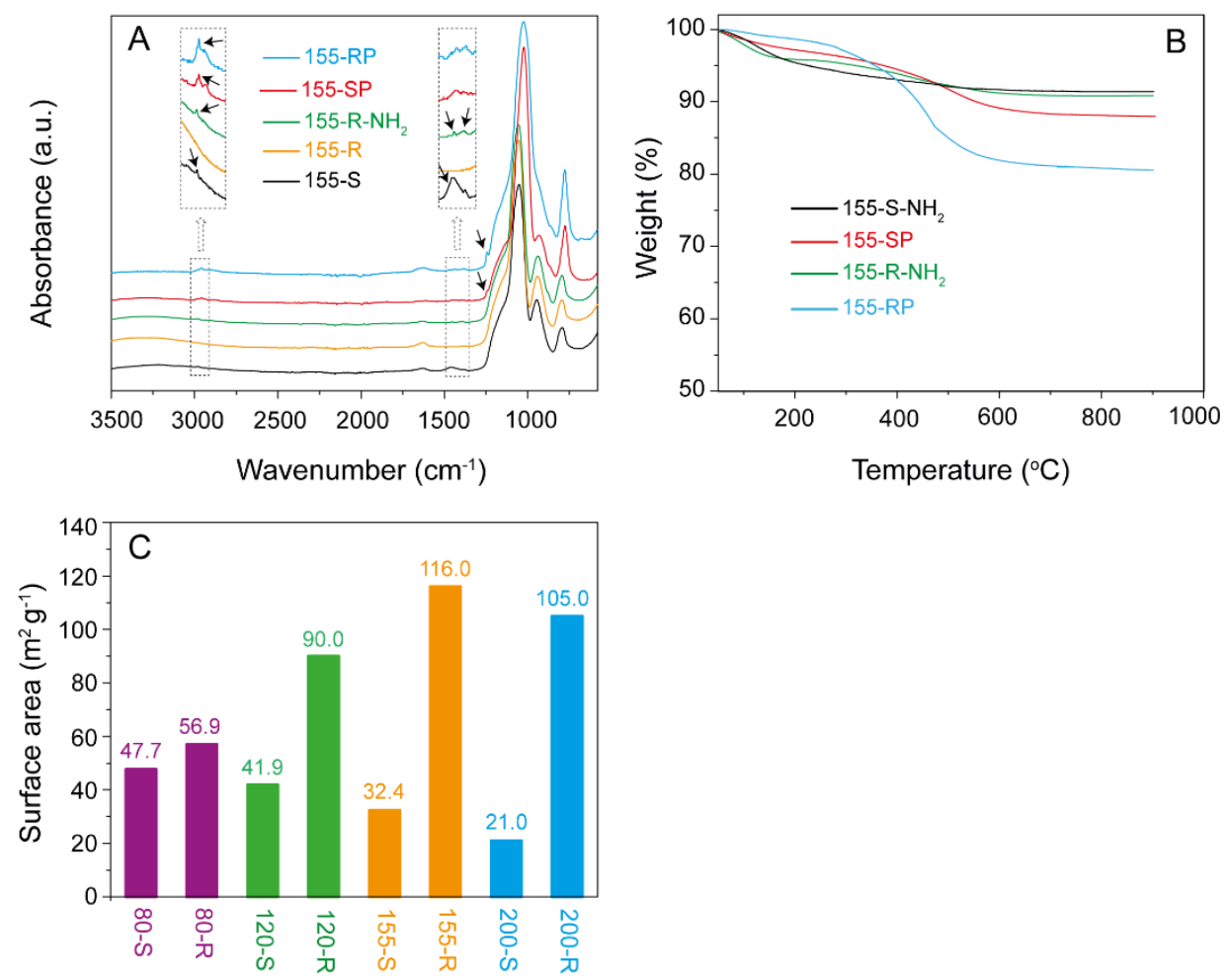

Figure 6.2 (A) Single reflection ATR-FTIR absorbance spectra of $155 \mathrm{SiO}_{2}-\mathrm{S}, 155 \mathrm{SiO}_{2}-\mathrm{R}$, $155 \mathrm{SiO}_{2}-\mathrm{R}-\mathrm{NH}_{2}, 155 \mathrm{SiO}_{2}-\mathrm{RP}$ and $155 \mathrm{SiO}_{2}-\mathrm{SP} \mathrm{NPs}$. The black arrows in the FTIR spectra indicate characteristic FTIR absorbances of the (modified) silica NPs. (B) Non-isothermal TGA thermograms of the $155 \mathrm{SiO}_{2}-\mathrm{S}_{-} \mathrm{NH}_{2}, 155 \mathrm{SiO}_{2}-\mathrm{R}-\mathrm{NH}_{2}, 155 \mathrm{SiO}_{2}-\mathrm{SP}$ and $155 \mathrm{SiO}_{2}-\mathrm{RP} \mathrm{NPs}$. In (C) the specific surface area determined by BET measurements of $\mathrm{SiO}_{2}-\mathrm{S}$ and $\mathrm{SiO}_{2}-\mathrm{R}$ NPs with a diameter of $\sim 80 \mathrm{~nm}, \sim 120 \mathrm{~nm}, \sim 155 \mathrm{~nm}$ and $\sim 200 \mathrm{~nm}$ is shown. (Note that for reasons of clarification $\mathrm{SiO}_{2}$ is removed from the abbreviations used in the Figure)

Finally, TEM was used to confirm the core-shell structure of the PDMS grafted NPs. Figure 6.3 shows TEM images of $155 \mathrm{~nm}$ bare and PDMS grafted spherical and raspberry-like NPs. From these TEM images it is clear that there is a thin PDMS shell around the $155 \mathrm{SiO}_{2}-\mathrm{SP}$ (Figure 6.3B) and $155 \mathrm{SiO}_{2}-\mathrm{RP}$ (Figure 6.3D) NPs. The tickness of the thin PDMS shell around the NPs was estimated to be around $6.0 \pm 1.5 \mathrm{~nm}$, which agrees well with the results reported in Chapter 4 for $\mathrm{SiO}_{2}$-SP NPs with silica core diameters from $12 \mathrm{~nm}$ to $120 \mathrm{~nm}$.

Hence, PDMS grafted core shell raspberry-like particle synthesis was succesful and the obtained particles were subsequently used as nucleating agents in the $\mathrm{CO}_{2}$ assited batch foaming of PMMA foams presented and discussed in the next sections. 

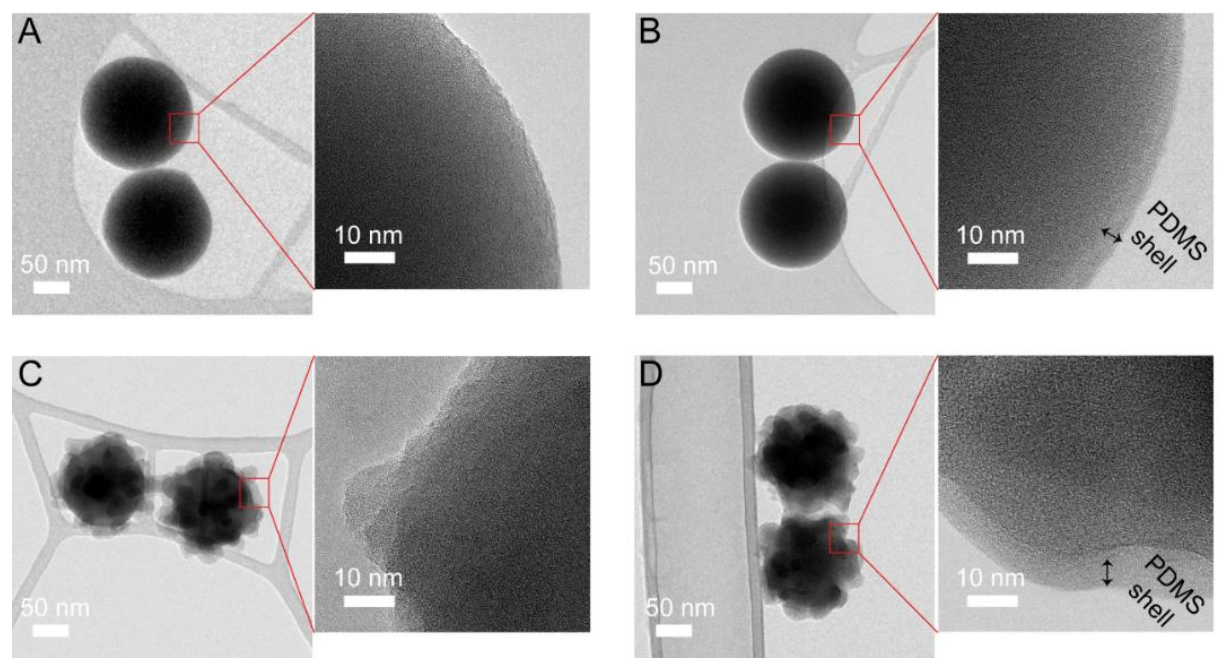

Figure 6.3 TEM images of $155 \mathrm{SiO}_{2}-\mathrm{S}(\mathrm{A}), 155 \mathrm{SiO}_{2}-\mathrm{SP} \mathrm{NPs}(\mathrm{B}), 155 \mathrm{SiO}_{2}-\mathrm{R}$ NPs (C) and $155 \mathrm{SiO}_{2}-\mathrm{RP}$ NPs (D).

\subsubsection{Nanocomposite foams}

Prior to foaming the prepared NPs were melt blended in a PMMA matrix and pressed to films with a thickness of around $200 \mu \mathrm{m}$. For comparison of the nucleation efficiency, the same volume number density of NPs (i.e. $1.07 \times 10^{13}$ particles $\mathrm{cm}^{-3}$ ) for each nanocomposite film were used. Thus assuming a good particle dispersion in the PMMA films and that each particle can nucleate the same amount of foam cells all nanocomposite films had the same volume number density of potential nucleation sites prior to foaming. The particles were well dispersed in PMMA prior to foaming as was observed from SEM images of cross sectioned PMMA nanocomposite films (data not shown).

Figure 6.4 shows SEM images of cross sectioned PMMA foams nucleated by $155 \mathrm{SiO}_{2}-\mathrm{S}, 155 \mathrm{SiO}_{2}-\mathrm{SP}, 155 \mathrm{SiO}_{2}-\mathrm{R}$ and $155 \mathrm{SiO}_{2}-\mathrm{RP}$ NPs. The used $\mathrm{CO}_{2}$ saturation pressure for the nanocomposite PMMA films was 55 bar and following quick depressurization foams were prepared at a foaming temperature of $40{ }^{\circ} \mathrm{C}$ for 1 second. This relatively short foaming time was chosen since we were primarily interested in the nucleation efficiency of the prepared particles and not in the well developed foam morphology at the end stages of foaming (i.e. after several tens of seconds to minutes). From the SEM images in Figure 6.4, it is clear that for the used foaming time of 1 second the PMMA foams have thick cell walls and struts as was expected. Furthermore, it is clear that the $155 \mathrm{SiO}_{2}-\mathrm{S}, 155 \mathrm{SiO}_{2}-\mathrm{SP}$ and $155 \mathrm{SiO}_{2}-\mathrm{R}$ NPs are present at the polymer foam cell wall surface. The $155 \mathrm{SiO}_{2}-\mathrm{S}$ NPs are slightly more embedded in the PMMA cell wall compared to the $155 \mathrm{SiO}_{2}-\mathrm{SP}$ which is in good agreement with the 
reported results in Chapter 4 for the nucleation behavior of pristine $\mathrm{SiO}_{2}$ and corresponding PDMS grafted core shell NPs with (core) diameters up to $120 \mathrm{~nm} \cdot{ }^{33}$

Remarkably, when examining the $155 \mathrm{SiO}_{2}$-RP NPs embedded in the PMMA foams it is clear that most of these particles are surrounded by a few primary polymer foam cells (see Figure 6.4D). Of particular interest is that the cell walls in between these primary foam cells is much thinner compared to the non nucleated/expanded PMMA matrix surrounding them and that the size of the cells around the $155 \mathrm{SiO}_{2}-\mathrm{RP}$ particles is fairly uniform. This points towards simultaneous multiple heterogeneous nucleation events per added particle. In addtion, the thin wall between some foam cells appears to be ruptured or partly disappeared. This indicates that cell coalescence of the cells growing in close proximity to each other occurs during the first second of foaming already. Regarding these observations, an explanation is provided later.
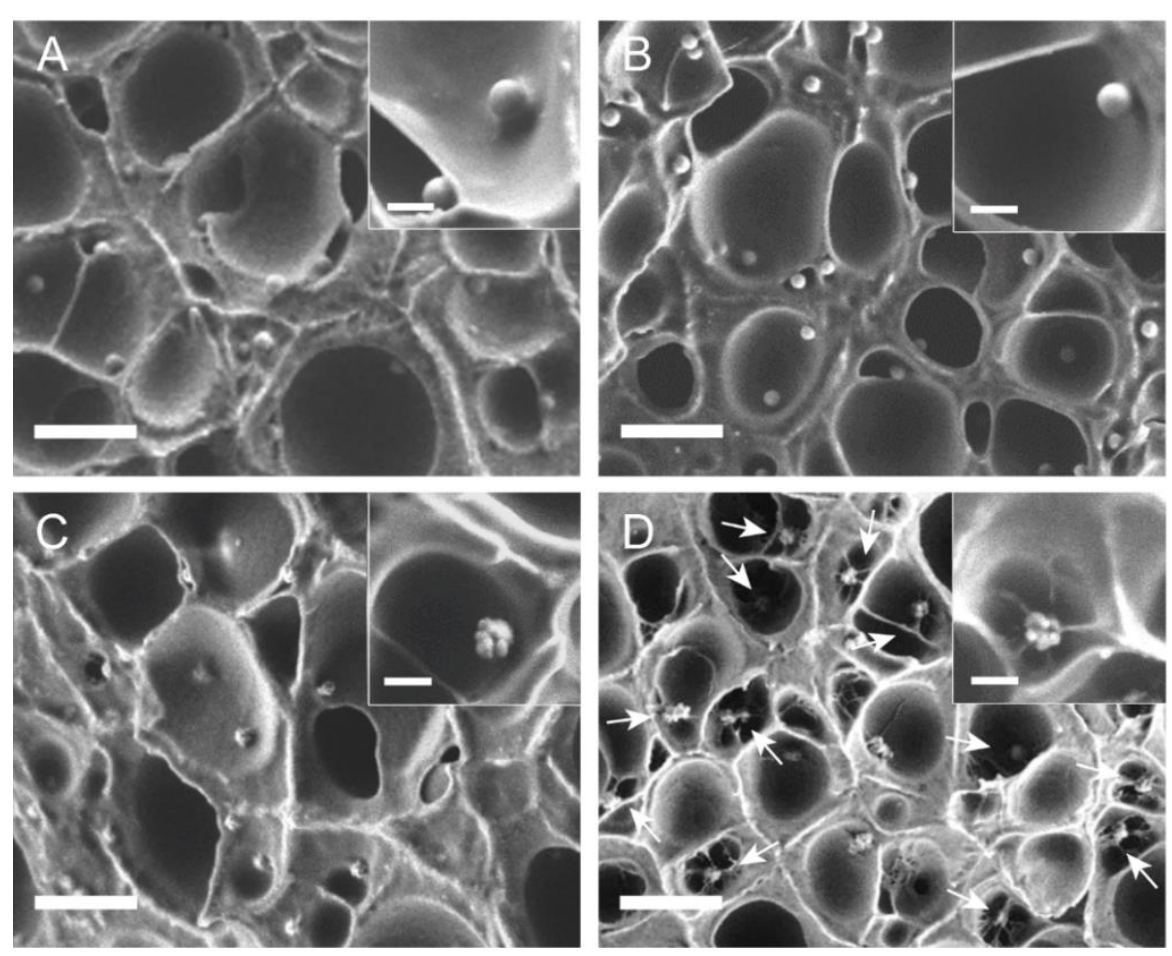

Figure 6.4 SEM images of cross sectioned PMMA foams nucleated by $155 \mathrm{SiO}_{2}-\mathrm{S}(\mathrm{A}), 155 \mathrm{SiO}_{2}-$ $\mathrm{SP}(\mathrm{B}), 155 \mathrm{SiO}_{2}-\mathrm{R}$ (C) and $155 \mathrm{SiO}_{2}-\mathrm{RP}$ (D) NPs. The white arrows in (D) point towards $155 \mathrm{SiO}_{2}-\mathrm{RP}$ particles showing multiple cell nucleation events per particle. The insets show higher magnification images of nucleating NPs in cross sectioned PMMA foam cells. The scale bars in the SEM images and insets represent $1 \mu \mathrm{m}$ and $200 \mathrm{~nm}$, respectively. The saturation pressure, foaming temperature and foaming time were $55 \mathrm{bar}, 40^{\circ} \mathrm{C}$ and 1 second, respectively. 


\subsubsection{PMMA nanocomposite foam morphology as a function of foaming time}

Based on the multiple foam cell nucleation events and early stage cell coalescence we were interested in the development of the foam morphology, i.e. cell size and cell density, as a function of the foaming time for PMMA foams nucleated by $155 \mathrm{SiO}_{2}-\mathrm{RP}$ NPs. Figure 6.5 shows SEM images of cross sectioned PMMA foams nucleated by $155 \mathrm{SiO}_{2}-\mathrm{RP}$ NPs as a function of the foaming time from 0.3 to 30 seconds. The shortest foaming time we could experimentally achieve was 0.3 seconds. From the SEM images shown in Figure 6.5 it is clear that for a foaming time of fewer than 5 seconds multiple primary cells around a nucleating $155 \mathrm{SiO}_{2}-\mathrm{RP} \mathrm{NP}$ are observed. While for foaming times longer than 5 seconds cell coalescence results in the formation of larger cells around the nucleating particles. This is obvious from the nearly smooth foam cell walls observed around the $155 \mathrm{SiO}_{2}-\mathrm{RP}$ NPs residing at the cell walls for foams prepared with foaming times of 10 and 30 seconds (Figure 6.5D and E).
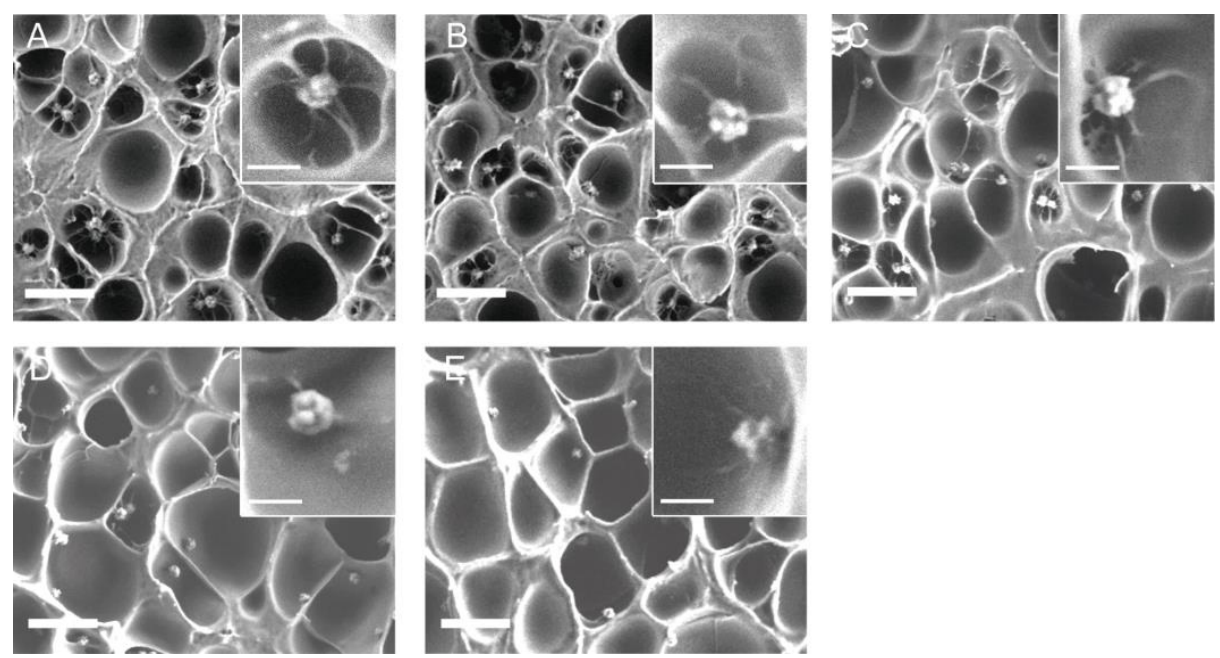

Figure 6.5 SEM images of cross sectioned PMMA foams nucleated by $155 \mathrm{SiO}_{2}-\mathrm{RP}$ NPs for 0.3 seconds (A), 1 second (B), 5 seconds (C), 10 seconds (D) and 30 seconds (E). The scale bars represent $1 \mu \mathrm{m}$. In the insets, the foam cell wall around a single $155 \mathrm{SiO}_{2}-\mathrm{RP}$ nanoparticle in a cross sectioned PMMA foam cell is shown. The scale bar in the insets represents $200 \mathrm{~nm}$. The saturation pressure and foaming temperature were 55 bar and $40{ }^{\circ} \mathrm{C}$, respectively. 


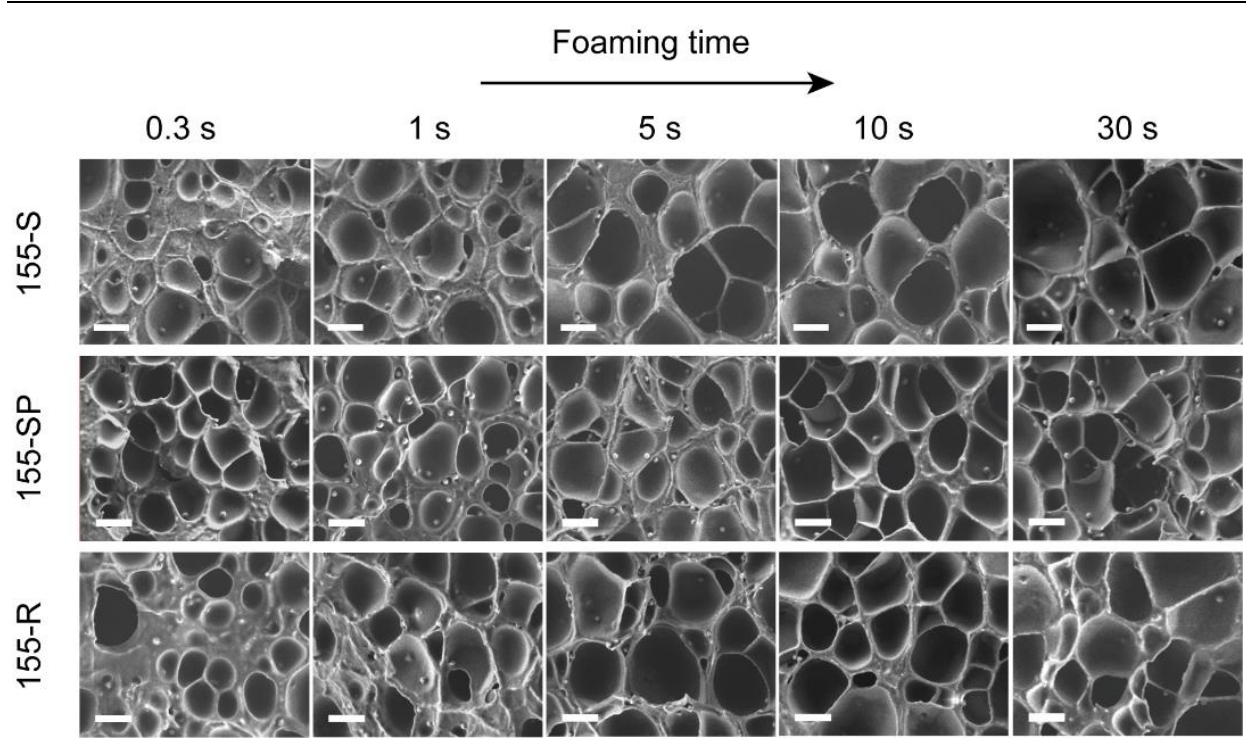

Figure 6.6 SEM images of cross sectioned PMMA foams nucleated by $155 \mathrm{SiO}_{2}-\mathrm{S}, 155 \mathrm{SiO}_{2}-\mathrm{SP}$ and $155 \mathrm{SiO}_{2}-\mathrm{R}$ NPs as a function of the foaming time. The scale bars represent $1 \mu \mathrm{m}$. The saturation pressure and foaming temperature were 55 bar and $40{ }^{\circ} \mathrm{C}$, respectively.

The SEM images of cross sectioned PMMA foams nucleated by $155 \mathrm{SiO}_{2}-\mathrm{S}$, $155 \mathrm{SiO}_{2}-\mathrm{SP}$ and $155 \mathrm{SiO}_{2}-\mathrm{R}$ with a foaming time of 0.3 seconds to 30 seconds are shown in Figure 6.6. No multiple cell nucleation events per particle were observed for foams nucleated by these NPs.

For quantitative comparison, the cell size, cell density and nucleation efficiency for PMMA foams nucleated by $155 \mathrm{SiO}_{2}-\mathrm{S}, 155 \mathrm{SiO}_{2}-\mathrm{SP}, 155 \mathrm{SiO}_{2}-\mathrm{R}$ and $155 \mathrm{SiO}_{2}-\mathrm{RP} \mathrm{NPs}$ were determined as a function of the foaming time. The results are shown in Figure 6.7. The nucleation efficiency was calculated as the ratio of the cell density divided by the number of NPs $\mathrm{cm}^{-3}$ added prior to foaming (i.e. $1.07 \times 10^{13} \mathrm{NPs} \mathrm{cm}^{-3}$ ). 

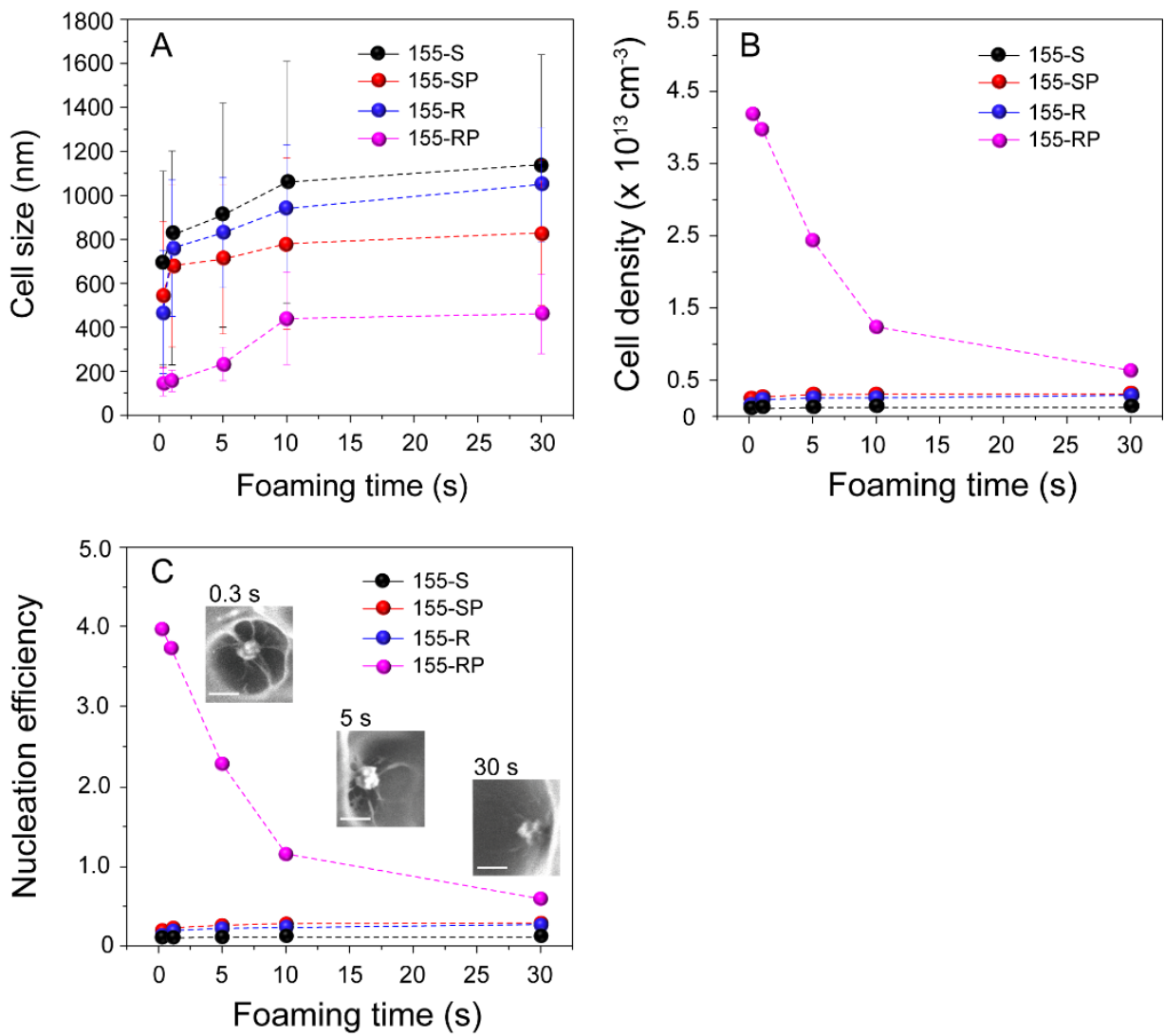

Figure 6.7 Foam cell size (A), cell density (B) and nucleation efficiency (C) as a function of foaming time for PMMA foams nucleated by $155 \mathrm{SiO}_{2}-\mathrm{S}, 155 \mathrm{SiO}_{2}-\mathrm{SP}, 155 \mathrm{SiO}_{2}-\mathrm{R}$ and $155 \mathrm{SiO}_{2}-$ RP NPs. The scale bar in the SEM images in the insets in (C) represent $200 \mathrm{~nm}$. The used saturation pressure and foaming temperature were 55 bar and $40{ }^{\circ} \mathrm{C}$, respectively. (Note that for reasons of clarification $\mathrm{SiO}_{2}$ is removed from the abbreviations used in the Figure)

From Figure $6.7 \mathrm{~A}$ it is obvious that independent of the use of $155 \mathrm{SiO}_{2}-\mathrm{S}, 155 \mathrm{SiO}_{2}-$ $\mathrm{SP}, 155 \mathrm{SiO}_{2}-\mathrm{R}$ and $155 \mathrm{SiO}_{2}-\mathrm{RP} \mathrm{NPs}$ as nucleation agent the cell size of the corresponding PMMA foams increases for foaming times up to 10 seconds after which it reaches a plateau value which absolute value depends on the nucleating particle type used. For instance when $155 \mathrm{SiO}_{2}-\mathrm{SP}$ or $155 \mathrm{SiO}_{2}-\mathrm{RP}$ were used as nucleating agents the final foam cell size was $830 \pm 330 \mathrm{~nm}$ and $460 \pm 180 \mathrm{~nm}$, respectively.

The larger foam cell size $(830 \pm 330 \mathrm{~nm})$ obtained for the $155 \mathrm{SiO}_{2}-\mathrm{SP}$ compared to our previously reported values of $430 \pm 131 \mathrm{~nm}$ for $\mathrm{SiO}_{2}$-SP with a core diameter of 80 nanometers, (see Chapter 4) is ascribed to a lower particle concentration (number $\mathrm{cm}^{-3}$ ) used for the $155 \mathrm{SiO}_{2}$-SP NPs in this Chapter (i.e. $1.07 \times 10^{13} \mathrm{~cm}^{-3}$ ) compared to the concentration used in Chapter 4 (i.e. $2.3 \times 10^{13} \mathrm{~cm}^{-3}$ ). Hence provided an assumed 
equally efficient heterogeneous nucleation the nuclei concentration in this Chapter is lower while as a consequence the available amount of $\mathrm{CO}_{2}$ for cell growth is larger, resulting in cells with an increased cell size.

The cell density of PMMA foams containing $155 \mathrm{SiO}_{2}-\mathrm{SP}$ is higher compared to those containing $155 \mathrm{SiO}_{2}-\mathrm{S}$ for the same foaming time (as shown in Figure 6.7B), which is ascribed to the high $\mathrm{CO}_{2}$-philicity and low surface energy of the thin PDMS shell of the $155 \mathrm{SiO}_{2}$-SP NPs. This agrees well with the trend in cell density that is reported in Chapter 4 for (PDMS grafted) $\mathrm{SiO}_{2} \mathrm{NPs}$ with a (core) diameter between 12 to $120 \mathrm{~nm}$ (Note: the saturation pressure, foaming temperature and time for these foams were 55 bar, $40{ }^{\circ} \mathrm{C}$ and $180 \mathrm{~s}$, respectively).

Interestingly, the raspberry-like NPs, i.e. $155 \mathrm{SiO}_{2}-\mathrm{R}$, show a higher cell density compared to that of $155 \mathrm{SiO}_{2}-\mathrm{S}$, as well. This is ascribed to the presence of cavities on the raspberry-like nanoparticle surfaces, resulting in energetically favorable cell nucleation. ${ }^{46}$ Furthermore, the cell density increases with the foaming time for PMMA foams containing $155 \mathrm{SiO}_{2}-\mathrm{S}, 155 \mathrm{SiO}_{2}-\mathrm{SP}$ and $155 \mathrm{SiO}_{2}-\mathrm{R}$ NPs for foaming times below 10 seconds. This is the result of the continuous increase in cumulative cell nucleation events in these foams for increased foaming times.

Strikingly, especially during the first 10 second of foaming in the presence of $155 \mathrm{SiO}_{2}-\mathrm{RP} \mathrm{NPs}$ the resulting foams exhibit a significantly higher cell density compared to that of $155 \mathrm{SiO}_{2}-\mathrm{S}, 155 \mathrm{SiO}_{2}-\mathrm{SP}$ and $155 \mathrm{SiO}_{2}-\mathrm{R}$. For instance, PMMA foams with $155 \mathrm{SiO}_{2}$-RP foamed for 1 second have a cell density of $\sim 4.0 \times 10^{13}$ cells $\mathrm{cm}^{-3}$, which is $\sim 25, \sim 37$ and $\sim 16$ times higher compared to PMMA foams containing $155 \mathrm{SiO}_{2}-\mathrm{R}, 155 \mathrm{SiO}_{2}-\mathrm{S}$ and $155 \mathrm{SiO}_{2}-\mathrm{SP}$ nucleating particles, respectively. In addition, the cell density of PMMA foams nucleated by $155 \mathrm{SiO}_{2}-\mathrm{RP}$ decreases upon increasing the foaming time. This is ascribed to the observed cell coalescence occurring during the early stages of foaming (see Figure 6.5).

The cell nucleation efficiencies as a function of the foaming time for PMMA foams containing $155 \mathrm{SiO}_{2}-\mathrm{S}, 155 \mathrm{SiO}_{2}-\mathrm{SP}, 155 \mathrm{SiO}_{2}-\mathrm{R}$ and $155 \mathrm{SiO}_{2}-\mathrm{RP}$ as shown in Figure 6.7C follows the same trend as the corresponding foam cell densities (compare Figure 6.7B). Remarkably, the nucleation efficiency of $155 \mathrm{SiO}_{2}-\mathrm{RP}$ is well above 1 within the first 10 seconds of foaming, which is ascribed to the multiple cell nucleation events occurring per nucleating $155 \mathrm{SiO}_{2}-\mathrm{RP}$ particle. For instance, 1 second foamed PMMA containing $155 \mathrm{SiO}_{2}-\mathrm{RP}$ had a nucleation efficiency of $\sim 3.7$ which is $\sim 37$ times higher compared to the nucleation efficiency of $155 \mathrm{SiO}_{2}-\mathrm{S}$ particles, as is shown in Figure 6.7C. Thus every single $155 \mathrm{SiO}_{2}$-RP resulted in the formation of almost 4 cells after foaming for 1 second. This is in good agreement with the visual observations in the SEM images shown in Figure 6.4. We note that the determined cell densities do not take the presence of cell coalescence into account. As a consequence, an even higher cell nucleation efficiency for the $155 \mathrm{SiO}_{2}-\mathrm{RP}$ nucleating NPs is anticipated. The excellent 
nucleation performance of $155 \mathrm{SiO}_{2}-\mathrm{RP}$ is ascribed to the energetically favorable cell nucleation from the particles surface cavities ${ }^{46}$ combined with the presence of a $\mathrm{CO}_{2}$ philic PDMS layer around the $155 \mathrm{SiO}_{2}$-RP NPs.

\subsubsection{PMMA foam cell nucleation versus surface roughness variation}

The presence of multiple nucleation events per $155 \mathrm{SiO}_{2}-\mathrm{RP}$ particles is promising for developing nanocellular foams with increased cell densities. To successfully exploit this it is of pivotal importance to obtain a deeper understanding of cell nucleation as a function of the surface roughness feature sizes. Therefore, we have prepared $\mathrm{SiO}_{2}-\mathrm{R}$ and $\mathrm{SiO}_{2}$-RP NPs with a diameter of $\sim 80 \mathrm{~nm}, \sim 120 \mathrm{~nm}$ and $\sim 200 \mathrm{~nm}$ as well to explore this qualitatively. Figure 6.8 shows $\mathrm{SEM}$ images of $80 \mathrm{SiO}_{2}-\mathrm{R}(6.8 \mathrm{~A})$ and $200 \mathrm{SiO}_{2}-\mathrm{R}$ (6.8B), as well as of cross sectioned PMMA foams nucleated by $80 \mathrm{SiO}_{2}-\mathrm{RP}(6.8 \mathrm{C})$ and $200 \mathrm{SiO}_{2}-\mathrm{RP}(6.8 \mathrm{D}) \mathrm{NPs}$. From the SEM images of the raspberry-like silica NPs it is clear that the feature sizes of the roughened surfaces are different for the $\sim 80 \mathrm{~nm}$ and $\sim$ $200 \mathrm{~nm}$ particles, i.e. $80 \mathrm{SiO}_{2}-\mathrm{R}$ has only a few attached small particles to its surface while $200 \mathrm{SiO}_{2}-\mathrm{R}$ reveals numerous larger attached particles. The SEM images of the cross sectioned PMMA foams nucleated by $80 \mathrm{SiO}_{2}-\mathrm{RP}\left(6.8 \mathrm{C}\right.$ ) and $200 \mathrm{SiO}_{2}-\mathrm{RP}$ (6.8D) reveal distinct differences in the foam morphology as well. For instance, $200 \mathrm{SiO}_{2}-\mathrm{RP}$ clearly shows the presence of multiple cells around single nucleating particles, however, no multiple cell nucleation events are observed around single $80 \mathrm{SiO}_{2}-\mathrm{RP} \mathrm{NPs}$.

It turned out that for the used etching method the initial Stöber silica nanoparticle size used directs more or less the final particle roughness obtained. ${ }^{51}$ Thus it was not possible to obtain particles with a similar surface roughness for particle diameters between 80 to $200 \mathrm{~nm}$.

Hence, below we present qualitatively how the nucleation efficiency of $\mathrm{SiO}_{2}-\mathrm{RP}$ NPs depends on the particles surface roughness for a PMMA foaming time of 1 second. Figure 6.9 shows the cell size (6.9A), cell density (6.9B) and nucleation efficiency (6.9C) for PMMA foams nucleated by $\mathrm{SiO}_{2}-\mathrm{S}, \mathrm{SiO}_{2}-\mathrm{SP}, \mathrm{SiO}_{2}-\mathrm{R}$, and $\mathrm{SiO}_{2}-\mathrm{RP}$ NPs as a function of the silica particle diameter. 

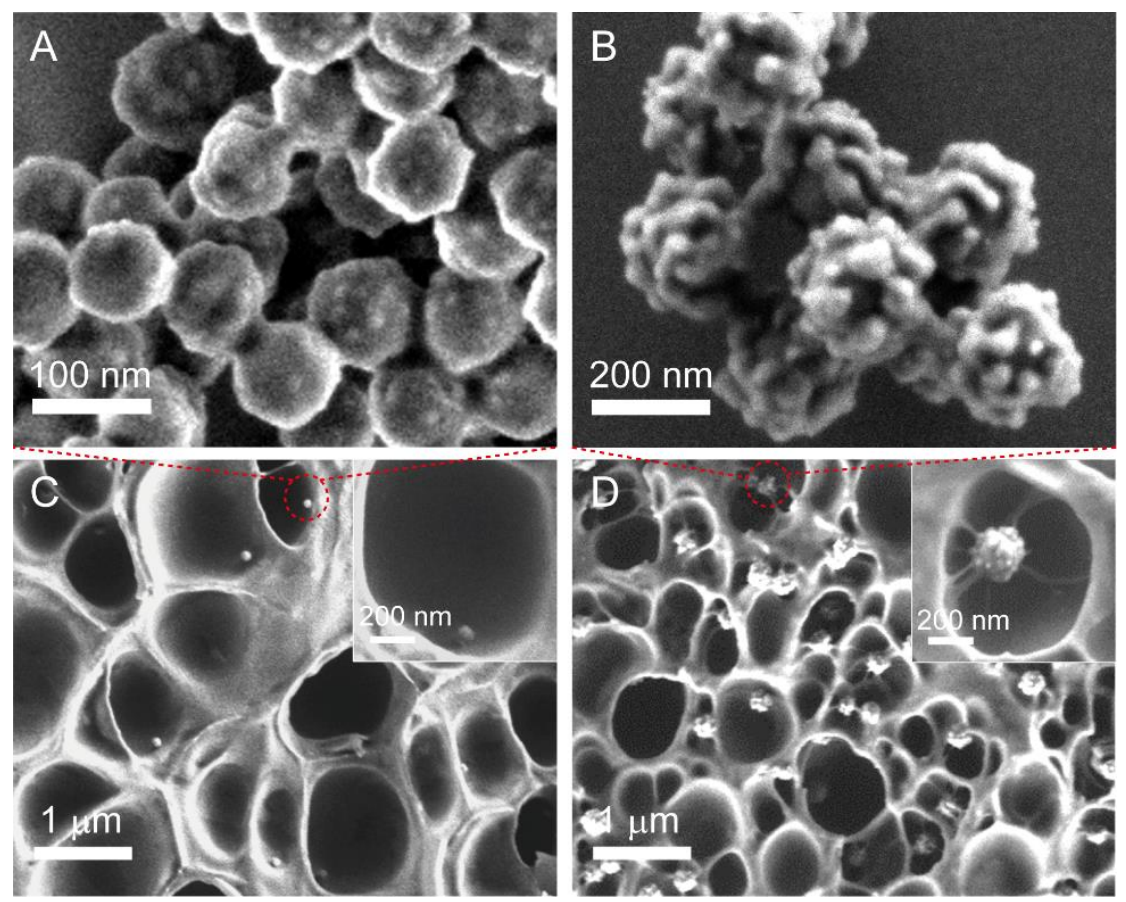

Figure 6.8 SEM images of $80 \mathrm{SiO}_{2}-\mathrm{R}(\mathrm{A})$ and $200 \mathrm{SiO}_{2}-\mathrm{R}$ (B) particles, as well as cross sectioned PMMA foams nucleated by $80 \mathrm{SiO}_{2}-\mathrm{RP}$ (C) and $200 \mathrm{SiO}_{2}-\mathrm{RP}$ (D). The saturation pressure, foaming temperature and foaming time were 55 bar, $40{ }^{\circ} \mathrm{C}$ and 1 second, respectively.

From Figure 6.9A it is obvious that the average cell size for foams nucleated with $\mathrm{SiO}_{2}$-RP NPs is smaller compared to its counterparts with the same diameter. In addition, upon increasing the particale diameter from 80 to 200 nanometer the average cell size decreases and the cell size distribution becomes narrower. SEM images of cross sectioned PMMA foams nucleated by $80 \mathrm{SiO}_{2}-\mathrm{RP}$ particles did not reveal any multilple cell nucleation events per particle (compare Figure 6.8C), while for $120 \mathrm{SiO}_{2}$ RP this was observed for some particles. The absence or reduced number of multiple nucleation events is ascribed to a lower surface roughness of the $80-\mathrm{SiO}_{2}-\mathrm{RP}$ and $120 \mathrm{SiO}_{2}-\mathrm{RP}$ NPs, i.e resulting in a reduced number of effective nanocativities. However, for PMMA foams nucleated by $155 \mathrm{SiO}_{2}-\mathrm{RP}$ and $200 \mathrm{SiO}_{2}-\mathrm{RP}$ particles multiple cell nulceation events were observed, which results in a higher $\mathrm{CO}_{2}$ consumption during cell growth compared to the foams without multiple cell nucleation events occuring. This explains the reduction in cell size to $156 \pm 49 \mathrm{~nm}$ and $107 \pm 58 \mathrm{~nm}$ for foams with $155 \mathrm{SiO}_{2}-\mathrm{RP}$ and $200 \mathrm{SiO}_{2}-\mathrm{RP}$ particles, respectivley. 

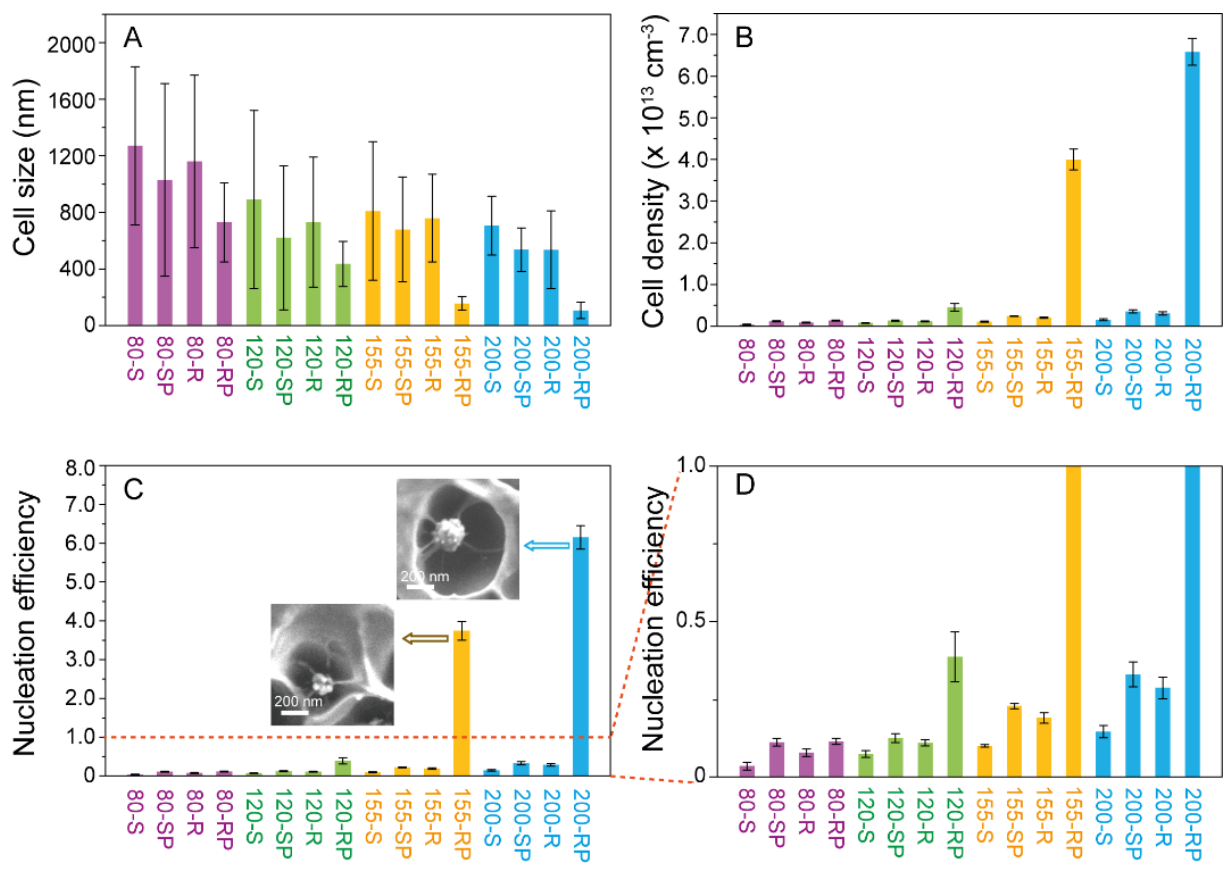

Figure 6.9 Foam cell size (A), cell density (B) and cell nucleation efficiency (C) for PMMA foams nucleated by $\mathrm{SiO}_{2}-\mathrm{S}, \mathrm{SiO}_{2}-\mathrm{SP}, \mathrm{SiO}_{2}-\mathrm{R}$ and $\mathrm{SiO}_{2}-\mathrm{RP}$ with diameters of $\sim 80 \mathrm{~nm}, \sim 120 \mathrm{~nm}$, $155 \mathrm{~nm}$ and $\sim 200 \mathrm{~nm}$. The saturation pressure, foaming temperature and foaming time for these nanocomposite PMMA foams were $55 \mathrm{bar}, 40{ }^{\circ} \mathrm{C}$ and 1 second, respectively. The insets in Figure $\mathrm{C}$ show SEM images of cross sectioned PMMA foam cells showing the presence of multiple cells around single $155 \mathrm{SiO}_{2}-\mathrm{RP}$ and $200 \mathrm{SiO}_{2}-\mathrm{RP}$ NPs. The scale bars represent $200 \mathrm{~nm}$. (Note that for reasons of clarification $\mathrm{SiO}_{2}$ is removed from the abbreviations used in the Figure)

The occurance of multiple cell nucleation events for $\mathrm{SiO}_{2}-\mathrm{RP}$ NPs with various roughnesses has as expected a significant effect on the obtained cell densities and nucleation effciencies (Figures 6.9B and C). The $200 \mathrm{SiO}_{2}-\mathrm{RP}$ NPs have, similar to the $155 \mathrm{SiO}_{2}-\mathrm{RP}$ NPs, a significant increase in cell density and cell nucleation efficiency ) compared to the other particle types. In fact for the $200 \mathrm{SiO}_{2}-\mathrm{RP} \mathrm{NPs}$ the nucleation efficiency was $\sim 6.2$, which is the highest nucleation efficiency reported so far.

In addition $120 \mathrm{SiO}_{2}-\mathrm{RP}$ particles have a higher nucleation efficiency compared to $120 \mathrm{SiO}_{2}-\mathrm{S}, 120 \mathrm{SiO}_{2}-\mathrm{R}, 120 \mathrm{SiO}_{2}-\mathrm{SP}$, as well (see Figure $6.9 \mathrm{C}$ ). This is qualitiatively explained by the presence of some nanocavities. However, $80 \mathrm{SiO}_{2}-\mathrm{RP}$ show a comparable nucleation efficiency with $80 \mathrm{SiO}_{2}-\mathrm{SP}$, which is ascribed to presence of mainly convex surface domains at its particle surface. Compared to concave surface roughness, convex structures have a higher cell nulceation free energy. ${ }^{47-48}$

In addition, from Figure 6.9 it is obvious that for the particle sizes evaluated the $\mathrm{SiO}_{2}-\mathrm{R}$ NPs have nucleation efficiencies comparable to $\mathrm{SiO}_{2}-\mathrm{SP} N P s$, while the $\mathrm{SiO}_{2}-\mathrm{S}$ 
particles are the least effective nucleating agents. Overall it is shown that NPs designed with a concave surface roughness are more efficient to be used as nucleation agents compared to the nearly spherical ones and that a combination of roughness with a $\mathrm{CO}_{2}$ philic low surface energy PDMS shell has a tremendous synergytic effect on PMMA foam cell nucleation.

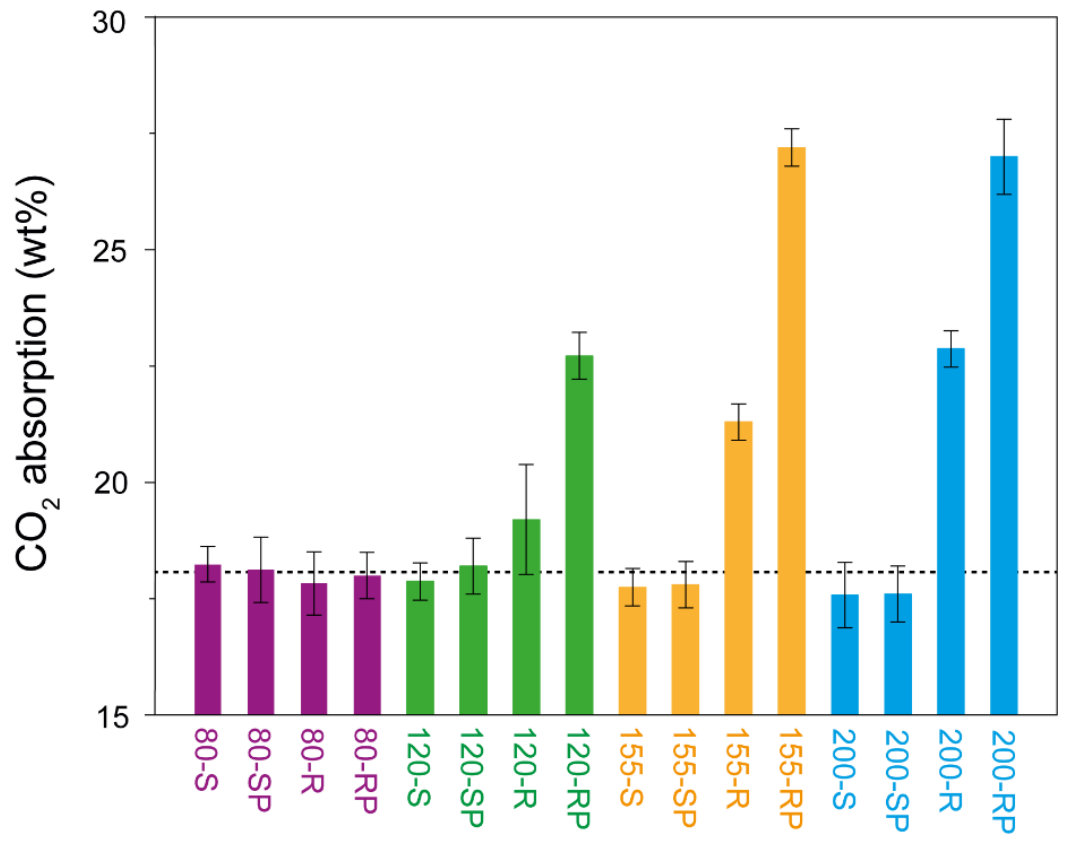

Figure 6.10 $\mathrm{CO}_{2}$ absorption for PMMA films containing $\mathrm{SiO}_{2}-\mathrm{S}, \mathrm{SiO}_{2}-\mathrm{SP}, \mathrm{SiO}_{2}-\mathrm{R}$ and $\mathrm{SiO}_{2}-\mathrm{RP}$ particles with diameters between $80 \mathrm{~nm}$ to $200 \mathrm{~nm}$. The saturation pressure and time were 55 bar and $4 \mathrm{~h}$, respectively. The dashed line shows the $\mathrm{CO}_{2}$ absorption of PMMA containing no NPs. (Note that for reasons of clarification $\mathrm{SiO}_{2}$ is removed from the abbreviations used in the Figure)

\subsection{5 $\mathrm{SiO}_{2}-\mathrm{RP}$ nucleation mechanism elucidated}

The synergetic effect of a PDMS shell with the presence of cavities on the nucleation efficiency of $\mathrm{SiO}_{2}$-RP NPs in the batch foaming of PMMA was much higher than expected. In fact, we reasoned that for the higher number of cells to grow more $\mathrm{CO}_{2}$ as a blowing agent had to be available as well. Thus the $\mathrm{CO}_{2}$ absorption of PMMA films containing $\mathrm{SiO}_{2}-\mathrm{S}, \mathrm{SiO}_{2}-\mathrm{SP}, \mathrm{SiO}_{2}-\mathrm{R}$ and $\mathrm{SiO}_{2}-\mathrm{RP}$ particles with diameters of 80 $\mathrm{nm}, 120 \mathrm{~nm}, 155 \mathrm{~nm}$ and $200 \mathrm{~nm}$ were determined in order to further elucidate the cell nucleation efficiency as a function of the particle type and size. The results are shown in Figure 6.10. As is obvious PMMA films containing $\mathrm{SiO}_{2}-\mathrm{S}$ and $\mathrm{SiO}_{2}-\mathrm{SP}$ have no significant differences in $\mathrm{CO}_{2}$ absorption independent of the particle diameter compared 
to PMMA containing no NPs. The same is observed for $80 \mathrm{SiO}_{2}-\mathrm{R}$ and $80 \mathrm{SiO}_{2}-\mathrm{RP}$ NPs. Hence for these particles the overall $\mathrm{CO}_{2}$ concentration is not altered while locally in the PMMA films the $\mathrm{CO}_{2}$ concentration may vary due to the presence of a PDMS shell. Upon increasing the surface roughness of the particles, e.g. for the $120 \mathrm{SiO}_{2}-\mathrm{R}, 155$ $\mathrm{SiO}_{2}-\mathrm{R}$ and $200 \mathrm{SiO}_{2}-\mathrm{R} \mathrm{NPs}$, the amount of $\mathrm{CO}_{2}$ absorbed is significantly increased. The presence of a PDMS shell increases the amount absorbed even more for these NPs. For instance for $200 \mathrm{SiO}_{2}-\mathrm{R}$ and $200 \mathrm{SiO}_{2}-\mathrm{RP}$ the increase in $\mathrm{CO}_{2}$ absorbed was $\sim 4.7 \mathrm{wt}$ $\%$ and $\sim 8.8 \mathrm{wt} \%$, respectivley, compared to the PMMA containing no particles $(\sim 18.2$ wt $\%$ ).

This increase in $\mathrm{CO}_{2}$ absorption for the rough particles is ascribed to $i$ ) capilary condensation of $\mathrm{CO}_{2}$ in the nanocavities ${ }^{63-65}$ and/or ii) to differences in the $\mathrm{CO}_{2}$ absorption mechanism for the raspberry-like NPs. The even larger increase in $\mathrm{CO}_{2}$ absorption for the rough particles with a PDMS shell with diamers of $\sim 120 \mathrm{~nm}, \sim 155$ $\mathrm{nm}$ and $\sim 200 \mathrm{~nm}$ compared to their bare counterparts is ascribed to the presence of $\mathrm{CO}_{2}$ philic molecules attached to the nanocavity surfaces, which is known to potentially enhance the absorption of $\mathrm{CO}_{2} \cdot{ }^{66-68}$

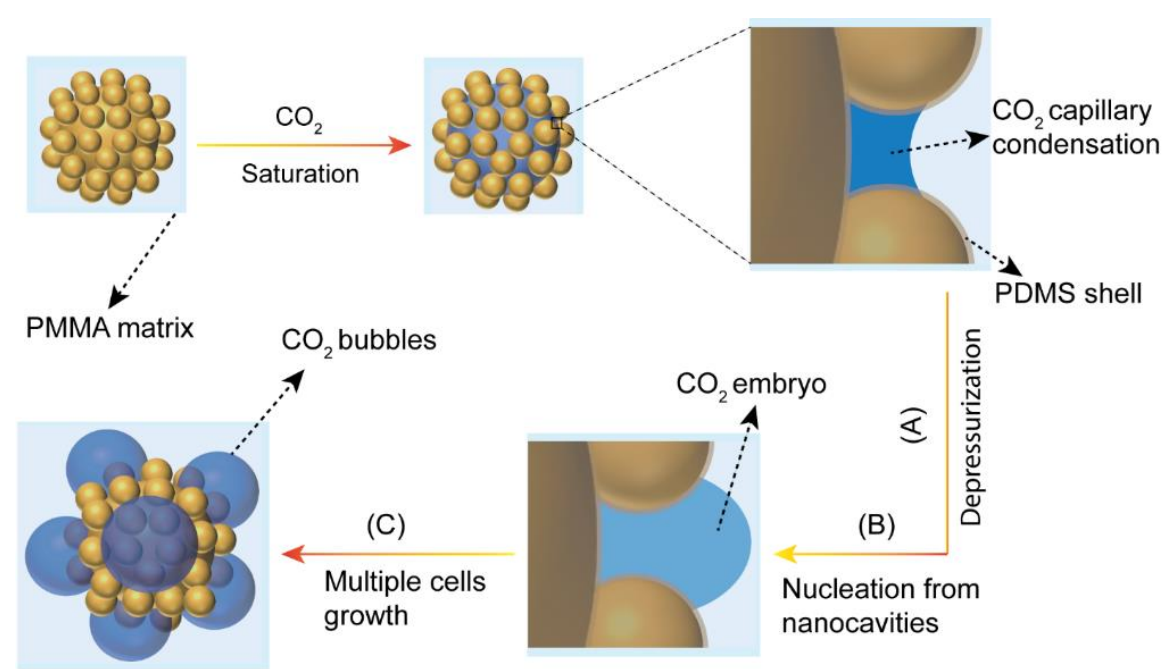

Figure 6.11 Schematic representation of the nucleation of multiple cells from PDMS grafted raspberry-like silica NPs. Upon saturation of PMMA films containing $\mathrm{SiO}_{2}-\mathrm{RP} N \mathrm{NPSO}_{2}$ capillary condensation in the cavities (step A) results in the presence of significantly increased amounts of $\mathrm{CO}_{2}$ in close proximity of the nucleating particle surface. The nanocavities are energetically favorable nucleating sites and together with the increased amount of available $\mathrm{CO}_{2}$ this results in more than 1 nucleating events per particle (step B) and subsequent cell growth (step C). 
The higher physical blowing agent concentration close to the particle surface is favorable for increasing the nucleation rate and combined with the presence of a low surface energy PDMS shell in the nanocavities the foam cell nucleation efficiency of these particles is significantly enhanced. Figure 6.11 shows a schematic representation of the assumed mechanism leading to multiple cell nucleation events for raspberry-like PDMS grafted silica NPs in the batch foaming of PMMA.

Overall we experimentally presented for the first time that multiple cell nucleation events on single NPs can be obtained with PDMS decorated core shell raspberry-like NPs as nucleation agents. These designer NPs exhibit a remarkably higher cell nucleation efficiency in PMMA nanocellular foaming compared to their bare and nearly spherical counterparts. We have also exploited $155 \mathrm{SiO}_{2}-\mathrm{RP}$ NPs in the $\mathrm{CO}_{2}$ assisted batch foaming of polystyrene and the corresponding SEM images revealed the occurrence of multiple cell nucleation events as well. Hence, these hybrid core shell NPs are very promising as highly efficient cell nucleation agents in polymer nanocellular foaming in general.

To fully exploit the high nucleation efficiency of $\mathrm{SiO}_{2}-\mathrm{RP}$ particles it is of pivotal importance to find foaming strategies and foam matrixes that allow not only the introduction of a high number of cell nuclei but as well that cells are stabilized early on in the foaming process, such that cell coalescence is prevented. For instance without optimization of any of the foam parameters and or composition of the PMMA nanocomposite matrix we have obtained a cell density of $\sim 6.6 \times 10^{13}$ cells cm$~^{-3}$, which is already very close to the order of magnitude of interest (i.e. $10^{14} \mathrm{cells}^{-3}$ ). Future work must direct to developing new strategies for sufficiently increasing the surface roughness of NPs with a particle diameter $<100 \mathrm{~nm}$. This is of interest since at the same weight percentage of particle loading a higher number of effective nucleation agents is available when smaller particles are used. Eventually using these particles it is assumed to reach nucleation site densities exceedeing $10^{15} \mathrm{cells} \mathrm{cm}^{-3}$.

\subsection{Conclusion}

Bare and PDMS decorated nearly spherical and raspberry-like silica NPs were synthesized and exploited as efficient nucleation agents in $\mathrm{CO}_{2}$ blown PMMA nanocellular foaming. Raspberry-like nanoparticles with a thin PDMS shell exhibit a higher nucleation efficiency compared to their nearly spherical counterparts. Multiple nucleating events per particle were observed for $\mathrm{SiO}_{2}-\mathrm{RP}$ NPs with core diameters of $150 \mathrm{~nm}$ and $200 \mathrm{~nm}$. The highest nucleation efficiency obtained was 6.2 for $200 \mathrm{SiO}_{2}-$ RP NPs. In this Chapter it is for the first time that a nucleation efficiency above unity in 
nanocellular foaming is reported. Eventually, cell coalescence results in a decrease in cell density and to an increase in foam cell size. The significantly higher nucleation efficiency of the core-shell raspberry-like nanoparticles is attributed to the higher $\mathrm{CO}_{2}$ absorption by their corresponding PMMA nanocomposites. This results in an increased physical blowing agent concentration available for nucleation close to the energetically favorable nanocavities as nucleating sites. Hence, PDMS decorated raspberry-like nanoparticles are very promising to be used as a new class of highly efficient nucleation agents. To increase our understanding of multiple cell nucleation events, future work should be directed to the quantification of the relationship between nucleation energy barrier and surface cavity structure dimensions, as well to optimization of foaming conditions to stabilize the nucleated multiple cells during the early stages of foaming.

\subsection{Materials and methods}

Materials. PMMA was bought from Arkema (VM100, i.e. a PMMA-co-EA polymer, $\left.\rho=1.18 \mathrm{~g} \mathrm{~cm}^{-3}\right)$ (La Garenne-Colombes, France). Ethanol absolute for analysis was purchased from Merck (Darmstad, Germany). Absolute Tetrahydrofuran (THF), 2propanol $99.8 \%$ and chloroform 99.9\% were purchased from Biosolve (Valkenswaard, the Netherlands). Poly(dimethylsiloxane) monoglycidyl ether terminated (PDMS-G) $\left(\mathrm{Mw}=1000 \mathrm{~g} \cdot \mathrm{mol}^{-1}\right)$, ammonium hydroxide solution $28-30 \%$, (3Aminopropyl)triethoxysilane $\geq 98 \%$ (APTES), Sodium borohydride purum p.a., $\geq 96 \%$ (gas-volumetric) $\left(\mathrm{NaBH}_{4}\right)$, Polyvinylpyrrolidone with molecular weight 40,000 $\mathrm{g} \cdot \mathrm{mol}^{-1}$ (PVP40), TEOS Tetraethyl orthosilicate (TEOS) $\geq 99.0 \%$ were purchased from SigmaAldrich (St. Louis, MO, USA). Milli-Q water was produced by a Millipore Synergy system (Billerica, MA, USA). Unless otherwise mentioned all other chemicals were used as received.

Stöber silica nanoparticles $\left(\mathrm{SiO}_{2}\right)$ synthesis. $\mathrm{SiO}_{2}$ with a diameter of $\sim 80 \mathrm{~nm}, 120$ $\mathrm{nm}, \sim 155 \mathrm{~nm}, \sim 180 \mathrm{~nm} \sim 200 \mathrm{~nm}$ and $\sim 310 \mathrm{~nm}$ were prepared by the Stöber method. To prepare Stöber silica nanoparticles $\left(\mathrm{SiO}_{2}\right)$ with a diameter of $\sim 155 \mathrm{~nm}, 100 \mathrm{ml}$ ethanol was mixed with $8 \mathrm{ml}$ Milli-Q water and $10 \mathrm{ml}$ TEOS in the presence of $5 \mathrm{ml}$ ammonium hydroxide while stirring at $500 \mathrm{rpm}$ at $50{ }^{\circ} \mathrm{C}$. After 4.5 hours the obtained $\mathrm{SiO}_{2}$ dispersion was centrifuged at $10,000 \mathrm{rpm}$ for $30 \mathrm{~min}$. Subsequently the collected $\mathrm{SiO}_{2}$ was redispersed in ethanol and centrifuged again. This washing step was repeated 2 more times followed by vacuum drying the collected $\mathrm{SiO}_{2}$ nanoparticles at room temperature for 12 hours. To prepare Stöber silica nanoparticles $\left(\mathrm{SiO}_{2}\right)$ with a diameter of $\sim 80 \mathrm{~nm}, 168 \mathrm{ml}$ ethanol was mixed with $28 \mathrm{ml} \mathrm{Milli-Q}$ water and $30 \mathrm{ml}$ TEOS in the 
presence of $2 \mathrm{ml}$ ammonium hydroxide while stirring for 1.5 hours at $500 \mathrm{rpm}$ at room temperature. To synthesize the $\sim 120 \mathrm{~nm}$ particles $100 \mathrm{ml}$ ethanol was mixed with $8 \mathrm{ml}$ Milli-Q water and $5 \mathrm{ml}$ TEOS in a round bottom flask stirring at $500 \mathrm{rpm}$ and subsequently $5 \mathrm{ml}$ of ammonium hydroxide was added and reacted for 3 hours at $50{ }^{\circ} \mathrm{C}$. To synthesize the $\sim 180 \mathrm{~nm}$ particles $100 \mathrm{ml}$ of ethanol was mixed with $8 \mathrm{ml}$ Milli-Q water and $10 \mathrm{ml}$ TEOS in the presence of $5.3 \mathrm{ml}$ ammonium hydroxide in a $250 \mathrm{ml}$ round bottom flask while stirring at $500 \mathrm{rpm}$. The reaction was conducted for 4.5 hours at $50{ }^{\circ} \mathrm{C}$. To synthesize the $\sim 200 \mathrm{~nm}$ particles $100 \mathrm{ml}$ of ethanol was mixed with $8 \mathrm{ml}$ Milli-Q water and $10 \mathrm{ml}$ TEOS in the presence of $5.6 \mathrm{ml}$ ammonium hydroxide in a 250 $\mathrm{ml}$ round bottom flask while stirring at $500 \mathrm{rpm}$. The reaction was conducted for 4.5 hours at $50{ }^{\circ} \mathrm{C}$. To synthesize the $\sim 310 \mathrm{~nm}$ particles $100 \mathrm{ml}$ ethanol was mixed with 8 $\mathrm{ml}$ Milli-Q water and $10 \mathrm{ml}$ TEOS in a round bottom flask stirring at $500 \mathrm{rpm}$ and subsequently $7.0 \mathrm{ml}$ of ammonium hydroxide was added and reacted for 4.5 hours at 50 ${ }^{\circ} \mathrm{C}$. The collecting, washing and drying step of nanoparticles were the same as described for nanoparticles of $\sim 155 \mathrm{~nm}$.

Hydrolysis. To introduce silanol groups on the surface of the prepared $\mathrm{SiO}_{2}$ nanoparticles, the particles were redispersed in Milli-Q water by sonication (BRANSON 2510, Canada) for 1 hour. Subsequently, hydrochloric acid was added to the dispersion while stirring at $500 \mathrm{rpm}$ until the $\mathrm{pH}$ of the solution reached a value of approximately 1 . After 4 hours the dispersion was centrifuged at 10,000 rpm for $30 \mathrm{~min}$. The collected nanoparticles were redispersed in Milli-Q water and centrifuged again. This washing step was repeated 2 more times followed by drying the silanol functional nanoparticles $\left(\mathrm{SiO}_{2}-\mathrm{OH}\right)$ in vacuum at room temperature for 12 hours.

APTES modification. $1.5 \mathrm{~g} \mathrm{SiO}_{2}-\mathrm{OH}$ nanoparticles were redispersed in $50 \mathrm{ml}$ ethanol followed by the addition of $7.5 \mathrm{ml}$ APTES. The dispersion was left to stir at $500 \mathrm{rpm}$ at room temperature for 17 hours. The APTES functionalized nanoparticles $\left(\mathrm{SiO}_{2}-\mathrm{NH}_{2}\right)$ were collected by centrifugation at $10,000 \mathrm{rpm}$ for $30 \mathrm{~min}$ and redispersed in ethanol and centrifuged again. This washing step was repeated 2 more times followed by drying the collected $\mathrm{SiO}_{2}-\mathrm{NH}_{2}$ nanoparticles in vacuum at room temperature for 12 hours.

Grafting to of PDMS-G to silica nanoparticles. $1.0 \mathrm{~g}$ of $\mathrm{SiO}_{2}-\mathrm{NH}_{2}$ nanoparticles were redispersed in $20.5 \mathrm{ml}$ THF and $15 \mathrm{~g}$ PDMS-G while stirring at $500 \mathrm{rpm}$ for 1 hour followed by sonication for 1 hour. Subsequently, THF was removed by rotary evaporation and the resulting silica nanoparticle dispersion in PDMS-G was immersed in an oil bath thermostated at $80{ }^{\circ} \mathrm{C}$ for $17 \mathrm{~h}$. Following cooling to room temperature the reaction mixture was washed with $\mathrm{THF}$ and centrifuged at $10,000 \mathrm{rpm}$ for $30 \mathrm{~min}$. This washing step was repeated 2 more times, followed by vacuum drying the PDMS-G grafted silica nanoparticles $\left(\mathrm{SiO}_{2}-\mathrm{SP}\right)$ at room temperature for 12 hours. 
Synthesis and modification of raspberry-like nanoparticles. To synthesize rough surface nanoparticles of $\sim 80 \mathrm{~nm}, 0.3 \mathrm{~g}$ Stöber silica nanoparticles of $\sim 80 \mathrm{~nm}$ and 0.25 g PVP were redispersed in $10 \mathrm{ml}$ Milli-Q water by sonication for $30 \mathrm{~min}$. Subsequently, $0.6 \mathrm{~g} \mathrm{NaBH}_{4}$ was added to the dispersion while stirring at $500 \mathrm{rpm}$ at room temperature for another $30 \mathrm{~min}$. The resulting mixture was reacted at $50{ }^{\circ} \mathrm{C}$ for 1 hour and $15 \mathrm{~min}$. To synthesize rough surface nanoparticles of $\sim 120 \mathrm{~nm}, 0.3 \mathrm{~g}$ Stöber silica nanoparticles of $\sim 155 \mathrm{~nm}$ and $0.25 \mathrm{~g}$ PVP were redispersed in $10 \mathrm{ml}$ Milli-Q water by sonication for $30 \mathrm{~min}$. Subsequently, $0.6 \mathrm{~g} \mathrm{NaBH} 4$ was added to the dispersion while stirring at 500 $\mathrm{rpm}$ at room temperature for another $30 \mathrm{~min}$. The resulting mixture was reacted at $50{ }^{\circ} \mathrm{C}$ for 3 hours and $20 \mathrm{~min}$. To synthesize rough surface nanoparticles of $\sim 155 \mathrm{~nm}, 0.3 \mathrm{~g}$ Stöber silica nanoparticles of $\sim 180 \mathrm{~nm}$ and $0.25 \mathrm{~g}$ PVP were redispersed in $10 \mathrm{ml}$ MilliQ water by sonication for $30 \mathrm{~min}$. Subsequently, $0.6 \mathrm{~g} \mathrm{NaBH}_{4}$ was added to the dispersion while stirring at $500 \mathrm{rpm}$ at room temperature for another $30 \mathrm{~min}$. The resulting mixture was reacted at $50{ }^{\circ} \mathrm{C}$ for 3 hours and $30 \mathrm{~min}$. To synthesis rough surface nanoparticles of $\sim 200 \mathrm{~nm}, 0.3 \mathrm{~g}$ Stöber silica nanoparticles of $\sim 310 \mathrm{~nm}$ and $0.25 \mathrm{~g}$ PVP were redispersed in $10 \mathrm{ml}$ Milli-Q water by sonication for $30 \mathrm{~min}$. Subsequently, $0.6 \mathrm{~g} \mathrm{NaBH}_{4}$ was added to the solution while stirring at $500 \mathrm{rpm}$ at room temperature for another $30 \mathrm{~min}$. The resulting mixture was reacted at $50{ }^{\circ} \mathrm{C}$ for 6 hours. The prepared rough surface nanoparticles were collected by centrifugation at 10,000 rpm for $30 \mathrm{~min}$ and redispersed in Milli-Q water and centrifuged again. This washing step was repeated 2 more times followed by drying the collected nanoparticles in vacuum at room temperature for 12 hours. The process of amino-functionalization and grafting to of PDMS-G to the rough surface nanoparticles were the same as described for the Stöber silica nanoparticles.

Nanocomposite preparation. Nanocomposites were prepared by dispersing the same amount (functional) silica nanoparticles $\left(1.07 \times 10^{13} \mathrm{~cm}^{-3}\right)$ in PMMA with a mini extruder (DSM Xplore, the Netherlands). In a typical procedure a dry blend of nanoparticles and PMMA was fed to the extruder followed by internal mixing for 3 minutes. The barrel temperature was set to $155^{\circ} \mathrm{C}$ and the screw speed was $100 \mathrm{rpm}$. Subsequently the PMMA nanocomposite was collected and left to cool to room temperature.

Film preparation. A hot press (Fortijne, the Netherlands) was used to press $\sim 0.2$ $\mathrm{mm}$ thick nanocomposite films in a mold $(4 \times 3 \mathrm{~cm})$. The press temperature, applied load and press time were $180{ }^{\circ} \mathrm{C}, 250 \mathrm{KN}$ and 10 minutes, respectively.

Batch foaming of nanocomposite films. The obtained nanocomposite PMMA films were saturated with $\mathrm{CO}_{2}$ (55 bar) in an autoclave for 4 hours at room temperature followed by rapid depressurization. Subsequently, the PMMA nanocomposite films 
were immersed in a water bath thermostated at $40{ }^{\circ} \mathrm{C}$ for different foaming time $(0.3$ second, 1 second, 5 second, 10 second and 30 second) after which the samples were quenched in an ice bath for 30 minutes. The samples were left to dry in air for at least 12 hours prior to further analysis.

Fourier transform infrared (FTIR) spectroscopy. FTIR spectra were collected with a Bruker ALPHA single attenuated total reflection (ATR) FTIR Spectrometer equipped with an ATR single reflection crystal (Bruker Optic GmbH, Ettlingen, Germany). The spectra were collected in the range of $400-4000 \mathrm{~cm}^{-1}$ (spectral solution of $4 \mathrm{~cm}^{-1}, 128$ scans). Background spectra were recorded against air.

Thermo gravimetric analysis (TGA). The weight loss of the (modified) particles as a function of temperature was measured with a TGA400 (PerkinElmer, Inc., Waltham, MA, USA). A sample weighing 3 to $6 \mathrm{mg}$ was loaded into the platinum pan and the temperature was set to $50{ }^{\circ} \mathrm{C}$ to stabilize. Subsequently the sample was heated to $900{ }^{\circ} \mathrm{C}$ at a heating rate of $20{ }^{\circ} \mathrm{C} \mathrm{min}^{-1}$. The applied air flow was $20 \mathrm{ml} \mathrm{min}$.

Transmission electron microscopy (TEM). To investigate the core-shell structure of the functionalized nanoparticles a FEI/Philips CM300 transmission electron microscope (Eindhoven, the Netherlands) was used. Diluted particle dispersions in THF were deposited on the carbon side of a carbon/copper grid (HC200-Cu) (EMS, Germany). Images were obtained in the bright field mode with a $300 \mathrm{kV}$ acceleration voltage.

Scanning electron microscopy (SEM). To investigate the morphology of the foamed nanocomposite films a high resolution scanning electron microscope (JEOL Field Emission JSM-633OF, JEOL Benelux, Nieuw-Vennep, the Netherlands) was used. The typically used electron acceleration voltage was $5 \mathrm{keV}$. Prior to analysis the nanocomposite foams were freeze fractured after cooling in liquid nitrogen for 5 minutes.

Surface Area measurement for nanoparticles. The specific surface area of the nanoparticles was measured from the nitrogen adsorption isotherm obtained at $300{ }^{\circ} \mathrm{C}$ using an ASAP 2010 Sorptometer (Micromeritics). Around $100 \mathrm{mg}$ nanoparticle powder was used for each measurement.

$\mathrm{CO}_{2}$ absorption measurement. To measure the absorption of $\mathrm{CO}_{2}$ PMMA nanocomposite films containing the same amount of the respective nanoparticles were saturated in $\mathrm{CO}_{2}$ at 55 bar for 4 hours. The weight of the PMMA (nanocomposite) films before and after $\mathrm{CO}_{2}$ saturation were measured.

Calculation of cell density and nucleation efficiency. The cell size and cell density were obtained by analyzing the obtained SEM cross sectional images. Cell density $\left(N_{v}\right)$ of the foams was calculated according to Kumar's theoretical approximation. ${ }^{69}$ No direct 
measurements of cell dimensions over the micrograph are required in this method, only the micrograph area $(A)$ and the total number of cells $(n)$ contained therein are measured. Together with the magnification factor of the micrograph $(M), N_{v}$ can be calculated according to equation 1 .

$$
N_{v}=\left[\frac{\left(n M^{2}\right)}{A}\right]^{3 / 2}
$$

By combining $N_{V}$ with the volume expansion ratio $(B)$ of nanocomposite films after foaming, the cell numbers per $\mathrm{cm}^{3}$ of unfoamed materials $(N)$ can be calculated according to equation 2 .

$$
N=N_{v} * B
$$

The mentioned cell density in the main text are all refer to $N$. In addition, the nucleation efficiency $(f)$ of nanoparticles during foaming can be calculated as:

$$
f=N / C
$$

eq. 3

where $C$ is the number of nanoparticles per $\mathrm{cm}^{3}$ (i.e., $1.07 \times 10^{13}$ ) used for foaming.

\section{References}

[1] Notario, B.; Pinto, J.; Rodriguez-Perez, M., Nanoporous polymeric materials: a new class of materials with enhanced properties. Progress in Materials Science 2016, 78, 93-139.

[2] Forest, C.; Chaumont, P.; Cassagnau, P.; Swoboda, B.; Sonntag, P., Polymer nano-foams for insulating applications prepared from $\mathrm{CO}_{2}$ foaming. Progress in Polymer Science 2015, $41,122-145$.

[3] Liu, S.; Duvigneau, J.; Vancso, G. J., Nanocellular polymer foams as promising high performance thermal insulation materials. European Polymer Journal 2015, 65, 33-45.

[4] Costeux, S., $\mathrm{CO}_{2}$-blown nanocellular foams. Journal of Applied Polymer Science 2014, 131, 41293-41308.

[5] Chen, L.; Rende, D.; Schadler, L. S.; Ozisik, R., Polymer nanocomposite foams. Journal of Materials Chemistry A 2013, 1, 3837-3850.

[6] Eaves, D., Handbook of polymer foams. Polimeri 2004, 25, 1-2.

[7] Notario, B.; Pinto, J.; Solorzano, E.; De Saja, J. A.; Dumon, M.; Rodríguez-Pérez, M. A., Experimental validation of the Knudsen effect in nanocellular polymeric foams. Polymer 2015, 56, 57-67. 
[8] Pinto, J.; Notario, B.; Verdejo, R.; Dumon, M.; Costeux, S.; Rodriguez-Perez, M. A., Molecular confinement of solid and gaseous phases of self-standing bulk nanoporous polymers inducing enhanced and unexpected physical properties. Polymer 2017, 113, 27-33.

[9] Lee, S.-T.; Scholz, D. P. K., Polymeric foams: Technology and developments in regulation, process, and products. CRC Press: 2008.

[10] Notario, B.; Pinto, J.; Rodríguez-Pérez, M., Towards a new generation of polymeric foams: PMMA nanocellular foams with enhanced physical properties. Polymer 2015, 63, 116-126.

[11] Li, L.; Shen, X.; Hong, S. W.; Hayward, R. C.; Russell, T. P., Fabrication of co-continuous nanostructured and porous polymer membranes: spinodal decomposition of homopolymer and random copolymer blends. Angewandte Chemie International Edition 2012, 51, 40894094.

[12] Zhang, X.; Chang, D.; Liu, J.; Luo, Y., Conducting polymer aerogels from supercritical $\mathrm{CO}_{2}$ drying PEDOT-PSS hydrogels. Journal of Materials Chemistry 2010, 20, 5080-5085.

[13] Hedrick, J. L.; Miller, R. D.; Hawker, C. J.; Carter, K. R.; Volksen, W.; Yoon, D. Y.; Trollsås, M., Templating nanoporosity in thin-film dielectric insulators. Advanced Materials 1998, 10, 1049-1053.

[14] Park, S. H.; Xia, Y., Macroporous membranes with highly ordered and three-dimensionally interconnected spherical pores. Advanced Materials 1998, 10, 1045-1048.

[15] Du Fresne Von Hohenesche, C.; Schmidt, D.; Schadler, V., Nanoporous melamineformaldehyde gels by microemulsion templating. Chemistry of Materials 2008, 20, 61246129 .

[16] Bledzki, A. K.; Faruk, O., Effects of the chemical foaming agents, injection parameters, and melt-flow index on the microstructure and mechanical properties of microcellular injectionmolded wood-fiber/polypropylene composites. Journal of Applied Polymer Science 2005, 97, 1090-1096.

[17] Klempner, D.; Frisch, K. C., Handbook of polymeric foams and foam technology. Hanser Munich etc.: 1991; Vol. 404.

[18] Zeng, C.; Han, X.; Lee, L. J.; Koelling, K. W.; Tomasko, D. L., Polymer-clay nanocomposite foams prepared using carbon dioxide. Advanced Materials 2003, 15, 17431747.

[19] Park, C. B.; Behravesh, A. H.; Venter, R. D., Low density microcellular foam processing in extrusion using $\mathrm{CO}_{2}$. Polymer Engineering \& Science 1998, 38, 1812-1823.

[20] Tomasko, D. L.; Li, H.; Liu, D.; Han, X.; Wingert, M. J.; Lee, L. J.; Koelling, K. W., A review of $\mathrm{CO}_{2}$ applications in the processing of polymers. Industrial \& Engineering Chemistry Research 2003, 42, 6431-6456.

[21] Jacobs, L. J.; Kemmere, M. F.; Keurentjes, J. T., Sustainable polymer foaming using high pressure carbon dioxide: a review on fundamentals, processes and applications. Green Chemistry 2008, 10, 731-738.

[22] Aram, E.; Mehdipour-Ataei, S., A review on the micro-and nanoporous polymeric foams: preparation and properties. International Journal of Polymeric Materials and Polymeric Biomaterials 2016, 65, 358-375. 
[23] Costeux, S.; Lantz, D. R.; Beaudoin, D. A.; Barger, M. A., Continuous process for extruding nanoporous foam. Google Patents: 2015.

[24] Sandler, J. K. W.; Francis, T.; Lopes, P. M. S., Nanoporous polymer foams. Google Patents: 2013.

[25] Costeux, S.; Zhu, L., Low density thermoplastic nanofoams nucleated by nanoparticles. Polymer 2013, 54, 2785-2795.

[26] Costeux, S.; Bunker, S. P.; Jeon, H. K., Homogeneous nanocellular foams from styrenicacrylic polymer blends. Journal of Materials Research 2013, 28, 2351-2365.

[27] Liao, Z.-E.; Yeh, S.-K.; Chu, C.-C.; Tseng, T.-W. In critical parameters of generating PMMA nanocellular foam, Annu. Tech. Conf.-Soc. Plast. Eng, 2016.

[28] Tammaro, D.; Astarita, A.; Di Maio, E.; Iannace, S., Polystyrene foaming at high pressure drop rates. Industrial \& Engineering Chemistry Research 2016, 55, 5696-5701.

[29] Pinto, J.; Dumon, M.; Pedros, M.; Reglero, J.; Rodriguez-Perez, M. A., Nanocellular $\mathrm{CO}_{2}$ foaming of PMMA assisted by block copolymer nanostructuration. Chemical Engineering Journal 2014, 243, 428-435.

[30] Li, L.; Nemoto, T.; Sugiyama, K.; Yokoyama, H., $\mathrm{CO}_{2}$ foaming in thin films of block copolymer containing fluorinated blocks. Macromolecules 2006, 39, 4746-4755.

[31] Spitael, P.; Macosko, C. W.; McClurg, R. B., Block copolymer micelles for nucleation of microcellular thermoplastic foams. Macromolecules 2004, 37, 6874-6882.

[32] Yokoyama, H.; Sugiyama, K., Nanocellular structures in block copolymers with $\mathrm{CO}_{2}$-philic blocks using $\mathrm{CO}_{2}$ as a blowing agent: crossover from micro-to nanocellular structures with depressurization temperature. Macromolecules 2005, 38, 10516-10522.

[33] Liu, S.; Zoetebier, B.; Hulsman, L.; Zhang, Y.; Duvigneau, J.; Vancso, G. J., Nanocellular polymer foams nucleated by core-shell nanoparticles. Polymer 2016, 104, 22-30.

[34] Lee, L. J.; Zeng, C.; Cao, X.; Han, X.; Shen, J.; Xu, G., Polymer nanocomposite foams. Composites Science and Technology 2005, 65, 2344-2363.

[35] Ji, G.; Zhai, W.; Lin, D.; Ren, Q.; Zheng, W.; Jung, D. W., Microcellular foaming of poly (lactic acid)/silica nanocomposites in compressed $\mathrm{CO}_{2}$ : critical influence of crystallite size on cell morphology and foam expansion. Industrial \& Engineering Chemistry Research 2013, 52, 6390-6398.

[36] Rende, D.; Schadler, L. S.; Ozisik, R., Controlling foam morphology of poly (methyl methacrylate) via surface chemistry and concentration of silica nanoparticles and supercritical carbon dioxide process parameters. Journal of Chemistry 2013, 2013, 864926864938 .

[37] Zhai, W.; Yu, J.; Wu, L.; Ma, W.; He, J., Heterogeneous nucleation uniformizing cell size distribution in microcellular nanocomposites foams. Polymer 2006, 47, 7580-7589.

[38] Yuan, H.; Xiong, Y.; Luo, G.; Shen, Q.; Zhang, L., The influence of in situ synthesized nanoparticles on microstructure and compression properties of polymer foams during supercritical carbon dioxide foaming. Journal of Applied Polymer Science 2017, 134, 44629-22636. 
[39] Liberman, A.; Mendez, N.; Trogler, W. C.; Kummel, A. C., Synthesis and surface functionalization of silica nanoparticles for nanomedicine. Surface Science Reports 2014, 69, 132-158.

[40] Bagwe, R. P.; Hilliard, L. R.; Tan, W., Surface modification of silica nanoparticles to reduce aggregation and nonspecific binding. Langmuir 2006, 22, 4357-4362.

[41] Yang, J.; Sang, Y.; Chen, F.; Fei, Z.; Zhong, M., Synthesis of silica particles grafted with poly (ionic liquid) and their nucleation effect on microcellular foaming of polystyrene using supercritical carbon dioxide. The Journal of Supercritical Fluids 2012, 62, 197-203.

[42] Siripurapu, S.; DeSimone, J. M.; Khan, S. A.; Spontak, R. J., Low-temperature, surfacemediated foaming of polymer films. Advanced Materials 2004, 16, 989-994.

[43] Chen, L.; Ozisik, R.; Schadler, L. S., The influence of carbon nanotube aspect ratio on the foam morphology of MWNT/PMMA nanocomposite foams. Polymer 2010, 51, 2368-2375.

[44] Miller, M. B.; Luebke, D. R.; Enick, R. M., $\mathrm{CO}_{2}$-philic oligomers as novel solvents for $\mathrm{CO}_{2}$ absorption. Energy \& Fuels 2010, 24, 6214-6219.

[45] Wang, H.; Li, W., Selective ultrasonic foaming of polymer for biomedical applications. Journal of Manufacturing Science and Engineering 2008, 130, 021004.

[46] Qiuxiang, L.; GYQY, Y. Z., Nucleation thermodynamics inside micro/nanocavity. Journal of Materials Sciences and Technology 2008, 24, 183.

[47] Qian, M.; Ma, J., The characteristics of heterogeneous nucleation on concave surfaces and implications for directed nucleation or surface activity by surface nanopatterning. Journal of Crystal Growth 2012, 355, 73-77.

[48] Maksimov, A. O.; Kaverin, A. M.; Baidakov, V. G., Heterogeneous vapor bubble nucleation on a rough surface. Langmuir 2013, 29, 3924-3934.

[49] Du, X.; Liu, X.; Chen, H.; He, J., Facile fabrication of raspberry-like composite nanoparticles and their application as building blocks for constructing superhydrophilic coatings. The Journal of Physical Chemistry C 2009, 113, 9063-9070.

[50] Qian, Z.; Zhang, Z.; Song, L.; Liu, H., A novel approach to raspberry-like particles for superhydrophobic materials. Journal of Materials Chemistry 2009, 19, 1297-1304.

[51] Du, X.; He, J., A self-templated etching route to surface-rough silica nanoparticles for superhydrophobic coatings. ACS Applied Materials \& Interfaces 2011, 3, 1269-1276.

[52] Li, D.; Zhu, Y.; Mao, C., One-pot synthesis of surface roughness controlled hollow silica spheres with enhanced drug loading and release profiles under ambient conditions in aqueous solutions. Journal of Materials Chemistry B 2013, 1, 5515-5520.

[53] Tsai, H.-J.; Lee, Y.-L., Facile method to fabricate raspberry-like particulate films for superhydrophobic surfaces. Langmuir 2007, 23, 12687-12692.

[54] Goren, K.; Chen, L.; Schadler, L. S.; Ozisik, R., Influence of nanoparticle surface chemistry and size on supercritical carbon dioxide processed nanocomposite foam morphology. The Journal of Supercritical Fluids 2010, 51, 420-427. 
[55] Zakiyan, S. E.; Famili, M. H. N.; Ako, M., Controlling foam morphology of polystyrene via surface chemistry, size and concentration of nanosilica particles. Journal of Materials Science 2014, 49, 6225-6239.

[56] Zhang, T.; Ge, J.; Hu, Y.; Zhang, Q.; Aloni, S.; Yin, Y., Formation of hollow silica colloids through a spontaneous dissolution-regrowth process. Angewandte Chemie 2008, 120, 58905895 .

[57] Zhang, T.; Zhang, Q.; Ge, J.; Goebl, J.; Sun, M.; Yan, Y.; Liu, Y.-s.; Chang, C.; Guo, J.; Yin, Y., A self-templated route to hollow silica microspheres. The Journal of Physical Chemistry C 2009, 113, 3168-3175.

[58] Musić, S.; Filipović-Vinceković, N.; Sekovanić, L., Precipitation of amorphous $\mathrm{SiO}_{2}$ particles and their properties. Brazilian Journal of Chemical Engineering 2011, 28, 89-94.

[59] Kim, H.; Kim, H.-G.; Kim, S.; Kim, S. S., PDMS-silica composite membranes with silane coupling for propylene separation. Journal of Membrane Science 2009, 344, 211-218.

[60] Thommes, M., Physical adsorption characterization of nanoporous materials. Chemie Ingenieur Technik 2010, 82, 1059-1073.

[61] Rouquerol, J.; Rouquerol, F.; Llewellyn, P.; Maurin, G.; Sing, K. S., Adsorption by powders and porous solids: principles, methodology and applications. Academic press: 2013.

[62] Thommes, M.; Cychosz, K. A., Physical adsorption characterization of nanoporous materials: progress and challenges. Adsorption 2014, 20, 233-250.

[63] Ally, J.; Molla, S.; Mostowfi, F., Condensation in nanoporous packed beds. Langmuir 2016, 32, 4494-4499.

[64] Ullah, R.; Atilhan, M.; Diab, A.; Deniz, E.; Aparicio, S.; Yavuz, C. T., Synthesis, characterization and evaluation of porous polybenzimidazole materials for $\mathrm{CO}_{2}$ adsorption at high pressures. Adsorption 2016, 22, 247-260.

[65] Jones, W.; Isaac, P.; Phillips, D., The adsorption of carbon dioxide and nitrogen at high pressures by porous plugs of lampblack. Transactions of the Faraday Society 1959, 55, 1953-1958.

[66] Fujiki, J.; Yamada, H.; Yogo, K., Enhanced adsorption of carbon dioxide on surfacemodified mesoporous silica-supported tetraethylenepentamine: role of surface chemical structure. Microporous and Mesoporous Materials 2015, 215, 76-83.

[67] Sanz-Pérez, E.; Arencibia, A.; Sanz, R.; Calleja, G., An investigation of the textural properties of mesostructured silica-based adsorbents for predicting $\mathrm{CO}_{2}$ adsorption capacity. RSC Advances 2015, 5, 103147-103154.

[68] Fujiki, J.; Yogo, K., The increased $\mathrm{CO}_{2}$ adsorption performance of chitosan-derived activated carbons with nitrogen-doping. Chemical Communications 2016, 52, 186-189.

[69] Kumar, V.; Suh, N. P., A process for making microcellular thermoplastic parts. Polymer Engineering \& Science 1990, 30, 1323-1329. 
Chapter 7

Outlook: New Particle Designs, Foaming

Strategies and Other Opportunities 
This Thesis reported our efforts to design and exploit low surface energy $\mathrm{CO}_{2}$-philic polymer decorated hybrid nanoparticles as efficient nucleating agents in nanocellular batch foaming of polymers. In particular, we demonstrated that line tension and its contribution to the nucleation free energy affects the nucleation efficiency of particles with a diameter below the line tension length. Meaning that nucleating particles need to have a relatively large diameter in order to be highly effective. Eventually, we have shown that nucleation efficiencies above unity can be realized for silica nanoparticles with a rough surface and a PDMS shell in the $\mathrm{CO}_{2}$ blown foaming of PMMA. Despite the attained insights and guiding principles for optimized particle designs challenges remain to be solved before nanocellular foams are produced at industrially relevant levels. Here I will briefly present and discuss some of these of challenges and potential opportunities.

\subsection{Designer particles}

It is of primary interest to develop new strategies for the fabrication of nanoparticles with high nucleation efficiencies and with a particle diameter $<100 \mathrm{~nm}$, because at the same weight percentage of particle loading a higher volume number density of potential nucleation sites is available when smaller particles are used. Our best performing nucleating particle had an increased $\mathrm{CO}_{2}$ absorption during saturation, resulting in the presence of larger amounts of blowing agent close the energetically favorable nucleating sites, i.e. PDMS grafted nanocavities. However, the synthesis of raspberry like silica nanoparticles with a diameter below $120 \mathrm{~nm}$ by the etching with $\mathrm{NaBH}_{4}$ (see Chapter 6) remains a challenge. ${ }^{1-2}$

In an initial attempt to locally increase the amount of $\mathrm{CO}_{2}$ close to the particle surfaces we synthesized hollow silica core shell particles. ${ }^{3-5}$ Their shell consisted of a low surface energy fluorinated polymer. However, these hollow nanoparticles turned out to be not as effective nucleating agents as expected, which is ascribed to the poor particle dispersion in the polymer matrix prior to foaming. In addition their synthesis was rather complex.

On the contrary PDMS grafted mesoporous silica nanoparticle are expected to be a very promising candidate for exploitation as highly efficient nucleation agents in nanocellular polymer foaming. This is ascribed to their expected high $\mathrm{CO}_{2}$ absorption in their PDMS decorated cavities ${ }^{6-10}$ as well as the energetically favorable cell nucleation from those cavities, resulting in multiple cell nucleation events per particle (see Figure 7.1). Furthermore, there is no technical/physical limitation considering the fabrication of mesoporous silica nanoparticles with diameters below $100 \mathrm{~nm}$. For instance, Kuroda and coworkers ${ }^{11}$ reported the successful synthesis of mesoporous silica nanoparticles with a 
diameters of approximately $50 \mathrm{~nm}$ by using a so called "seed growth" method. For further details about the synthesis of mesoporous silica nanoparticles the interested reader is directed to the following references: references 12-17.

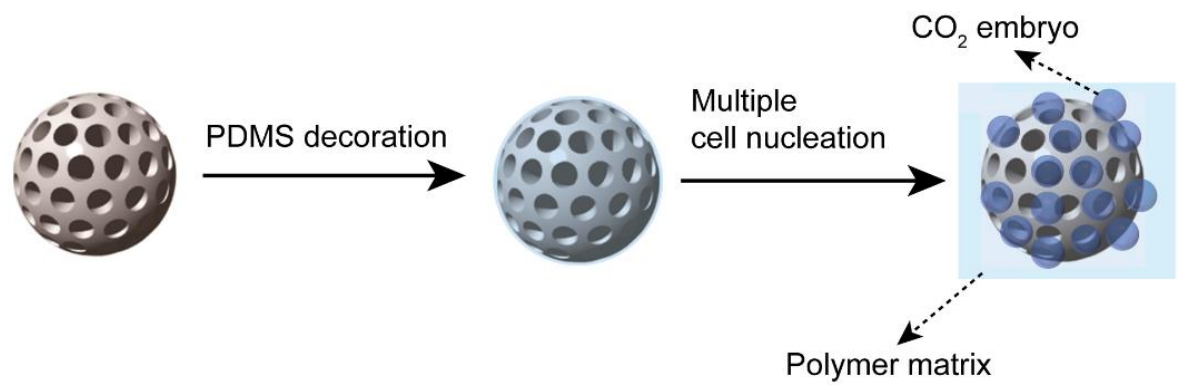

Figure 7.1 PDMS decorated mesoporous silica nanoparticles as heterogeneous nucleation agents in $\mathrm{CO}_{2}$ assisted polymer nanocellular foaming. The image of a mesoporous silica nanoparticles is from reference [11].

It is expected that the grafting of PDMS to mesoporous silica will enhance the adsorption of $\mathrm{CO}_{2}$ but moreover decrease the nucleation free energy of its nanocavities leading to multiple nucleation events per particle. If the mesoporous inner structure allows an even higher amount of $\mathrm{CO}_{2}$ to be "stored" for nucleation and foam cell growth, the proper selection of foam cell matrix materials becomes of pivotal importance.

\subsection{Polymer foam matrix materials}

In Chapter 6 we have demonstrated that cell coalescence of neighboring nucleated cells on a particle occurs already during the first few seconds of foam expansion. This is ascribed to the absence of effective foam cell stabilization mechanisms. In most of the Chapters PMMA VM100 was exploited as the polymer foam matrix. The choice for this material was based on its known high affinity for $\mathrm{CO}_{2}$ and good foamability. ${ }^{18}$ In addition, we tried other more randomly chosen types of PMMA as well as other polymers, e.g. SAN and PC. None of the polymers screened were as good as VM100 in terms of their foamability. However, recent reported work confirms that optimization of the polymer foam matrix is unambiguously required. ${ }^{19-21}$ For instance, Tseng and coworkers ${ }^{21}$ reported the successful fabrication of nanocellular PMMA foams with a cell density above $10^{14}$ cells $\mathrm{cm}^{-3}$ and a cell size below $100 \mathrm{~nm}$ by using PMMA with a molecular weight (Mn) of $\sim 81 \mathrm{kDa}$. For identical foaming conditions different cell sizes and cell densities were obtained for PMMA with a Mw of $\sim 64 \mathrm{kDa}$ and $\sim 58 \mathrm{kDa}$. To obtain these high cell 
densities without nucleating agents the typically used saturation pressure and temperature were above 100 bar and below $0{ }^{\circ} \mathrm{C}$, respectively. The authors attributed the observed variations in foam structure to the differences in viscosities of the expanding $\mathrm{CO}_{2}$ saturated PMMA. It was assumed by them that the higher viscosity of the PMMA with a higher molecular weight resulted in better foam cell stabilization and a decrease in cell coalescence.

In fact preliminary foaming tests with various types of PMMA have already resulted in new PMMA candidates for future work. Furthermore, it is expected that increasing the melt strength of PMMA, e.g. by branching, results in improved foam cell stabilization as well. $^{22}$

In addition, the foaming conditions used were revisited and this resulted in some promising processing windows as well. Overall it is envisaged that by combining new particle designs with improved foam matrix materials high cell density nanocellular foams can be obtained by low pressure saturation, i.e. below 60 bar.

\subsection{Bulk production challenges}

The requirement to nucleate a large number of growing foam cells and rapidly vitrify them renders currently used foam extrusion processes not applicable for nanocellular foaming. For instance common extrusion processes today first melt the polymer at temperature above the polymer melting temperature followed by injection of a physical blowing agents. Provided that enough physical blowing agents can be absorbed by the polymer melt one can imagine that it is hard to rapidly bring down the $\mathrm{CO}_{2}$ saturated polymer temperature down to temperatures that would allow the rapid vitrification. For PMMA we would run the extruder at approximately $180^{\circ} \mathrm{C}$ followed by injection of $\mathrm{CO}_{2}$, while the foaming temperature is $\sim 40{ }^{\circ} \mathrm{C}$ to $100{ }^{\circ} \mathrm{C}$.

We have identified bead foaming ${ }^{23-25}$ as a potentially interesting processing route for the production of nanocellular polymers. In bead foaming polymer beads, e.g. PMMA with nucleating particles, are dispersed in a medium like water while being saturated with the blowing agent. Since the polymer beads are small ( $\sim$ millimeter) gas diffusion and saturation are rather fast. Upon a rapid pressure release the beads can be exposed to the required foaming temperature rapidly for nucleation and expansion. In this way foaming times and temperatures are easy to control. Following expansion of the beads they have to be fused together to yield the foamed product. The interested reader is directed to references: 23, 26-30.

Another advantage of bead foaming is its easy shapeability in the final foam product, which enables the fabrication of light weight structural parts with large dimensions, 
complex geometries and a high dimensional accuracy. ${ }^{31}$ Currently, expanded polyethylene (EPE), expanded polypropylene (EPP) and expandable polystyrene (EPS) are three commonly used polymers for the fabrication of bead foams in the market. ${ }^{23}$
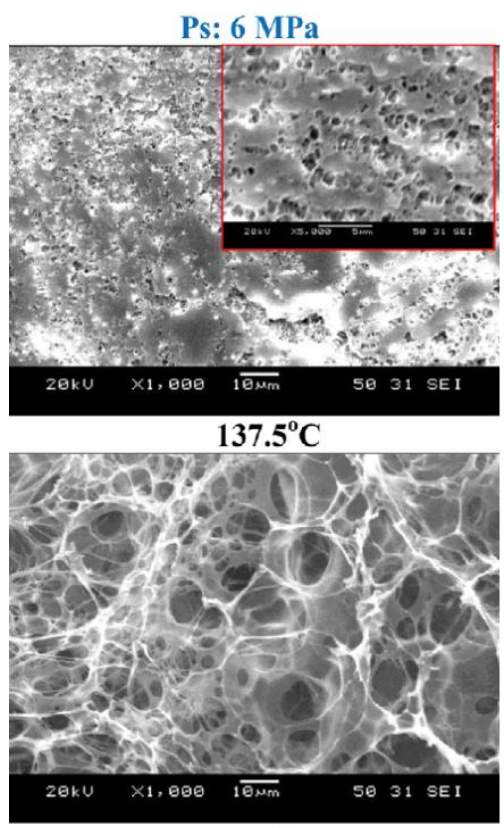

$140^{\circ} \mathrm{C}$

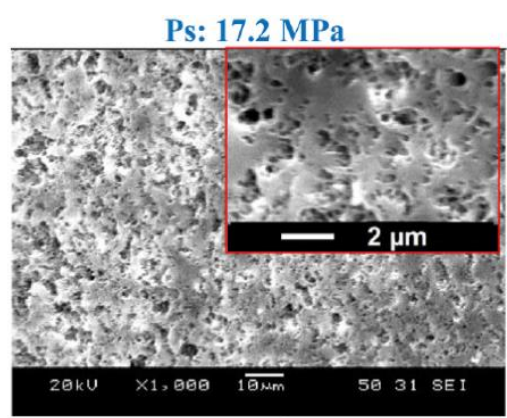

$110^{\circ} \mathrm{C}$

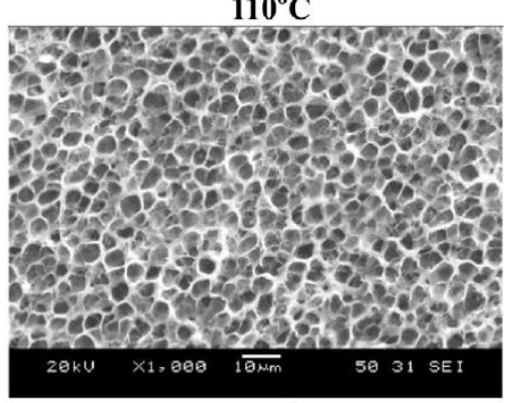

$112.5^{\circ} \mathrm{C}$

Figure 7.2 Cross sectional SEM images of PLA bead foams obtained at $6 \mathrm{MPa}$ and 17.2 MPa and at various saturation temperatures after $60 \mathrm{~min} \mathrm{CO}_{2}$ saturation. ${ }^{24}$

As a potential green substitute for EPS foams, polylactide (PLA) bead foams recently received increasing attention. ${ }^{24,30,32}$ For instance, Park and coworkers ${ }^{24}$ reported the fabrication of PLA bead foams with expansion ratios of 3 to 30 and average cell sizes from $350 \mathrm{~nm}$ to $15 \mu \mathrm{m}$, as shown in Figure 7.2. The authors demonstrated that the cell structure of PLA foams was significantly affected by the $\mathrm{CO}_{2}$ saturation pressure, as well as by the amount of perfected crystals that were generated during $\mathrm{CO}_{2}$ saturation. Despite the relatively poor nanocellular PLA foams obtained (see Figure 7.2) the work by Park and coworkers indicates that bead foaming is promising for the bulk production of nanocellular polymer foams. In addition it is expected that the utilization of our designer nanoparticles with high nucleation efficiencies will further increase the cell density of the prepared foams while cell sizes are reduced. 


\subsection{Nanocellular foam thermal conductivity measurements}

During the last months of this Thesis work, a thermal conductivity meter was constructed. Figure 7.3 shows a schematic of the build thermal conductivity meter. ${ }^{33}$ The device consists of a heating plate and a cooling plate that are maintained at a constant temperature. Between two sample slabs, a heat flow meter is present to monitor the heat flux and temperature in the middle of the sample sandwich. By this device, the thermal conductivity of relatively small samples, i.e $6 \times 6 \mathrm{~cm}$, can be determined.

The PMMA nanocomposite foams presented in this Thesis were about $1 \times 1 \mathrm{~cm}^{2}$ and their thickness was in the order of 0.4 millimeter. These dimensions did not allow us to determine the thermal conductivity of the foams experimentally. Attempts to increase the foam sample dimensions to $6 \times 6 \mathrm{~cm}^{2}$ were successful. Unfortunately, the samples were not flat foam sheets. This rendered the home build thermal conductivity meter useless. Future work should be directed to obtain flat foam sheets. For instance by constraining foam expansion in a mold. First attempts were promising, but not good enough. The balance between mold volume and PMMA unfoamed film needs more attention. Eventually, it is our aim to establish thermal conductivity foam morphology structureproperty relationships.

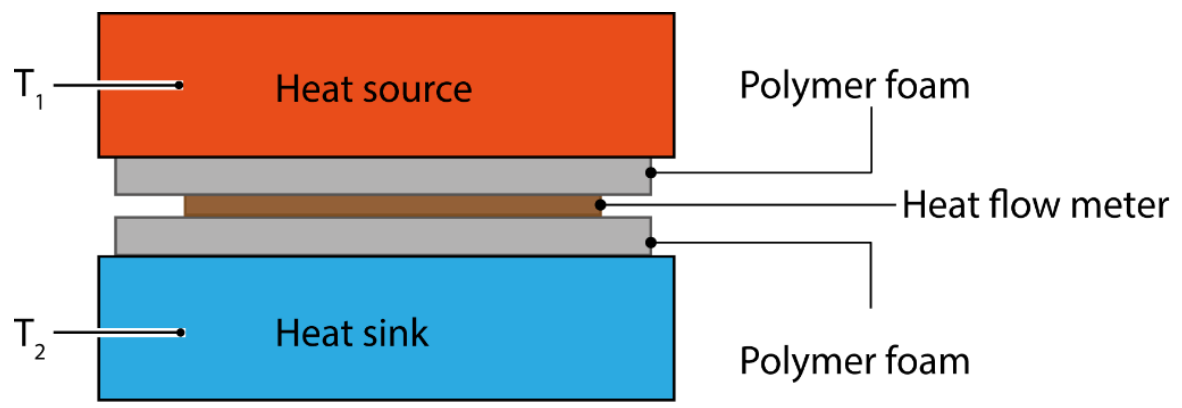

Figure 7.3 Schematic illustration of the setup build for measuring the thermal conductivity of the prepared polymer foams. $\mathrm{T}_{1}$ and $\mathrm{T}_{2}$ represent temperature sensors. 


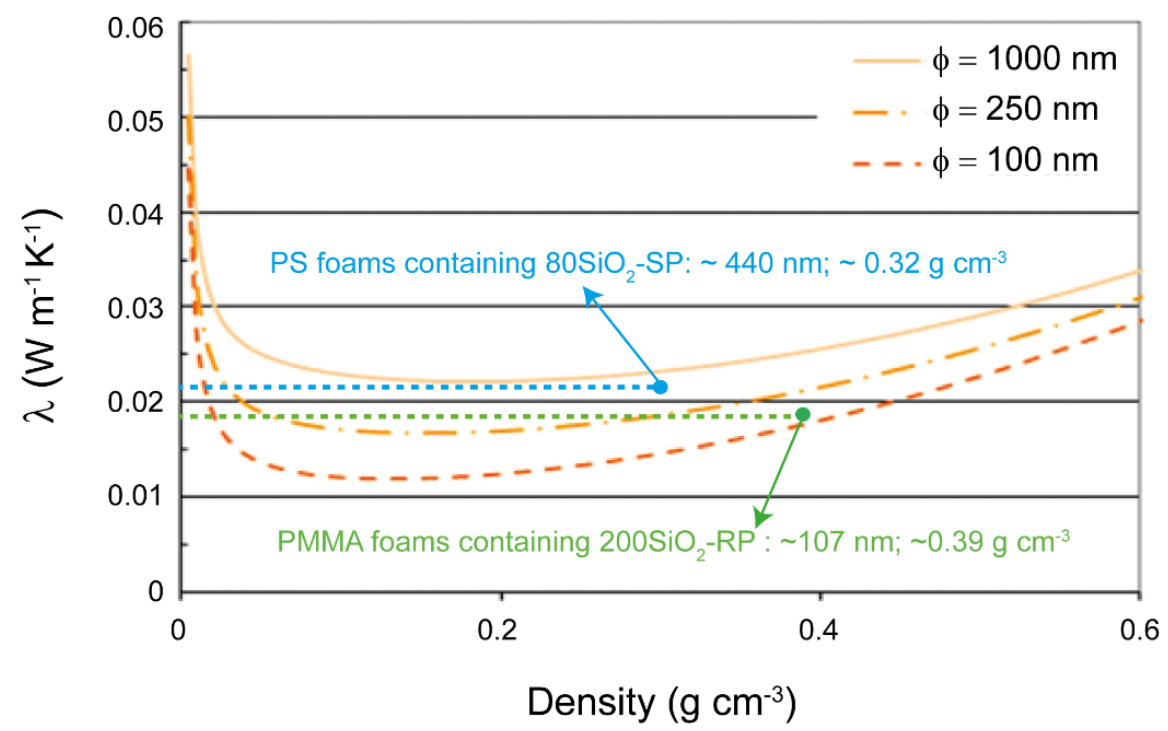

Figure 7.4 Estimation of the thermal conductivity of PMMA and polystyrene nanocomposite foams (obtained at 55 bar). This image was adapted from reference [34].

Figure 7.4 shows the thermal conductivity as a function of the foam density for PMMA foams with various cell sizes according to a model developed and reported by Sonntag and coworkers. ${ }^{34}$ The green and blue dots represent the calculated thermal conductivity of some of our PMMA and polystyrene (PS) nanocomposite foams, respectively. From Figure 7.4 it is clear that the estimated thermal conductivity of PMMA foams containing $200 \mathrm{SiO}_{2}-\mathrm{RP}$ particles is around $18 \mathrm{~mW} \mathrm{~m}^{-1} \mathrm{~K}^{-1}$, which is already lower compared to the conventional polymer foams on the market today. In addition, the obtained PS nanocomposite foam with a lower foam density and a larger cell size has a thermal conductivity of $\sim 22 \mathrm{~mW} \mathrm{~m}^{-1} \mathrm{~K}^{-1}$, which is significantly lower compared to conventional PS based foams. Based on these results, it is not difficult to imagine that a decrease in both cell size and foam density are of pivotal importance to fabricate polymer nanocellular foams with high thermal insulation. We believe that with designer NPs like ours and different foam matrixes a new generation of commercially viable thermal insulation materials is within reach. 


\section{References}

[1] Du, X.; He, J. A self-templated etching route to surface-rough silica nanoparticles for superhydrophobic coatings. ACS Applied Materials \& Interfaces 2011, 3, 1269-1276.

[2] Zhang, T.; Zhang, Q.; Ge, J.; Goebl, J.; Sun, M.; Yan, Y.; Liu, Y.; Chang, C.; Guo, J.; Yin, Y. A self-templated route to hollow silica microspheres. The Journal of Physical Chemistry C 2009, 113, 3168-3175.

[3] Chen, J.; Ding, H.; Wang, J.; Shao, L. Preparation and characterization of porous hollow silica nanoparticles for drug delivery application. Biomaterials 2004, 25, 723-727.

[4] Li, Z.; Xu, S.; Wen, L.; Liu, F.; Liu, A.; Wang, Q.; Sun, H.; Yu, W.; Chen, J. Controlled release of avermectin from porous hollow silica nanoparticles: influence of shell thickness on loading efficiency, UV-shielding property and release. Journal of Controlled Release 2006, $111,81-88$.

[5] Li, Z.; Wen, L.; Shao, L.; Chen, J. Fabrication of porous hollow silica nanoparticles and their applications in drug release control. Journal of Controlled Release 2004, 98, 245-254.

[6] Wei, J.; Zhou, D.; Sun, Z.; Deng, Y.; Xia, Y.; Zhao, D. A controllable synthesis of rich nitrogen-doped ordered mesoporous carbon for $\mathrm{CO}_{2}$ capture and supercapacitors. Advanced Functional Materials 2013, 23, 2322-2328.

[7] Li, L.; Yokoyama, H. Nanoscale silica capsules ordered on a substrate: oxidation of nanocellular thin films of poly (styrene-b-dimethylsiloxane). Angewandte Chemie International Edition 2006, 45, 6338-6341.

[8] Miller, M. B.; Luebke, D. R.; Enick, R. M. $\mathrm{CO}_{2}$-philic oligomers as novel solvents for $\mathrm{CO}_{2}$ absorption. Energy \& Fuels 2010, 24, 6214-6219.

[9] Liu, S.; Zoetebier, B.; Hulsman, L.; Zhang, Y.; Duvigneau, J.; Vancso, G. J. Nanocellular polymer foams nucleated by core-shell nanoparticles. Polymer 2016, 104, 22-30.

[10] Qi, G.; Wang, Y.; Estevez, L.; Duan, X.; Anako, N.; Park, A. H. A.; Li, W.; Jones, C. W.; Giannelis, E. P. High efficiency nanocomposite sorbents for $\mathrm{CO}_{2}$ capture based on aminefunctionalized mesoporous capsules. Energy \& Environmental Science 2011, 4, 444-452.

[11] Yamamoto, E.; Kitahara, M.; Tsumura, T.; Kuroda, K. Preparation of size-controlled monodisperse colloidal mesoporous silica nanoparticles and fabrication of colloidal crystals. Chemistry of Materials 2014, 26, 2927-2933.

[12] Li, Z.; Barnes, J. C.; Bosoy, A.; Stoddart, J. F.; Zink, J. I. Mesoporous silica nanoparticles in biomedical applications. Chemical Society Reviews 2012, 41, 2590-2605.

[13] Slowing, I. I.; Vivero-Escoto, J. L.; Wu, C.; Lin, V. S. Mesoporous silica nanoparticles as controlled release drug delivery and gene transfection carriers. Advanced Drug Delivery Reviews 2008, 60, 1278-1288.

[14] Wu, S.; Mou, C.; Lin, H.. Synthesis of mesoporous silica nanoparticles. Chemical Society Reviews 2013, 42, 3862-3875.

[15] Nandiyanto, A. B. D.; Kim, S.-G.; Iskandar, F.; Okuyama, K. Synthesis of spherical mesoporous silica nanoparticles with nanometer-size controllable pores and outer diameters. Microporous and Mesoporous Materials 2009, 120, 447-453. 
[16] Slowing, I. I.; Trewyn, B. G.; Giri, S.; Lin, V. Y. Mesoporous silica nanoparticles for drug delivery and biosensing applications. Advanced Functional Materials 2007, 17, 1225-1236.

[17] Tang, F.; Li, L.; Chen, D. Mesoporous silica nanoparticles: synthesis, biocompatibility and drug delivery. Advanced Materials 2012, 24, 1504-1534.

[18] Costeux, S. $\mathrm{CO}_{2}$-blown nanocellular foams. Journal of Applied Polymer Science 2014, 131, 41293-41308.

[19] Guo, H.; Nicolae, A.; Kumar, V. Solid-state poly(methyl methacrylate) (PMMA) nanofoams. Part II: low-temperature solid-state process space using $\mathrm{CO}_{2}$ and the resulting morphologies. Polymer 2015, 70, 231-241.

[20] Notario, B.; Pinto, J.; Rodríguez-Pérez, M. Towards a new generation of polymeric foams: PMMA nanocellular foams with enhanced physical properties. Polymer 2015, 63, 116-126.

[21] Liao, Z.-E.; Yeh, S.-K.; Chu, C.-C.; Tseng, T. T.-W. In Critical Parameters of Generating PMMA Nanocellular Foam, Annual Technical Conference-ANTEC, Conference Proceedings, 2016.

[22] Gotsis, A.; Zeevenhoven, B.; Tsenoglou, C. Effect of long branches on the rheology of polypropylene. Journal of Rheology 2004, 48, 895-914.

[23] Raps, D.; Hossieny, N.; Park, C. B.; Altstädt, V. Past and present developments in polymer bead foams and bead foaming technology. Polymer 2015, 56, 5-19.

[24] Nofar, M.; Ameli, A.; Park, C. B. Development of polylactide bead foams with double crystal melting peaks. Polymer 2015, 69, 83-94.

[25] Pontiff, T. M., Moldable shrunken thermoplastic polymer foam beads. Google Patents: 1991.

[26] Nakai, S.; Taki, K.; Tsujimura, I.; Ohshima, M. Numerical simulation of a polypropylene foam bead expansion process. Polymer Engineering \& Science 2008, 48, 107-115.

[27] Mills, N.; Gilchrist, A. Shear and compressive impact of polypropylene bead foam. Cellular Polymers 1999, 18, 157-174.

[28] Stupak, P.; Frye, W.; Donovan, J. The effect of bead fusion on the Energy absorption of polystyrene foam. Part I: fracture toughness. Journal of Cellular Plastics 1991, 27, 484-505.

[29] Stupak, P.; Donovan, J. The effect of bead fusion on the energy absorption of polystyrene foam. Part II: energy absorption. Journal of Cellular Plastics 1991, 27, 506-513.

[30] Park, C. B.; Nofar, M., A method for the preparation of PLA bead foams. Google Patents: 2013.

[31] Lee, E. K. Novel manufacturing processes for polymer bead foams. 2010.

[32] Tang, L.; Zhai, W.; Zheng, W. Autoclave preparation of expanded polypropylene/poly (lactic acid) blend bead foams with a batch foaming process. Journal of Cellular Plastics 2011, 47, 429-446.

[33] Agarwal, K.; Verma, V. A quick method of measuring thermal conductivity and thermal diffusivity of building fabrics. Building Science 1967, 2, 165-172. 
[34] Forest, C.; Chaumont, P.; Cassagnau, P.; Swoboda, B.; Sonntag, P. Polymer nano-foams for insulating applications prepared from $\mathrm{CO}_{2}$ foaming. Progress in Polymer Science 2015, 41, 122-145. 


\section{Summary}

Low density nanocellular polymer nanocomposite foams are considered as a promising new class of materials with many potential applications, for instance, in high performance thermal insulation. Nanoparticles in these foams act as energetically favorable heterogeneous nucleation sites. However, the currently reported cell nucleation efficiency in polymer nanocomposite foaming is very low, i.e. below 0.01 . This results in foams with relatively low cell densities. In this Thesis the design and synthesis of surface functionalized nanoparticles and their exploitation as highly efficient cell nucleation agents in $\mathrm{CO}_{2}$ assisted polymer nanocellular foaming is presented and discussed. Poly(methyl methacrylate) (PMMA) was selected as the foam matrix polymer due to its reported potential for the fabrication of nanocellular foams with a high porosity. As a comparison, polystyrene (PS) was used, as well. The influence of nanoparticles size, surface chemistry and surface texture on foam cell nucleation are discussed in detail. The investigation of interfacial interactions between individual nanoparticle and $\mathrm{CO}_{2}$ swollen polymer matrix is presented as well. Decoration of silica nanoparticles with a low surface energy and high $\mathrm{CO}_{2}$-philic thin polymer shell, e.g. PDMS, is found to be an efficient strategy to increase the nucleation efficiency of silica nanoparticles. The low surface energy and relatively high $\mathrm{CO}_{2}$ sorption in the PDMS shell is favorable for heterogeneous nucleation and as a consequence these particles outperform every currently known nanoparticles as heterogeneous nucleation sites.

In Chapter 1, a short introduction to the topics, the motivation and an overview of the work described in this Thesis are presented.

A literature review concerning the general topics discussed in this Thesis is described in Chapter 2. Emphasis is on $\mathrm{CO}_{2}$ based foaming strategies, limitations and challenges of heterogeneous nucleation in polymer foaming and thermal insulation performance of nanocellular polymer foams. In addition, the synthesis and subsequent surface derivatization strategies for silica nanoparticles are elucidated, as well.

Chapter 3 describes the synthesis of hybrid silica polymer core-shell nanoparticles and their exploration as highly efficient nucleation agents in $\mathrm{CO}_{2}$ batch foaming of PS and PMMA. Silica nanoparticles with a diameter of $80 \mathrm{~nm}$ were synthesized and surface 
grafted with PS, Fluorolink E10 and poly(dimethylsiloxane) (PDMS). Following melt blending of the prepared nanoparticles with PS and PMMA, batch foaming was used to produce nanocomposite foams. The results emphases that proper selection of the polymer grafts, e.g. PDMS, results in achieving nucleation efficiencies of up to approximately 0.5 (i.e. 1 foam cell per 2 particles on average).

In Chapter 4, the influence of nanoparticle curvature on cell nucleation is described. Bare and PDMS grafted nanoparticles with (core) diameter from $12 \mathrm{~nm}$ to $120 \mathrm{~nm}$ were synthesized and used as heterogeneous nucleation agents in $\mathrm{CO}_{2}$ batch foaming of PMMA. The results show that nanoparticles with a diameter below $40 \mathrm{~nm}$ were less efficient as nucleation agents compared to particles with a diameter of $60 \mathrm{~nm}$ or larger. This is ascribed to the presence of a line tension at the three phase contact line of a nucleated bubble with the nanoparticle and viscoelastic polymer. The line tension contributes to a higher nucleation energy and thus renders these particles less efficient compared to their larger counter parts. This extra energy penalty is not considered in the classical nucleation theory and its adaptations. Experimentally the presence of a positive line tension was confirmed by the absence of the smallest nanoparticles (diameter $<40 \mathrm{~nm}$ ) at the polymer cell wall gas phase interface, i.e. the particles were engulfed by the polymer. Particularly interesting is the fact that when the $\mathrm{CO}_{2}$ saturation pressure was increased from 55 bar to 300 bar, which resulted in an increase $\mathrm{CO}_{2}$ concentration in the PMMA matrix, 60 and 80 nanometer particles were also nearly completed engulfed. This is ascribed to an expected increase in the line tension length. As a consequence of this effect, in combination with an increased homogenous nucleation rate the heterogeneous nucleation efficiency was low. The results emphasize the need for the development of new particle designs that are expected to further enhance the nucleation efficiency of nanoparticles in polymer nanocellular foaming.

In Chapter 5, the quasi 2D foaming mimicking experiments confirms the results as described in Chapter 4. More importantly it is demonstrated that the position of particles existing at the gas viscoelastic polymer interface is strongly size-dependent. The embedding of nanoparticles in $\mathrm{CO}_{2}$ swollen PMMA films exhibits a double transition upon reducing particle size, from adhesion to wetting and eventually to engulfment. Complete particle engulfment is observed for nanoparticles with a diameter of approximately $12 \mathrm{~nm}$ or less. These findings are explained quantitatively by a thermodynamic analysis, combining elasticity, capillary adhesion and line tension.

To further enhance the cell nucleation efficiency of nanoparticles, In Chapter 6, PDMS decorated core-shell raspberry-like nanoparticles were synthesized and exploited as nucleation agents in PMMA nanocellular foaming. With these particles we report for the first time that a cell nucleation efficiency of above 1 was achieved. The highest nucleation efficiency obtained was $\sim 6.2$ for PDMS decorated raspberry-like nanoparticles with a silica core of $\sim 200 \mathrm{~nm}$, which is approximately 40 times higher 
compared to that of a pristine nearly spherical silica nanoparticle with a similar diameter. The unusual high nucleation efficiency of these nanoparticles is ascribed to $\mathrm{CO}_{2}$ capillary condensation in the surface cavities combined with the known favorable nanocavity nucleation energy. Hence the results show that PDMS decorated raspberry-like nanoparticles are very promising to be used as a new class of highly efficient nucleation agents.

Following the experimental work as described in the previous Chapters, Chapter 7 provides an outlook concerning new particle designs (e.g. PDMS decorated mesoporous particles), optimization of polymer foam matrix and foaming strategies, as well as for the measurement of the thermal insulation properties of nanocellular polymer foams.

Overall, in this Thesis, nanoparticles with specifically designed surfaces were synthesized and exploited as highly efficient nucleation agents in $\mathrm{CO}_{2}$ assisted nanocellular polymer foaming. The obtained fundamental insights into heterogeneous cell nucleation at the nanometer length scale offers a framework for the design of highly efficient nucleation agents in the relevant foam processing windows. Future work on these particles is expected to result in foams with a desired cell density and cell size, especially when these nanoparticles are combined with different polymer matrixes that allow $i$ ) a good foam cell nucleation and ii) vitrification of the foam matrix at a time scale fast enough so that cell coalescence is prevented. 


\section{Samenvatting}

Lage dichtheid nanocellulaire nanocomposiete polymeerschuimen worden beschouwd als een veelbelovende nieuwe klasse van materialen met vele mogelijke toepassingen, bijvoorbeeld als zeer efficiënte thermische isolatiematerialen. Nanodeeltjes toegevoegd aan de polymeren alvorens deze te schuimen dienen als energetisch gunstige heterogene nucleatie punten voor schuimvorming. De huidige nucleatie efficiëntie in schuimprocessen voor nanocomposiete polymeren is lager dan 0.01 . Het resultaat is een schuim met een relatief lage schuimcel dichtheid. In dit proefschrift worden het ontwerp en de synthese van oppervlakte gemodificeerde nanodeeltjes en de toepassing daarvan als zeer efficiënte schuimcel nucleatie middelen in $\mathrm{CO}_{2}$ geblazen nanocellulaire schuimen gepresenteerd en bediscussieerd.

Poly(methylmethacrylaat) (PMMA) was geselecteerd als de schuimmatrix vanwege het eerder gerapporteerde potentieel voor de fabricage van nanocellulaire schuimen met een hoge porositeit voor dit polymeer. Daarnaast werd polystyreen (PS) ook gebruikt. De invloed van nanodeeltje diameter, oppervlakte chemie en oppervlakte textuur op schuimcel nucleatie worden in detail besproken. Het onderzoek naar de invloed van grensvlak interacties tussen een individueel nanodeeltje en de $\mathrm{CO}_{2}$ gezwollen polymeer matrix wordt ook beschreven. Het modificeren van silica nanodeeltjes met een lage oppervlakte energie, dunne polymeerschil met een hoge affiniteit voor $\mathrm{CO}_{2}$, zoals bijvoorbeeld van poly(dimethylsiloxaan) (PDMS), is een doeltreffende strategie gebleken om de nucleatie efficiëntie van silica nanodeeltjes te verhogen. De lage oppervlakte energie en relatief hoge $\mathrm{CO}_{2}$ opname in de PDMS schil is gunstig voor heterogene nucleatie en als gevolg daarvan functioneren deze deeltjes beter dan de huidige bekende nanodeeltjes welke gebruikt worden als heterogene nucleatie punten.

In Hoofdstuk 1 wordt een korte introductie tot de onderwerpen, de motivatie en een overzicht van het werk beschreven in dit proefschrift gegeven.

Een literatuur overzicht betreffende de onderwerpen besproken in dit proefschrift wordt gegeven in Hoofdstuk 2. De nadruk ligt op $\mathrm{CO}_{2}$-gebaseerde schuimstrategieën, beperkingen en uitdagingen van heterogene nucleatie in polymeer schuimprocessen en de thermische isolatieprestaties van nanocellulaire polymeerschuimen. Daarnaast worden de 
synthese en de daaropvolgende oppervlakte modificatie strategieën voor silica nanodeeltjes toegelicht.

Hoofdstuk 3 beschrijft de synthese van hybride silica kern-schil nanodeeltjes en het exploratieve gebruik daarvan als zeer efficiënte nucleatiemiddelen in $\mathrm{CO}_{2}$ batch schuimprocessen van PS en PMMA. Silica nanodeeltjes met een diameter van $80 \mathrm{~nm}$ werden gesynthetiseerd en oppervlakte gemodificeerd met PS, Fluorolink E10 en PDMS. $\mathrm{Na}$ het mengen van de bereide nanodeeltjes met PS en PMMA in de smelt werd een batch schuimproces gebruikt om nanocomposiete schuimen te produceren. De resultaten benadrukken dat een juiste selectie van de polymeerschil, b.v. PDMS, resulteert in het bereiken van een nucleatie-efficiëntie van maximaal ongeveer 0,5 (dat wil zeggen gemiddeld 1 gevormde schuimcel per 2 toegevoegde deeltjes).

In Hoofdstuk 4 wordt de invloed van nanodeeltjekromming op schuimcel nucleatie beschreven. PDMS gemodificeerde en ongemodificeerde nanodeeltjes met een (kern)diameter van $12 \mathrm{~nm}$ tot $120 \mathrm{~nm}$ werden gesynthetiseerd en gebruikt als heterogene nucleatiemiddelen voor het $\mathrm{CO}_{2}$ batchschuimen van PMMA. Uit de resultaten blijkt dat nanodeeltjes met een diameter onder de $40 \mathrm{~nm}$ minder efficiënt waren vergeleken met nucleatiemiddelen met een diameter van $60 \mathrm{~nm}$ of groter. Dit wordt toegeschreven aan de aanwezigheid van een lijnspanning op de driefase-contactlijn van een nucleërende schuimcel met het nanodeeltje en het viscoelastische polymeer. De lijnspanning draagt bij aan een hogere nucleatie energie en maakt deze deeltjes minder efficiënt in vergelijking met de grotere deeltjes. Deze extra benodigde energie wordt niet beschouwd in de klassieke nucleatie theorie of in de aanpassingen daarop. Experimenteel werd de aanwezigheid van een positieve lijnspanning bevestigd door de afwezigheid van de kleinste nanodeeltjes (diameter $<40 \mathrm{~nm}$ ) op het grensvlak van de schuimcel met de polymeercelwand, d.w.z. de deeltjes werden volledig door het polymeer omgeven. Bijzonder interessant is het feit dat wanneer de $\mathrm{CO}_{2}$-verzadigingsdruk werd verhoogd van 55 bar tot 300 bar, wat resulteerde in een toename van de $\mathrm{CO}_{2}$ concentratie in de PMMAmatrix, de 60 en 80 nanometer deeltjes ook bijna volledig in de polymeer celwand waren opgenomen. Dit is toe te schrijven aan een verwachte toename van de lijnspanningslengte. Als gevolg van dit effect, in combinatie met een verhoogde homogene nucleatie snelheid, was de heterogene nucleatie-efficiëntie van de nanodeeltjes bij deze schuimdrukken laag. De verkregen resultaten benadrukken de noodzaak voor de ontwikkeling van nieuwe deeltje stypen die naar verwachting de nucleatie efficiëntie van nanodeeltjes in nanocellulaire schuimprocessen verder zullen verhogen.

In Hoofdstuk 5 bevestigen de quasi 2D model schuimproces experimenten de resultaten zoals beschreven in Hoofdstuk 4. Belangrijker nog is dat werd aangetoond dat de positie van deeltjes aanwezig aan het grensvlak tussen gas en viscoelastisch polymeer sterk afhankelijk is van de deeltjes diameter. De inbedding van nanodeeltjes in $\mathrm{CO}_{2}$ gezwollen PMMA-films vertoont een dubbele overgang bij het verminderen van de 
deeltjesgrootte, namelijk van adhesie tot bevochtiging en uiteindelijk tot volledige inbedding in de matrix. Volledige deeltjesopname door het polymeer wordt waargenomen voor nanodeeltjes met een diameter van ongeveer $12 \mathrm{~nm}$ of minder. Deze bevindingen worden kwantitatief verklaard door een thermodynamische analyse, die de elasticiteit, de capillaire adhesie en de lijnspanning combineert.

Om de nucleatie efficiente van nanodeeltjes verder te verbeteren werden in Hoofdstuk 6, PDMS versierde kern-schil 'framboosachtige' nanodeeltjes gesynthetiseerd en gebruikt als nucleatiemiddelen voor PMMA nanocellulaire schuimvorming. Met deze deeltjes werd voor het eerst een nucleatie efficiëntie van boven de 1 bereikt en gerapporteerd. De hoogste nucleatie efficiëntie verkregen was $\sim 6,2$ voor PDMS gemodificeerde 'framboosachtige' nanodeeltjes met een silica kern van $\sim 200 \mathrm{~nm}$. Deze efficiënte is ongeveer 40 keer hoger dan die van een ongemodificeerd nagenoeg rond silica nanodeeltje met een vergelijkbare diameter. De ongebruikelijke hoge nucleatie efficiëntie van deze nanodeeltjes wordt toegeschreven aan capillaire condensatie van $\mathrm{CO}_{2}$ in de oppervlakte caviteiten, gecombineerd met de bekende gunstige nucleatie-energie voor schuimcel vorming in nanocaviteiten. Uit de resultaten blijkt dat PDMS gemodificeerde 'framboosachtige' nanodeeltjes veelbelovend zijn om te worden gebruikt als een nieuwe klasse van zeer efficiënte schuim nucleatiemiddelen.

Op basis van het experimentele werk beschreven in de voorgaande hoofdstukken, geeft Hoofdstuk 7 een perspectief voor nieuwe deeltjesontwerpen (bijvoorbeeld PDMS gemodificeerde mesoporeuze deeltjes), de optimalisatie van de polymeer schuimmatrix en schuimstrategieën, evenals voor de meting van thermische isolatie-eigenschappen van nanocellulaire polymeerschuimen.

Samengevat werden in dit proefschrift nanodeeltjes met specifiek ontworpen oppervlakken gesynthetiseerd en benut als zeer efficiënte nucleatiemiddelen in $\mathrm{CO}_{2}$ gebaseerde nanocellulaire polymeer schuimprocessen. De verkregen fundamentele inzichten in heterogene celnucleatie op de nanometer lengteschaal bieden een kader voor het ontwerpen van zeer efficiënte nucleatiemiddelen toe te passen binnen de relevante schuimverwerkingsparameters. Toekomstige werkzaamheden ten aanzien van deze deeltjes zullen naar verwachting resulteren in schuimen met een gewenste celdichtheid en celgrootte, vooral wanneer deze nanodeeltjes worden gecombineerd met verschillende polymeermatrixen die $i$ ) een goede schuimcelnucleatie mogelijk maken en $i$ ) snel genoeg vitrificieren zodat cel coalescentie wordt voorkomen. 


\section{Acknowledgement}

Before finishing the writing of my Thesis, I would like to use some more pages to express my deepest gratitude to all those who have supported me along these four years.

First and foremost, I would like to express my deepest gratitude and sincere appreciation to my promotor, Prof. Julius Vancso. Dear Julius, it is a great pleasure and honor to be your student and to be part of MTP. Thank you very much for your supervision and great support during my Ph.D. study. Your broad knowledge and precise perspectives towards science and technology have benefited me a lot. The advices and comments you made on my presentations and manuscripts have taught me how to present the results in a more effective and precise way. Your patient guidance and encouragement provided me the great motivation and enjoyments that kept me going.

The second person I would like to express my deepest gratitude and appreciation to is my supervisor/assistant promotor, Dr. Joost Duvigneau. Dear Joost, thanks a lot for your supervision and endless help during all these four years. Your professional and sharp insights towards scientific research and writing have inspired me a lot. Every discussion and meeting with you ends with constructive suggestions and encouragements, which highly motivated me in fulfilling my research activities. I am very grateful for the plentiful efforts and time that you have spent on guiding me. You are not only a great supervisor, but also a great friend for me. I enjoyed every scientific discussion and daily conversation with you.

Dearest Julius and Joost, without the guidance and support from you, the work described in this Thesis would not be accomplished. Words are powerless to express my gratitude and thanks to both of you. I sincerely wish you and your families all the best in the coming future.

The next person I would like to express my sincere gratitude to is Clemens Padberg. Dear Clemens, you are one of the most amazing persons in the MTP group. You can fix almost every instrument failure in our group (and others) and are always willing to help with anything. This makes everyone chasing after you for help every day, certainly, including me. But no matter how busy you are, you are always glad and timely to help me with the SEM measurements. I counted the number of SEM images that you have obtained for me, more than 5000 SEM images! For me you are not just a colleague, but 
also a great friend. Thanks you so much for everything and for the friendship that you have shared with me. Wish you and Sabine all the best in your future life.

My Sincere thanks would also go to Dr. Sissi de Beer. Dear Sissi, thanks a lot for helping me with the simulations, I enjoyed the simulation work and discussion with you a lot. The next person I would like to thank is Dr. Mark Hempenius. Dear Mark, many thanks for your help. You are a very good working companion in our chemistry lab, especially during the weekends. I would also like to thank Hubert for AFM training and sharing with us the delicious Polish food.

I am very grateful for the endless help from Marion Steenbergen and Geneviève Rietveld (Gen). Dear Marion, thank you very much for helping me with all the paperwork and the arrangement of the MMMs in our group. Dear Gen, I would also like to thank you for helping with my VISA and registration before I came to the Netherlands.

Particularly, I would like to acknowledge the rest of my graduation committee members, Prof. Frieder Mugele, Prof. Imre Dékány, Prof. Jacco Snoeijer, Prof. Nieck Benes, Prof. Leon Govaert and Dr. Louis Reuvekamp. It is of great pleasure and honor to have you as my graduation committee members.

My sincere thanks would also go to my dear cooperators, Prof. Jacco Snoeijer and Anupam Pandey. Dear Jacco and Anupam, thank you very much for your time and efforts on our manuscript (Chapter 5 in this Thesis). I appreciate a lot the help and cooperation from both of you. I learned a lot.

Next I would like to give my special thanks to my best Chinese friends from MTP, Kaihuan, Yan, Sida and Chongnan. Dear Kaihuan, thanks a lot for your help in MTP and in my daily life during these years. I can still clearly remember the scene that you picked me up at Enschede train station on my first day in the Netherlands. Wish you and Sijia all the best in your coming future. Dear Yan, thank you very much for being my paranymph and for your help during my stay. Wish you and Weiya great success in your Ph.D. research. Dear Sida, I had the pleasure to supervise and work with you during your M.Sc. and B.Sc. projects. Thanks a lot for your contribution to Chapter 6 of my Thesis and for helping me with Matlab. Wish you success with your nanoparticles in the coming three years. Dear Chongnan, thanks a lot for your help in my daily life and for sharing with me useful information. Wish you all the best in your coming Ph.D. study.

My special thanks goes to Marco for been my paranymph. Dear Marco, lots of thanks for your help and for the enjoyment that you have brought to me and to our group. I enjoy our daily talk a lot and I like your humor. I would also like to thank Michel for sharing with me his experience on AFM and for helping me with other stuff. I also want to thank Maciek very much for the discussion on ATRP. 
Now I would like to thank the other five students that I had the pleasure to work with during these four years, Rik, Kevin, Hugo, Matthijs and Ece. Dear Rik, I acknowledge your contribution to Chapter 4 of my Thesis. Dear Kevin, I appreciate very much your independent work on the simulations and the work you did on our polymer foams. Dear Hugo, you are the last student that I supervised during my Ph.D., and the contribution from you on nanocellular polymer foaming is impressive. Dear Matthijs, I am already missing the time that we worked together on the amazing aerogels synthesis. Dear Ece, I enjoyed a lot the time that we spent together for the grafting of polystyrene brushes from nanoparticles. I would like to thank all of you for the research contributions and the joyful moments from you. I sincerely wish all of you success in your future career.

I also wish to thank Olivier, Lucie, Andreas, Ramon, Lehani, Sinem and Elio. Thanks a lot for the help from you guys, and I really enjoyed the time we have spent together. I would also like to thank all the present and former MTP members during my stay, Hairong, Xueling, Bram, William, Yunlong, Bart, Luuk, Ezgi, Thomas, Järvi, Aleksandra, Aysegul, Areliza, Barbara and Guido. They were so many that it is difficult to mentioned them all. It is of great pleasure to have the chance to work with you.

Next I would like to express my sincere thanks for the support and company from my friends I have met during my Ph.D. study, Lijie, Minmin, Jie Zhu, Yanbo, Pengyu, Weiyu, Honglin, Qingqian, Aijie, Zhaoliang, Lin Li, Qirong, Yang Wang, Xiaofeng, Liulin, Zhiliang, He huang, Jin Cui, Jing Xu, Lantian and Xiaozhen.

In particular, I would like to thank Wei Jiang and Yiming Wu. Wei, I am very thankful to know you, and I enjoy every moment that we have spent together. Yiming, thank you so much for your help when I was in Shanghai.

Finally, I would like to express my deepest gratitude to my families and relatives. I am very grateful for the endless love and support from my dearest father (Xuanqing Liu), mother (Meinv Wang), grandma (Zhumei Liu), brother (Shanyou Liu), sister-inlaw (Jingjing Zhang) and my adorable nephew (Zelin Liu). Shanyou and Jingjing, thank you so much for taking care of the whole family when I am not around. My deepest gratitude also goes to my dearest godparents, Mr. Xinglin Yang and Mrs. Yifang Chen. I am very grateful for the numerous love and care from the both of you. Without all your suggestions and support, I would not be at the point where I am now. Sincerely wish all of you a healthy and happy life. I love you all.

刘善秋

Shanqiu Liu

Enschede, 2017 


\section{Publications}

1. Shanqiu Liu, Bram Zoetebier, Lars Hulsman, Yuanyuan Zhang, Joost Duvigneau, G. Julius Vancso. "Nanocellular polymer foams nucleated by core-shell nanoparticles." Polymer 104 (2016): 22-30.

2. Shanqiu Liu, Joost Duvigneau, and G. Julius Vancso. "Nanocellular polymer foams as promising high performance thermal insulation materials." European polymer journal 65 (2015): 33-45.

3. Shanqiu Liu, Rik Eijkelenkamp, Joost Duvigneau and G. Julius Vancso. "Silica assisted nucleation of polymer foam cells with nanoscopic dimensions: impact of particle size, line tension and surface functionality." ACS Applied Materials \& Interfaces. Accepted.

4. Shanqiu Liu, Anupam Pandey, Joost Duvigneau, Jacco Snoeijer and G. Julius Vancso. "Transition from adhesion to engulfment of nanoparticles at the meltpolymer interface." Submitted.

5. Shanqiu Liu, Joost Duvigneau, and G. Julius Vancso. "Multiple polymer foam cell nucleation events from PDMS grafted raspberry-like silica nanoparticles”. To be submitted.

6. Shanqiu Liu, Joost Duvigneau, and G. Julius Vancso. "Manipulation of cell nucleation by surface designed nanoparticles: new insights from the world of interfaces" In preparation.

7. Shanqiu Liu, Joost Duvigneau, and G. Julius Vancso. "Polyacrylate-based nanocomposite aerogels as superlight electrical conductors" In preparation.

\section{Others}

8. Shanqiu Liu, Weiguang Gong, and Baicun Zheng. "The effect of peroxide crosslinking on the properties of low-density polyethylene." Journal of Macromolecular Science, Part B 53.1 (2014): 67-77. 
9. Shanqiu Liu, Weiguang Gong, Baicun Zheng. "Investigation on non-isothermal cross-linking kinetics of peroxide cross-linked polyethylene" Plastics 42 (2013): 3233.

10. Shanqiu Liu, Weiguang Gong, Baicun Zheng. "Investigation on the structureproperty correlation of peroxide cross-linked low density polyethylene." China Plastics Industry 5 (2013): 33-37. 


\section{Curriculum Vitae}

Shanqiu Liu was born on Sep. $14^{\text {th }}, 1987$ in Jiangxi, China. After finishing his B.Sc. from Anhui University of Science and Technology in 2010, he started his master studies in polymer materials science at the East China University of Science and Technology in the same year. This research project was conducted in the group of Prof. dr. Baicun Zheng and focused on the functionalization of polyethylene. After graduation in 2013, he continued as a Ph.D. student under the supervision of Prof. dr. Julius Vancso and Dr. Joost Duvigneau in the group of Materials Science and Technology of Polymers (MTP) at the University of Twente, the Netherlands. His Ph.D. project focused on $\mathrm{CO}_{2}$ assisted nanocellular polymer foaming with designer nanoparticles as efficient nucleation agents. The results of his research are described in this Thesis. 
